\title{
Gotthold Ephraim Lessing
}

\section{ADAM NEUSER (1774)}

précédé de Confession et migration: L'islam des Lumières

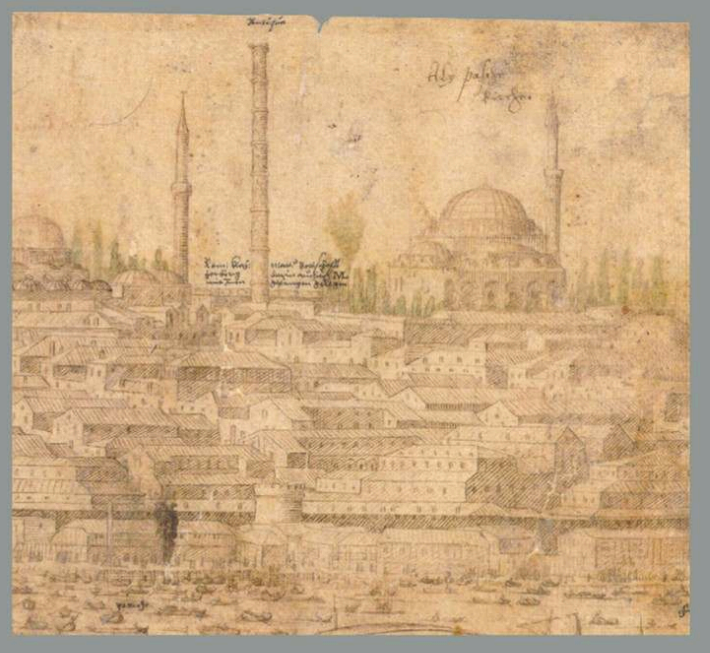

Traduction, introduction et notes par Philippe Büttgen 


\section{Adam Neuser (1744)}

Précédé de Confession et migration: L'Islam des Lumières

\section{Gotthold Ephraim Lessing}

Philippe Büttgen (éd.)

DOI : 10.4000/books.demopolis. 920

Éditeur : Demopolis

Année d'édition : 2017

Date de mise en ligne : 18 janvier 2019

Collection : Quaero

ISBN électronique : 9782354571610

\section{Qbooks}

http://books.openedition.org

\section{Édition imprimée}

ISBN : 9782354571078

Nombre de pages : 238

\section{Référence électronique}

LESSING, Gotthold Ephraim. Adam Neuser (1744) : Précédé de Confession et migration : L'Islam des Lumières. Nouvelle édition [en ligne]. Paris : Demopolis, 2017 (généré le 02 octobre 2020). Disponible sur Internet : <http://books.openedition.org/demopolis/920>. ISBN : 9782354571610 . DOI : https:// doi.org/10.4000/books.demopolis.920.

\section{(c) Demopolis, 2017}

Conditions d'utilisation :

http://www.openedition.org/6540 

Cet ouvrage a été publié avec le soutien du laboratoire d'excellence Transfers (programme Investissements d'avenir ANR-10-IDEX-0001-02 PSL* et ANR-10-LABX-0099).

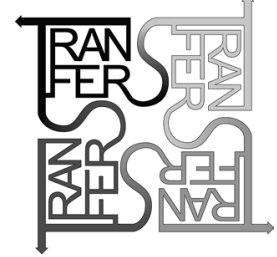


ADAM NEUSER 


\section{« QUAERO »}

Collection dirigée par Jean-Christophe Tamisier

\section{"D’Allemagne ", série dirigée par Michel Espagne}

Michel Espagne, Sandrine Maufroy (dir.), L'hellénisme de Wilhelm von Humboldt et ses prolongements européens

Richter, Vie de Maria Wutz, le joyeux petit maître d'école d'Auenthal (traduit et introduit par Geneviève Espagne)

Illustration de couverture:

Melchior Lorichs, Panorama d'Istanbul(1559), f. 9, détail (DR).

(C) Éditions Demopolis, 2017

67, rue Saint-Jacques

75005 Paris

www.demopolis.fr

ISBN : 978-2-35457-107-8 


\section{G. E. LESSING}

\section{ADAM NEUSER}

(1774)

TRADUCTION ET NOTES PAR

PHILIPPE BÜTTGEN

\section{PRÉCÉDÉ DE \\ CONFESSION ET MIGRATION \\ L'ISLAM DES LUMIÈRES}

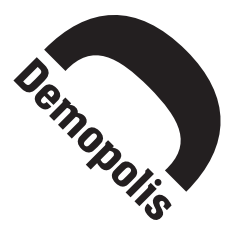





\section{INTRODUCTION}

\section{CONFESSION ET MIGRATION L'ISLAM DES LUMIÈRES}



dam Neuser raconte l'histoire vraie d'une conversion à l'islam à la fin du Xvi ${ }^{\mathrm{e}}$ siècle. C'est du moins ce qu'on croit lire, mais c'est un leurre, le premier du texte. Lessing suppose que le pasteur réformé Adam Neuser (v. 1530-1576) se prêta en 1572 à une " comédie " de conversion, au terme d'une longue migration de Heidelberg à Constantinople ${ }^{1}$. "Comédie" concède le fait de la conversion pour écarter toutes les questions qu'il pose: sincérité, apostasie... Le problème pour Lessing est autre - mais lequel? Cette première traduction française propose quelques hypothèses.

Deuxième leurre: Lessing édite une lettre d'Adam Neuser, dont il a découvert une copie dans les fonds de la bibliothèque de Wolfenbüttel. Son commentaire milite pour la " révision du procès " fait au «malheureux unitarien ». Quel procès? Lessing ne retient qu'un chef d'accusation: non pas l'apostasie donc, qui pourtant fascina, mais l'affaire d'une lettre - une autre - dans laquelle Neuser, en 1570, avait offert au sultan Selim II le soutien des antitrinitaires allemands à une marche des Turcs sur l'Allemagne. La question posée est spectaculairement secondaire: elle est de savoir si cette lettre, une fois écrite, a été envoyée au sultan. Lessing mène la discussion, avec entrain, jusqu'à l'enlisement. Était-ce vraiment le but?

Il y a d'autres leurres encore dans Adam Neuser. L'art d'écrire lessingien mérite les dizaines d'études qu'on lui a consacrées. Mais pas lui seulement. Le Neuser de Lessing livre une image de ce que penser librement a pu signifier dans les conditions religieuses et politiques du Saint-Empire moderne; en cela, c'est un des livres les plus étrangement rigoureux de la philosophie des Lumières. Son problème, celui de la confession comme acte de foi et marque 
d'appartenance, peut nous sembler lointain. Il en éclaire toutefois un autre, celui des migrations, qui ne saurait nous être plus présent qu'aujourd'hui.

\section{Une bibliothèque des Lumières}

Adam Neuser. Quelques informations authentiques paraît à l'automne 1774 à Brunswick, dans la troisième livraison des Contributions à l'histoire et à la littérature. Lessing avait fondé la revue l'année précédente pour y publier les "trésors de la bibliothèque ducale de Wolfenbüttel »: il en avait la garde depuis 1770, dans l'établissement où Leibniz notamment l'avait précédé ${ }^{2}$. Avant cette série des Beiträge, dès les années 1750, Lessing avait inauguré une formule, celle de la Rettung, " sauvetage » ou apologie, qui a fait une partie de sa postérité ${ }^{3}$. Le Neuser, à vingt ans de distance, prolonge ce qui fut le premier projet de l'auteur: sauver des morts par leurs documents. L'apologie a dès l'origine un lieu: la bibliothèque, et une discipline: l'édition de textes ${ }^{4}$.

Il s'agit ici de sauver la mémoire d'un " malheureux unitarien ", croyant en un seul Dieu, sans Fils ni Trinité, hérétique pour toutes les Églises ${ }^{5}$. La publication d'une lettre de Neuser sera l'instrument du sauvetage. C'était déjà le procédé des apologies en 1754; de même encore dans le texte sur Béranger de Tours, Berengarius Turonensis, de 1770 et dans plusieurs articles des Beiträge, sur Leibniz notamment. Au cœur de l'apologie se trouve le Fund, découverte du savant, nouveauté du document qui brise la chaîne des jugements ${ }^{6}$. On aborde le Neuser comme toutes les apologies de Lessing: par son centre, où se trouve l'inédit.

Adam Neuser excède cependant toutes les mesures. Sa minutie ne trouve d'équivalent ni dans les Rettungen des années 1750, ni dans les contributions Zur Geschichte und Literatur vingt ans plus tard. Le Berengarius avait ouvert la voie, avec ses longues mises au point chronologiques qui ne pouvaient manquer d'égarer le lecteur; déjà Lessing subvertissait les codes de l'érudition ecclésiastique. Le Neuser fait encore plus: avec son discours indéfiniment repris, rectifié, son art de l'auto-réfutation, sa peinture nuance sur nuance, il instaure une forme d'érudition saturée dont nous devrons saisir le sens.

Avant Nietzsche qui le révérait, Lessing a beaucoup fait pour imposer un certain mythe du philologue à la philosophie. Avec lui, à côté de l'écrivain et du penseur, l'érudit a émergé comme 
personnage conceptuel. Le plus sûr moyen de ne pas céder à la fascination devant l'étourdissante virtuosité de Lessing est de retenir d'abord que ses découvertes sont des découvertes. Adam Neuser est, encore aujourd'hui, un jalon de la recherche sur les dissidences antitrinitaires de la Réforme, tout comme Berengarius Turonensis a contribué à l'histoire du dogme eucharistique au Moyen Âge. C'est un travail qu'on va lire, validé par la science.

Il faut en effet prendre au sérieux l'intention que Lessing, dès 1770, confie à celui qui est alors le prince des bibliothécaires, Christian Gottlob Heyne à Göttingen: l'enquête sur Béranger de Tours ne doit pas être lue comme autre chose qu'un "travail de bibliothécaire, assimilable à du nettoyage de poussière ${ }^{7}$ ». Rien n'a changé en 1773, au moment d'envoyer à Heyne la première livraison des Beiträge:

Si vous avez la bonté de croire que j'étais en mesure d'écrire quelque chose de mieux, n'oubliez pas cependant qu'un bibliothécaire ne doit rien écrire de mieux. C'est ce que je suis maintenant, et je ne n'aimerais pas l'être que de nom ${ }^{8}$.

Entre-temps, après la création d'Emilia Galotti en mars 1772, Lessing s'est éloigné de son métier d'homme de théâtre. De la scène à l'étude: il est convenu de voir dans le choix de l'érudition, à Wolfenbüttel, un tournant qui en prépare un autre, celui de Lessing vers la controverse religieuse, avec la publication des fragments déistes de Reimarus, dès la troisième livraison des Beiträge où paraît également le Neuser ${ }^{9}$. La représentation de Nathan le Sage, en 1779, ne doit pas se comprendre comme un retour au théâtre, mais comme une métamorphose. On y reviendra.

Acceptons pour le moment de voir le travail de bibliothèque comme une ascèse que s'imposa Lessing - et qui d'ailleurs ne le rendit pas heureux ${ }^{10}$. C'est la condition pour approcher une caractéristique importante du Neuser. L'érudition n'y est plus la posture ou "mine savante" (gelehrte Miene) dont parlent les apologies de $1754^{11}$. Certes, après 1770 , l'ironie demeure, et Lessing peut retourner à son profit l'opposition imaginée par son ami Ebert entre le fier " chêne " d'Emilia Galotti et les " mousses " qui nourrissent l'arbre à partir de ses travaux en prose: les Beiträge de Wolfenbüttel sont bien un " chariot de fumier, rempli de mousses et d'éponges ${ }^{12} »$. Mais quelque chose est clairement dit ici: Lessing ne 
veut pas plaire. Plus encore, il ne cherche pas à tout prix à se faire comprendre. Les textes des Beiträge n'ont rien de "populaire", selon le terme prisé à l'époque ${ }^{13}$. Les Lumières du Neuser sont autres: savantes, on l'a vu; aristocratiques, peut-être pas, mais exigeantes; ésotériques, pas toujours, mais très peu didactiques.

\section{Qu'est-ce qu'une apologie?}

La tâche qui s'impose - toujours recommencée, à vrai dire, s'agissant de Lessing - est de définir le type exact de rationalisme auquel correspondent ces Lumières savantes. La lecture du Neuser est aujourd'hui ralentie par quantité de noms propres qui ne nous disent plus rien: compilateurs, mémorialistes, historiens ecclésiastiques, controversistes, leurs confessions et affiliations d'origine constituant autant d'enjeux obscurs. On a vu les leurres qui jalonnent le texte. Il faut ajouter les nombreuses digressions, qui vont jusqu'à l'anecdotique, comme cette dissertation animalière permettant l'identification d'un nom latin dans une chronique: tout est prétexte à mentionner les « découvertes » du savant — qui, encore une fois, sont des découvertes ${ }^{14}$.

Les premières apologies ont mis au point le procédé consistant à diriger l'attention vers un détail spectaculairement anodin, qui doit révéler la probité du philologue et, à partir de là, modifier le jugement du lecteur sur le personnage discuté. Ainsi sur Cochlaeus, le polémiste catholique, "calomniateur fou " de Luther, mais qui, si l'on se penche sur tel argument de controverse autour de 1520, ne fut pas le premier à y recourir, Valdès l'ayant précédé. " Détail " assurément (Kleinigkeit), mais qui montre que "même contre le diable il n'en faut pas faire trop ${ }^{15} »$ : probité et modération vont de pair. Le procédé se répète et peut en apparence se retourner contre l'érudit, comme dans la Rettung d'Horace:

On voit qu'au moins je suis très honnête et que je n'ai aucun scrupule à affaiblir mon propre argument. Mais qui sait si je le ferais si je ne me fiais pas d'autant plus à mes autres arguments ${ }^{16}$ ?

De cette alliance durable entre micrologie et hypercritique, l'apologie de Jérôme Cardan déduit une première leçon pour le philosophe: 
L’honnêteté est donc ce que j'exige en premier lieu d'un philosophe. Il ne doit me cacher aucune proposition, au prétexte qu'elle s'accorderait moins à son système qu'au système d'un autre; non plus qu'aucune objection, au prétexte qu'il ne pourrait y répondre avec toute l'énergie requise ${ }^{17}$.

Vingt ans plus tard dans le Neuser, Lessing livre une leçon d'histoire, en introduisant ses remarques " sans ordre » sur le texte qu'il publie:

Elles seront faites une bonne fois, ces remarques; et quand bien même elles ne devraient pas en elles-mêmes se révéler d'une grande importance, elles pourront toujours épargner à celui qui travaille dans une petite parcelle de ce domaine, tantôt un petit effort, tantôt une petite erreur. Que ne faut-il pas écrire de mauvais, dans la discipline historique, avant d'écrire quelque chose de bon ${ }^{18}$ !

L'écriture historique est défrichage. Son procédé est la digression, qui exerce une fonction dilatoire: elle empêche d'aller trop vite à la fin du récit, imposant au lecteur — si du moins il tient bon! - une sorte de principe du moindre tri dans l'information disponible. Noli finem respicere, principe du philologue. À propos de Neuser, ce " malheureux qu'à force de poursuites on a chassé de la chrétienté ", on dira donc:

Si la fin doit être l'âme de l'histoire, si par elle doit être jugé tout ce qui est venu avant, alors il serait aussi bien de n'avoir pas d'histoire du tout ${ }^{19}$.

Refus des téléologies, probité philologique, transposition en philosophie des exigences de l'histoire: cela nous parle, mais ne nous dit pas tout du Neuser. Bien habile celui qui d'un coup d'œil atteindrait le but de la démonstration: plaidoyer pour la tolérance, pour l'islam, pour l'hérésie antitrinitaire, pour l'hérésie en général, pour la religion naturelle? Les apologies précédentes avaient déjà validé une partie de ces hypothèses, comme le Berengarius dans son éloge de l'hérétique ${ }^{20}$. Adam Neuser fait plus: il encourage toutes les interprétations, sans les hiérarchiser. Lessing proteste contre la soif de sang des hommes de Dieu ${ }^{21}$. Dans le recueil des Beiträge, le texte précède un De la tolérance pour les déistes, premier fragment de Reimarus publié par Lessing ${ }^{22}$. Adam Neuser ne dissimule pas ses procédés: au contraire de ce que feront voir les textes des dernières 
années, malgré aussi une brillante vulgate straussienne, son art d'écrire n'est pas un art du secret ${ }^{23}$. Il se peut que pour Lessing le plus fort des cryptages ait d'abord consisté à communiquer ses codes. Le retrait, en 1778, de la liberté de censure dont il jouissait le forcera à adopter des procédés plus classiques de camouflage ${ }^{24}$.

Pour tout sceller, un leurre est encore posé dans les dernières lignes. Au-delà de toute doctrine déiste ou musulmane, c'est un sentiment qui finalement émerge. Leibniz avait, en français, exprimé sa " compassion du malheur de Servet ", l'antitrinitaire d'Aragon brûlé à Genève ${ }^{25}$. Lessing, en allemand, veut faire de même pour Neuser:

Mais on m'autorisera à conclure, en imitant ses paroles: J'ai d'autant plus de compassion pour Neuser, qu'il me semble avoir été encore quelque chose de plus qu'un antitrinitaire: une bonne tête mécanique $^{26}[\ldots]$

L'affect du Neuser est la pitié, et il est en ce sens bien de son siècle, rousseauiste, sentimental ${ }^{27}$. Toutefois cette pitié, inspirée d'abord par le "malheureux unitarien", va pour finir à une "bonne tête mécanique ». A-t-on pitié d'une "tête", d'un esprit? Le sens de la formule doit encore rester en suspens. On verra pour finir qu'il contient l'explication de cet ultime virage de l'apologie, la clé aussi du rationalisme lessingien. Le plaidoyer a recouru à tous les instruments de l'érudition, jusqu'à l'épuisement du lecteur; son objet véritable ne s'est pas dévoilé. De fixe ne reste qu'un nom: Adam Neuser. C'est aussi un titre, comme dans l'autre grande apologie d'hérétique des années 1770: Berengarius Turonensis. Aussi bien s'agit-il des deux grandes découvertes laissées par Lessing savant et bibliothécaire. Repartons donc du nom.

\section{Adam Neuser}

Adam Neuser est né au début des années 1530 sur le territoire de l'actuelle Bavière, dans le margraviat d'Ansbach, au sein d'une famille sans doute déjà luthérienne ${ }^{28}$. Ses premières années sont obscures; elles incluent peut-être une formation supérieure à Berne, qui aurait impliqué une exposition précoce aux courants nouveaux, non luthériens de la Réforme. C'est en tout cas dans un territoire protestant en passe de sortir du luthéranisme, l'électorat palatin, qu'on retrouve Neuser en 1560: il est alors écarté d'une 
chaire de théologie à l'université de Heidelberg, contre le choix de l'université qui souhaitait l'élire.

D’emblée, le sort de Neuser est lié à l'évolution du Palatinat vers ce qu'il est convenu d'appeler la seconde Réforme, celle qui, en Suisse, en France et dans le sud-ouest de l'Empire, relaie et supplante la rupture luthérienne. Le rival de Neuser lors de l'élection de Heidelberg, Caspar Olevian (1536-1587), oriente le choix du souverain, le prince-électeur Frédéric III (1515-1576, règne à partir de 1559), en faveur de l'option genevoise de la Réforme. Le catéchisme de Heidelberg, source doctrinale de la seconde Réforme dans l'Empire germanique, est adopté en 1563 à l'initiative de l'électeur. Il est intégré à un nouveau règlement ecclésiastique, qui porte des traits calviniens.

Neuser, repoussé de l'Université, n'est pas proscrit pour autant: il entame une carrière de prédicateur dans la plus ancienne paroisse de Heidelberg, la Peterskirche, et y jouit d'un réel succès. La disgrâce survient en 1565: Neuser est déplacé vers une autre paroisse, la Heiliggeistkirche, et relégué aux offices du matin. La sanction n'est pas infamante: l'église en question reste importante, elle vient d'accueillir les fonds de la Bibliothèque palatine et d'autres pasteurs ont pour leur part été démis de leurs fonctions. Neuser paie toutefois clairement son opposition à la modification de la discipline ecclésiastique. En 1564, l'éminent médecin Thomas Erastus (Lüber, 1524-1583) avait démissionné du consistoire pour protester contre le nouveau règlement, dont beaucoup craignaient qu'il n'imposât le principe d'une administration des affaires ecclésiastiques à l'échelon des paroisses, dans l'esprit genevois. De fait, une nouvelle théologie politique s'esquissait dans l'électorat palatin, par laquelle le souverain semblait confier aux communautés de base la tâche de réformer l'Église.

$\mathrm{Au}$ centre de cette discipline des âmes et des corps devenue marque et fonction de l'Église véritable, l'excommunication a focalisé le débat à Heidelberg. La réaffirmation du principe, appelée par la nouvelle doctrine, et l'idée que son application devait être confiée aux paroisses attisèrent les oppositions au sein de l'Église. En mars 1570, les minutes du consistoire enregistrent les premières discussions en vue de suspendre Neuser de toute prédication. La décision est effective à l'été.

Entre-temps a démarré un processus obscur où le refus des transformations ecclésiastiques se lie, chez Neuser et quelques 
autres ministres de l'Église palatine, à un travail intense sur les sources bibliques et patristiques qui mettent en cause le dogme nicéen de la Trinité. Les historiens ont parlé de "radicalisation", terme commode - plus que jamais aujourd'hui - pour camoufler l'ignorance des mobiles. Quel rapport entre le rejet d'un règlement ecclésiastique et celui de l'éternelle divinité de Jésus-Christ? Du point de vue doctrinal, on le verra, l'affaire est obscure: il se pourrait qu'en dehors du débat ecclésiologique proprement dit, Neuser et les siens aient cru faire preuve d'une fidélité calvinienne redoublée ${ }^{29}$.

Au cours de l'été 1570, le scandale éclate: on apprend que Neuser et un pasteur de Ladenburg, Johann Sylvan (Sylvanus, ?-1572), se sont secrètement rendus à la diète impériale alors réunie à Spire, non loin de Heidelberg. Leur but était de prendre contact avec Gáspár Bekes, émissaire du souverain (voïvode) de Transylvanie, pour passer dans ce territoire où l'antitrinitarisme était depuis 1568 religion reconnue voire, croyaient-ils peut-être, officielle: Bekes était lui-même unitarien. Ils ne pouvaient pas choisir pire moment: Bekes était venu à Spire pour faire part du souhait du voïvode de se rapprocher du voisin germanique. Les lettres que les deux pasteurs destinaient au voïvode sont transmises à l'électeur et, plus grave, à l'empereur. Frédéric III est contraint d'apporter des gages de loyauté: Sylvan et un autre pasteur, Matthias Vehe, sont arrêtés. La maison de Neuser est fouillée: on retrouve le brouillon de la lettre qu'il avait rédigée pour le sultan en mars 1570. Le canevas en a été décrit: appel à l'invasion ottomane de l'Empire, mais aussi éloge de l'islam, critique de la Trinité, dénonciation de la tyrannie des prêtres et des princes. L'hérésie et la critique sociale se mêlaient à la haute trahison.

Neuser, averti à temps sur le chemin du retour, de Spire à Heidelberg, put fuir. Ce n'était pas sa première tentative: à l'été 1569, il avait déjà voulu de gagner la Transylvanie, mais avait dû rebrousser chemin à Presbourg (Bratislava), faute de contacts. Cette deuxième tentative n'est pas plus concluante: après Spire, Neuser est arrêté sur la route de Buda. Relâché, il s'agrège à un groupe de marchands hongrois en route vers Debrecen, mais ne parvient pas à passer la frontière délimitée en 1568 entre le Saint-Empire et l'Empire ottoman. Neuser se résout à se constituer prisonnier du comte palatin Louis VI, fils de Frédéric III, resté luthérien. Il est transféré à Heidelberg où il est interrogé et torturé, en présence de 
l'électeur, mais parvient à s'évader grâce à de nouvelles complicités. Lors des interrogatoires, il avait admis — au nom de Calvin! — ses convictions antitrinitaires, envisagé puis refusé de les rétracter, et livré un nom, un seul, celui de Sylvan déjà arrêté. Celui-ci sera décapité en décembre 1572.

La troisième fuite, en mai 1571, est la bonne. Le chemin pris d'abord est celui de l'ouest, vers Londres puis Paris, mais Neuser réalise qu'il ne peut échapper au dilemme: soit il préserve son incognito et ne peut faire valoir ses titres à prêcher, soit il est rattrapé par le scandale, avec les risques afférents. Il choisit donc de repartir vers l'est. Cracovie l'accueille, mais la situation n'est toujours pas sûre et Neuser préfère, en mai 1572, se diriger de nouveau vers la Transylvanie. Cette fois il passe la frontière. Clausenbourg (Cluj ou Kolozsvár) lui offre un havre de répit et d'étude, mais aussi maintes occasions de controverse avec la communauté antitrinitaire, puissante dans la ville. Ferenc Dávid (Franciscus Davidis, 1520-1579) est depuis 1568 évêque de l'église unitarienne de Transylvanie. Il cherche une solution à l'affaire Neuser, pour faire droit à la fois à la politique officielle de rapprochement avec l'Empire et au souhait de son coreligionnaire de s'expliquer publiquement - car le scandale enfle. Un compromis est trouvé: Neuser passe dans les environs de Temesvár (Timişoara), région contrôlée depuis 1552 par les Turcs, où il pourra, lui dit-on, publier en toute liberté son apologie. Immanquablement, il est pris par les Turcs et, après quelques paroles qu'il prononce sur son intérêt pour le Coran, transféré à Constantinople.

Adam Neuser arrive en novembre 1572 à Istanbul. Son séjour est notamment documenté par le journal de Stephan Gerlach (1546-1612), prédicateur luthérien de l'ambassadeur impérial David Ungnad, plus tard théologien à Tübingen, qui rapporte plusieurs entretiens avec l'exilé. On sait par Gerlach que Neuser obtint un emploi subalterne auprès des drogmans (traducteurs) de la cour du sultan; qu'il fut spahi, cavalier, mais sans cheval; qu'il but beaucoup, avec une poignée de compatriotes, dans l'arrièreboutique d'un barbier; qu'il blasphéma, aima des hommes, s'essaya à la magie noire et à la fausse monnaie. Qu'un tel récit, parmi d'autres également mentionnés par Lessing, relève très largement de l'édification est une évidence. Les sources ottomanes sur Neuser restent à explorer. Seule est sûre la date de sa mort: le 12 octobre 1576, de dysenterie. 


\section{Philosophie du Saint-Empire}

Le cas Neuser est assurément isolé; ce n’est pourtant pas une simple curiosité. Pour l'historien du Saint-Empire, Neuser va pour ainsi dire au-devant des évolutions récentes de sa discipline: l'émigré d'Istanbul est un condensé d'histoire allemande du $\mathrm{XVI}^{\mathrm{e}}$ siècle. C'est à peine un paradoxe.

On le sait, l'histoire du Saint-Empire moderne est l'histoire de sa confessionnalisation: après la Réforme, la partition de la chrétienté latine en confessions (catholique, luthérienne, réformée), Églises divisées et intégrées aux appareils d’État naissants, a transformé le sens du politique et du social dans l'espace germanique ${ }^{30}$. La recherche sur la confessionnalisation a pris corps, à l'orée des années 1980, à travers l'étude de la " seconde Réformation ", qui offrait un terrain propice à l'examen des nouvelles disciplines imposées par les pouvoirs confessionnels ${ }^{31}$. L'affaire Neuser a commencé dans la contestation de la discipline ecclésiastique du Palatinat: elle constitue d'abord un épisode de l'histoire de ce territoire, exemplaire par sa position éminente dans l'Empire comme par sa situation religieuse $^{32}$. La dissolution brutale du groupe Sylvan-Neuser en 1570 s'explique par le danger que la présence d'antitrinitaires sur son territoire faisait courir à Frédéric III, au moment où sa réorientation confessionnelle risquait d'exclure le Palatinat des règles de coexistence définies en 1555 par la Paix d'Augsbourg entre catholiques et "affiliés de la Confession d'Augsbourg"33". La conversion de Neuser à l'islam est la conséquence d'une autre conversion, celle de l'électeur palatin à la religion réformée; à sa manière, elle confirme le principe d'Augsbourg, qui a consolidé la confessionnalisation de l'Empire: cuius regio, eius religio.

Neuser est passé d'un empire à un autre, du Saint-Empire à l'Empire ottoman. On oublie aujourd'hui que ces empires étaient voisins. Après la bataille de Mohács en 1526, la ligne de front passe à travers la Hongrie et la Transylvanie. La problématique d'Adam Neuser est donc, très littéralement, celle des frontières et des confins. On connaît le paradoxe de l'Allemagne, pays hérissé de frontières intérieures, celles des innombrables principautés de l'Empire médiéval et moderne, mais qui jusqu’à récemment ne voulait pas savoir où passaient ses frontières extérieures. L'historiographie du Saint-Empire, désormais attentive aux réalités géographiques de cette entité fractale, éclatée, trouvera dans le texte un témoignage 
de première importance sur ce que passer une frontière voulait dire dans le monde germanique au XvI ${ }^{\mathrm{e}}$ siècle ${ }^{34}$.

Dans le sillage des études sur la confessionnalisation, une historiographie des migrations s'est mise en place; elle revisite des épisodes bien connus, comme celui du Refuge huguenot dont on reparlera ${ }^{35}$. Le cas de la Transylvanie, région frontière, vassale de l'Empire ottoman depuis la partition de la Hongrie par Soliman le Magnifique, accroît la complexité et l'intérêt de la question. La Transylvanie paie un tribut au sultan, mais l'autonomie religieuse dont elle jouit lui permet d'officialiser en 1568 la coexistence de quatre religions "reçues » ou " acceptées »: catholiques, luthériens, réformés et antitrinitaires. La situation est unique en Europe et lance un défi aux théories de la confessionnalisation, qui postulent l'homogénéité de la confession et du territoire ${ }^{36}$.

La conversion même de Neuser fait partie des phénomènes au travers desquels les historiens du Saint-Empire moderne cherchent à se former une compréhension plus fine desidentités confessionnelles, dans la variété de leurs déclinaisons sociales et genrées. En marge des contraintes structurelles de la confessionnalisation, mais aussi en leur centre lorsque les conversions princières devinrent un enjeu de politique impériale, un grand nombre de récits d'itinéraires transconfessionnels donnent le point de vue des acteurs singuliers sur ce qu'a pu signifier, il y a quatre ou cinq siècles, l'appartenance religieuse et ses variations à l'échelle d'une vie de femme ou d'homme $^{37}$. La lettre de Neuser est un de ces récits, très tôt édité par Lessing.

Confession, discipline, frontières, migration, conversion: le cas Neuser donne l'impression de réfracter l'historiographie récente du Saint-Empire dans ses principaux enjeux. Un problème se pose alors: comment interpréter le texte de Lessing, qui semble luimême surinvesti par les débats confessionnels?

Un exemple suffira. À côté des allusions directes aux débats théologico-politiques de Heidelberg, notamment à la "querelle de la discipline " ou à "l'Esprit saint qui soufflait depuis Genève ${ }^{38}$ ", la controverse entre "éditeurs réformés " et "théologiens luthériens " joue un grand rôle dans la séquence du texte consacrée à la "révision" du procès Neuser ${ }^{39}$. Dans ce débat, Lessing, bibliothécaire d'un duché luthérien et luthérien lui-même, affecte de se rendre à la nécessité de prendre position; le texte joue avec le devoir d'impartialité qui s'impose à l'érudit et avec la non moins 
contraignante obligation de laisser deviner une appartenance ${ }^{40}$. Le parti pris confessionnel de Lessing est faussement discret, c'est-àdire, pour qui sait lire, discrètement faux.

Ce premier exemple livre un enseignement. Adam Neuser peut être lu comme un texte-emblème de la confessionnalisation dans le Saint-Empire, à relier, dans une histoire globale, à l'étude des relations entre chrétiens et musulmans en Méditerranée ${ }^{41}$. Son intérêt documentaire, plus encore, la prise qu'il offre sur la discussion historiographique sont immenses: le Neuser est un observatoire des appartenances confessionnelles de 1570 et de 1770 simultanément.

$\mathrm{Au}$ travers de l'érudition se déploie en effet une méditation des cultures confessionnelles, de l'intérieur de ces cultures, explorées à cette occasion dans leur étirement maximal, jusqu'à leurs marges: seconde Réforme palatine, unitarisme transylvanien, islam ottoman, tout cela a pu, en Europe, faire système. Entendons par là que les appartenances confessionnelles et leurs conversions - être et devenir réformé, antitrinitaire, musulman... - livrent à Lessing un cadre mais aussi l'occasion d'une prise de distance. Nous dirions aujourd'hui: auto-réflexion des Lumières allemandes dans leur historicité, qui fut confessionnelle. C'est cette réflexion qu'il faut suivre à présent.

\section{La lettre trouvée}

Adam Neuser est un traité sur deux lettres. Dans l'ordre de leur apparition, la première est celle que Lessing édite: Neuser l'envoya d'Istanbul peu avant Pâques 1574 à un "compatriote ", "Herr Casper ", Kaspar Baumann, alors prédicateur en Hongrie. Cette lettre $\mathrm{L}_{1}$ évoque une autre lettre, $\mathrm{L}_{2}$, rédigée par Neuser à l'adresse du sultan Selim II en mars 1570, et qui fut saisie après son passage à la diète de Spire. $\mathrm{L}_{2}$ a une longue histoire éditoriale, que Lessing retrace $^{42}$. L'original latin est perdu. Le texte émerge d'abord en version allemande dans les Antiquitates Palatinae de Jakob Beyrlin (1576-1618), texte d'érudition régionale tardivement édité au début du $\mathrm{XVIII}^{\mathrm{e}}$ siècle; il est réimprimé dans les histoires ecclésiastiques du Palatinat ${ }^{43}$. L'érudition des Lumières a bien diffusé ce texte scandaleux: il en existe aussi une traduction française, toujours à partir de l'allemand, publiée par le huguenot Mathurin Veyssière de 
La Croze (1661-1739), bibliothécaire du roi de Prusse. On la trouvera en annexe du présent volume ${ }^{44}$.

La comparaison des deux lettres dévoile une part de la stratégie de Lessing. $L_{1}$ est un inédit. Par contraste, $L_{2}$ paraît engluée dans sa propre diffusion, dont le Neuser souligne le caractère tardif et incertain, de nouveau surdéterminé par les enjeux confessionnels: les premiers éditeurs furent des réformés de Heidelberg, peu enclins à la bienveillance envers Neuser. La traduction allemande concentre sur elle les doutes, que Lessing se plaît à formuler de la manière la plus modérée: "je ne soutiens pas que la lettre tout entière ait été inventée ${ }^{45}$ ".

Sur ce point, il a vu juste. La recherche sur Adam Neuser a franchi en 2014 un pas important avec la découverte, à la bibliothèque de Gotha, de deux exemplaires latins de la lettre au sultan de la main même de Neuser $^{46}$. Il ne s'agit pas à proprement parler de l'original, saisi pendant l'été 1570 et qui a dû dormir dans quelque grenier d'État avant de se perdre. Le texte, ramené d'Istanbul par le prédicateur Gerlach dont il a déjà été question, s'apparente à une reconstitution de mémoire, par Neuser, des arguments de sa lettre à Selim II. Les deux versions, très peu différentes, ont été rédigées dans l'été 1572 et en 1575 pour compléter le projet d'apologie caressé au moment de la fuite en Transylvanie ${ }^{47}$. Dans l'attente d'une publication complète, Martin Mulsow a montré ce qui distingue cette reconstruction manuscrite $\mathrm{L}_{3}$ de la version $\mathrm{L}_{2}$ éditée au XVIII ${ }^{\mathrm{e}}$ siècle.

Le Neuser de Lessing peut alors se lire comme une apologie continuée, la poursuite d'un plaidoyer, celui de Neuser lui-même, dont nous possédons aujourd'hui les matériaux et que Neuser, selon toute vraisemblance, ne mena pas à bien ${ }^{48}$. On a vu que l'argumentation de Lessing se concentre, voire s'engloutit dans la démonstration que la lettre au sultan n'a pas été envoyée à son destinataire. C'est en bonne partie déjà le scopus de $\mathrm{L}_{1}$, qui se présente de ce fait comme une lettre sur une lettre ${ }^{49}$. Nulle mise en abyme chez Neuser, simplement une tentative de défense, pour se justifier de l'accusation de haute trahison au bénéfice de laquelle $\mathrm{L}_{2}$ livrait une pièce à conviction. Tout au plus peut-on souligner, sous la plume de Neuser, l'effet de cette extraordinaire dénégation: je ne suis pas un traître, je n'ai pas envoyé de lettre au sultan, d'ailleurs je suis auprès du sultan ${ }^{50}$. 
Lessing toutefois fait davantage. Il est significatif que pour exposer l'argument principal, le Neuser passe de la citation à la paraphrase:

Je l'ai écrite, dit Neuser, cette malheureuse lettre, si incomprise; mais je ne l'ai jamais envoyée; je ne l'ai donnée à lire à personne; par une clause ajoutée de ma main, je l'ai pour ainsi dire anéantie; et j'ai fait en réalité le contraire de ce que j'avais l'intention de faire ${ }^{51}$.

Simple reformulation, pour remédier à ce que les protestations de Neuser peuvent avoir de laborieux? Peut-être, mais la voix de l'exilé s'en trouve couverte par celle de son avocat. Cela n'est pas sans effet. Si l'on y prête attention, le contenu de la lettre au sultan est très largement passé sous silence dans le Neuser. Lessing n'en cite que rarement le texte dans les versions allemandes existantes et se contente pour l'essentiel d'une citation indirecte, en latin, dans une paraphrase due au théologien réformé Heinrich Alting ${ }^{52}$. Le début du Neuser avait pourtant pris soin d'indiquer que le texte d'Alting avait été " intégré " en 1701 au recueil des Monumenta de l'Église palatine, qui contiennent la première édition imprimée de la lettre ${ }^{53}$. C'est dire que Lessing avait le choix et qu'il l'avoue.

Poursuivons: le bref aperçu de $\mathrm{L}_{2}$ donné via Alting s'en tient à la proposition d'alliance des antitrinitaires avec le sultan: "... et cum ipso coniungi ". La conversion de Neuser en est absente: là-dessus, Lessing ne laisse rien dire aux sources imprimées. D'une certaine manière, ce choix accrédite l'argumentation des réformés: l'affaire antitrinitaire n'aurait été jugée que pour des raisons de politique impériale, et non de religion. La " révision du procès " doit d'abord se placer sur ce terrain. Lessing cependant distingue. L'érudition réformée soutient que c'est pour haute trahison que Sylvan a été exécuté, mais précisément: il s'agit de Sylvan et non de Neuser, qui assure que son compagnon ne savait rien de ses projets ottomans ${ }^{54}$. Juridiquement, Sylvan ne pouvait être convaincu de haute trahison, il n'a pas écrit au sultan et " c'est seulement à cause de sa doctrine et de ses blasphèmes contre le Christ qu'il a été mis à mort »: rabies theologica, furie des théologiens, tel fut le vrai motif ${ }^{55}$. S'en tenir au volet politique pour présenter l'affaire, c'est faire voir l'hypocrisie des sources. En cantonnant sa restitution de la lettre au sultan à sa tradition la plus indirecte, sans en citer le texte, Lessing marque sa défiance 
envers la documentation disponible, dans laquelle, par ailleurs, il n'est pas loin de noyer son lecteur.

Il faut y insister: rien n'empêchait Lessing de citer $\mathrm{L}_{2}$ dans l'une des versions imprimées qui circulaient. Lui-même déclare que le texte n'en a pas été " tout entier " inventé56: la modération du philologue vient maintenant en renfort d'un scrupule drastique, qui interdit de citer un texte existant! Le résultat est clair: l'inédit $L_{1}$ devient la seule source autorisée pour rouvrir le dossier Neuser. Il suffit toutefois de le lire pour s'apercevoir qu'il dit peu de choses, et mal. Qu'importe: Lessing parlera à la place de Neuser, pour Neuser, mieux que lui.

Le procédé est pour le coup parfaitement ésotérique: silence et bavardage se combinent pour dévoiler le sens. De la lettre au sultan saisie par les autorités, nous ne saurons rien, hormis cette pure négation: qu'elle n'a pas été envoyée. Ici Lessing précède Poe et le complique déjà. La lettre saisie reste une lettre volée, jamais adressée mais partout consultable, sauf dans le texte de Lessing, où elle se cache sous une autre lettre qui d'ailleurs ne parle que d'elle.

On en oublierait presque que Neuser est mort musulman à Istanbul. Peut-être faut-il l'oublier. Peut-être n'est-ce déjà plus l'essentiel. Lessing le dit: la fin n'est pas l'âme de l'histoire ${ }^{57}$. Qu'estce qui compte alors?

\section{Lessing et l'islam}

Ce n'est pas que l'islam laisse Lessing indifférent. Au contraire, on est frappé par la constance chez lui d'un intérêt musulman, qui s'éveille tôt. En 1753-1754, à vingt-quatre ans, Lessing traduit et préface l'Histoire des Arabes sous le gouvernement des Califes de l'abbé de Marigny ${ }^{58}$ (1750); il s'était frotté au sujet l'année précédente dans sa traduction des écrits historiques de Voltaire, qui incluait un "Von dem Korane und Mahomed ${ }^{59}$ ". Son rapport à l'islam est immédiatement un rapport à la science de l'islam ${ }^{60}$. Pour défendre Marigny et sa "légèreté " d'historien français, comme il la qualifie lui-même ${ }^{61}$, le jeune traducteur se lance dans une pesée encore hésitante des autorités orientalistes: Herbelot, Ockley, Eusèbe Renaudot, Assemani, Schultens, Sale ${ }^{62}$. Il s'agit de tenir tête à la "pesante érudition ${ }^{63}$ ", mais sans opposition de principe: la conscience philologique de Lessing s'est formée, on l'a vu, dès les années $1750^{64}$. 
Il n'est donc pas surprenant que le savoir sur l'islam prenne place, au même moment, dans l'entreprise des Rettungen. C'est ici un premier fil qui se tire en direction du Neuser. L'apologie de Jérôme Cardan, en 1754, retourne une accusation: par sa "comparaison des religions ", le savant humaniste n'a pas attenté à la religion chrétienne, ce sont les autres religions qu'il a au contraire maltraitées. Ses "sophismes " n'ont que partiellement l'excuse de l'ignorance:

Les informations dont on disposait à son époque sur Mahomet et ses doctrines étaient très insuffisantes, mêlées de mensonges que les polémistes chrétiens prenaient d'autant plus volontiers pour des vérités qu'ils faisaient leur jeu. Nous n'en avons acquis une connaissance honnête qu'à travers les œuvres d'un Reland et d'un Sale, qui ont le mieux permis de voir que Mahomet n'est pas cet imposteur fou et que sa religion n'est pas ce tissu d'absurdités et de faussetés mal reliées les unes aux autres. Mais tout ceci n'excuse pas encore Cardan: lui qui s'est intéressé à tant de choses inconnues aurait pu aussi s'intéresser à celles-ci avant de s'attaquer à une comparaison qui, si elle doit être digne d'un philosophe, suppose des connaissances complètes ${ }^{65}$.

Entre-temps la liste des autorités islamologiques s'est encore enrichie $^{66}$, et Lessing a renoncé à ménager l'équilibre entre les agréments du récit à la française et la rigueur érudite du Nord. L'islam apparaît désormais comme l'objet d'un savoir neuf, enrôlé comme tel dans le projet apologétique.

Cardan, dit Lessing, aurait dû acquérir des « connaissances complètes » sur l'islam. La probité du philologue lui impose de retrouver ces connaissances sans faire appel à une science à laquelle Cardan n'avait pas accès. Il suffit pour cela d'écouter un musulman, "qui n'a pas besoin d'être le plus savant ${ }^{67}$ ». Ce que celui-ci expose est la religion naturelle, contenue dans la loi du Prophète:

Qu'y trouves-tu qui ne soit en accord avec la raison la plus rigoureuse? Nous croyons en un Dieu unique; nous croyons en une sanction et en une rétribution dans le futur, qui l'une ou l'autre nous atteindront en fonction de nos actions. C'est cela que nous croyons, ou plutôt, pour éviter de me servir de vos mots profanés, c'est de cela que nous sommes convaincus, et de rien d'autre! Sais-tu ce que tu dois faire, si tu veux entrer en controverse avec nous? Il te faut prouver l'insuffisance de nos principes! Il te faut prouver que l'homme 
est tenu à quelque chose de plus qu'à connaître Dieu et qu'à être vertueux, ou tout au moins que ces deux choses-là ne peuvent lui être enseignées par la raison, qui lui a pourtant été donnée pour cela ${ }^{68}$ !

Lessing bien sûr se retranche derrière le propos d'un autre, qu'il regretterait presque d'avoir fait trop parler ${ }^{69}$. Le procédé, classique, se retrouve à l'identique vingt ans plus tard dans le texte De la tolérance pour les déistes (Von Duldung der Deisten), qui suit Adam Neuser dans les Beiträge. Cette fois, il s'agit d'une citation directe de l'"anonyme ", auteur du fragment édité, Hermann Samuel Reimarus:

J'oserais même, si c'était là principalement mon intention, montrer que ce qu'il y a de plus élevé dans la religion naturelle se retrouve clairement et en partie même élégamment exprimé dans le Coran, et je crois que je rencontrerais sans peine l'assentiment des spécialistes si je disais que l'essentiel ou presque de la doctrine de Mahomet aboutit à la religion naturelle ${ }^{70}$.

On aura garde d'oublier que Reimarus était professeur de langues orientales ${ }^{71}$. La suite du passage cité par Lessing mentionne ses collègues et prédécesseurs: Sale encore, Thomas Hyde ${ }^{72}$. De l'intérieur du savoir orientaliste, le parallèle musulman a fini par mener à une forme d'approximation de la religion naturelle. La critique historique de la Bible, dans les textes de Reimarus publiés plus tard par Lessing, viendra la renforcer d'arguments négatifs. De ce point de vue, l'islam et sa science créent une liaison entre les premiers essais de Lessing traducteur et les grandes controverses, avec Goeze notamment, qui animeront les dernières années à Wolfenbüttel.

\section{La synthèse islamo-naturelle}

Von Duldung der Deisten commence là où le Neuser s’arrête. Dans les premières lignes, l' " observation principale " à laquelle tout " lecteur pensant " doit être conduit à la lecture du Neuser est présentée comme une évidence ${ }^{73}$. Le sens du texte semble enfin stabilisé:

Car lorsque Neuser en fut arrivé au point de n'avoir aucun scrupule à se convertir à la religion mahométane, il n'était vraisemblablement pas devenu un visionnaire qui se fût convaincu de la vérité 
de la religion mahométane, comme religion révélée, de préférence à la religion chrétienne. C'était un déiste, qui considérait les religions révélées à égalité comme des inventions, et que seule la persécution la plus dure mena à une tromperie à laquelle il n'eût jamais songé, s'il avait pu trouver dans la chrétienté la tolérance que notre Anonyme réclame pour ce genre d'hommes ${ }^{74}$.

L'évidence cependant vacille, et le commentaire perd vite en assurance. Un terme étrange apparaît:

Il se peut cependant que Neuser ait eu aussi une sorte de prédilection (Prädilection) pour la religion mahométane et qu'il lui ait rendu la justice que des savants aussi courageux qu'irréprochables ont cru depuis peu de temps devoir lui témoigner ${ }^{75}$.

Comme souvent, le latinisme signale une difficulté. Quelle est cette " Prädilection " pour l'islam? Lessing rapproche Neuser des " savants " des Lumières, et la "justice " rendue à l'islam relève de la probité dont le philologue a fait son idéal. Pourtant, aucun des orientalistes, déistes ou non, que Lessing cite depuis 1753 ne s'est approché d'aussi près que Neuser de l'islam: jusqu'où va donc la "prédilection »? Lessing ne s’attarde pas et feint de réserver l'examen du problème à la redécouverte des notes laissées par Neuser sur son exemplaire du Coran $^{76}$.

La question est pourtant de principe. La "prédilection " musulmane de Neuser dit le contraire de l'attitude du déiste qui considère "à égalité " les religions révélées. Elle signale une affinité particulière, à travers l'approximation de religion naturelle que Reimarus, dans le même passage, va chercher dans l'islam. Ici s'ouvre un espace incertain, entre la religion naturelle et les confessions: l'espace d'une religion, celle de Neuser, qui n'est pas une confession mais qui s'établit, s'atteste dans le contact avec une confession, l'islam, l'espace encore d'une nature religieuse qui s'institue dans le choix d'une confession. Il faut pour le moment laisser flottant le sens de cette " nature " religieuse, entre l'idiosyncrasie du personnage Neuser — nature étrange assurément - et l'affirmation déiste d'une naturalité de la religion: tout homme est religieux. C'est dans cet espace en tout cas rétif aux versions convenues de la religion naturelle qu'il va falloir situer Lessing. 


\section{La synthèse islamo-hérétique}

Von Duldung der Deisten est un point d'arrivée. Comment s'est ouvert l'espace que nous venons de repérer? La réponse se trouve encore dans les Beiträge. La deuxième livraison de Zur Geschichte und Literatur (1773) inclut une Défense de la Trinité de Leibniz (1669), avec le détail des objections du socinien Andreas Wissowatius auxquelles Leibniz répond ${ }^{77}$. Le commentaire de Lessing contient ce passage particulièrement difficile:

Leibniz n'avait pas de scrupule, s'agissant de ces sociniens à qui leurs frères rechignent à décerner ce titre parce qu'ils concèdent librement qu'ils ne parviennent pas à vénérer celui qu'ils ne tiennent pas pour Dieu, qu'il s'agisse de le prier comme Dieu ou d'une autre manière, avec Dieu ou à côté de Dieu ou en relation avec Dieu — il n'avait pas de scrupule, dis-je, à les tenir pour les meilleurs et les plus raisonnables des sociniens. Car si ceux-ci ne sont pas des sociniens à proprement parler, ils sont à l'évidence les meilleurs et les plus raisonnables des unitariens. Avec les sociniens, ils ont en commun une même erreur; mais au regard de cette erreur, ils agissent de façon plus conséquente. Quant à savoir ensuite s'ils diffèrent peu ou beaucoup des mahométans: quelle importance? Ce n'est pas le nom qui compte, mais la chose même; et qui a le courage d'enseigner la chose même, ou de l'insinuer, devrait être assez franc pour ne pas se dérober au nom. Aussi bien, qu'ont-ils à objecter de sérieux aux conséquences qui découlent avec nécessité de leur doctrine, et que personne n'a poussées contre eux plus loin qu'Abbadie? À savoir que si le Christ n'est pas le vrai Dieu, alors la religion mahométane constitue une indiscutable amélioration de la religion chrétienne, et Mahomet lui-même est un homme incomparablement plus grand et plus digne que le Christ; dès lors qu'il fut bien plus sincère, bien plus prudent et plus zélé pour la gloire du Dieu unique que le Christ, lequel, s'il ne s'est certes jamais donné pour Dieu, a du moins déclaré une bonne centaine de choses ambiguës pour laisser entendre qu'il se considérait comme une Personne de ce Dieu, alors qu'aucune ambiguïté de ce genre n'est imputable à Mahomet ${ }^{78}$.

Le point de départ est à chercher dans les controverses internes à la mouvance antitrinitaire sur la question de l'adoration de Jésus. Nous verrons qu'elles reviendront en force dans le Neuser ${ }^{79}$. Leibniz n’en fait pas directement état dans le texte de 1669 édité par Lessing, mais il en a eu connaissance. La suite du commentaire cite en effet 
longuement une lettre de 1706 de Leibniz à Veyssière de La Croze, dont le texte complet mentionne le différend du superintendant unitarien de Transylvanie Ferenc Dávid avec Faust Socin et Giorgio Biandrata sur l'adoration du Christ: exactement, donc, le milieu où évolua Neuser ${ }^{80}$. L'argument de Lessing est leibnizien jusqu'à la lettre. L'idée que les unitariens regroupés autour de Ferenc Dávid furent plus "conséquents " que les sociniens dans leur hérésie est directement transposée de la lettre à La Croze: en refusant de rendre un culte à Jésus-Christ, disait Leibniz, les musulmans "agissent plus conséquemment que les sociniens ${ }^{81}$ ". Les unitariens font preuve de la même " conséquence »: le Neuser y reviendra dans un long développement anti-socinien, également introduit par la correspondance de La Croze ${ }^{82}$. "Conséquemment ", " consequent »: Lessing a transformé l'adverbe français de Leibniz en un Fremdwort promis à un riche avenir philosophique.

Lessing lit donc Leibniz selon un mouvement rétrograde: 1669 s'éclaire par 1706. Dans quel but? S'agit-il d'introduire l'islam et d'ouvrir le fil de discussion qui va se poursuivre dans le Neuser et dans le texte sur les déistes? Les effets de série sont très étudiés dans les Beiträge: le texte sur Leibniz et Wissowatius prend luimême la suite d'un texte sur Leibniz et le médecin socinien Ernst Soner ${ }^{83}$. Pourtant la question de la proximité entre unitariens et musulmans est écartée aussi vite qu'elle est introduite, dans la même phrase: "quelle importance? " L'opposition est entre le "nom ", l'appellation confessionnelle, et une "chose même " que Lessing ne définit pas: "ce n'est pas le nom qui compte, mais la chose même". L'instant qui suit toutefois, la chose fait le nom: "qui a le courage d'enseigner la chose même, ou de l'insinuer, devrait être assez franc pour ne pas se dérober au nom ». Le texte ne dissimule pas sa contradiction: les unitariens seraient donc des musulmans?

La réponse de Lessing ne viendra pas: nous sommes à mi-chemin du " nom » et de la " chose ", de la même façon que Neuser s'est placé entre unitarisme et islam, islam et religion naturelle. En lieu et place de la réponse attendue, une digression détaille les « conséquences » de la doctrine des unitariens et prend les traits convenus de la comparaison entre Jésus et Mahomet. Le propos évite de se clore, et Lessing renoue avec sa critique des sociniens: 
Pour s'assurer plus encore de la répugnance sincère de notre philosophe envers tous les principes des sociniens, il suffira de se souvenir de son insatisfaction face à toute leur philosophie, qu'il plaçait très en-deçà de celle des mahométans ${ }^{84}$.

On pourra dire que l'islam fournit la surface de comparaison qui permet de disqualifier le socinianisme, à proportion de son inconséquence. L'islam des Beiträge serait alors l'autre religion, face à laquelle les hérésies chrétiennes peuvent se mesurer les unes aux autres et prendre leurs distances, dans une nouvelle hiérarchie des systèmes religieux et de leurs " conséquences ".

L'hypothèse est plausible mais elle est incomplète. Il s'agit ici d'un rapport entre hérésies chrétiennes (socinianisme et unitarisme), mesuré par l'islam. Nous ne savons encore rien du concept d'orthodoxie que Lessing place en regard de son étude des antitrinitarismes. L'idée comporte en outre un risque, celui d'inférer que l'islam ne compterait pas pour lui-même ou qu'il serait instrumentalisé dans la discussion. Ce serait faire peu de cas du fort intérêt musulman qu'on a vu chez Lessing.

Ce que nous savons permet déjà une observation. Nous avons vu comment Lessing exploite l'identification des appartenances confessionnelles dans sa pratique de l'érudition ${ }^{85}$. Le texte de 1773 sur les Objections de Wissowatius possède une tonalité confessionnelle très reconnaissable. Lessing cite et glose Leibniz écrivant à Veyssière de La Croze, bibliothécaire lui aussi mais réformé du Refuge, alors que Leibniz et Lessing sont luthériens. La digression de notre passage, sur les "conséquences" musulmanes de l'unitarisme, mentionne Jacques Abbadie (vers 1654-1727), premier aumônier de la colonie huguenote de Berlin après la révocation de l'édit de Nantes et apologète à succès ${ }^{86}$. Abbadie et La Croze sont deux pôles, ecclésial et érudit, d'un même monde, le monde réformé de Berlin, où la discussion sur le socinianisme fut vive ${ }^{87}$.

Un indice supplémentaire est laissé à la fin du Wissowatius. Lessing écrit:

Précisément [du] vivant [de Leibniz], un débat s'éleva parmi plusieurs réformés sur une question préjudicielle, celle de savoir s'il est possible, et si oui, utile de fonder la religion chrétienne sur des preuves purement naturelles, et de confier à la seule raison le soin de convaincre de leur vérité. Toutefois, soit que Leibniz n’ait pas eu connaissance de ce débat, soit qu'il l'ait cru tranché en faveur de 
l'opinion qui avait jusqu'ici prévalu, dans tous les cas il continua à penser sur ce sujet comme on le lui avait enseigné dans sa jeunesse ${ }^{88}$.

Cette mention du débat sur la religion naturelle prend la suite du développement sur Jésus et Mahomet. De fait, "du vivant de Leibniz » et parmi les réformés, c’est vers Abbadie et son Traité de la vérité de la religion chrétienne qu'on pouvait se tourner pour trouver une fondation du christianisme par la "révélation naturelle ${ }^{89}$ ". Pour Lessing, un tel best-seller apologétique se trouvait encore à portée de main, mais le choix peut étonner. Comment expliquer la concentration du propos sur la discussion réformée, au regard du caractère très général de la question traitée, la religion naturelle, et de l'identité particulière des parties prenantes, Leibniz et Wissowatius, un luthérien et un socinien?

Pour l'érudition confessionnalisée de 1770, la réponse est claire: Lessing renvoie à ce que la controverse intra-protestante désigne avec insistance, à partir de la seconde moitié du XVI ${ }^{\mathrm{e}}$ siècle, comme la collusion du calvinisme avec l'hérésie antitrinitaire ${ }^{90}$. Le Wissowatius lance plusieurs signaux de connivence avec Leibniz et l'enseignement luthérien qu'il a reçu " dans sa jeunesse ${ }^{91}$ ». Dans ce prolongement, Lessing retrouve deux lignes anciennes de l'apologétique luthérienne, qui relient le calvinisme à l'antitrinitarisme et à l'islam. Neuser lui-même faisait état de la première, dans une note manuscrite recueillie par son interlocuteur Gerlach:

Personne de nos jours ne devient arien sans avoir été calviniste. [...]

Celui qui craint de tomber dans l'arianisme, qu'il prenne garde au calvinisme $^{92}$.

Lessing laisse une trace de ces débats anciens en mentionnant les " théologiens luthériens » qui avaient voulu " attribuer l'apostasie de Neuser à son calvinisme ". "À tort ", ajoute-t-il fugacement ${ }^{93}$, mais son exposé est tout entier construit sur la discussion de ce biais confessionnel.

L'assimilation des réformés à des musulmans est elle aussi un thème luthérien. Dans les triangulations de la première modernité allemande entre catholiques, luthériens et réformés, chaque confession est "turque " pour les deux autres: calvinoturcismus, turcopapismus $^{94}$... Depuis les années 1570 au plus tard, les luthériens scrutent intensément dans la discipline calviniste, mais aussi dans la christologie des réformés ou dans leur réticence à chercher les 
preuves de la Trinité dans la Bible hébraïque, les preuves de ce que " $99 \%$ " de leur doctrine concorde avec celle des " Ariens » et des "Turcs ${ }^{95} »$.

La Prädilection de Neuser était donc encore un leurre: la synthèse islamo-hérétique dans le Dieu un non trine ne se nourrit d'aucune mystérieuse affinité de l'islam avec l'antitrinitarisme, non plus qu'avec le calvinisme censé le préfigurer. Elle s'objective, prend corps dans l'antagonisme des confessions à l'échelle de l'Empire, sous la forme de ce qu'on serait d'abord tenté de considérer comme la simple reprise d'un argument de controverse. C'est toutefois la condition pour que l'effet de série déjà évoqué dans les Beiträge puisse jouer à plein: avant même le Neuser, le rapprochement entre musulmans et antitrinitaires est pour ainsi dire calculé à partir d'un repère réformé. Lessing prend même soin de rappeler que Wissowatius, après l'expulsion des Frères polonais, se réfugia en 1663 à Mannheim, future résidence de l'électeur palatin ${ }^{96}$.

Le passage du Wissowatius au Neuser suggère ainsi la poursuite d'une histoire souterraine dans deux grands territoires de l'Empire, l'histoire des liens entre calvinisme et hérésie dans la Prusse du Refuge et le Palatinat du second $\mathrm{XvI}^{\mathrm{e}}$ siècle. Abbadie, La Croze, les réformés berlinois récusent le socinianisme en le comparant à l'islam, mais l'histoire plus ancienne de leurs coreligionnaires palatins laisse penser qu'ils cherchent surtout à conjurer le trauma Neuser. La suggestion est faite depuis un poste d'observation où Lessing rejoint Leibniz, son prédécesseur à Wolfenbüttel: une bibliothèque dans une principauté provinciale et luthérienne, une foi « démodée " en la Trinité divine, une insistante orthodoxie ${ }^{97}$.

Une difficulté est donc réglée, une autre demeure. On a compris qu'il serait trop simple d'estimer que l'islam est instrumentalisé par la polémique confessionnelle. L’intérêt orientaliste de Lessing et celui qu'il prend à la théologie de controverse ne se laissent pas hiérarchiser: ils diffèrent en nature mais vont de pair. La série formée par le Wissowatius et le Neuser actionne et déforme en même temps les ressorts des cultures confessionnelles, qui peuvent alors fournir la matière d'un travail théorique. De ce travail chez Lessing, nous tenons le point de départ: entre la religion naturelle et les religions révélées, la distinction est surdéterminée par une autre distinction, celle des confessions, dont il faut partir. Le constat s'impose à Lessing, érudit confessionnalisé, qui l'exploite en philosophe du confessionnel. 
Dans quel but toutefois? En 1773, l'affaire Neuser était depuis longtemps un cold case dans l'affrontement des confessions. Fallaitil donc encore, pour parler de déisme et d'hérésie, s'intéresser aux réformés de 1570 et de 1680, aux détails de leur discipline et de leur doctrine? Entre confessions protestantes, le débat était devenu aussi "démodé ", comme le dit Lessing, que le dogme de la Trinité: à quoi bon y revenir? À ce stade domine l'impression d'une manie documentaire sans mobile apparent: l'intention réelle des synthèses lessingiennes ne s'est pas encore dévoilée.

\section{La conversion d'Adam Neuser}

Von Duldung der Deisten assimile la conversion de Neuser à l'islam à une tromperie, "Tausch" ${ }^{98}$ ". Le terme est encore plus fort que la "comédie " qu'évoquait le Neuser ${ }^{99}$. Si la "prédilection" musulmane de Neuser était une fausse piste, il reste une manière simple de lire Lessing: la conversion de Neuser à l'islam, expédient d'un antitrinitaire persécuté, livre un argument en faveur de la religion naturelle. Sans Tolérance pour les déistes, il y aura toujours des Adam Neuser: en se faisant musulman, Neuser ne cherchait qu'à "s'en sortir de la meilleure manière ${ }^{100}$ ». Cette version a sa robustesse; elle trouve une formulation nette à au moins un endroit du Neuser ${ }^{101}$. Voyons ce qui peut l'accréditer.

L'histoire d'abord: nous savons que Neuser eut des sincérités successives, y compris après son transfert à Istanbul. Lessing cite un passage du journal de Gerlach évoquant un retour possible " chez les protestants ${ }^{102}$ ». Les faits sont connus: à l'occasion de l'ambassade de David Ungnad à Constantinople, Neuser, autour de 1575, a œuvré comme agent double, restituant aux émissaires impériaux les lettres interceptées (encore!) qu’il était chargé de déchiffrer pour le compte du sultan ${ }^{103}$. Par ce rachat, il pouvait espérer un retour dans sa patrie, ainsi que la libération de son fils retenu en otage. À cette occasion, Neuser s'est inventé un destin: les papiers découverts à Gotha le montrent se comparant à Zopyre, le satrape perse qui se mutila devant Babylone pour faciliter la prise de la ville par Darius I ${ }^{\text {er104}}$. On avait donc mal compris: le passage à Istanbul était un sacrifice à la cause impériale !

À supposer qu'ils aient eu vent de ces justifications, les diplomates impériaux ne semblent pas s'en être beaucoup émus. Neuser fut vite 
abandonné à son sort et ses dernières déclarations, selon Gerlach, furent pour nier l'immortalité de l'âme ${ }^{105}$.

Lessing connaissait pour sa part une autre explication, développée par Neuser dans la lettre qu'il édite. Elle précède de quelques mois la fantaisie perse retrouvée à Gotha. Dans cette version des faits, le passage à Istanbul aurait été une sorte de voyage d'étude:

Voyant que j'errais sur les matières de Trinité, je décidai à part moi de tout tenter pour apaiser ma conscience inquiète et errante. Comment cela devait-il se faire? De quelle façon? L'usage, quand on doute d'une chose, est de partir et de se rendre sur place, sur les lieux où les choses se sont passées, et d'y explorer la vérité pour être certain des faits. Car nous savons que le pape n'a cessé de nous raconter des mensonges et de fausses histoires et qu'il s'est toujours empressé de bannir la droite vérité par le fer et par le feu. Or où pouvait-on mieux s'enquérir de la vérité sur la Trinité, sinon à l'endroit où la querelle et la controverse se sont d'abord menées? Or cette controverse a commencé à Constantinople, comme le rapportent tous les livres d'histoire ${ }^{106}$.

La suite confond curieusement les siècles ${ }^{107}$, mais Neuser, avant Zopyre, se donne déjà un modèle, Paul, "devenu tout pour tous, pour les juifs un juif, pour les païens un païen » - et pour les Turcs un Turc ${ }^{108}$. Le voyage d'étude était donc aussi apostolat!

Sur ce point, Lessing prend une décision remarquable, sans doute la plus importante du texte:

[...] ce que [Neuser] allègue pour son excuse semble en partie relever du pur et simple enjolivement: je parle de ce qu'il dit de l'intention dans laquelle il a écrit cette lettre. L'exemple de saint Paul est très manifestement maltraité ${ }^{109}$.

Cette brusque mise à l'écart des justifications de Neuser peut s'expliquer: l'adhésion de Neuser à l'islam était exprimée avec une parfaite netteté dans la lettre à Selim II. Elle y prenait la forme d'une confession de foi:

Car par la grâce du Dieu tout-puissant, je reconnais et je crois de tout mon cœur que votre doctrine ou religion est vraie, pure, sincère, et qu'elle plaît à Dieu ${ }^{110}$.

Dans ces conditions, comment prendre au sérieux ce que Neuser, quatre années plus tard, a pu avancer pour sa défense? 
Neuser s'est évidemment converti à l'islam, mais cela va sans dire, cela doit aller sans dire. L'extrême rapidité de Lessing sur ce point, sa manière expéditive de traiter les motivations alléguées par Neuser n'ont d'égales que la clarté de la lettre au sultan, qu'il ne cite presque jamais dans son apologie. On a vu pourquoi: parce qu'il juge le texte en partie interpolé, et surtout parce qu'il estime que son contenu importe moins que le fait que la lettre n'a jamais été envoyée à son destinataire. Le Neuser ajoute une troisième raison: de sa conversion, "Neuser lui-même ne dit rien dans sa lettre ", celle qu'il envoie depuis Constantinople ${ }^{111}$. Lessing, en somme, dissimule ce que Neuser en 1574 a choisi de faire oublier, et même $\mathrm{d}^{\prime}$ '" enjoliver ${ }^{112}$ ".

Cette décision doit être rapportée à celle que nous avons déjà relevée, à propos des pièces du procès à Heidelberg. La lettre de 1570 au sultan constituait un acte d'adhésion formel à l'islam, mais on n'en restituera rien et l'on se concentrera sur l'accusation de haute trahison plutôt que sur celle d'apostasie. Dans les deux cas, l'essentiel est caché sous couvert d'évidence, à l'image de la lettre de Neuser à Selim, clandestine et manifeste.

Tout cela a un effet: chez Lessing, le séjour du " malheureux unitarien » à Istanbul n'est en apparence motivé que par la " force des choses » et la nécessité de la fuite ${ }^{113}$. La réduction à la contrainte extérieure doit donc confirmer l'hypothèse: la conversion d'Adam Neuser à l'islam ne fut qu'un stratagème. L'affirmation concorde mal cependant avec les informations dont nous disposons, et dont Lessing disposait. Nous savons en effet que Neuser fut un lecteur attentif du Coran dès ses années à Heidelberg: la lettre au sultan en fournit la preuve, avec en son centre la démonstration que le Coran "rend témoignage " à Moïse et au Christ, " enseigne le sens vrai »< de l'Écriture, falsifié par les chrétiens ${ }^{114}$. La piste de la "prédilection " musulmane doit être rouverte, pour comprendre pourquoi Lessing, d'ordinaire si minutieux, si philologue, peut ici se montrer tellement désinvolte.

\section{La confession de foi d'Adam Neuser}

Dans l'univers confessionnel de Neuser et de Lessing, se convertir n'est pas d'abord tourner son cœur, se laisser convaincre dans le secret du soi: c'est confesser en parole une foi nouvelle, faire 
solennellement savoir qu'on a changé de camp. Cette accentuation particulière de l'acte public de confession se lit dès le début du texte, dans l'assemblage d'autorités qui fait l'ouverture. Chez Jöcher, "misérable compilateur", Neuser "se convertit publiquement à la religion mahométane "; pour Heineccius, source jugée plus fiable, il «se fit circoncire et professa publiquement la foi des mahométans ${ }^{115}$ ».

Il est intéressant de voir comment Neuser décrit le moment de sa conversion. La scène est non loin de Temesvár en Transylvanie, devant le pacha du lieu:

Et je dis: mon Dieu, je passais en Allemagne pour un ennemi des Allemands et pour un ami des Turcs, et ici parmi les Turcs on me prend pour un ennemi des Turcs et pour un ennemi de ma patrie, tout cela parce que, pour ce qui est de la Trinité, je ne crois qu'en un Dieu, tout comme les Turcs, ce pour quoi on a voulu me tuer. À quoi le pacha répond: s'il est vrai que comme nous tu crois au Dieu unique qui a créé le Ciel et la Terre, et si pour cette raison tu as été pris pour un Turc par les tiens, alors prouve-le par le fait, fais-toi Turc, et tu auras ensuite toute liberté pour publier tout ce qui te plaît contre tes ennemis. Mais si tu ne fais pas cela, tu devras t’attendre à courir tous les risques qui t’ont été décrits. Je répondis alors que j'avais lu l'Alcoran, et avec plaisir, raison pour laquelle on m'a pris pour un Turc. À peine le pacha entend-il cela, qu'il déclare qu'il veut m'envoyer à l'empereur à Constantinople; c'est là que je suis encore aujourd'hui, auprès du premier truchement de l'empereur, qui est allemand ${ }^{116}$.

Entre le fuyard et le gouverneur, le dialogue prend la forme d'un échange accéléré de confessions de foi, avec leurs formulaires caractéristiques: " pour ce qui est de la Trinité, je ne crois qu'en un Dieu ", "s'il est vrai que comme nous tu crois au Dieu unique qui a créé le Ciel et la Terre ». Le moment n'est pas à l'argumentation, le pacha n'est pas un intellectuel, l'affaire est vite réglée: Neuser confesse le Dieu unique, il dit aimer le Coran, « on [l']a pris pour un Turc », il est donc musulman.

L'envoi de Neuser à Istanbul résulte ainsi de ce que le pacha interprète comme une confession de foi publique, une shahâda qui justifie que l'affaire soit instruite auprès d'autorités plus élevées. La chose frappante est que Neuser n'ait pas fait état d'une conversion, voire qu'il ait laissé entendre, à cet endroit du texte, que celle-ci pourrait avoir relevé d'un malentendu. Sur ce point, les 
formulations cultivent l'ambiguïté: dans le journal de Gerlach cité par Lessing, le fuyard dit au contraire avoir été envoyé à Istanbul " sans qu'[il] ne s’y oppose en rien, et bien plutôt en [s']en félicitant [lui]-même ». Le texte continue:

Car j'avais vu que l'Alcoran n'était pas étranger à la vérité et que sur tous les chapitres de religion ses opinions étaient les miennes ${ }^{117}$.

Le problème est celui-ci: Neuser a "vu » la vérité du Coran, mais l'a-t-il vraiment confessée? La zone grise que nous avons localisée tout à l'heure entre les confessions et la religion naturelle se déplace ici et s'étend sur l'adhésion de Neuser à l'islam et les modalités, confessantes ou non, prises par cette adhésion. La lettre à Selim II présente sans la moindre ambiguïté les deux composantes de la shahâda: affirmation du Dieu unique, reconnaissance de Mahomet comme son prophète - Neuser recourt à la formule rituelle: "Que la paix de Dieu soit sur lui ${ }^{118}$." On a affirmé que le texte ne constituait pas un acte d'abjuration formelle ${ }^{119}$. C'est vrai au sens des chrétiens, mais Neuser soutient l'idée authentiquement coranique que la révélation faite à Mahomet effacerait les falsifications et " malentendus " des révélations précédentes ${ }^{120}$ : quel besoin alors d'abjuration?

Certains érudits (Sand, Arnold, Gerber) ont douté de la conversion de Neuser. Lessing est catégorique: ils se trompent, Neuser est devenu musulman "selon toutes les formes requises ${ }^{121}$ ». Il faut décrypter: le pacha de Temesvár a vu juste, Neuser a bien prononcé sa "confession du Coran", sein Bekenntnis von dem Alkoran. Il s'abstient simplement de le dire en toutes lettres, et cela peut se comprendre:

Il dit seulement: "À peine le pacha entend-il cela (à savoir sa confession du Coran) qu'il dit qu'il veut m'envoyer à l'empereur à Constantinople; c'est là que je suis encore aujourd'hui, auprès du premier truchement de l'empereur, qui est allemand ». Mais devait-il en dire plus? Qui raconterait une comédie qu'il a dû laisser jouer avec lui-même? Pour un homme qui n'est pas totalement dépourvu de sentiment et de pudeur, s'y soumettre coûte les plus grands efforts: quoi d'étonnant qu'il évite toute nouvelle occasion de s'en souvenir ${ }^{122}$ ?

Neuser en 1574 contournerait ou escamoterait l'aveu de sa shahâda, comme en 1570 il avait retenu l'envoi de sa lettre de 
conversion. Les témoignages appelés à la suite soutiennent cette étrange preuve par le silence:

On n'aura pas le droit de mettre en doute ce que Neuser ne fait ici que taire sur lui-même, dès lors que la chose est confirmée par d'autres personnes crédibles qui ont pu en recueillir l'information sur place ${ }^{123}$.

Nous comprenons l'impression déjà ressentie d'un rapide oubli de l'islam dans le Neuser. Reconnaître, aussi vite que possible, et pour clore toute discussion, le fait de la conversion de Neuser, c'est en négliger délibérément les motivations. La conversion est traitée par Lessing comme elle l'a été par le pacha: elle est expédiée. À nouveau il ne semble plus pouvoir être question d'une " prédilection » musulmane.

L'énigme est donc celle-ci: Neuser s'est converti et il ne s'est pas converti. Il a eu recours à toutes les "formes requises ", mais les a comme désactivées. La shahâda qui nous reste de lui est écrite et clandestine, elle n'est donc pas une shahâda, elle est même le contraire d'une shahâda, qui doit être orale et publique, mais elle comporte les mêmes articles de foi. Sans doute a-t-il récité aussi la shahâda, du moins un officiel ottoman a-t-il cru l'entendre, mais Neuser est resté celui qu'il était - un antitrinitaire. De même, il s'est fait circoncire et n'est pas devenu musulman. Le texte cite un nouveau témoignage de Gerlach:

Et quand ses amis lui reprochent son apostasie (car ici toute religion est libre), il répond qu'il n’a pas changé de foi et qu'il nourrit dans son cœur celle qu'il a toujours eue. De sa circoncision, il se justifie en invoquant l'exemple de certains peuples convertis par saint Matthieu — je ne sais desquels il s'agit —, qui de toute antiquité ont maintenu à la fois le baptême et la circoncision ${ }^{124}$.

\section{Lessing commente:}

Le sophisme de la circoncision ne peut avoir été une invention des abrutis dépravés qui tenaient compagnie à Neuser; il n’a pas été non plus une invention de Gerlach, qui reconnaît lui-même que les faits qui le justifient lui sont inconnus. On peut donc raisonnablement estimer qu'il vient de Neuser lui-même et qu'il démontre plus que toute autre chose que l'opération que Neuser a voulu enjoliver par ce sophisme a réellement été pratiquée sur lui. Ce sont les chrétiens 
d’Éthiopie qui, comme chacun le sait désormais, ont les deux choses, circoncision et baptême. Neuser en a sans aucun doute eu connaissance parmi les Grecs. L'ignorance de Gerlach sur ce point montre que la chose semblait encore totalement incroyable dans l'Allemagne de l'époque. Du reste je note que ce n'est qu'en 1574 que nos compatriotes ont pris connaissance de la Confession de foi éthiopienne, telle qu'elle fut transmise en 1534 par Zaga Zabo au Portugal ${ }^{125}$.

La circoncision de Neuser fut un "sophisme" comme sa confession de foi fut une " comédie ». L'une et l'autre, chez Lessing, sont d'autant moins significatives qu'elles sont mieux authentifiées ou plus vraisemblables, et elles sont d'autant plus vraisemblables qu'elles sont plus fortement niées, recouvertes par un silence de honte ou un remords d'ivrogne, comme dans les divagations de Neuser sur les chrétiens d'Afrique. Les marques de la conversion sont méthodiquement rendues triviales dans Adam Neuser: évidentes et un peu infâmantes.

C'est peu dire que l'énigme de la conversion n'est pas éclaircie par ce portrait de Neuser en artiste de la dénégation. Le problème est finalement résumé dans cette exclamation:

Il est très bien que les religions se soient elles-mêmes compliqué le passage, au point de rendre difficile à un honnête homme d'aller de l'une à l'autre ${ }^{126}$ !

Qu'y a-t-il de si heureux à ce que les religions se ferment les unes aux les autres? Pourquoi se réjouir des entraves à la conversion? Il n’est pas étonnant que la réponse ait été apportée, cinq ans après Adam Neuser, non pas précisément dans une "comédie ", mais dans un " poème dramatique »: Nathan le Sage.

\section{Nathan et l'interdit de la conversion}

Nul n'ignore que Nathan le Sage plaide l'égale dignité et l'origine unique des trois religions, judaïsme, christianisme, islam. L'unité des religions est déduite de l'humanité de l'homme ( le chrétien et le juif sont-ils chrétiens et juifs avant que d'être hommes? ») et on y insiste moins - de l'indisponibilité de Dieu ( Q Qu'est-ce qu’un Dieu qui appartient à l'homme ${ }^{127}$ ? »). L'indisponibilité de Dieu s'étend à la vraie foi, " introuvable » et indémontrable au terme de 
la célèbre parabole des trois anneaux ${ }^{128}$. Il faut toutefois ajouter que le Nathan, pièce sur la tolérance, est, en outre ou peut-être d'abord, une pièce sur l'impossibilité de la conversion. Cette impossibilité est le corollaire oublié et nécessaire de la démonstration principale.

$\mathrm{Au}$ début de la pièce, Nathan, riche marchand de retour à Jérusalem, apprend que sa fille Recha a été sauvée des flammes par un jeune templier captif à qui le sultan Saladin avait laissé la vie sauve en raison de sa ressemblance avec un frère défunt. À ce moment, Recha comme son sauveur ignorent qu'elle est née chrétienne, recueillie et adoptée par Nathan après qu'il eut perdu sa femme et ses sept fils dans un massacre perpétré par, précisément, des chrétiens. Bien entendu, Recha et le templier s'éprennent l'un de l'autre, mais Nathan résiste. On en apprend la raison dans la scène finale: Recha et le templier sont frère et sœur, tous deux enfants du frère disparu du sultan. Celle qui se croyait juive est chrétienne et fille de musulman, comme est fils de musulman le templier gracié par le sultan.

Dans l'Orient du Nathan, les appartenances se mêlent mais ne changent pas. Que Recha élevée juive se découvre chrétienne n'implique aucune conversion: changer de religion est aussi impossible que d'épouser son frère. Le rêve de sa gouvernante chrétienne Daja, à l'idée d'un mariage de Recha et du templier:

Alors la jeune fille reviendra parmi les chrétiens,

Redeviendra ce qu'elle est et sera de nouveau

Ce qu'elle devenait ${ }^{129}$,

ce rêve est qualifié par Nathan de "vieille chanson " (alte Leier) et ne tarde pas à être brisé par la découverte des liens du sang. Daja du reste avait par avance renoncé à son rêve, au moment de trahir au templier le secret de la naissance de Recha:

Je voudrais le voir, celui qui la convertira!

Sa chance est d'être depuis longtemps

Ce qu'elle ne pourra plus devenir ${ }^{130}$.

Être ce qu'on ne devient plus: pour les personnages du Nathan, les évolutions ne se produisent pas entre les confessions mais en elles. Les destins religieux s'enroulent dans les appartenances confessionnelles et y creusent des espaces qui font penser à ceux du Neuser entre confessions et religion naturelle. Recha, 
née chrétienne, est juive et n'a pas à "devenir " autre chose, car elle est aussi bien chrétienne. Les liens de l'adoption la font indiscernablement juive et chrétienne, inaccessible donc à toute exigence de conversion. Sa gouvernante, qui s'y résigne, est une chrétienne des plus confessantes, raison pour laquelle elle est qualifiée d'" exaltée ", Schwärmerin. Il faut peut-être toutefois cette exaltation pour dire l'obscurité des devenirs religieux quand aucune conversion ne vient les réguler ${ }^{131}$.

Le cas n'est pas isolé. Dans le Nathan, l'impossibilité de la conversion est actée par ceux qui y tiennent le plus. Vaincu par son amour pour Recha mais piqué par le refus de Nathan, le templier avoue:

J'ai rêvé qu'un juif pouvait

Désapprendre à être un juif; j’ai rêvé cela

Éveillé ${ }^{132}$.

Encore ce " rêve » antisémite est-il motivé, chez le templier, par l'anticipation qu'il fait d'une demande de conversion au judaïsme de la part de Nathan. Ce serait dans son esprit la condition du mariage avec Recha. Saladin toutefois s'empresse de rectifier:

SALADIN

[...]

Combien de temps ses refus

Peuvent-ils encore durer? Va-t-il donc exiger de toi

Que d'abord tu te fasses juif?

TEMPLIER

Qui sait?

SALADIN

Qui sait? - celui qui connaît ce Nathan mieux que toi ${ }^{133}$.

À la fin, c'est le templier lui-même qui non seulement renonce à rendre celle qu'il aime à la chrétienté, mais prévoit les pires conséquences si la chose devait arriver. Recha doit rester juive, sinon:

Ne le prenez pas mal, Nathan. - Ne devra-t-elle pas

Jouer la chrétienne parmi les chrétiens?

Et ce qu'elle aura feint d'être pendant un certain temps,

Ne le deviendra-t-elle pas finalement? L'ivraie ne finira-t-elle pas

Par étouffer le bon grain

Que vous avez semé ${ }^{134}$ ? [...] 
Nathan le Sage pose une question: si toutes les religions sont sœurs, à quoi bon en changer? La mise au jour des parentés entre individus s'équilibre d'un sens aigu des appartenances confessionnelles et de leur fixité. Nathan et Saladin sont hommes avant d'être juif et musulman, mais ils sont et resteront juif et musulman: "Ich bin ein Jud'- Und ich ein Muselmann ${ }^{135}$ ». Dans ses premiers transports, le templier en vient à formuler ce qui dans toute la pièce constitue le principal motif d'admiration pour la sagesse de Nathan:

[...] Quel juif! -

Et qui ne veut paraître que juif et pleinement juif ${ }^{136}$ !

Tout cela sonne étrangement à nos oreilles démocratiques, pour qui les identités sont mouvantes et la conversion un droit. À vrai dire, l'intrigue familiale de Nathan le Sage doit nécessairement reposer sur une première union des confessions, un mariage, celui d'Assad, frère de Saladin, alias "Wolf von Filnek ", avec la mère de Recha et du templier, "une allemande", " une Stauffen ${ }^{137}$ ". L'accélération des reconnaissances dans la scène finale accentue l'énigme de la pièce, qui fait signe, sinon vers une conversion, du moins vers un choix religieux premier.

Ce choix, cependant, ne se déduit qu'à mots couverts et figure un passé lointain. Dans leur premier dialogue, Saladin et sa sœur Sittah se sont dit leur dégoût de la conversion chrétienne par temps de croisade:

Tu ne connais pas les chrétiens, tu ne veux pas les connaître.

Leur fierté est d'être chrétiens plutôt qu’hommes.

[...]

Le nom, le nom, voilà ce qui leur importe ${ }^{138}$.

On se souvient du Wissowatius: " ce n'est pas le nom qui compte, mais la chose même ${ }^{139}$. " Le " nom " confessionnel, déjà fragilisé en 1773, n'a ici même plus à changer: la jeune juive restera juive et le templier chrétien, mais juive, mais chrétien comme on ne l'a jamais été, dans une co-appartenance traversée par le lien fraternel, et dans la filiation commune de l'islam. Comme dans Adam Neuser encore, la subversion du confessionnel se fait de l'intérieur des confessions: elle atteint Recha et le templier comme elle avait atteint le réformé Neuser et le luthérien Lessing. 
De l'Adam au Nathan, le refus de la conversion s'est radicalisé: la réserve mentale est devenue interdit de l'inceste. Rarement la religion naturelle aura été pensée aussi près d'un universel anthropologique, rarement aussi il aura semblé aussi justifié de dire que la religion naturelle est le début de la culture. Ce rapprochement avec la prohibition de l'inceste a un effet. La religion naturelle ne se proclame pas, elle ne s'affirme pas, à la manière trop simple des apologétiques (" tout homme est religieux »); elle ne se conçoit pas comme condition de possibilité de la morale ou de la civilité. Elle se pense d'abord comme proscription, universel de contrainte, pour régler depuis les confessions ce qui excède les confessions.

Dans la religion naturelle, le Nathan souligne en effet une injonction: ne vous convertissez jamais. Il formalise une prudence du Neuser: Neuser s'est converti, mais quelle importance? L'injonction se comprend logiquement: ne vous convertissez jamais, car vous passeriez seulement d'une confession à une autre. Elle a cependant un corolaire: on ne se convertit pas à la religion naturelle. Et un autre encore: on n'abjure pas la religion dans laquelle on a grandi. Le fixisme confessionnel de Lessing est théorisé par le Nathan, après avoir été préfiguré dans le Neuser, dont nous avons compris qu'il est tout sauf un éloge de la conversion.

On objectera que le réformé Neuser s'est converti deux fois: à l'islam, par " comédie ", mais d'abord à l'unitarisme, sérieusement. Est-ce toutefois si sûr? Ses convictions ont changé, certes; mais s'est-il converti en toute rigueur de terme? On l'a vu: la conversion, en régime confessionnel, suppose la confession de foi. Mais nous avons aussi vu les détours que prend la shahâda de Neuser, dans le récit du fuyard comme dans son commentaire par Lessing. Pour ce qui concerne son virage antitrinaire, nous savons seulement que Neuser a étudié les Pères et les anciennes confessions de foi, pour les réfuter. Le peu qu'il dit des confessions de foi antitrinitaires a trait à un désaccord:

À quoi s’ajoutèrent plusieurs affaires avec les autres ministres de Clausenbourg, au motif que je n'adhérais pas en tout point à leur confession, notamment pas sur le de differentia novi et veteris Testamenti, le de Iustificatione coram deo, ou encore le de Interpretatione primi capitis apud Ioannem Evangelistam ${ }^{140}$.

Nous pouvons donc faire un pas de plus: l'interdit de la conversion est chez Lessing un interdit de la profession de foi, de 
la foi confessante. Derrière l'interdit de la conversion, une autre injonction se profile: ne confessez jamais. C'est chez Lessing l'ultime mot d'ordre, qui donnera accès à sa version de la religion naturelle.

\section{Lessing et l'interdit de la confession}

Quatre ans après le Neuser et un an avant le Nathan, dans un des grands textes de la controverse sur les fragments de Reimarus, les Axiomata de 1778, on peut lire:

Je suis amant de la théologie et non théologien. Je n’ai dû jurer sur aucun système particulier. Rien ne m'oblige à parler une autre langue que la mienne ${ }^{141}$.

Seule l'indifférence des critiques lessingiens - et des historiens de la philosophie - pour les réalités politiques du Saint-Empire a jusqu'ici empêché de voir dans ce passage célèbre entre tous une prise de position sur l'autorité des confessions de foi. Le "système particulier » sur lequel Lessing refuse de " jurer » est celui des libri symbolici ou Bekenntnisschriften, "textes de confession de foi", incluant chez les luthériens la Confession d'Augsbourg de 1530 et la Formule de Concorde de 1580. C'est sur des textes de ce type, dans toutes les confessions, que les aspirants à des fonctions civiles ou ecclésiastiques durent prêter serment jusqu'à la dissolution du SaintEmpire en 1806. Le "serment de confession " (Konfessionseid) avait ainsi la particularité de répéter la confession de foi (Bekenntnis), dans un remarquable bégaiement ou redoublement des actes de parole: jurer et confesser ${ }^{142}$. Lessing lui-même dut prêter serment pour devenir bibliothécaire de Wolfenbüttel ${ }^{143}$ : il n'en dit rien, comme il relativise la shahâda de Neuser. Tout pourtant renvoie à ce serment dans la déclaration des Axiomata, étrange confession de foi inversée: "rien ne m'oblige", mich verbindet nichts, fait écho à la Bindung, terme technique du droit et de la théologie des confessions de foi qui désigne la valeur contraignante de ces textes doctrinaux.

Ce refus, chez Lessing, vient de loin. Le chemin qu'il s'est frayé passe par les apologies. Il vise d'abord toute cérémonie ou formulaire d'abjuration: les héros de Lessing n'abjurent jamais ou presque, et en ce sens précis ils ne se convertissent pas. Les odes d'Horace, dit la Rettung de 1754, ne contiennent pas 
d' «abjuration sérieuse " de son épicurisme, et il est impossible d'invoquer la moindre " conversion " morale chez le poète ${ }^{144}$. C'est vrai encore de Béranger de Tours dans l'apologie de 1770, d'une manière un peu différente. Béranger a certes abjuré sa doctrine de l'Eucharistie, mais, précise Lessing, pas aussi souvent que ne l'ont dit les historiens ${ }^{145}$. La seule condamnation qui aurait dû le "lier " (verbinden à nouveau), car il s'y soumit, fut celle du synode de Rome de 1059. Lessing ajoute que Béranger ne se sentit pas concerné par le jugement ${ }^{146}$ : sa rétractation fut donc, comme la confession de Neuser, une " comédie " imposée par la nécessité.

De fait, comme dans le Neuser, c'est un argument de vraisemblance psychologique qui est utilisé pour minorer l'importance de l'abjuration de Béranger:

La prétendue conversion de Béranger repose sur des témoignages tellement insignifiants et paraît en tous points si invraisemblable et incompréhensible que je prendrais encore la liberté d'en douter quand bien même elle reposerait sur des témoignages mille fois plus valables. [...] - Un homme comme Béranger aurait recherché la vérité; il aurait cru trouver la vérité qu'il cherchait à un âge où son intelligence avait atteint sa pleine maturité; il aurait courageusement confessé la vérité qu'il avait trouvée et l'aurait enseignée à d'autres; il serait demeuré dans cette vérité confessée et enseignée pendant trente, quarante ans, en dépit de tous les dangers, et malgré la crainte qu'il avait de ces dangers - et d'un seul coup, précisément au moment où parmi tous les trésors qu'un homme a acquis aucun ne peut lui sembler plus précieux que le trésor de la vérité, le seul qu’il puisse espérer emmener avec lui dans la mort — c'est à ce moment que toute son âme se serait convertie, au point que ce qui lui apparaissait comme la vérité aurait cessé d'être la vérité? - Celui qui me convaincra de cela pourra aussi bien me convaincre de renoncer dès maintenant à toute recherche de la vérité ${ }^{147}$.

Chez Béranger comme chez Neuser, la conversion est à peine croyable. Non pas au sens où, trop haute, elle relèverait du miracle: l'indifférence affichée ici pour la qualité des témoignages disqualifie cette hypothèse, bonne pour les hagiographies. C'est le contraire: la conversion, trop basse, est à peine croyable pour ces figures qui comptent parmi «les plus étranges de l'univers moral ${ }^{148}$ ». Comparés aux personnages du Nathan, chez qui la religion naturelle triomphe parce qu'ils ne se convertissent pas, Neuser, Béranger restent d'une humanité faible. Il faut donc se résoudre à constater 
leur conversion, se souvenir de la pression des circonstances, et aller vite à l'essentiel:

Un Béranger meurt comme il a enseigné, c'est certain; et c'est ainsi que meurent tous ceux qui enseignent aussi honnêtement et sérieusement que lui ${ }^{149}$.

On objectera que pour Lessing Béranger a non seulement " enseigné » mais aussi confessé. Au synode de Tours (1054), dit le texte, il a donné sa " confession de foi ", affirmant " par serment " qu'elle contenait « son opinion véritable, authentique ${ }^{150}$ ». C'était cependant sa confession: Béranger a juré mais, comme Lessing dans les Axiomata, il a parlé sa langue et non celle d'un formulaire.

Neuser, lui, dit s'être rendu à Constantinople pour apprendre la "droite vérité " sur les anciennes querelles trinitaires: c’était, explique-t-il, poursuivre sur place l'enquête menée sur une confession de foi, le Symbole d'Athanase, dont l'authenticité avait déjà été contestée par le luthérien Camerarius ${ }^{151}$. Il n'y a bien sûr aucun hasard à ce qu'Adam Neuser, dans la troisième livraison des Beiträge, soit précédé d'une brève étude sur un manuscrit du Symbole des apôtres, en grec translittéré en alphabet latin, retrouvé aussi à Wolfenbüttel ${ }^{152}$. Le recueil de Lessing a construit un triptyque: si le Neuser trouve son aboutissement dans la Tolérance pour les déistes, son point de départ, ou d'arrachement, se trouve dans les formules du credo. Le trajet mène bien sûr vers la religion naturelle. On n'aura garde cependant d'oublier la spécificité de ce trajet, qui passe à travers les confessions, comme groupes, pour abolir la confession, comme acte.

\section{Confession et conséquence}

De la confessionnalisation, le Neuser nous a donc conduits à la confession de foi. Cet objet, le Bekenntnis, nous semble désormais lointain, réservé à la sphère liturgique. Son omniprésence dans les terres confessionnalisées de l'Empire germanique a pourtant fait de lui une forme de la pensée. Nous pouvons demander: qu'estce qu'une pensée confessante? et répondre d'abord à partir des caractéristiques les plus visibles de tout credo. L’affirmation ( je crois ") est proclamation d'appartenance: la confession de foi, confessio fidei, comme texte rédigé et récité, atteste l'inclusion dans 
un type de communauté que le $\mathrm{XvI}^{\mathrm{e}}$ siècle commence précisément à nommer confessio, au sens de notre actuel "confessionnel ${ }^{153}$ ". Le pathos de la profération n'a d'égale que l'exigence d'absolue précision des formules proférées, le besoin, consubstantiel à l'histoire de l'Église depuis les premiers conciles, d'une explicitation sans reste du contenu du dogme, la recherche, en un mot, d'une forme de parole qui fasse norme de foi - orthodoxie.

L'effort de Lessing dans ses apologies est de définir l'alternative à la confession. Nous l'avons vu louer en 1770 l'« honnêteté " de Béranger $^{154}$ : la vertu du philologue se transfère chez l'hérétique. Ce point est décisif: l'alternative à la confession ne se trouve pas dans l'allusion, la demi-vérité ou le camouflage. Lessing réfute le soupçon que Béranger se serait " appliqué à exposer son opinion de façon obscure et équivoque, pour éviter qu'elle n'apparaisse trop effrayante ". C'est la première réponse au reproche de "faiblesse " auquel l'a exposé ensuite son abjuration:

Je ne sais si c'est un devoir de sacrifier son bonheur et sa vie à la vérité; dans tous les cas, le courage et la résolution nécessaires à cela ne sont pas des dons que nous puissions nous donner à nous-mêmes. Ce que je sais en revanche, c'est que le devoir, quand on veut enseigner la vérité, est de l'enseigner tout entière ou pas du tout; de l'enseigner tout de go, sans énigme, sans réserve, sans douter de sa force ni de son utilité; et les dons requis pour cela sont en notre pouvoir. Celui qui ne veut pas l'acquérir ou, quand il l'a acquise, ne veut pas en faire usage, celui-là ne rend pas grand service à l'intelligence des hommes s'il se contente de nous libérer des erreurs les plus grossières tout en dissimulant la vérité complète, cherchant ainsi à nous satisfaire avec un mélange de vérité et de mensonge. [...]

Que Béranger ait été faible, soit; doit-il pour autant avoir été intentionnellement faux? Qu'il faille que je le plaigne, soit; dois-je pour autant le mépriser? L’homme qui, quand le danger menace, devient infidèle à la vérité, il se peut qu'il aime pourtant beaucoup la vérité, et la vérité lui pardonne son infidélité à proportion de son amour. Celui qui en revanche pense faire paraître la vérité derrière toutes sortes de masques et d'apprêts, il se peut qu'il veuille en être le souteneur; mais il est certain qu'il n'en a jamais été l'amant ${ }^{155}$.

Ce texte du Berengarius, en invoquant les « amants » de la vérité, prépare la formule des Axiomata de 1778, où Lessing se présente en " amant de la théologie ${ }^{156}$ ". L'amour en question se définit comme un engagement sans déclaration, mais sans dissimulation: le choix 
n'est pas entre la confession de foi et la réserve mentale, entre la proclamation et un larvatus prodeo. La faiblesse de Béranger contraint d'abjurer sa doctrine s'excuse paradoxalement par son désir de l'enseigner tout entière. Nous revenons ainsi à Leo Strauss, avec un mystère à percer: l'art d'écrire des apologies, les nombreux leurres dont Adam Neuser livre l'exemple le plus virtuose, vont de pair avec un désir de véracité plénière.

La question est donc: quelle est cette "vérité complète " que Lessing recherche en dehors de la confession? Les textes de controverse contre Goeze, en 1778, formaliseront la réponse: la vérité est dans la recherche sincère de la vérité ${ }^{157}$. Pour donner son sens plein à cette formule, les apologies de 1773-74 ont cependant dû dépasser une première opposition, entre hérésie et orthodoxie. Elles ont réuni l'hérétique absolu, Neuser, et le parfait luthérien, Leibniz. L'hérétique n'est en effet pas le seul chercheur de vérité, et l'orthodoxe n'écrit pas que des confessions de foi. Les textes des années 1770 explorent cette jachère des institutions confessionnelles, entre l'hérésie, la foi des orthodoxes et leurs credo.

Les deux études sur Leibniz parues dans les Beiträge insistent sur la "rigoureuse orthodoxie " du philosophe, inchangée de sa jeunesse luthérienne à l'âge d'homme ${ }^{158}$. Sur l'éternité des peines de l'enfer, Leibniz aura préféré " en faire un peu trop aux côtés des orthodoxes ", plutôt que d'en faire " trop peu " avec les partisans de l'apocatastase ${ }^{159}$. On glosa beaucoup, dès 1770 , sur un retour de Lessing à l'orthodoxie luthérienne, et les amis de son cercle berlinois, à commencer par Friedrich Nicolai, en furent désemparés ${ }^{160}$ : la vie de province à Wolfenbüttel, les rigueurs de l'érudition semblaient avoir remis l'ancien libertin, admirateur d'Anacréon, sur le droit chemin de son Église. Dans sa correspondance avec son frère, Lessing est pourtant parfaitement clair:

Ainsi j'aurais réellement voulu, avec mes réflexions sur les peines éternelles, faire la cour aux orthodoxes? Tu crois que je n’y ai pas réfléchi? Cela ne pourra pas leur suffire, ne leur suffira pas. Que m’importent les orthodoxes? Je les méprise tout autant que toi. Simplement, je méprise encore plus nos pasteurs à la mode, qui sont bien trop peu théologiens, et loin d'être assez philosophes. Et je suis très convaincu que si on laisse monter ces esprits fades, ils finiront par être plus tyranniques que les orthodoxes ne l'ont jamais été ${ }^{161}$. 
Les histoires de la théologie identifient les « esprits fades » dont il s'agit: "néologues ", théologiens des Lumières épris de synthèse entre foi et raison, promoteurs d'un christianisme éthique et pratique; de braves gens, à condition de ne pas leur donner trop de pouvoir ${ }^{162}$. À rebours, Lessing plaide pour le respect de l'ancienne orthodoxie luthérienne, celle du siècle précédent, avec une série d'arguments aussi ciselés que paradoxaux. La dogmatique, dit-il, est un système de séparation, une " cloison " entre raison et révélation qui permet à la philosophie et à la théologie de suivre librement leur cours ${ }^{163}$. Elle est en outre une science des "suppositions" ou arguments probables, qui permet de confesser sans certitude - comme si l'exercice du doute avait été l'objectif principal de la théologie dogmatique ${ }^{164}$ !

Quelque chose demeure de ces étranges arguments au-delà des tactiques de Lessing face à la théologie de son temps ${ }^{165}$, et nous devrons le définir à la fin. Il faut accepter d'abord de les voir inaboutis dans les apologies comme dans la correspondance des années 1770. Le Wissowatius souligne l'inutilité d'un retour au fond de la querelle qui opposa Leibniz au théologien socinien; le but est de réfléchir à la "manière dont Leibniz, à cette époque et tout au long de sa vie, s'est comporté166 $»$. Le texte sur Leibniz et les peines éternelles adoptait le même point de vue: l'important n'est pas la "vérité défendue " mais son "défenseur ", avec ses «intentions " et ses " raisons ${ }^{167}$ ".

Lessing observe donc un comportement théologique - ou, puisqu'il ne s'agit pas que de théologie, cette pratique théorique - à travers une série de correspondances qui mobilisent le réseau entier des Beiträge. Le Wissowatius cite Leibniz sur Locke, sa sympathie pour les sociniens et leur " pauvre philosophie ", paupertina, petite, chétive ${ }^{168}$. L'épithète est suivie d'une autre qui marquera au fer les philosophies anglo-saxonnes. Locke est "plat ", seicht, et le constat prépare l'appréciation portée sur la néologie, sa synthèse bon marché de philosophie et de théologie:

Est-ce la même platitude qui fait qu'aussi bien en théologie qu'en philosophie on reste à mi-chemin ${ }^{169}$ ?

C'est exactement ce que Lessing écrit à son frère des néologues: " bien trop peu théologiens, et loin d'être assez philosophes ${ }^{170}$ ". Et c'est ce qu'il avait dit peu avant des sociniens : en continuant d'adorer 
le Christ, ils sont moins "conséquents " que les unitariens ${ }^{171}$; ils restent, eux aussi, « à mi-chemin ». En même temps que le parallèle socino-réformé ${ }^{172}$, Lessing suggère donc un rapprochement socinonéologue ou, si l'on préfère, socino-rationaliste, selon cette forme de critique des Lumières par elles-mêmes qui fait le projet des Beiträge. Dans les deux cas, l'opération constitue un évident scandale pour les intéressés.

Adam Neuser reprend la critique au vol, lorsqu'il loue " l'audacieux unitarien, fidèle à ses principes ", qui " va beaucoup plus loin que le socinien à proprement parler, lequel n'est ni froid ni chaud et qui, sans qu'on sache pourquoi, aimerait bien conserver le nom d'une religion dont il anéantit pourtant la vie intérieure ${ }^{173}$ ». Lessing y insiste: c'est une erreur et une offense de voir en Neuser un socinien, une offense pour Neuser comme pour les sociniens ${ }^{174}$. Dans le Wissowatius, la même critique avait été faite d'abord sous l'égide de Leibniz. Il est intéressant que les prédicats puissent ainsi glisser sans difficulté d'un nom à l'autre: quelque chose du "philosophe froid, sans préjugés " du Wissowatius, à propos de Leibniz, se retrouve dans le " sang-froid " que Lessing reconnaît à Neuser, tout " apostat " et " mamelouk " qu'il ait été aux yeux de beaucoup ${ }^{175}$. Rappelons que le socinien n'est « ni froid ni chaud ${ }^{176}$ ".

On l'a compris: Lessing construit, dans les Beiträge, l'alliance Neuser-Leibniz, l'alliance du fuyard et du philosophe, de l'unitarien et du luthérien, de l'hérétique et de l'orthodoxe. Ce que Leibniz confiait en 1706 à propos des sociniens et de l'islam pouvait fournir une base historique ${ }^{177}$, mais il s'agissait surtout d'une intuition à approfondir. Qu'en est-il de ce comportement théorique qui s'observe identiquement dans l'hérésie et l'orthodoxie, et dans lequel, même, hérésie et orthodoxie parviennent à correspondre? Le Wissowatius passait par le français de Leibniz et parlait de la " conséquence " des unitariens. Adam Neuser invoque une fidélité: "l'audacieux unitarien, fidèle à ses principes ${ }^{178}$ »...

En première approche, les textes des années 1770 livrent une sorte de phénoménologie de l'esprit de système en contexte confessionnel. Neuser est l'unitarien absolu, celui qui franchit les pas " que toute saine raison exige de faire aussitôt qu'on a fait le premier $^{179}$ ": la radicalité est affaire de raison. L'exil de Neuser fait preuve, la preuve paradoxale d'une cohérence dans l'errance, une démonstration par la migration. Ses premiers partisans, à 
l'image de la communauté polonaise qui voulut l'accueillir en 1574, sont allés "aussi loin qu'une paroisse unitarienne pouvait aller, c'est-à-dire plus loin qu'elle n'aurait dû aller si elle voulait garder un certain droit à porter le nom d'une paroisse chrétienne ${ }^{180}$ ". Cette suggestion d'une sortie du christianisme contrebalance la déploration sur le "malheureux qu'à force de poursuites on a chassé de la chrétienté181 ». Le reste relève de la conjecture: les Polonais de Neuser, admirateurs du Coran, peuvent avoir été des "Turcs non circoncis" ou des "déistes", cette question est de nouveau simplement de "nom ", comme le disait le Wissowatius ${ }^{182}$.

Le "système" de Leibniz fournit lui aussi l'occasion d'une réflexion d'ampleur. Il s'agit de défendre Leibniz contre le soupçon d'avoir "adapté sa philosophie aux opinions dominantes de tous les partis", de préférence les plus puissants - attitude d'un "démagogue rampant", durement jugée par les néologues ${ }^{183}$. Lessing inverse la formule d'accusation: Leibniz a plutôt cherché à " adapter les opinions dominantes de tous les partis à son système ", au profit de celui-ci ${ }^{184}$. Pour cela, il a mis au point un procédé consistant à considérer dans toute opinion le côté par lequel elle peut être "vraie en un certain sens ": fondement, selon Lessing, d'un mode d'" exposé exotérique ", qui provisoirement " laissait le système de côté " pour mieux « conduire tout un chacun sur le chemin de la vérité185 ".

Cette distinction de l'ésotérique et de l'exotérique permet de définir le rapport que Leibniz a entretenu avec l'orthodoxie luthérienne. Le philosophe a pu entendre la doctrine des peines éternelles en un sens bien distinct de son exposé exotérique, en l'occurrence comme l'expression, conforme à son système, de ce que « rien dans le monde n'est isolé, rien n’est sans conséquences, rien sans conséquences éternelles ${ }^{186} »$. L'essentiel est toutefois de le sauver du reproche de n'avoir pas été "d'accord avec lui-même " et d'avoir "confessé publiquement, en paroles" la doctrine des peines éternelles tout en l'ayant " secrètement niée en son fond ${ }^{187}$ ". Pas plus que chez Béranger ou Neuser, il n'y a chez Leibniz de "doctrine secrète", au sens que Rousseau forgera contre ses adversaires philosophes ${ }^{188}$.

Lessing a sur ce point une formule remarquable: 
Car ceci serait tout de même trop grave, et ne pourrait être simplement excusé au nom d'une politique didactique, ou du désir d'être tout pour tous ${ }^{189}$.

Comme pour Béranger ou pour Neuser encore, il y a un problème de la confession de foi pour Leibniz - Leibniz qui, quelques années après avoir répondu à Wissowatius, rédigeait une Confessio philosophi ${ }^{190}$. Il faut ici relever le souvenir biblique: " être " tout pour tous ", la sentence paulinienne est celle dont Neuser se réclamait pour justifier son transfert à Constantinople ${ }^{191}$. On a vu avec quelle dureté Lessing repousse cette explication ${ }^{192}$; il en va de même ici, d'une façon qui renforce l'alliance de l'hérétique et du philosophe.

À la question: les prises de position orthodoxes de Leibniz sontelles les confessions d'une foi?, Lessing a deux réponses. Il faut d'abord donner raison à ses détracteurs: "Leibniz n'a cru à rien de ce dont il voulait convaincre le monde ". Suit un éloge du philosophe froid, de son talent pour débrouiller en toute impartialité les querelles théologiques les plus complexes:

Leibniz n'a cru en rien: lui en était-il moins possible d'envisager les différentes opinions au sujet du Christ, en les prenant comme autant d'hypothèses à partir desquelles expliquer et harmoniser les passages de l'Écriture qui parlent de lui? Ne pouvait-il pas rendre un jugement fondé quant à l'hypothèse qu'il fallait préférer à l'autre, au prétexte qu'il n'était au fond convaincu par aucune? [...] Ne devraiton considérer son jugement comme d'autant plus impartial qu'il ne penchait en lui-même d'aucun côté et qu'il ne croyait ni en l'un ni en l'autre ${ }^{193}$ ?

Ici le sens du système remplace toute foi à confesser. La théologie est un ensemble d'hypothèses corrélées entre lesquelles il est d'autant plus facile de trancher qu'on n'y mêlera aucune conviction: d'une thèse ou d'une doctrine donnée, il est tout à la fois simple et audacieux de définir l'« extension naturelle et nécessaire ", comme les unitariens l'ont fait à partir de leur affirmation du Dieu unique ${ }^{194}$. La conséquence a supplanté la confession. La fin du Wissowatius le répète:

Et à présent, pour revenir à ce qui précède, à la foi. Leibniz pourra s'être aussi sincèrement qu'il voudra opposé aux sociniens, il suffit, dira-t-on, qu'il ait été, au fond, tout aussi éloigné de l'opinion ortho- 
doxe. Il croyait en l'une aussi peu qu'il croyait en l'autre; bref, dans toute cette affaire, il ne croyait rien ${ }^{195}$.

À la suite pourtant, le propos est rectifié: savons-nous vraiment ce que " croire " veut dire? Au sens que les néologues ont imposé, où croire signifie " tenir pour vrai à partir de raison naturelles ", il est certain que Leibniz n'a pas cru en la Trinité, non plus qu'en aucune doctrine révélée ${ }^{196}$ : en ce sens précis, il n’a cru " en rien ". Mais la théologie moderne nous fait perdre le sens des mots. Il faut, plaide Lessing ironiquement, pardonner au vieux Leibniz, qui a suivi son "opinion démodée ", pensant que la religion avait, outre ses preuves " humaines " et " explicables ", des " preuves divines " et "inexplicables", et que la meilleure preuve de la Bible était encore la Bible elle-même ${ }^{197}$.

À la fin du Wissowatius, deux voies sont donc ouvertes: celle, rationaliste, de l'esprit de système en théologie, celle, historiciste, du monde perdu de la foi orthodoxe. Il n'est pas nécessaire de choisir. À sa manière, la pauvre théologie des Lumières a fait œuvre providentielle: en nous dérobant l'intelligence du dogme, elle nous empêche de trancher la question de la sincérité de Leibniz. Cette question est en effet secondaire. L'important se trouve dans le souci de la conséquence, l'amour du système qui, chez Leibniz comme chez Neuser, sont pensés au plus loin de toute proclamation: c'est la condition première de toute religion naturelle. L'alliance de l'hérétique et du philosophe fait entrevoir une sorte de hantise chez Lessing: celle du moment où la conséquence finit en confession, où le sens de la théorie dérape en protestation d'appartenance. La liberté de penser est hérétique et obédiente, orthodoxe et hétérodoxe. Son contraire n'est pas le dogme, encore moins le système, c'est la confession.

\section{Deux hommes-machines}

Les dernières lignes du Neuser scellent définitivement l'alliance entre Leibniz et l'hérétique. C'est le moment de la synthèse entre le système et l'érudition, les deux côtés de l'art lessingien de l'apologie, le moment où éclate l'affect de pitié dont il a déjà été question ${ }^{198}$. Nous pouvons maintenant lire de près cet ultime paragraphe:

À qui trouverait que j'ai passé bien trop de temps dans une vieille histoire confuse, je demanderai de réfléchir à tout ce qui a été écrit 
sur Servet, et ce par des Allemands! Ou bien faut-il être étranger pour mériter notre attention? Leibniz a écrit quelque part: "I'ai [sic] d'autant plus de compassion du malheur de Seruet, que son merite devoit être extraordinaire puisqu'on a trouvé de nos jours, qu'il avoit une connoissance de la circulation du sang ». Certes Leibniz se trompait, ainsi qu'il l'a relevé plus tard. Mais on m'autorisera à conclure en imitant ses paroles: j'ai d'autant plus de compassion pour Neuser, qu'il me semble avoir été encore quelque chose de plus qu'un antitrinitaire: une bonne tête mécanique, qui a travaillé à une découverte assez similaire à celle qui cent ans plus tard traversa l'esprit de Leibniz. " Neuser ", écrit Gerlach, " avait entrepris de fabriquer une voiture qui devait se déplacer toute seule; il se promettait de grandes choses de sa vitesse, une fois mise en route. " Ce que Leibniz voulait obtenir, on le sait par Becher; ou plutôt c'est par lui qu'on ne le sait pas, puisqu'il a jugé meilleur de s'en moquer que de dire de quoi il s'agissait $^{199}$.

À un premier regard, ces lignes offrent pêle-mêle l'orgueil national, la découverte médicale et l'invention technique. Les leurres du textes, rassemblés dans une "vieille histoire confuse ", semblent se chercher une dernière justification dans le patriotisme: l'Allemagne revendique l'hérésie au nom de la science. Assez loué l'Espagnol Servet, les Allemands aussi ont leur dissident: Adam Neuser. C'est ici le Lessing écrivain allemand qui parle ou qui se contrefait, passant de la promotion de la scène nationale (Dramaturgie de Hambourg, 1767-68) à une réfutation qu'il voudrait authentiquement germanique de la Trinité divine. Défense et illustration d'une hérésiologie nationale: "Faut-il être étranger pour mériter notre attention?»

La question n'est pas faite pour qu'on s'y attarde: la fierté allemande n'est qu'une entrée dans un problème que Lessing ne formule jamais mais que nous pouvons désormais cerner ${ }^{200}$. Aussi bien est-ce encore d'un Allemand qu'il s'agit à la suite: Leibniz savant universel, Leibniz "qui lisait tout", Leibniz qui pensait " de façon très concise, sinon tout à fait exacte ${ }^{201}$ ". En ces termes, Lessing compile et juge les hypothèses de Leibniz sur Neuser. Pour lui, Leibniz a trop accordé à Neuser en lui attribuant "la pensée de cabaler dans la Chrétienté en faveur des Turcs ". La réalité est plus triviale: Neuser a simplement voulu «s'en sortir ${ }^{202}$ ". Nous avons déjà rencontré cet argument de nécessité à propos de la conversion ${ }^{203}$. Le contexte a cependant évolué: est-ce ici un 
avertissement contre l'esprit de système? On pressent que c'est tout le contraire.

Car le Leibniz dont il s'agit ici n'est plus celui qui prêtait à Neuser de trop grands desseins; c'est celui qui, par son éloge d'un Servet savant, dit son dégoût des bûchers d'hérétiques. Lessing semble vouloir avancer d'un pas en suggérant des voies de rapprochement entre science et dissidence. Sur ce chemin, toutefois, les leurres sont encore nombreux.

L'antitrinitaire Servet, prétend Leibniz, aurait eu "une connaissance de la circulation du sang »; un tel " mérite » inspire la " compassion ». Lessing va " imiter " Leibniz mais devra auparavant le corriger. Plus exactement, il prend acte d'une rétractation: Leibniz aurait reconnu "plus tard " qu'en matière de circulation sanguine il se " trompait » et que la " connaissance » de Servet ne pouvait être assimilée à une découverte ${ }^{204}$.

À vrai dire, c'est Lessing qui se trompe. La lettre qu'il cite de Leibniz à Veyssière de La Croze - la même que dans le Wissowatius - est tardive (décembre 1706); elle affirme sans réserve la part prise par Servet dans la découverte de la circulation du sang ${ }^{205}$. C'est auparavant, et à plusieurs reprises, que Leibniz avait émis des doutes sur cette attribution ${ }^{206}$. Les choses sont peu claires: les doutes de Leibniz pourraient provenir d'un malentendu de la correspondance, un "sbaglio", comme il dit ${ }^{207}$. Le fait est en tout cas que l'attribution à Servet de la découverte de la circulation sanguine semble toujours plus décidée chez Leibniz. Parmi les textes ultérieurs à la correspondance de 1706 que Lessing avait le plus de chances de connaître, la mention de Servet dans le Discours préliminaire de la Théodicée (1710) reste tout à fait affirmative ${ }^{208}$.

Pourquoi fallait-il alors que Leibniz se rétracte, fût-ce imaginairement? L'ostentation de probité philologique se donne une dernière fois libre cours dans Adam Neuser. En Leibniz, Lessing cherche un miroir: dans leurs hésitations, errata, aveux d'ignorance, les deux bibliothécaires de Wolfenbüttel sont supposés se retrouver. Chez Lessing lisant Leibniz, la pratique philologique partagée passe avant l'adhésion philosophique et la fonde; Lessing n'est jamais aussi leibnizien que quand il corrige Leibniz, Leibniz jamais aussi lessingien que lorsqu'il se corrige lui-même ou qu'il est censé le faire, comme ici ${ }^{209}$.

Telles sont les conditions initiales et assurément complexes de l'« imitation » de Leibniz: n'étant pas servile, elle peut être littérale. 
"J'ai d'autant plus de compassion »: l'allemand de Lessing répète le français de Leibniz, pour Neuser après Servet. La répétition signale une même rencontre chez les unitariens, celle de la science et de l'hérésie. L'une semble compenser l'autre, si l'on en croit du moins la formule de Lessing sur Neuser, "quelque chose de plus qu'un antitrinitaire ", à la bénignité calculée.

Le rapprochement entre la circulation du sang et la " bonne tête mécanique " de Neuser n'étonnera pas: c'est l'application stricte d'une leçon leibnizienne, celle des vivants comme "machines de la nature " dans le Système nouveau, le "purement naturel, et tout à fait mechanique " des écrits à Clarke, où l'organisme est un emboîtement infini de machines, du corps qui vit à la goutte d'eau ${ }^{210}$. La "découverte " mécanique de Neuser peut alors venir après la circulation du sang chez Servet: c'est la philosophie de Leibniz qui rend le rapprochement plausible.

À ce stade, l' «imitation " des "paroles " de Leibniz semble donc avoir dépassé la confraternité bibliothécaire pour inclure un élément doctrinal. La comparaison entre Servet et Neuser, faite sous l'égide de Leibniz et validée par une démonstration de scrupule philologique, est leibnizienne aussi par le mouvement qu'elle imprime au texte. La "bonne tête mécanique " de Neuser rassemble les progrès de la dynamique; elle les mène dans une direction inattendue, des "machines de la nature " à l'hérésie. En quoi l'hérésie antitrinitaire, et la position de Lessing à son sujet, s'en trouvent-elle éclairées? Les difficultés, si jamais elles avaient pris fin, recommencent ici.

La "bonne tête mécanique " de Neuser est attestée par une invention dont nous ne savons presque rien. Nous lisons dans le texte:

"Neuser », écrit Gerlach, " avait entrepris de fabriquer une voiture qui devait se déplacer toute seule; il se promettait de grandes choses de sa vitesse, une fois mise en route ».

Le texte cite Gerlach, non pas dans son journal, mais dans un autre texte que Lessing prélève au bas d'une longue note trouvée dans les annexes d'un Tableau de l'Église d'Orient, ancienne et moderne dû à l'érudit hallois Johann Michael Heineccius (1674-1722), déjà évoqué211. Nouveau raffinement, nouvelle démonstration appuyée de scrupule savant: l'anecdote se trouve aussi dans le journal de 
Gerlach, avec même un peu plus de détail ${ }^{212}$, mais Lessing s'est explicitement défié de cette traduction tardive ${ }^{213}$. Cette fois, le jeu savamment subverti de la surcorrection vise à polir l'unité de l'ensemble: la citation d'Heineccius clôt Adam Neuser comme elle l'avait ouvert ${ }^{214}$. Son retour donne à l'anecdote "mécanique", détachée d'un portrait à charge, la saveur obligée d'une allégorie.

Allégorie de quoi? Les pistes se brouillent une dernière fois, avec une nouvelle mention de Leibniz. L' « invention " de Neuser, que nous ne connaissons que par Gerlach, est rapprochée d'une invention de Leibniz, abordée tout aussi indirectement. La source de Lessing est ici la Närrische Weisheit und weise Narrheit (Folle sagesse et sage folie) de Johann Joachim Becher (1682), recueil d'inventions curieuses en physique, économie et - à nouveau " mécanique ». Le texte, qui n’est pas reproduit par Lessing, dit:

28. La voiture de poste de Leibniz, pour aller de Hanovre à Amsterdam en six heures.

Ce Leibniz est bien connu par ses écrits: un homme très savant, qui a voulu réformer le Corpus Iuris, qui a écrit sa propre philosophie et d'autres choses encore; mais je ne sais pas qui l'a fait monter sur cette voiture de poste dont il ne veut pas descendre, alors même qu'il est depuis plusieurs années dessus et qu'il voit que cette voiture ne veut pas avancer ${ }^{215}[\ldots]$

Nous connaissons un peu mieux l'invention dont il est question ici, par quelques études récentes sur l'institution des voitures de poste dans le Saint-Empire et sur les réflexions de Leibniz à ce sujet $^{216}$. Dans une lettre au landgrave de Hesse-Rheinfels de 1683, Leibniz proteste longuement contre la "malice très noire " de Becher et parle d'un "chariot imaginaire ", évoque sa conviction " qu'on pouuoit corriger quelque chose aux voitures " mais affirme que le trajet de poste de Hanovre à Amsterdam en six heures est une pure "invention " de son adversaire: d'un tel projet, Leibniz assure qu'il n'a "presque jamais parlé à d'autres", et qu'il a «encore moins tâché de l'exécuter ${ }^{217}$ ".

On aura bien sûr reconnu Neuser: son projet d'alliance des antitrinitaires avec le sultan a bien été forgé, ourdi, machiné, il n’a pas été mis à exécution. Sa lettre à Selim II n'est pas partie, et Leibniz n'a jamais publié ses méditations postales. Que Lessing ait eu ou non connaissance de ses justifications - il insiste sur « ce qu'on ne sait pas » du projet leibnizien —, le fait est que le dernier 
paragraphe d'Adam Neuser, tirant la leçon des textes antérieurs sur Leibniz, place sous un seul regard les esquisses « mécaniques " d'un philosophe et les songeries théologico-politiques d'un antitrinitaire, les rendant d'un seul coup comparables. Mais à quoi?

Il faut, une dernière fois, revenir en arrière. Sur Servet et Harvey, Leibniz s'est " trompé », dit Lessing. C'est pourtant bien de la circulation du sang que semble le plus s'approcher le mouvement de cette voiture qui, dans l'idée de Neuser, devait "aller toute seule »: sur cette formulation étrange, les témoignages concordent, au point de donner à cette invention l'allure d'un défi au principe d'inertie. Mais c'est aussi bien de sang qu'il s'agit lorsque Lessing salue le "sang-froid" de Neuser, dans un éloge qui, on l'a vu, consonne avec celui du " philosophe froid» dans le Wissowatius ${ }^{218}$. Froideur du philosophe, sang-froid de l'hérétique: deux expressions d'un même rationalisme qui, en admettant le dogme trinitaire tout comme son hérésie, rebat tout le jeu de la raison et de la foi.

La construction finale d'Adam Neuser reloge ainsi les choix théologiques au cœur d'un rationalisme supérieur. Le goût de la doctrine, de sa froide et "mécanique " nécessité, trouve son expression dans le secret ou la velléité, l'inachevé ou l'impubliable, à l'image des papiers privés de Leibniz et Neuser. Que cette rigueur, ce secret et ces faiblesses aient pu s'entrevoir dans les lois du mouvement, au cœur de cette science qu'on dit classique, n'a rien d'étonnant. Nous avons atteint ici le terme d'une volonté théorique, l'une des plus complexes de la raison des Lumières.

\section{La religion naturelle aujourd'hui}

À cette raison, nous pouvons bien donner son vieux nom, celui des manuels: religion naturelle, "déisme " d'un Dieu tout simple, sans Fils, sans Trinité. Neuser crut en cela et pour cela il partit jusqu'à Istanbul. Mais il ne le professa pas, ou à peine, et ce manque d'ardeur proclamatrice change tout à l'idée que nous nous faisons de la religion naturelle. Lessing est un de ceux qui ont le plus profondément pensé son aporie là où elle a émergé, en régime européen et moderne de confessionnalisation: comment éviter que la religion naturelle ne soit érigée en confession parmi les confessions? La réponse traditionnelle a été: en l'instaurant comme dénominateur commun et "credo minimum" ${ }^{219}$ ". Lessing est plus radical: la religion naturelle est la religion qu'on ne confesse 
pas. Adam Neuser soulève une question nouvelle: qu'est-ce qu'une foi non confessée, si elle ne doit pas être une religion privée?

On comprend maintenant l'impression que donne le Neuser de ne rien dire des religions dont il traite. Il ne dit rien de l'unitarisme, sinon qu'il est plus rigoureux que le socinianisme; rien de l'islam, sinon qu'il est la tentation des unitariens et des réformés; rien même de la religion naturelle, sinon que l'unitarisme y fait penser et qu'elle divise, derechef, les réformés.

Nous pouvons formaliser: tout énoncé sur une confession, que celle-ci se pense comme telle (calvinisme) ou non (islam), est par nécessité un énoncé sur une autre confession. La règle s'applique aussi à la religion naturelle, dont on ne peut parler qu'en parlant d'une confession. Ce n'est pas une stratégie d'écriture, c'est le régime même d'une confessionnalisation de la pensée que Lessing, parce qu'il y était pris, a choisi de penser.

Nos philosophies de la religion sont trop imprécises quand elles opposent à la religion naturelle des "religions révélées ». Ce à quoi toute idée de religion naturelle se mesure, si du moins elle veut se mesurer à du réel, ce ne sont pas des "religions révélées " ou "positives", ce sont les confessions ou c'est le confessionnel. Les historiens en ont depuis trente ans défini la loi, qui est de distinction: les confessions modernes se nourrissent de leurs différences, catholiques versus protestants, luthériens versus réformés, orthodoxes versus néologues, etc., dans une perpétuelle méiose qu'entretiennent les intérêts du politique et le travail du dogme.

Si donc nous voulons éviter que la religion naturelle ne finisse comme une confession parmi les autres, soumise à cette loi de division, nous devrons y voir un devenir qui ne passe pas entre les religions instituées mais dans chacune d'entre elles. C'est le sens du Neuser. Chaque confession se dissocie d'elle-même au contact des autres, qui forment ainsi plus qu'un plan de comparaison: l'opérateur d'une scission dans, par exemple, le calvinisme au contact de la contestation antitrinitaire, puis dans l'unitarisme au contact de l'islam. La religion naturelle est cette scission. D’une certaine manière, elle pousse à son extrémité la logique de division: elle n'apaise pas, mais au contraire exhibe la scission confessionnelle.

Lessing définit donc la religion naturelle par son œuvre. Il $\mathrm{y}$ insiste tant qu'on en vient à douter qu'elle ait un contenu. Ceci précisément la distingue de toutes les quêtes de "credo 
minimum ". Après tout, la religion naturelle du Vicaire savoyard, douze ans avant le Neuser, avait sa Profession de foi. Un credo, même "minimum ", reste un credo, une confession de foi, et donc, dans l'univers de Lessing comme dans celui de Neuser, une confession possible, une organisation religieuse. Le devenir historique de l'unitarisme, si proche en apparence de la religion naturelle, mais " accepté ", institué en Transylvanie et travaillé de l'intérieur par l'islam ottoman, fournissait de ce point de vue un test.

Si la religion naturelle ne se pense qu'au contact des confessions, elle pense aussi les confessions jusqu'au fond de leur essence, qui est la confession. Le refus de la proclamation constitue une solution à son aporie, en même temps qu'il fonde chez Lessing une éthique de la parole à laquelle tout son art d'écrire se subordonne: parole discrète mais complète, non confessante mais non dissimulée. Adam Neuser médite l'équivoque de la confession: comment les collectifs religieux en sont-ils arrivés à se désigner du nom qu'ils donnent au texte de leur credo, confessio, qui lui-même reprend le nom de l'acte vocal par lequel le croyant confesse sa foi?

Une conclusion facile verrait dans le projet de Lessing la résurgence moderne d'une théologie négative, "négatif » signifiant ici «qui ne confesse pas». Une certaine post-théologie postderridienne s'en satisfera peut-être. Dans la mesure cependant où Lessing rompt d'emblée le contrat des théologies négatives - son problème n'est pas qu'il ne peut pas confesser, mais qu'il refuse de le faire - , je préfère envisager une autre conséquence.

Si le slogan du « retour du religieux " nous irrite tant, c'est parce que nous n'avons pas besoin qu'on nous explique l'évidence: nous savons depuis un moment que nous ne sortirons pas de sitôt du religieux. Même la France est entrée, à cause de l'islam ou sous prétexte d'islam, dans une nouvelle confessionnalisation, à moins que ce ne soit la première dans sa longue histoire de catholicité et de laïcité. Dans ces conditions, mieux vaut aller droit à ceux qui, comme Lessing, ont voulu penser la confessionnalisation à partir d'elle-même.

Repartons de notre nouvelle définition de la religion naturelle: qu'est-ce qu'une religion sans credo, sans aucune confession, même minimale? L'originalité du Neuser est d'exclure les solutions intuitives: une religion sans confession n'est pas une religion de la nature (le « grand horloger »), elle n'est pas non plus une religion du 
sentiment, religion a-dogmatique de l'intuition et de la dépendance, comme Schleiermacher l'imaginera vingt ans après Lessing. On chercherait en vain, dans toutes les Rettungen, la moindre émotion religieuse, qu'elle soit cosmique ou intime. La religion naturelle chez Lessing est affaire de philosophe froid; elle s'est fabriquée en dehors du monde, en bibliothèque; peut-être reste-t-elle protestante par cet acosmisme. Nous saisissons le sens de l'érudition saturée dont il était question au début: conjurer toute illusion naturaliste au sujet de la religion naturelle.

Quoi de moins naturel et de plus institué qu'un système? Or la religion naturelle, contre toutes les apparences, ne se définit pas par exclusion, mais au contraire par approfondissement de la revendication systématique: aller au bout de ce que veulent les dogmes, plutôt que d'écarter a priori leur extraordinaire pouvoir de fondation. Cette extrémisme du dogme, Lessing après Leibniz lui a donné un nom: conséquence, le contraire de la confession. La conséquence désigne chez Leibniz comme chez Neuser une exigence exorbitante à la profération, car il faut pour l'un et l'autre choisir, entre proclamer en parole et suivre son idée. C'est ce choix que Lessing ne cesse de mettre en scène, comme si la proclamation arrêtait l'idée - mais alors comment dire l'idée? Pour qu'il y eût un jour un "idéalisme allemand " après deux cent cinquante ans de confessionnalisation catholique, luthérienne et réformée dans l'Empire germanique, peut-être fallait-il avoir reconnu que la conséquence, c'est-à-dire le système, n'était articulable en aucune langue, identifiable par aucune confession de foi.

Faisons encore un pas: la religion naturelle aujourd'hui, c'est le sens des doctrines - quelque chose qui a certainement plus à voir avec la culture qu'avec la piété. En ce sens, elle n'a que des approximations, qui sont des doctrines instituées: antitrinitarisme, islam, d'autres aussi sans doute. C'est la leçon de l'anti-naturalisme lessingien, et nous la vérifions sur nous-mêmes. Comment se fait-il que nous préférions toujours, même si nous nous le reprochons parfois, les positions théologiques tranchées aux banalités édifiantes de la tolérance et du " vivre ensemble " ? Les raisons sont multiples: parce que nous sommes reconfessionnalisés sans doute, et ce n'est pas une bonne nouvelle, mais aussi parce que toute revendication articulée est préférable, hélas, aux protestations sentimentales. Il est sûr, en revanche, que notre sens des dogmes ne relève en aucune façon du vintage postmoderne, ou alors il faudrait que 
les Lumières de Lessing, avec leur goût prononcé pour l'ancienne dogmatique, soient postmodernes elles aussi.

Face aux dominations, dévotes comme laïques, nous savons que les confessions de bonnes intentions ne sont plus de mise; au mieux, elle soulagent sans guérir. Sans doute nos sécularismes, quand ils s'avancent comme des causes à défendre, restent-ils travaillés de l'intérieur par le rêve de la conversion. Le problème n'est pas d'intention: dire que toute revendication séculariste est une croisade qui s'ignore est d'une confondante bêtise. Le problème est d'énonciation. Avant de condamner, sauver ou réformer ici les sécularismes, nous devons nous demander pourquoi ils sont si mal reçus ailleurs quand nous les proclamons, c'est-à-dire les confessons. Et nous souvenir qu'en islam plus encore que pour le christianisme, la confession est la voie de la conversion.

Reste donc la " conséquence ". L’équilibre Leibniz-Neuser, dans Lessing, nous enseigne qu'en religion le sens du système dépasse l'opposition trop simple de l'orthodoxie et de l'hérésie. Justement parce qu'il est un livre sur la liberté de pensée, le Neuser prend au sérieux l'exigence du dogme. Il donne ainsi un sens à un programme de recherche invoqué depuis un moment, sans qu'on sache toujours bien ce que l'idée recouvre: les rationalités religieuses, orthodoxes et hétérodoxes.

C'est à partir de là qu'on pourra reparler de religion naturelle aujourd'hui: non pas comme d'un arbitrage qui chercherait à loger la raison et la religion ensemble dans un credo prédéfini, mais comme d'une médiation chargée "à la fois de réunir les religions et de reconnaître l'irréductibilité de leur conflit ", et cela à partir de l'effort de chacune pour faire doctrine, système, enseignement définitif. Chercher, non pas le minimum de croyance requise pour fonder la coexistence, mais le maximum de raison pour exposer les conflits confessionnels. Les exposer, c'est-à-dire les formuler, les articuler, mais aussi les exposer à la critique en les critiquant comme conflits, ne plus les commenter, ne plus les subir enfin ${ }^{220}$. C'est désormais la voie pour repasser à l'extérieur des confessions, à travers les confessions. Personne ne dit que la tâche est simple, personne ne pense qu'elle est inutile.

Il y eut un temps où les esprits libres migraient vers Istanbul, et où c'est d'Europe qu'on fuyait les conflits religieux; un temps où les religions étaient libres surtout à Istanbul. Les "flux ", comme on dit, peuvent s'inverser. Le rappeler aujourd'hui n'aidera aucun hôte 
Adam Neuser

ni aucun migrant. Lessing dirait cependant: si ce rappel peut aider le philosophe, il n'aidera pas que lui.

Rome, septembre 2016 


\section{Notes de l'introduction}

1. Von Adam Neusern, einige authentische Nachtrichten, in Zur Geschichte und Literatur. Aus den Schätzen der Herzoglichen Bibliothek zu Wolfenbüttel, Dritter Beitrag, XVII, Braunschweig 1774, p. 119-194 (abr. AN). Je cite d'après l'édition originale et d'après l'édition d'Arno SCHILSON, dont j'adopte l'orthographe partiellement modernisée: G. E. LESSING, Werke und Briefe (abr. WuB), éd. W. Barner et alii, Frankfurt a. M., Deutscher Klassiker Verlag (1985-2003), t. 8, 1989, p. 55-114, ici p. 160/88. J'indique à la suite la pagination dans la présente traduction (ici p. 112).

2. Lessing prêta serment le 7 mai 1770 pour prendre ses fonctions de directeur de la bibliothèque ducale de Wolfenbüttel. II les conserva jusqu'à sa mort en 1781. Sur l'histoire de la bibliothèque, voir plus bas, traduction, n. 3.

3. Voir Michael Multhammer, Lessings 'Rettungen'. Geschichte und Genese eines Denkstils, Berlin-New York, De Gruyter (Frühe Neuzeit, 183), 2013, ainsi que Michel ESPAGNE, « Lessing et les hérétiques », Revue germanique internationale 9 (2009), p. 133-145; Friedrich VoLLHARDT, "Lessings Lektüre. Anmerkungen zu den Rettungen, zum Faust-Fragment, zu der Schrift über Leibnitz von den ewigen Strafen und zur Erziehung des Menschengeschlechts ", Euphorion 100 (2006), p. 360-393.

4. Sur la place de la bibliothèque dans le premier projet de Lessing, cf. M. MULTHAMMER, « Die Bibliothek als akademischer Untergrund. Der junge Lessing in Wittenberg », in M. MuLsow (dir.), Kriminelle - Freidenker - Alchemisten. Räume des Untergrunds in der Frühen Neuzeit, KölnWeimar-Wien, Böhlau, 2014, p. 575-595.

5. Sur l'unitarisme à l'époque moderne, voir traduction, n. 2.

6. Sur la notion, voir Berengarius Turonensis (abr. BT), WuB 7, 26-27.

7. Lettre à Christian Gottlob Heyne, 20 novembre 1770, WuB 11/2, 93: "Ich will aber nicht, daß man so etwas für mehr ansehen soll, als für die Arbeit eines Bibliothekars, die mit dem Staubkehren in einer Klasse steht ». Sur Heyne, la philologie et les bibliothèques des Lumières, voir Balbina BÄBLER et Heinz-Günther NESSELRATH (dir.), Christian Gottlob Heyne. Werk und Wirkung nach zweihundert Jahren, Berlin-New York, De Gruyter (Abhandlungen der Akademie der Wissenschaften zu Göttingen, Neue Folge, 32), 2015, ainsi que M. EsPAGNE, «De Heyne à Lachmann. Biographies héroïques de philologues allemands », in Ch. KöNIG et D. THOUARD (dir.), La Philologie au présent. Pour Jean Bollack, Villeneuve d'Ascq, Presses universitaires du Septentrion, 2010, p. 127-139 et les recherches d'Anne SAADA sur la bibliothèque de Göttingen, dont «Die Universität Göttingen. Traditionen und Innovationen gelehrter Praktiken», in H. E. BöDEKER, Ph. BütTGEN et M. EsPAgne (dir.), Die Wissenschaft vom Menschen in Göttingen. Wissenschaftliche Praktiken, institutionelle Geographie, europäische Netzwerke, Göttingen, Vandenhoeck \& Ruprecht (Veröffentlichungen des Max-Planck-Instituts für Geschichte, 237), 2008, p. 23-46.

8. Lettre à Christian Gottlob Heyne, 13 janvier 1773, WuB 11/2, 499: "Wenn Sie so gütig sind, und glauben, daß ich wohl etwas besseres hätte schreiben können: so vergessen Sie nicht, daß ein Bibliothekar nichts besseres schreiben soll. Der bin ich einmal, und möchte es nicht gern bloß dem Namen nach sein ». Voir aussi la lettre à Karl Lessing du 5 décembre 1772, WuB 11/2, 483 : «[...] denn ich will auch nicht umsonst Bibliothekar heißen ".

9. Sur cette périodisation du point de vue du Neuser, voir M. MULTHAMMER, Lessings 'Rettungen', op. cit., p. 345-351.

10. On peut voir les témoignages rassemblés par Klaus BoHNEN dans WUB 7, 585-595.

11. Voir la préface de Lessing à la publication des troisième et quatrième parties de ses E Euvres (1754) contenant les quatre Rettungen d'Horace, Cardan, de l'Ineptus religiosus et de Cochlaeus, WuB 3, 153. 


\section{Adam Neuser}

12. Lettres à Johann Arnold Ebert, 12 janvier et 5 octobre 1773, WuB 11/2, 498 et 588, cf. WuB 7, 987 : "Hier haben Sie einen ganzen Mistwagen voll Moos und Schwämme ».

13. Cf. Philippe Beck et Denis Thouard (dir.), Popularité de la philosophie, Fontenay-aux-Roses, ENS Éditions (Theoria), 1995.

14. AN 184-185/WuB 8, 106-107/129. Sur le sens de cette découverte, voir Christopher J. BuRCHILL, The Heidelberg Antitrinitarians. Johann Sylvan, Adam Neuser, Matthias Vehe, Jacob Suter, Johann Hassler, Baden-Baden/Bouxwiller, Koerner (Bibliotheca dissidentium. Répertoire des non-conformistes religieux des XVI ${ }^{e}$ et XVII ${ }^{e}$ siècles, XI), 1989, p. 15.

15. Rettung des Cochläus, aber nur in einer Kleinigkeit, WuB 3, 244.

16. Rettungen des Horaz, WuB 3, 165, à propos d'une variante du texte de Suétone rapportant l'inconduite du poète: "Man sieht, daß ich wenigstens sehr aufrichtig bin, und mir kein Bedenken mache, meinen Grund selbst zu entkräften. Doch wer weiß, ob ich es tun würde, wenn ich nicht den übrigen Gründen desto mehr zutraute ».

17. Rettung des Hieronymus Cardanus, WuB 3, 211 : " Die Aufrichtigkeit ist daher das erste, was ich an einem Weltweisen verlange. Er muß mir keinen Satz deswegen verschweigen, weil er mit seinem System weniger überein kömmt, als mit dem System eines andern; und keinen Einwurf deswegen, weil er nicht mit aller Stärke darauf antworten kann». Sur le concept d'honnêteté dans le texte, voir aussi WuB 3, 198, 208, 212, 214.

18. AN 158/WuB 8, 86/110 : "Gemacht sind sie einmal, diese Anmerkungen; und wenn sie schon an und für sich selbst nicht sehr wichtig sein sollten, so werden sie doch immer dem, der irgend einmal in diesem Winkel des Feldes zu arbeiten hätte, bald eine kleine Mühe, bald einen kleinen Fehlgriff ersparen können. Wie viel Schlechtes muß in dem historischen Fache geschrieben werden, ehe sich etwas Gutes schreiben läßt! »

19. AN 170/WuB 8, 96/119: "Wenn der Ausgang die Seele der Geschichte sein soll, wenn man nach diesem alles Vorhergegangene urteilen soll: so wäre es eben so gut, als hätten wir keine Geschichte ».

20. Pour l'éloge de l'hérétique, « homme qui a au moins voulu voir de ses yeux », cf. BT, WuB 7 , 15.

21. AN 170/WuB 8, 96/119, cf. 166/WuB 8, 93/116, à propos des théologiens, orthodoxes comme sociniens.

22. Von Duldung der Deisten. Fragmente eines Ungenannten, in Zur Geschichte und Literatur, Dritter Beitrag, XVIII, éd. citée (cf. n. 1), p. 195-226/WuB 8, 115-134.

23. Voir Marc DE LAUNAY, "Leo Strauss et la découverte du classicisme ésotérique chez Lessing ", Les Études philosophiques, 2/2003, p. 245-259.

24. Voir le rappel des faits par K. BoHnEn et A. SCHILSON en WuB 9, 731-734 et Horst StREBE, Lessing und die Zensur, Wolfenbüttel, Lessing-Akademie (Wolfenbütteler Vortrags-Manuskripte, 11), 2011.

25. Voir traduction, n. 230.

26. AN 194/WuB 8, 114/136: "Aber doch sei es mir erlaubt, in Nachahmung dieser seiner Worte, zu schließen: Ich habe um so vielmehr Mitleiden mit Neusern, da ich finde, daß er etwas mehr als ein Antitrinitarier gewesen; daß er auch ein guter mechanischer Kopf gewesen zu sein scheint [...] ».

27. C'est l'esquisse d'interprétation de M. MulthammeR, Lessings 'Rettungen', op. cit., p. 351.

28. La plupart des sources disponibles sur Neuser sont rassemblées dans Christopher J. BURCHILL, The Heidelberg Antitrinitarians, op. cit., p. 107-156. Pour une actualisation, voir plus bas, n. 46.

29. Voir plus bas, n. 95. 


\section{Confession et migration}

30. Dans la production francophone, voir Jean-Marie VALENTIN et Patrice VeIT (dir.), La confessionnalisation dans le Saint-Empire, $X V l^{e}-X V I I l^{e}$ siècles = Études germaniques $57 / 3$, juilletseptembre 2002 ; Philippe BütTGEN et Christophe DuHAMELLE (dir.), Religion ou confession? Un bilan franco-allemand sur l'époque moderne (XVI'-XVIII siècles), Paris, Éditions de la Maison des Sciences de l'Homme (Colloquium), 2010.

31. C'est l'objet du premier livre de Heinz SCHILLING, Konfessionskonflikt und Staatsbildung. Eine Fallstudie über das Verhältnis von religiösem und sozialem Wandel in der Frühneuzeit am Beispiel der Grafschaft Lippe, Gütersloh, Mohn (Quellen und Forschungen zur Reformationsgeschichte, 48), 1981, suivi d'un recueil qui fit date: ID. (dir.), Die reformierte Konfessionalisierung in Deutschland. Das Problem der "Zweiten Reformation », Gütersloh, Mohn (Schriften des Vereins für Reformationsgeschichte (abr. SVRG), 195), 1985, avec sur l'électorat palatin la contribution de Volker PRESS, "Die Zweite Reformation in der Kurpfalz», p. 104-129. - J'indique dans cette introduction les études les plus importantes et renvoie pour une vue plus complète à la bibliographie en fin de volume.

32. V. PRESS, Calvinismus und Territorialstaat. Regierung und Zentralbehörden in der Kurpfalz 7559 1619, Stuttgart, Klett (Kieler historische Studien, 7), 1970 ; Eike WoLgast, Reformierte Konfession und Politik im 16. Jahrhundert. Studien zur Geschichte der Kurpfalz im Reformationszeitalter, Heidelberg, Winter (Schriften der Philosophisch-Historischen Klasse der Heidelberger Akademie der Wissenschaften, 10), 1998; sur les aspects doctrinaux, voir toujours Derk VISSER (dir.), Controversy and Conciliation. The Reformation and the Palatinate 1559-1583, Eugene, OR, Pickwick, 1986. Pour une vue régionale, voir Anton SCHINDLING et Walter ZIEGLER (dir.), Die Territorien des Reichs im Zeitalter der Reformation und Konfessionalisierung, t. 7 : Der Südwesten, Münster, Aschendorff (Katholisches Leben und Kirchenreform im Zeitalter der Glaubensspaltung, 35), 1993. - Les règlements ecclésiastiques palatins ont intéressé un précurseur des théories de la confessionnalisation, Ernst Walter ZEEDEN: "Calvinistische Elemente in der Kurpfälzischen Kirchenordnung von $1563 »$ (1962), in ID., Konfessionsbildung. Studien zur Reformation, Gegenreformation und katholischen Reform, Stuttgart, Klett-Cotta, 1985, p. 286-313. La notion de discipline ecclésiastique s'est ensuite imposée dans la discussion: voir Helga ScHNABELSCHÜLE, «Der große Unterschied und seine kleinen Folgen. Zum Problem der Kirchenzucht als Unterscheidungskriterium zwischen lutherischer und reformierter Konfession in der frühen Neuzeit », in M. HAgEnMAIER et S. Holz (dir.), Krisenbewußtsein und Krisenbewältigung in der Frühen Neuzeit - Crisis in Early Modern Europe. Festschrift für Hans-Christoph Rublack, Frankfurt a. M. etc., Lang, 1992, p. 197-214 et le tour d'horizon dans H. SCHILLING (dir.), Kirchenzucht und Sozialdisziplinierung im frühneuzeitlichen Europa, Berlin, Duncker \& Humblot (Zeitschrift für Historische Forschung, Beiheft 16), 1994. En histoire du droit, avec un retour sur l'affaire Neuser, cf. Isabelle DEFLERS, «Die Einführung der Kirchenzuchtordnung von 1570 in der Pfalz - ein Beispiel für Kompetenzstreitigkeiten um die geistliche Strafgerichtsbarkeit », Zeitschrift der Savigny-Stiftung für Rechtsgeschichte 124 (2007), p. 393-405. Sur l'enjeu théologico-politique, voir Ruth WESEL-Roth, Thomas Erastus. Ein Beitrag zur Geschichte der reformierten Kirche und zur Lehre von der Staatssouveränität, Lahr/Baden, Schauenburg (Veröffentlichungen des Vereins für Kirchengeschichte in der Evangelischen Landeskirche in Baden, 15), 1954 et désormais Charles D. GunnoE, Jr., Thomas Erastus and the Palatinate. A Renaissance Physician in the Second Reformation, Leiden-Boston, Brill (Brill's Studies in Church History and Religious Culture, 48), 2011.

33. Cf. Ph. BütTGEN, «Philosophie et religion en Allemagne. Le droit des confessions », Études germaniques 70 (2015), p. 659-670.

34. L'historiographie française se distingue: voir Christine LEBEAU (dir.), L'Espace du SaintEmpire. Du Moyen Âge à l'époque moderne, Strasbourg, Presses universitaires de Strasbourg, 2004 ; Ch. Duhamelle (dir.), Les Espaces du Saint-Empire à l'époque moderne = Histoire, Économie et Société, 2004/1. Sur le passage des frontières intérieures dans l'Empire, cf. ID., La Frontière au village. Une identité catholique allemande au temps des Lumières, Paris, Éditions de l'École des Hautes Études en Sciences Sociales (En Temps \& Lieux, 20), 2010. 


\section{Adam Neuser}

35. Voir p. ex. H. ScHILLING, «Die frühneuzeitliche Konfessionsmigration. Calvinisten und sephardische Juden im Vergleich », in H. P. Jürgens et Th. WELLER (dir.), Religion und Mobilität. Zum Verhältnis vom raumbezogener Mobilität und religiöser Identitätsbildung im frühneuzeitlichen Europa, Göttingen, Vandenhoeck \& Ruprecht (Veröffentlichungen des Instituts für Europäische Geschichte Mainz, Beiheft 81), 2010, p. 113-136.

36 Pour une introduction, voir Harald RoTH, Kurze Geschichte Siebenbürgens (1996), KölnWeimar-Wien, Böhlau, $2007^{3}$ et sur les aspects religieux Ulrich A. WIEN, Julia BRANDT et András F. BALOGH (dir.), Radikale Reformation. Die Unitarier in Siebenbürgen, Köln-Weimar-Wien, Böhlau (Studia Transylvanica, 44), 2013; Volker LEPPIN et U. A. WIEN (dir.), Konfessionsbildung und Konfessionskultur in Siebenbürgen in der Frühen Neuzeit, Stuttgart, Steiner (Quellen und Studien zur Geschichte des östlichen Europa, 66), 2005. Pour un tableau d'ensemble depuis la Réforme, voir Erich Roth, Die Reformation in Siebenbürgen. Ihr Verhältnis zu Wittenberg und der Schweiz, Köln-Wien, Böhlau (Siebenbürgisches Archiv, Dritte Folge, 2/4), 2 vol., 1962-1964 et désormais István KEUL, Early Modern Religious Communities in East-Central Europe. Ethnic Diversity, Denominational Plurality and Corporative Politics in the Principality of Transylvania (1526-1591), Leiden-Boston, Brill (Studies in Medieval and Reformation Traditions, 143), 2009. Plus généralement sur le Saint-Empire et les Turcs au temps d'Adam Neuser, voir Winfried SCHULZE, Reich und Türkengefahr im späten 16. Jahrhundert. Studien zu den politischen und gesellschaftlichen Auswirkungen einer äußeren Bedrohung, München, Beck, 1978, et l'étude de Thomas KAUFMANN, "Türckenbüchlein ». Zur christlichen Wahrnehmung " türckischer Religion » in Spätmittelalter und Reformation, Göttingen, Vandenhoeck \& Ruprecht (Forschungen zur Kirchenund Dogmengeschichte, 97), 2008. - L'antitrinitarisme en Transylvanie a été bien étudié par la recherche hongroise: voir Antal PIRNÁT, Die Ideologie der Siebenbürger Antitrinitarier in der 1570er Jahren, Budapest, Verlag der Ungarischen Akademie der Wissenschaften, 1961 ; Robert DÁN et ID. (dir.), Antitrinitarianism in the Second Half of the 16th Century, Budapest, Akademiai Kiadó (Studia Humanitatis, 5), 1982 ; Mihály BALÁzs, Early Transylvanian Antitrinitarianism (15661571). From Servet to Palaeologus, Baden-Baden/Bouxwiller, Koerner (Bibliotheca dissidentium, VII), 1996; ID., Ungarländische Antitrinitarier IV. Ferenc Dávid, Baden-Baden/Bouxwiller, Koerner (Bibliotheca dissidentium, XXVI), 2008.

37. Voir Kaspar von GREYERZ, Manfred JAKUBOWSKI-TIESSEN, Thomas KAUFMANN et Hartmut LEHMANN (dir.), Interkonfessionalität - Transkonfessionalität - binnenkonfessionelle Pluralität. Neue Forschungen zur Konfessionalisierungsthese, Gütersloh, Gütersloher Verlagshaus (SVRG, 201), 2003 et Ute Lotz-HeumanN, Jan-Friedrich Missfelder et Matthias PoHlig (dir.), Konversion und Konfession in der Frühen Neuzeit, Gütersloh, Gütersloher Verlagshaus (SRVG, 205), 2007, ainsi que Jörg DEVENTER, « Konversion und Konvertiten im Zeitalter der Reformation und Konfessionalisierung. Stand und Perspektiven der Forschung », Aschkenas. Zeitschrift für Geschichte und Kultur der Juden 15 (2005), p. 257-270 et Kim SIEBENHÜNER, « Glaubenswechsel in der Frühen Neuzeit. Chancen und Tendenzen einer historischen Konversionsforschung », Zeitschrift für Historische Forschung 34 (2007), 243-272. Sur les conversions princières, voir ÉricOlivier MADER, «Fürstenkonversionen zum Katholizismus in Mitteleuropa im 17. Jahrhundert. Ein systematischer Ansatz in fallorientierter Perspektive », Zeitschrift für Historische Forschung 34 (2007), p. 403-440; David M. LUEBKE, Jared POLEY, Daniel C. RYAN, David Warren SABEAN (dir.), Conversion and the Politics of Religion in Early Modern Germany, New York, etc., Berghahn (Spektrum, 3), 2012. Importante pour la perspective retenue ici est l'étude de Kai BREMER, "Konversionalisierung statt Konfessionalisierung? Bekehrung, Bekenntnis und das Politische in der Frühen Neuzeit », in H. JAUMANN (dir.), Diskurse der Gelehrtenkultur in der Frühen Neuzeit. Ein Handbuch, Berlin-New York, de Gruyter, 2010, p. 369-408.

38. AN 191-192/WuB 8, 112/134 (sur Neuser, Erastus et le "Streit über die Kirchenzucht ») et 174-175/WuB 8, 99-100/122-123. Dans la lettre de Neuser éditée par Lessing, cf. AN 142/WuB $8,74 / 99$.

39. AN 169-171/WuB 8, 95-96/118-120. 


\section{Confession et migration}

40. Dans l'exposé de ses doutes sur la légalité de l'exécution de Sylvan par les autorités de l'électorat palatin, on notera le recours de Lessing au traité De Mortibus Socinianorum d'Ernst Salomon Cyprian (1673-1745), bibliothécaire de Gotha, luthérien farouchement anti-socinien, mais amené par son luthéranisme à rejeter le chef d'inculpation de haute trahison: AN 171172/WuB 8, 96-97/120. À la suite, dans un geste typique de correction érudite, Lessing reprend Cyprian sur un aspect de son argumentation mais impute l'erreur à sa source, Heinrich Alting, qui est réformé. - Pour une démonstration de luthéranisme érudit avant AN, voir BT, WuB 7, 20-21.

41. Cf. Michele BernardinI, Clara Borrelli, Anna Cerbo, Encarnación SÁNCHez García (dir.), Europa e Islam tra i secoli XIV e XVI, 2 vol., Napoli, Istituto universitario orientale (collana « Matteo Ripa », XVIII), 2002; Bernard HeYBERGER, Mercedes GARcíA-ArenAL, Emanuele Colombo et Paola VISMARA (dir.), L'Islam visto da Occidente. Cultura e religione del Seicento europeo di fronte all'Islam, Milano, Mariotti, 2009 ; Jocelyne DAKHLIA, Wolfang KAISER et Bernard VINCENT (dir.), Les Musulmans et l'histoire de l'Europe, 2 vol., Paris, Seuil, 2011-2013. Sur les voyages et migrations d'Europe vers l'Empire ottoman, cf. Ralf C. MüLLER, Franken im Osten. Art, Umfang, Struktur und Dynamik der Migration aus dem lateinischen Westen in das Osmanische Reich des 15./16. Jahrhunderts auf der Grundlage von Reiseberichten, Leipzig, Eudora, 2005 et sa somme documentaire, ID., Prosopographie der Reisenden und Migranten ins Osmanische Reich (13961677), 10 vol., Leipzig, Eudora, 2006.

42. AN 125-126/WuB 8, 60-61/84.

43. Voir traduction, n. 27-29.

44. Voir plus bas, p. 169-176. Sur Veyssière de La Croze, cf. AN 178, 181/WuB 8, 102, 104/125, 127 et traduction, $n .188$.

45. AN 153-157/WuB 8, 83-86/107-110. Lessing souligne.

46. Martin MuLsow, "Adam Neusers Brief an Sultan Selim II und seine geplante Rechtfertigungsschrift. Eine Rekonstruktion anhand neuer Manuskriptfunde », in F. VOLLHARDT (dir.), Religiöser Nonkonformismus und frühneuzeitliche Gelehrtenkultur, Berlin, Akademie-Verlag (Quellen und Darstellungen zur Geschichte des Antitrinitarismus und Sozinianismus in der Frühen Neuzeit, 2), 2014, p. 293-318; ID., «Fluchträume und Konversionsräume zwischen Heidelberg und Istanbul. Der Fall Adam Neuser», in ID. (dir.), Kriminelle - Freidenker Alchemisten, op. cit., p. 33-60. Voir encore ID., «Adam Neuser », in D. THOMAS et J. CHESWORTH (dir.), Christian-Muslim Relations. A Bibliographical History, t. 7 : Central and Eastern Europe, Asia, Africa and South America (1500-1600), Leiden-Boston, Brill, 2015, p. 420-425.

47. $L_{1}$ fait mention de ce projet d'apologie: voir AN 130-131/WuB 8, 64-65/88-89. Selon Mulsow ("Adam Neusers Brief an Sultan Selim ॥ », art. cité, p. 302), cette apologie aurait mêlé documents (dont la reconstitution de $L_{2}$ ), récits de voyage et arguments théologiques.

48. Sur ce dernier point, je suis de nouveau Mulsow, ibid., p. 310.

49. AN 134/WuB 8,67/91 : "... auf daß ihr verstehet, wie es eine Gestalt habe mit obgemeldtem Briefe... », et le développement en AN 137-141/WuB 8, 70-74/94-98.

50. Voir notamment AN 141/WuB 8, 73-74/98.

51. AN 148/WuB 8, 79/104 : "Ich habe ihn geschrieben, sagt Neuser, diesen unglücklichen, so mißverstandenen Brief: aber ich habe ihn nie abgeschickt; ich habe ihn keinen Menschen zu lesen gegeben; ich habe ihn durch eine eigenhändig beigefügte Clausel, so gut als vernichtet; ich habe von dem, was ich darin zu tun vorhatte, wirklich das Gegenteil getan ». La stratégie de Lessing requiert une sortie ostentatoire de l'ambiguïté, à travers la prosopopée qu'on vient de lire.

52. Le passage est cité deux fois, AN 126-127/WuB 8, 61/85 et 149/WuB 8, 79/104, en latin sur la "lettre de traître », " in qua fassus [...] plures esse in Germania Arianae factioni addictos, quibus nihil magis in votis esset, quam Turcarum Monarchae viam sternere in Imperio, et cum ipso coniungi ». Sur Alting, voir traduction, $n$. 27. Deux autres rapides citations de $L_{2}$ se trouvent en AN 149-150, 155/WuB 8, 80, 84/104-105, 108-109. 


\section{Adam Neuser}

53. AN 125-126/WuB 8, 60-61/84 et traduction, n. 28.

54. AN 171/WuB 8, 96/119, qui consonne avec le passage cité plus haut, n. 51 : "je ne l'ai donnée à lire à personne». Lessing insiste sur ce point à partir d'une autre source, deux lettres à l'électeur palatin envoyées par Neuser de Pologne - disons $L_{4 a}-L_{4 b}$. Ces lettres sont mentionnées en $L_{1}$ (AN 137/WuB 8, 69-70/94), et Neuser lui-même doute qu'elle soient parvenues à leur destinataire. Elles sont en tout cas perdues aujourd'hui. Soit donc Lessing y a eu accès, soit (plus probablement) il force le témoignage de Neuser.

55. AN 172/WuB 8, 97/120 et plus haut, n. 21.

56. Voir plus haut, n. 45.

57. Voir plus haut, n. 19.

58. Des Abts von Marigny Geschichte der Araber unter der Regierung der Califen. Aus dem Französischen, 3 vol., Berlin 1753-1754. La préface de Lessing est reprise en WuB 2, 579-592. Sur la part de Lessing dans la traduction des trois volumes parus, voir WuB 2, 1162-1163. Lessing s'est chargé lui-même de l'annonce et des recensions: annonce de la traduction allemande, Berlinische Priviligirte Staats- und gelehrte Zeitung 20 (15 février 1753), WuB 2, 487-488; recension du t. 1, ibid. 65 (31 décembre 1753), WuB 2, 106-107; recension du t. 2, Berlinische Priviligirte Zeitung 79 (2 juillet 1754), WuB 3, 57-58; recension du t. 3, ibid. 145 (3 décembre 1754), WuB 3, 97-98.

59. Des Herrn von Voltaire Kleinere Historische Schriften. Aus dem Französischen übersetzt, Rostock 1752, préface de Lessing en WuB 2, 311-330.

60. Dans une littérature inégale, on peut retenir Peter M. HOLT, «The Study of Islam in Seventeenth- and Eighteenth Century England », Journal of Early Modern History 2 (1998), p. 113123; Dietrich KLEIN et Birte PLATOW (dir.), Wahrnehmung des Islam zwischen Reformation und Aufklärung, Paderborn, Fink, 2008; Ziad ELMARSAFY, The Enlightenment Qur'an. The Politics of Translation and the Construction of Islam, Oxford, Oneworld, 2009 ; Humberto GARCIA, Islam and the English Enlightenment 1670-1840, Baltimore, Johns Hopkins University Press, 2012. Sur la période immédiatement ultérieure, voir Michel ESPAGNE, Nora LAFI et Pascale RABAULT-FEUERHAHN (dir.), Silvestre de Sacy. Le projet européen d'une science orientaliste, Paris, Cerf-a, 2014. Sur Lessing et l'islam, la littérature est apologétique: Karl-Josef KuSCHEL, Vom Streit zum Wettstreit der Religionen. Lessing und die Herausforderung des Islam, Düsseldorf, Patmos (Weltreligionen und Literatur, 1), 1998; Silvia HoRSCH, Rationalität und Toleranz. Lessings Auseinandersetzung mit dem Islam, Würzburg, Ergon (Ex Oriente lux, 5), 2005 ; Zahim M. M. AL-SHAMmARY, Lessing und der Islam, Berlin, Schiler, 2011. Pour un aperçu d'ensemble, cf. Ian ALMOND, History of Islam in German Thought. From Leibniz to Nietzsche, New York, Routledge, 2011.

61. Des Abts von Marigny Geschichte der Araber, recension du t. 3 (voir plus haut, n. 58), WuB 3, 97.

62. Des Abts von Marigny Geschichte der Araber, Vorrede des Übersetzers, WuB 2, 581-583. Pour la mention des sources, je suis l'ordre du théologien hallois Jakob Simon Baumgarten (1706-1757) dans sa recension de Marigny discutée ici par Lessing: Barthélemy d'Herbelot de Molainville (1625-1695), auteur de la Bibliothèque orientale (1697) (cf. Henry LAURENS, La " Bibliothèque orientale » de Barthélemi d'Herbelot. Aux sources de l'orientalisme, Paris, Maisonneuve et Larose (Publications du Département d'islamologie de I'Université Paris-Sorbonne, 6), 1978); Simon Ockley (1678-1720), professeur d'arabe à Cambridge à partir de 1711, auteur d'une History of the Saracens traduite en allemand en 1746 (cf. A. J. ARBERRY, Oriental Essays. Portraits of Seven Scholars, London, Allen \& Unwin, 1960, p. 11-47); Eusèbe Renaudot (1646-1720), janséniste, traduit de l'arabe et commente les Anciennes Relations des Indes et de la Chine de deux voyageurs mahométans qui y allèrent dans le neuvième siècle (1718) (cf. Detlev G. MüLLER, "Eusèbe Renaudot», in Biographisch-Bibliographisches Kirchenlexikon, Herzberg, Bautz, t. 8, 1994, col. 34-44) ; Joseph Simon Assemani (1687-1768), maronite du Mont-Liban, préfet de la Bibliothèque Vaticane à partir de 1738, auteur de la Bibliotheca orientalis Clementino-Vaticana (4 vol., 1719-1728) ; Albert Schultens (1686-1750), hébraïste et arabisant, professeur à Franeker 


\section{Confession et migration}

puis Leyde; George Sale (1697-1736, dénommé « Salem » dans le texte!), publie en 1734 une traduction anglaise du Coran retraduite en allemand en 1746 et diffusée dans toute l'Europe.

63. Des Abts von Marignys Geschichte der Araber, Vorrede des Übersetzers, WuB 2, 580.

64. Voir plus haut, n. 4

65. Rettung des Hieronymus Cardanus, WuB 3, 214: "Die Nachrichten, die man zu seinen Zeiten, von dem Mahomet und dessen Lehren hatte, waren sehr unzulänglich, und mit tausend Lügen vermengt, welche die christlichen Polemici desto lieber für Wahrheiten annahmen, je ein leichtres Spiel sie dadurch erhielten. Wir haben nicht eher eine aufrichtige Kenntnis davon erhalten, als durch die Werke eines Relands und Sale; aus welchen man am meisten erkannt hat, daß Mahomet eben kein so unsinniger Betrieger, und seine Religion eben kein bloßes Gewebe übel an einander hangender Ungereimtheiten und Verfälschungen sei. Aber bei dem allen ist Cardan noch nicht entschuldiget: er, der sich um so viel unbekannte Sachen bekümmerte, hätte sich auch hierum erst bekümmern müssen, ehe er eine Vergleichung wagte, die völlige Erkenntnis voraussetzt, wenn sie einem Philosophen nicht unanständig sein soll ».

66. Hadrian Reland (1676-1718), professeur de langues orientales à Utrecht à partir de 1701, auteur d'études sur la Palestine biblique et d'un De religione mohammedica (1705). Voir J. T.P. DE BRUIJN, "The Persian Studies of Adriaan Reland (1676-1718)», in Ch. VAN RUYMBECKE (dir.), Mais "comment peut-on être persan?". Éléments persans en Orient et Occident. Liber amicorum Annette Donckier de Donceel, Leuven, Peeters, 2003, p. 37-50; Bernd RoLING, " Humphrey Prideaux, Eric Fahlenius, Adrian Reland, Jacob Ehrhardt und die Ehre des Propheten : Koranpolemik im Barock», in D. KLEIN et B. PLATOW (dir.), Wahrnehmung des Islam zwischen Reformation und Aufklärung, op. cit., p. 61-76.

67. Rettung des Hieronymus Cardanus, WuB 3, 214.

68. Ibid., WuB 3, 215 : «Wirf einen Blick auf sein [sc. Mahomets] Gesetz! Was findest du darinne, das nicht mit der allerstrengsten Vernunft übereinkomme? Wir glauben einen einigen Gott: wir glauben eine zukünftige Strafe und Belohnung, deren eine uns, nach Maßgebung unserer Taten, gewiß treffen wird. Dieses glauben wir, oder vielmehr, damit ich auch eure entheiligten Worte nicht brauche, davon sind wir überzeugt, und sonst von nichts! Weißt du also, was dir obliegt, wann du wider uns streiten willst? Du mußt die Unzulänglichkeit unsrer Lehrsätze beweisen! Du mußt beweisen, daß der Mensch zu mehr verbunden ist, als Gott zu kennen, und tugendhaft zu sein; oder wenigstens, daß ihm beides die Vernunft nicht lehren kann, die ihm doch eben dazu gegeben ward! »

69. Ibid., WuB 3, 217.

70. Von Duldung der Deisten (abr. VDD, cf. plus haut n. 22), 222-223/WuB 8, 131 : "Ich getraute mir, wenn dieses mein Hauptabsehen wäre, das vornehmste der natürlichen Religion aus dem Alkoran gar deutlich und zum Teile gar schön ausgedruckt darzutun, und glaube, daß ich bei Verständigen leicht darin Beifall finden werde, daß fast alles Wesentliche in Mahomets Lehre auf natürliche Religion hinauslaufe ».

71. Voir Ulrich GRoETSCH, Hermann Samuel Reimarus (1694-1768). Classicist, Hebraist, and Enlightenment Radical in Disguise, Leiden-Boston, Brill (Brill's Studies in Intellectual History, 237), 2015, ainsi que M. MuLsow (dir.), Between Philology and Radical Enlightenment. Hermann Samuel Reimarus (1694-1768), Leiden-Boston, Brill (Brill's Studies in Intellectual History, 203), 2011. Sur les liens de Lessing à Wolfenbüttel avec l'orientaliste Johann Jakob Reiske (17161774), professeur à Leipzig, voir WuB 7, 588-589 et Heinrich SCHNEIDER, "Lessing und das Ehepaar Reiske », in ID., Lessing. Zwölf biographische Studien, Bern, Francke, 1951, p. 110-165; Hans-Georg EBERT et Thoralf HANSTEIN (dir.), Johann Jacob Reiske. Ein Leipziger Byzantinist und Begründer der Orientalistik im 18. Jahrhundert, Leipzig, Evangelische Verlags-Anstalt (Beiträge zur Leipziger Universitäts- und Wissenschaftsgeschichte, 6), 2005.

72. VDD, 223/WuB 8, 131. Thomas Hyde (1636-1703), interprète de la cour d'Angleterre à partir de 1660, bibliothécaire de la Bodleian de 1665 à 1701. Au passage, Reimarus réfute un 


\section{Adam Neuser}

survivant de la controverse anti-musulmane, Humphrey Prideaux (1648-1724), auteur en 1697 d'une Vie de Mahomet déjà critiquée par Sale dans les notes de sa traduction du Coran.

73. VDD, 197/WuB 8, 115.

74. VDD, 221/WuB 8, 130: "Denn als Neuser so weit gekommen war, daß er sich kein Bedenken machte, zur Mahometanischen Religion überzutreten, war er doch vermutlich kein Phantast, der sich von der Wahrheit der Mahometanischen Religion, als geoffenbarter Religion, vorzüglich vor der Christlichen, überzeugt fühlte: sondern er war ein Deist, der Eine geoffenbarte Religion für so erdichtet hielt, als die andere, und den nur die äußerste Verfolgung zu einem Tausche brachte, an den er nie würde gedacht haben, wenn er irgendwo in der Christenheit die Duldung zu finden gewußt hätte, auf welche unser Unbekannte für solcher Art Leute dringet ».

75. VD, 222/WuB 8, 130: "Indes kann es auch doch gar wohl sein, daß Neuser auch eine Art Prädilection für die Mahometanische Religion gehabt, und daß er ihr bereits alle die Gerechtigkeit widerfahren lassen, die seit neurer Zeit freimütige und unverdächtige Gelehrte ihr erzeigen zu müssen geglaubt haben ». Je corrige le texte de WuB, qui reproduit une erreur d'impression de la première édition.

76. VD, 223/WuB 8, 131: "Wie weit nun dieses auch Neuser zu seiner Zeit bereits erkannt, würden wir mit Gewißheit sagen können, wenn es den Herausgebern der Monumentorum Palatinorum beliebt hätte, uns seine Anmerkungen über den Alkoran mitzuteilen, die sie vor sich gehabt zu haben versichern ». Sur les Monumenta de Mieg et Nebel, voir traduction, n. 28: le passage visé par Lessing se trouve dans la préface, f. [ ${ }^{\star} 6$ ] et est cité dans AN 169/WuB 8, 95/118. Sur les Corans de Neuser, voir M. MuLsow, "Adam Neusers Brief an Sultan Selim II ", art. cité, p. 310-311, et sur le projet de retraduction que Neuser pourrait avoir caressé à Istanbul, ID., "Fluchträume und Konversionsräume », art. cité, p. 52-53. À Heidelberg, Neuser a lu le Coran dans la traduction latine de Bibliander (Zurich, 1543) : voir Hartmut BoBZIN, Der Koran im Zeitalter der Reformation. Studien zur Frühgeschichte der Arabistik und Islamkunde in Europa, Stuttgart, Steiner, 1995, réimp. Würzburg, Ergon (Beiruter Texte und Studien, 42), 2008; Th. KAUfMANN, "Türckenbüchlein», op. cit., p. 39-41/169-174 (= n. 260-297). Lessing mentionne à travers le journal de Gerlach la lettre conservée du superintendant unitarien de Pologne, Piotr Witrousk, du 2 juillet 1574 qui interroge Neuser sur l'authenticité du Coran de Bibliander, le créditant ainsi d'une compétence d'arabisant (AN 187/WuB 8, 108-109/131 et Ch. J. BURCHILL, The Heidelberg Antitrinitarians, op. cit., p. 155-156 sur la lettre de Witrousk).

77. Sur ce texte, voir Maria Rosa AntognazZA, Leibniz on Trinity and the Incarnation. Reason and Revelation in the Seventeenth Century, New Haven, Yale University Press, 2007 (= Trinità e incarnazione. II rapporto tra filosofia e teologia rivelata nel pensiero di Leibniz, Milano, Vita e Pensiero (Pubblicazioni dell'Università Cattolica del Sacro Cuore, 64), 1999), p. 137-149. Sur Andreas Wissowatius (Andrzej Wiszowaty, 1608-1678), petit-fils de Faust Socin, l'information est rassemblée dans l'édition de la Religio rationalis par Zbigniew OGoNOWSKI, Wolfenbüttel, Herzog-August-Bibiothek (Wolfenbütteler Forschungen, 20), 1980, p. 9-14. Sur I'histoire intellectuelle du mouvement socinien, voir Kestutis DAUGIRDAS, Die Anfänge des Sozinianismus. Genese und Eindringen des historisch-ethischen Religionsmodells in den universitären Diskurs der Evangelischen in Europa, Göttingen, Vandenhoeck \& Ruprecht (Veröffentlichungen des Instituts für Europäische Geschichte Mainz, 240), 2016 et sur la réception Lech SzcucKı (dir.), Faustus Socinus and His Heritage, Kraków, Polish Academy of Arts and Sciences, 2005. Sur d'autres ramifications du socinianisme, en lien avec Leibniz, voir l'étude de Tristan DAGRoN, Leibniz et Toland. L'invention du néo-spinozisme, Paris, Vrin (Bibliothèque d'histoire de la philosophie), 2009.

78. Des Andreas Wissowatius Einwürfe gegen die Dreieinigkeit, in Zur Geschichte und Literatur, Zweiter Beitrag, XII, Braunschweig 1773 (abr. AWE), WuB 7, 576-577: "Leibnitz machte sich daher auch kein Bedenken, diejenigen von den Socinianern, welche ihre Brüder kaum dieses Namens würdigen wollen, weil sie frei gestehen, daß sie den, welchen sie nicht für Gott halten, auch weder als Gott anbeten, noch sonst auf eine Weise mit Gott, oder neben Gott, oder in Beziehung auf Gott, verehren mögen; diese, sage ich, für die bessern und vernünftigern Socinianer zu halten. Denn, wenn 


\section{Confession et migration}

sie schon keine eigentliche Socinianer sind, so sind sie doch offenbar die bessern und vernünftigern Unitarier. Sie haben mit den Socinianern den nemlichen Irrtum gemein; aber sie handeln diesem Irrtume mehr consequent. Ob sie aber sonach viel oder wenig von den Mahometanern verschieden sind: was liegt daran? Nicht der Name macht es, sondern die Sache; und wer die Sache zu lehren oder zu insinuieren den Mut hat, der müßte auch freimütig genug sein, dem Namen nicht ausweichen zu wollen. Was haben sie denn auch je gründliches jenen Folgen entgegengesetzt, die notwendig aus ihrer Lehre fließen, und die niemand gegen sie betrieben hat, als Abbadie? Nemlich, daß wenn Christus nicht wahrer Gott ist, die mahometanische Religion eine unstreitige Verbesserung der christlichen war, und Mahomet selbst ein ungleich größrer und würdigerer Mann gewesen ist, als Christus; indem er weit wahrhafter, weit vorsichtiger und eifriger für die Ehre des einzigen Gottes gewesen, als Christus, der, wenn er sich selbst auch nie für Gott ausgegeben hätte, doch wenigstens hundert zweideutige Dinge gesagt hat, sich von der Einfalt dafür halten zu lassen, dahingegen dem Mahomet keine einzige dergleichen Zweideutigkeit zu Schulden kommt ».

79. Voir plus bas, p. 45-46.

80. Sur Socin, Biandrata et Dávid, voir traduction, n. 8, 9, 52. Dans le texte édité par Lessing, le seul point d'appui est fourni par la brève explication qui accompagne l'envoi par Wissowatius de ses arguments antitrinitaires au baron Boineburg. L'adoration socinienne de Jésus-Christ est définie par la formule " adorati [o] divina non suprema, sed supremae proxima, et subordinata » (AWE, WuB 7, 555), que Lessing glose au début du passage cité. Dans l'édition Dutens avec laquelle Lessing travaillait, voir la lettre de Leibniz du 2 décembre 1706 à Mathurin Veyssière de La Croze, Opera omnia, Genevae 1768 (réimpr. Hildesheim-New York, Olms, 1990, abr. Dutens), t. V, p. 481 : «François Davidis avoit raison en cela de s'élever contre Blandrata \& Socin; nous n'adorons formellement \& précisément que l'éternel \& l'infini ; \& l'union du créateur avec la créature, quelque grande qu'elle soit, ne doit pas altérer ce culte». Le passage cité par Lessing (AWE, WuB 7,577) se trouve quelques lignes plus loin. Leibniz commente ici l'envoi par La Croze des Réflexions historiques et critiques sur le mahométisme et sur le socinianisme qui seront éditées l'année suivante au t. I des Dissertations historiques et critiques sur divers sujets (Rotterdam 1707), avec la lettre de Leibniz et celle de Neuser (voir Annexe dans ce volume). Sur ce traité et sur l'ambivalence de La Croze face au socinianisme, voir M. MuLsow, Die drei Ringe. Toleranz und clandestine Gelehrsamkeit bei Mathurin Veyssière La Croze (1661-1739), Tübingen, Niemeyer (Hallesche Beiträge zur europäischen Aufklärung (abr. HABEI), 16), 2001, p. 66-85, sp. 78. Cf. aussi Mogens LAERKE, «Leibniz, la censure et la libre pensée », Archives de philosophie 70 (2007), p. 273-287.

81. Lettre à Veyssière de La Croze, in Dutens V, 481.

82. AN 181-184/WuB 8, 104-106/127-129.

83. Leibnitz von den ewigen Strafen, in Zur Geschichte und Literatur, Erster Beitrag, Braunschweig 1773, VII, WUB 7, 472-501.

84. AWE, WuB 7, 575: "Um sich der aufrichtigen Abneigung unsers Philosophen von allen Lehrsätzen der Socinianer noch mehr zu versichern, darf man sich nur erinnern, wie unzufrieden er auch mit ihrer anderweitigen Philosophie war, nach welcher er sie noch weit unter die Mahometaner setzte ».

85. Voir plus haut, n. 38-40.

86. Abbadie quitta Berlin pour l'Église française de Londres après la mort en 1688 de FrédéricGuillaume I" ${ }^{\text {er }}$ électeur de Brandebourg. Voir Ruth WHELAN, "The Dean of Killaloe », Lias 14 (1987), p. 101-117; EAD., «From Christian Apologetics to Enlightened Deism. The Case of Jacques Abbadie (1656-1727) », Modern Language Review 87 (1992), p. 32-40 ; EAD., "Le Christ de Jacques Abbadie », in M.-C. PITASSI (dir.), Le Christ entre orthodoxie et Lumières, Genève, Droz (Histoire des idées et critique littéraire, 332), 1994, p. 139-162; EAD., « Jacques Abbadie, ou le seuil politique de l'apologétique », in N. BRUCKER (dir.), Apologétique 1650-1802. La nature et la grâce, Bern-Berlin etc., Lang (Recherches en littérature et spiritualité, 18), 2010, p. 109-125. Le 


\section{Adam Neuser}

passage paraphrasé dans le texte de WuB 7, 576-577 (voir plus haut, n. 78) se trouve dans le Traité de la divinité de notre Seigneur Jésus-Christ, Rotterdam 1689, I, I, p. 6-12 ("Que si JésusChrist n'est pas d'une même essence que son Père, le Christianisme que nous professons, est la corruption de la Religion Chrétienne, et que le Mahométisme en est le rétablissement »). Voir aussi Dominique URVOY, "La religion musulmane et la preuve de la divinité de Jésus selon Jacques Abbadie (1656-1727)», Islamo-Christiana 12 (1986), p. 73-91.

87. Cf. M. Mulsow, Die drei Ringe, op. cit., p. 72.

88. AWE, WuB 7, 579: "Es erhub sich, nur eben erst bei seinen [sc. Leibniz'] Lebzeiten, unter einigen Reformierten der Streit über die vorläufige Frage, ob es möglich sei, und wenn es möglich, ob es dienlich sei, die christliche Religion auf bloß natürliche Beweise zu gründen, der Vernunft allein die Überzeugung von ihrer Wahrheit anheimzustellen. Aber es sei nun, daß Leibnitz von diesem Streite entweder nichts in Erfahrung brachte, oder ihn für die bisherige Meinung entschieden zu sein glaubte: genug, er fuhr fort, hierüber zu denken, wie er es in seiner Jugend war gelehret worden ».

89. Jacques ABBADIE, Traité de la vérité de la religion chrétienne (1684), Rotterdam 1689³, t. IV, I, 4, p. 544, cité par R. WHELAN, «From Christian Apologetics to Enlightened Deism», art. cité, p. 34. Cf. Jacqueline LAGRÉE, La Raison ardente. Religion naturelle et raison au XVII siècle, Paris, Vrin (Philologie et Mercure), 1991, p. 29, 31, 35-36. Sur l'implication de Leibniz dans les querelles entre huguenots berlinois, voir Sebastian KüHN, «Dissimulatio als gelehrte Praxis? Politik sozialer Beziehungen in gelehrten Netzwerken », in W. LI et S. NoREIK (dir.), G. W. Leibniz und der Gelehrtenhabitus. Anonymität, Pseudonymität, Camouflage, Köln-Weimar-Wien, Böhlau, 2016, p. 35-48, sp. 41-44.

90. Pour une vue d'ensemble, cf. M. Mulsow et Jan RoHls (dir.), Socinianism and Arminianim. Antitrinitarians, Calvinists and Cultural Exchange in Seventeenth-Century Europe, Leiden-Boston, Brill (Brill's Studies in Intellectual History, 134), 2005.

91. AWE, WuB 7, 579 (voir plus haut, n. 88). Avant de mentionner ici les enseignements théologiques de la "jeunesse » de Leibniz, le commentaire avait fait état de sa maîtrise de la logique «depuis l'enfance» (WuB 7, 571). Logique et théologie se fondent dans la figure étrange d'un Leibniz enfant.

92. Voir Ch. J. BURCHILL, The Heidelberg Antitrinitarians, op. cit., p. 156 et Dorothea WENDEBOURG, Reformation und Orthodoxie. Der ökumenische Briefwechsel zwischen der Leitung der Württembergischen Kirche und Patriarch Jeremias II. von Konstantinopel in den Jahren 1573-7581, Göttingen, Vandenhoeck \& Ruprecht (Forschungen zur Kirchen- und Dogmengeschichte, 37), 1986, p. 375-376. Le texte est rapporté par Gerlach dans son traité contre le théologien réformé Lambert Daneau, Antidanaeus, Tübingen 1580, p. 39, en menaçantes capitales: "NVLLVS NOSTRO TEMPORE (MIHI NOTVS) FACTVS EST ARRIANVS, QVI NON ANTEA FVERIT CALVINISTA, SERVETVS, BLANDRATA, ALCIATVS, FRANCISCVS DAVIDIS, GENTILIS, GRIBALDVS, SYLVANVS, ET ALII. IGITVR QVI TIMET, NE INCIDAT IN ARRIANISMVM, CAVEAT CALVINISMVM ». Neuser a porté cette annotation en marge de la lettre du superintendant Witrousk de 1574 (voir plus haut, n. 76), selon Burchill pour garder en mémoire un argument de Gerlach. Elle est connue de Lessing, qui cite l'Antidanaeus (AN 187, 189/WuB 8, 108, 110/131-132). La formule sert encore de point de départ à Benjamin R. MERKLE dans son étude Defending the Trinity in the Reformed Palatinate. The Elohistae, Oxford, Oxford University Press (Oxford Theology and Religion Monographs), 2015.

93. AN 169/WuB 8, 95/118.

94. Voir Th. KAUFMANN, « Türckenbüchlein », op. cit., p. 42-55, sur la « turcisation » de l'adversaire confessionnel. "Calvinoturcismus » a en outre des résonances diplomatiques et renvoie à des spéculations d'alliance avec l'Empire ottoman chez les réformés: cf. M. E. H. N. Mout, "Calvinoturcismus und Chiliasmus im 17. Jahrhundert », Pietismus und Neuzeit 14 (1988), p. 72-84. Sur le parallèle islamo-socinien plus généralement, cf. M. MuLsow, «Islam und Sozinianismus. Eine Parallelwahrnehmung der Frühen Neuzeit », in D. KLEIN et B. PLATo (dir.), 


\section{Confession et migration}

Wahrnehmung des Islam zwischen Reformation und Aufklärung, op. cit., p. 27-39; ID., " Socinianim, Islam and the Radical Uses of Arabic Scholarship », Al-Qantara. Revista de estudios árabes 31 (2010), p. 549-586.

95. Un pamphlet luthérien de 1621 porte ce titre: Preuve évidente de ce que les calvinistes s'accordent sur quatre-vingt dix-neuf points avec les Ariens et les Turcs. Voir Th. KaUfMANN, Dreißigjähriger Krieg und Westfälischer Friede. Kirchengeschichtliche Studien zur lutherischen Konfessionskultur, Tübingen, Mohr Siebeck (Beiträge zur Historischen Theologie, 104), 1998, p. 43, n. 119. Cf. ID., "Türckenbüchlein», op. cit., p. 46/189-191 (= n. 353-355) ; ID., « Die theologische Bewertung des Judentums im Protestantismus des späteren 16. Jahrhunderts (1530-1600) », in ID., Konfession und Kultur. Lutherischer Protestantismus in der zweiten Hälfte des Reformationsjahrhunderts, Tübingen, Mohr Siebeck (Spätmittelalter und Reformation, Neue Reihe, 29), 2006, p. 112-154, sp. 114-117 : la critique des réformés « judaïsants » et celle de leur supposée inclination musulmane vont de pair chez les luthériens. - Sur la qualification des antitrinitaires en «Ariens », voir traduction, n. 2, 40, 69.

96. AWE, WuB 7, 551. Cf. Jürgen Voss, " Mannheim. Residenz der Kurfürsten von der Pfalz », in K. ANDERMANN (dir.), Residenzen. Aspekte hauptstädtischer Zentralität von der Frühen Neuzeit bis zum Ende der Monarchie, Sigmaringen, Thorbecke (Oberrheinische Studien, 10), 1992, p. 323336.

97. AWE, WuB 7,579, sur la différence entre vérités humaines et vérités divines et la "altvätersche Meinung» de Leibniz à ce sujet. Le passage joue sur l'intériorisation dans la culture confessionnelle luthérienne, dès le début du $X \mathrm{~V} \|^{\mathrm{e}}$ siècle, d'un complexe provincialobsidional face à l'expansion de la Réforme calvinienne, sa discipline ecclésiale et ses solidarités européennes. Voir Th. KAUFMANN, Dreißigjähriger Krieg und Westfälischer Friede, op. cit., p. 142-143, 154.

98. Voir plus haut, n. 74 .

99. Voir plus haut, n. 1.

100. AN 180/WuB 8, 104/126 : "Er [sc. Neuser] suchte nichts, als mit guter Weise heraus zu kommen ».

101. AN 166/WuB 8, 93/116 : «Dans notre lettre Neuser raconte qu'il n'a jamais eu la moindre intention de se convertir à la religion turque en partant pour la Hongrie, mais simplement celle d'y publier une réfutation de ses adversaires, ou toute autre chose utile, et que seule une nécessité majeure (äußerste Not), celle de ne pas aussi se retrouver persécuté par les Turcs, l'a poussé à franchir le pas ultime. Ici, il ne raconte rien d'autre ».

102. AN 188-189/WuB 8, 110/132.

103. M. Mulsow, «Adam Neusers Brief an Sultan Selim II», art. cité, p. 307-308. Sur l'ambassade Ungnad, dépêchée en 1573 pour négocier une nouvelle trêve avec l'Empire ottoman, voir D. Wendebourg, Reformation und Orthodoxie, op. cit., p. 31-46 et Ralf C. MüLLER, «Der umworbene "Erbfeind". Habsburgische Diplomatie an der Hohen Pforte vom Regierungsantritt Maximilians I. bis zum "Langen Türkenkrieg" - ein Entwurf », in M. KURZ, M. SCHEUTZ, K. Vocelka et Th. WinkelbaueR (dir.), Das Osmanische Reich und die Habsburgermonarchie, Wien, Böhlau (Mitteilungen des Instituts für Österreichische Geschichtsforschung, Ergänzungsbd. 48), 2005, p. 251-279.

104. M. Mulsow, «Adam Neusers Brief an Sultan Selim II», art. cité, p. 306-307. L'histoire est rapportée par Hérodote, Hist. III, 153-158. Lessing connaissait par Gerlach les contacts de Neuser avec Ungnad (AN 188/WuB 8, 109-110/132) mais ignorait les modalités précises du double jeu: AN 162/WuB 8, 89-90/113.

105. M. MuLsow, «Adam Neusers Brief an Sultan Selim II », art. cité, p. 312.

106. AN 135/WuB 8,68/92 : "Hält sich nun die Sache also: dieweil ich, soviel die Dreyfaltigkeit belangt, irrig war, beschloß ich bei mir alles zu versuchen, bis ich mein bekümmert und verirret 


\section{Adam Neuser}

Gewissen zufrieden gestellt hätt. Wie hat nun dieses sollen geschehen? auf was Weise? Es ist der Brauch, wenn man an einem Dinge zweifelt, daß man hinzeucht und schickt an diese Ortt, da etwas sich zugetragen hat, und daselbst die Wahrheit erforscht, will man anders der Sachen gewiß seyn. Dann wir wissen, wie uns der Pabst immerdar Lügen und falsche Historien, anstatt der Wahrheit vorgelegt hat, und wie fast er die rechte Wahrheit verboten habe mit Feuer und mit Schwerd. Wie sollte man aber besser können die Wahrheit erfahren von der Dreyfaltigkeit, weder allein an diesem Ort, da sich am allerersten allhier zu Constantinopel angefangen, wie alle Historien bezeugen ».

107. Voir traduction, $\mathrm{n} .72$.

108. AN 136/WuB 8, 69/93 et traduction, n. 74. Un autre unitarien radical, le Génois Jacob Palaeologus, originaire de Chios (voir traduction, n. 207), qui rendit visite à Neuser en 1573 à Istanbul, argumenta aussi à partir de saint Paul le rapprochement des chrétiens et des musulmans : voir M. MuLsow, «Fluchträume und Konversionsräume », art. cité, p. 54-55.

109. AN 148/WuB 8, 79/103 : "Sogar, was er [sc. Neuser] zu seiner Entschuldigung desfalls beibringt, scheinet zum Teil nichts als kahle Beschönigung zu sein: das nemlich, was er von der Absicht sagt, in welcher er den Brief geschrieben. Das Exempel des hl. Paulus ist offenbar gemißbraucht ».

110. Je cite d'après le texte édité par Mieg et Nebel dans les Monumenta pietatis (voir traduction, n. 28), sous le titre "Adami Neuseri, gewesenen Predigers zu Heydelberg Schreiben an den Türckischen Kayser Selym dieses Namens den Andern », p. 337 : "Dann von Gnad des Allmaechtigen Gottes/ erkenne und glaube ich von gantzem Hertzen/ daß Euer Lehr oder Religion waar/ rein/ lauter und GOtt gefaellig sey ».

111. AN 159/WuB 8, 88/111-112.

112. L'idée d'un " enjolivement » (Beschönigung) de la vérité chez Neuser paraît trois fois dans le texte: AN 145, 148, 164/WuB 76, 79, 91/101, 103, 115.

113. AN 133/WuB 8, 67/91 : «aus Not».

114. «Adami Neuseri, gewesenen Predigers zu Heydelberg Schreiben an den Türckischen Kayser Selym », loc. cit., p. 340-341 : entre ces deux affirmations, Neuser cite et interprète six passages du Coran.

115. AN 123/WuB 8, 58/82 et 125/WuB 8, 60/83. Sur Jöcher et Heineccius, voir traduction, ก. 4 et 15 .

116. AN 133/WuB 8, 66-67/90-91 : " [...] sprach: Ach lieber Gott, in Deutschland bin ich für einen Feind der Deutschen und für einen Freund der Türken gehalten worden, hier unten den Türken werd ich für einen Feind der Türken und für einen Feind meines Vaterlands geachtet, darum daß ich, soviel die Dreyfaltigkeit belangt, nur Einen Gott geglaubt hatt, als wie die Türken, und haben mich darum wollen ertödten. Darauf spricht der Bascha, wenn dem also ist, daß du allein an den einigen Gott glaubst, der Himmel und Erden erschaffen hat, als wie wir, und bist darum von den Deinen für einen Türken gehalten worden, so beweis itzt solches mit dem Werk; werd zu einem Türken, so sollst du nachmals zu drucken Macht haben wider deine Feinde alles, was dir gefällt; thust du aber solches nicht, so hast du diese Gefährlichkeit zu erwarten, wie dir angezeigt ist. Darauf antwortet ich, daß ich auch den Alkoran gelesen hätt, und einen Gefallen daran gehabt hätt, darum ich denn für einen Türken wäre gehalten worden. Solbald der Bascha diese Wort höret, spricht er, er wolle mich gen Constantinopel dem Kaiser schicken, da ich noch auf den heutigen Tag bin, bey des Kaisers oberstem Dolmetsch, welcher ein Deutscher ist ».

117. AN 167/WuB 8, 93/116-117 : «[...] Bassae Temewarensi proditus fui, qui me Constantinopolim misit nihil reluctantem, sed potius de eo gratulantem mihi ipsi: quod Alcoranum a veritate non alienum esse, et in omnibus capitibus religionis mecum sentire cognouissem ». Sur les récits de conversion à l'islam ottoman à l'époque moderne, voir Tijana KRSTIć, Contested Conversions to Islam. Narratives of Religious Change in the Early Modern Ottoman Empire, Stanford, CA, Stanford University Press, 2011, ch. IV. 


\section{Confession et migration}

118. «Adami Neuseri, gewesenen Predigers zu Heydelberg Schreiben an den Türckischen Kayser », loc. cit., p. 338, sur la « vérité indubitable » de la doctrine de Mahomet: " [...] bezeuge fuer Gott/ daß die Lehr Eueres Propheten (ueber welchem sey der Friede GOttes) die ungezweiffelte Warheit sey ». Sur l'article de l'« invocation du Dieu unique », cf. ibid., p. 339.

119. Voir Ch. J. BURCHILL, The Heidelberg Antitrinitarians, op. cit., p. 108.

120. «Adami Neuseri, gewesenen Predigers zu Heydelberg Schreiben an den Türckischen Kayser », loc. cit., p. 341.

121. AN 158-159/WuB 8, 86-87/110-111, où l'on notera l'insistance de Lessing sur la nécessité d'une conversion formelle: "Ob er aber darum auch selbst ein Türke geworden, ob er den Türkischen Glauben in aller erforderlichen Form angenommen [...] », et plus loin : "Neusers förmliche [r] Übergan [g] zur Türkischen Religion ». Sur les savants désignés par Lessing, voir traduction, ก. 122,129 et 130 .

122. AN 159-160/WuB 8, 88/112 : "Er sagt bloß: "Sobald der Bascha diese Worte höret," (nemlich, sein Bekenntnis von dem Alkoran) "spricht er, er wolle mich gen Constantinopel zu dem Kayser schicken, da ich noch heutigen Tag bin, bey des Kaysers oberstem Dolmetsch, welcher ein Deutscher ist". Denn was sollte er auch mehr sagen? Wer erzählt gern eine Komödie, die er mit sich müssen spielen lassen? Einem Manne, der nicht ganz ohne Gefühl und Scham ist, kostet es der äußersten Überwindung, sich ihr zu unterziehen: was Wunder, daß er jeder Gelegenheit ausbeugt, sich ihrer wiederum zu erinnern?»

123. AN 160/WuB 8, 88/112: "Was also Neuser von sich hier bloß verschweigt, hat man kein Recht darum in Zweifel zu ziehen, wenn es von andern glaubwürdigen Leuten, die an Ort und Stelle davon Nachricht einziehen können, bestätiget wird».

124. AN 164/WuB 8, 91/114-115: "Et cum ipsi a sociis (nam hic religio omnis libera est) Apostasia obiicitur, non se fidem mutasse, sed pristinam adhuc in corde alere, respondet. Circumcisioni vero exemplo, nescio quorum populorum, a Diuo Matthaeo conuersorum, patrocinatur, qui antiquitus et baptismum et circumcisionem retinerent ». Le procédé se raffine encore ici : à première vue, dit Lessing, même un témoin fiable comme Gerlach semble douter de la circoncision de Neuser. Son journal n'en dit rien. II faut donc aller chercher une source supplémentaire (le texte cite une lettre de Gerlach au théologien Jakob Heerbrand [voir traduction, n. 146-147]) pour que la circoncision de Neuser apparaisse comme ce qu'elle est : une évidence

125. AN 164-165/WuB 8, 91-92/115 : "Das Sophisma für die Beschneidung kann keine Erfindung der lüderlichen dummen Spießgesellen des Neusers gewesen sein; auch war es keine Erfindung des Gerlachen, welcher selbst gestehet, daß ihm die Tatsache, auf welcher es beruhe, unbekannt sei: folglich kam es zuverlässig von Neusern selbst, und beweiset mehr als alles andere, daß das wirklich an ihm vollzogen worden, was er damit beschönigen wollen. Es sind aber die Äthiopischen Christen, welche, wie itzt von einem jeden bekannt, beides, Beschneidung und Taufe, haben. Neuser hatte hiervon ohne Zweifel unter den Griechen Nachricht erhalten. Denn aus Gerlachs Unwissenheit sieht man, daß es in Deutschland damals noch eine ganz unerhörte Sache gewesen; wie ich denn auch finde, daß unsere Landsleute erst 1574 das äthiopische Glaubensbekenntnis näher kennen lernen, so wie es Zaga Zabo 1534 in Portugal übergeben hatte ». Sur le détail des explications de Lessing, voir traduction, n. 150.

126. AN 160/WuB 8, 88/112 : "Recht wohl, daß sich die Religionen unter einander den Übertritt selbst so erschweret haben, daß nicht leicht ein ehrlicher Mann zu einer von der andern laufen wird! »

127. Nathan der Weise (abr. NW), WuB 9, acte II, scène 5, v. 1310-1311 ; III, 1, v. 1556-1557. Les traductions sont de moi.

128. NW, III, 7, v. 447: "Fast so unerweislich, als/ Uns itzt - der rechte Glaube ». Je renonce à introduire à l'immense littérature sur la parabole des trois anneaux: on pourra voir dernièrement Achim AURNHAMMER, Giulia CANTARUTTI et Friedrich VolLHARDT (dir.), Die drei Ringe. Entstehung, Wandel und Wirkung der Ringparabel in der europäischen Literatur und Kultur, Berlin-Boston, De Gruyter (Frühe Neuzeit, 200), 2016. 


\section{Adam Neuser}

129. NW, IV, 6, v. 512-514 : "So kömmt das Mädchen wieder unter Christen ;/ Wird wieder was sie ist, ist wieder, was/ Sie ward [...]».

130. NW, III, 10, v. 824-826 : "Den will ich sehn, der die bekehren soll!/ Ihr Glück ist, längst zu sein, was sie zu werden/Verdorben ist ».

131. Pour la confession de foi de Daja, cf. NW, I, 6, v. 751-752: « Meint Ihr etwa,/ Ich fühle meinen Wert als Christin nicht? » Sur la Schwärmerei, voir I, 1, v. 136-141, 166; I, 2, 329 ; IV, 4, v. 420-421 ; V, 5, v. 250-251 et sur Daja particulièrement V, 6, v. 434-438.

132. NW, IV, 4, v. 343-344 : "Daß mir/ Geträumt, ein Jude könn'wohl ein Jude/ Zu sein verlernen, daß mir wachend so/ Geträumt », à rapprocher de I, 6, v. 777 : " Jud'ist Jude ».

133. NW, IV, 4, 372-376 : «[SALADIN] Wie lange können seine Verweigerungen/ Denn dauern? Wird er denn von dir verlangen,/ Daß du erst Jude werden sollst?/ [TEMPELHERR] Wer weiß!/ [SALADIN] Wer weiß? - der diesen Nathan besser kennt ».

134. NW, V, 5, v. 321-326: "Nehmt mirs nicht ungut, Nathan. - Wird sie nicht/Die Christin spielen müssen, unter Christen?/ Und wird sie, was sie lange gnug gespielt,/ Nicht endlich werden? Wird den lautern Weizen,/ Den Ihr gesä't, das Unkraut endlich nicht/Ersticken? ", à rapprocher du moment de la scène finale où le templier refuse même que Nathan désigne sa fille par son «nom de chrétienne » $(\mathrm{V}, 8,656-660)$.

135. NW, III, 5, v. 325-326

136. NW, III, 8, v. 639-640 : " [...] Welch ein Jude! -/ Und der so ganz nur Jude scheinen will! ».

137. NW, V, 8, v. 636, 620.

138. NW, II, 1, v. 81, 92-93 : "[SITTAH] Du kennst die Christen nicht, willst sie nicht kennen. Ihr Stolz ist: Christen sein ; nicht Menschen [...]/Um den Namen, um den Namen/Ist ihnen nur zu tun »

139. AWE, WuB 7, 576, voir plus haut, n. 78.

140. AN 129/WuB 8, 63/86 : "Dazu trugen sich etliche Sachen zu zwischen mir und andern Ministris zu Clausenburg, dieweil ich ihrer Confession nicht in allen Dingen zufiel, als nemlich de Differentia novi \& veteris Testamenti, de lustificatione coram deo, item de Interpretatione primi capitis apud loannes Evangelistam ». Sur les confessions de foi transylvaniennes dans la période qui nous occupe, voir Ludwig BINDER, "Theologie und Bekenntnis auf Synoden der evang.-sächsischen Kirche 1545-1578», in U. A. WIEN (dir.), Reformation, Pietismus, Spiritualität. Beiträge zur siebenbürgisch-sächsischen Kirchengeschichte, Köln-Weimar-Wien, Böhlau (Siebenbürgisches Archiv, 41), 2011, p. 37-122.

141. Axiomata, wenn es deren in dergleichen Dingen giebt, WuB 9, 57: "Ich bin Liebhaber der Theologie, und nicht Theolog. Mich verbindet nichts, eine andre Sprache, als die meinige zu reden ». Pour des raisons qu'on verra plus tard, je choisis de traduire "Liebhaber » par « amant » (cf. en ce sens Johannes VON LÜPKE, Wege der Weisheit. Studien zu Lessings Theologiekritik, Göttingen, Vandenhoeck und Ruprecht (Göttinger theologische Arbeiten, 41), 1989, p. 12), plutôt que par « amateur », également possible. Sur ce texte, voir Ph. BüTTGEN, «Lessing et la question du prêche. Philosophie, théologie, pastorat », Les Études Philosophiques, 2/2003, p. 213-243, sp. 217-218.

142. Je me permets encore de renvoyer à Ph. BütTgEn, "Confession de foi et survie du serment», Droits 60 (2014), p. 39-52. Les études fondatrices sur le serment religieux moderne sont celles de Klaus SCHREINER, «luramentum religionis. Entstehung, Geschichte und Funktion des Konfessionseides der Staats- und Kirchendiener im Territorialstaat der Frühen Neuzeit», Der Staat (1985), p. 211-246 et ID., "Rechtgläubigkeit als "Band der Gesellschaft". Zur eidlichen Verpflichtung von Staats- und Kirchendienern auf die Formula Concordiae und das "Konkordienbuch" », in M. BRECHT et R. SCHWARZ (dir.), Bekenntnis und Einheit der Kirche. Studien zum Konkordienbuch, Stuttgart, Calwer Verlag, 1980, p. 351-379. En contexte spécifiquement luthérien, cf. Th. KAUFMANN, "Das Bekenntnis im Luthertum des konfessionellen Zeitalters», Zeitschrift für Theologie und Kirche 105 (2008), p. 281-314. 


\section{Confession et migration}

Le lien entre serment de confession et émigration est étudié par Matthias ASCHE, "Von Konfessionseiden und gelehrten Glaubensflüchtlingen, von Konvertiten und orthodoxen Gelehrten. Mobilitätsphänomene konfessionell devianter Professoren zwischen obrigkeitlicher Duldung, Landesverweis und freiwilligem Abzug », in H. P. JüRGENS et Th. WELLER (dir.), Religion und Mobilität, op. cit., p. 375-400.

143. Voir plus haut, n. 2.

144. Rettungen des Horaz, WuB 3, 191-192.

145. BT, WuB 7, 114.

146. BT, WuB 7, 115.

147. BT, WuB 7, 33-34: "Die so genannte Bekehrung des Berengarius beruhet auf so unerheblichen Zeugnissen, und sie ist an und für sich selbst so unwahrscheinlich, so unbegreiflich, daß wenn sie auch auf ungleich gültigern Zeugnissen beruhte, ich mir dennoch die Freiheit nehmen würde, daran zu zweifeln. [...] - Ein Mann, wie Berengarius, hätte die Wahrheit gesucht; hätte die gesuchte Wahrheit in einem Alter, in welchem sein Verstand alle ihm mögliche Reife haben mußte, zu finden geglaubt; hätte die gefundene Wahrheit mutig bekannt, und mit Gründen andere gelehret; wäre bei der bekannten und gelehrten Wahrheit, Trotz aller Gefahren, Trotz seiner eignen Furchtsamkeit vor diesen Gefahren, dreißig, vierzig Jahre beharret: und auf einmal, in eben dem Augenblicke, da unter allen erworbenen Schätzen, dem Menschen keine werter sein müssen, als die Schätze der Wahrheit, die einzigen, die er mit sich zu nehmen Hoffnung hat, - eben da, auf einmal, hätte seine ganze Seele so umgekehret werden können, daß Wahrheit für ihn Wahrheit zu sein aufhörte? - Wer mich dieses bereden könnte, der hätte mich zugleich beredet, alle Untersuchungen der Wahrheit von nun an zu entsagen ».

148. AN 121/WuB 8, 57/81.

149. BT, WuB 7, 34-35: "Ein Berengarius stirbt sicherlich, wie er lehrte; und so sterben sie alle, die eben so aufrichtig, eben so ernstlich lehren, wie er ».

150. BT, WuB 7, 115.

151. Voir plus haut, n. 106 et AN 136/WuB 8, 69/93. Voir traduction, n. 73.

152. Griechischer Text des apostolischen Glaubensbekenntnisses mit lateinischen Buchstaben, in Zur Geschichte und Literatur, Dritter Beitrag, XVI, édition citée, p. 113-119. Sur l'auteur, Franz Anton Knittel (1721-1792), superintendant général de Wolfenbüttel en 1766, de Brunswick en 1776, explorateur avec Lessing des manuscrits de la bibliothèque ducale, voir Heinrich DöRING, "Franz Anton Knittel», in ID., Die deutschen Kanzelredner des achtzehnten und neunzehnten Jahrhunderts, Neustadt a. d. Orla 1830, p. 171-175.

153. Sur cette évolution sémantique, notée par l'historien Wolfgang Reinhard en 1983, voir les éléments d'enquête rassemblés dans Naïma GHERMANI, "Confession », in O. CHRISTIN, Dictionnaire des concepts nomades en sciences humaines, Paris, Métailié, 2011, p. 117-132; Ph. BüTTGEN, "Portrait d'autrui en groupe. Premières recherches sur la sémantique de la confession dans le Saint-Empire », in Ch. BERNAT et H. Bost (dir.), Énoncer, dénoncer l'autre. Discours et représentations du différend confessionnel à l'époque moderne, Turnhout, Brepols (Bibliothèque de l'École des Hautes Études, Sciences religieuses, 151), 2012, p. 173-184; Ch. Duhamelle, "Confession, confessionnalisation », Histoire, Monde et Cultures religieuses 26 (2013), p. 159-174.

154. Voir plus haut, n. 149.

155. BT, WuB 7, 23: "Ich weiß nicht, ob es Pflicht ist, Glück und Leben der Wahrheit aufzuopfern; wenigstens sind Mut und Entschlossenheit, welche dazu gehören, keine Gaben, die wir uns selbst geben können. Aber das, weiß ich, ist Pflicht, wenn man Wahrheit lehren will, sie ganz, oder gar nicht, zu lehren; sie klar und rund, ohne Rätsel, ohne Zurückhaltung, ohne Mißtrauen in ihre Kraft und Nützlichkeit, zu lehren: und die Gaben, welche dazu erfordert werden, stehen in unserer Gewalt. Wer die nicht erwerben, oder, wenn er sie erworben, nicht brauchen will, der macht sich um den menschlichen verstand nur schlecht verdient, wenn er grobe Irrtümer uns benimmt, die volle 


\section{Adam Neuser}

Wahrheit aber vorenthält, und mit einem Mitteldinge von Wahrheit und Lüge uns befriedigen will. [...]/ Weil Berengarius schwach war: muß er darum mit Vorsatz auch falsch gewesen sein? Weil ich ihn beklagen muß, soll ich ihn auch verachten müssen? Der Mann, der, bei drohenden Gefahren, der Wahrheit untreu wird, kann die Wahrheit doch sehr lieben, und die Wahrheit vergiebt ihm seine Untreue, um seiner Liebe willen. Aber wer nur darauf denkt, die Wahrheit unter allerlei Larven und Schminke an den Mann zu bringen, der möchte wohl gern ihr Kuppler sein, nur ihr Liebhaber ist er nie gewesen ».

156. Voir plus haut, n. 141.

157. Voir Eine Duplik (1778), WuB 8, 510 : ce qui fait la valeur de l'homme n'est pas «la vérité dans la possession de laquelle on se trouve ou croit se trouver » mais "l'effort sincère qu'on déploie pour l'atteindre ». Avec l'épithète aufrichtig appliqué à la recherche de la vérité, l'exigence de probité du philologue poursuit son trajet pour atteindre l'intérieur de la controverse théologique (voir plus haut, n. 16-17). Un passage d'AN (148/WuB 8, 79/103-104) montre bien que pour Lessing Neuser n'a pas atteint cet idéal de recherche véritable : «[...] zugegeben sogar, daß seine Absicht augescheinlich gewesen, nicht die Wahrheit zu erforschen, sondern in Überzeugung der schon erforschten und gefundenen Wahrheit [...] »

158. Voir plus haut, n. 88 et AWE, WuB 7, 573.

159. Leibnitz von den ewigen Strafen (voir plus haut, n. 83, abr. LES), WuB 7, 487.

160. Voir les documents dans WuB 7, 624-641 (sur BT), 985-989, 1093-1100 (sur les Beiträge).

161. Lettre à Karl Lessing, 8 avril 1773, WuB 11/2, p. 540 : "So habe ich wirklich, meinst Du, mit meinen Gedanken über die ewigen Strafen den Orthodoxen die Cour machen wollen? Du meinst, ich habe es nicht bedacht, daß auch sie damit weder zufrieden sein können noch werden? Was gehen mich die Orthodoxen an? Ich verachte sie eben so sehr, als Du; nur verachte ich unsere neumodischen Geistlichen noch mehr, die Theologen viel zu wenig, und Philosophen lange nicht genug sind. Ich bin von solchen schalen Köpfen auch sehr überzeugt, daß, wenn man sie aufkommen läßt, sie mit der Zeit mehr tyrannisieren werden, als es die Orthodoxen jemals getan haben ».

162. À côté de la présentation toujours valable de Karl ANER, Die Theologie der Lessingzeit, Halle 1929, réimpr. Hildesheim, Olms, 1964, voir Albrecht BEUTEL, Kirchengeschichte im Zeitalter der Aufklärung. Ein Kompendium, Göttingen, Vandenhoeck \& Ruprecht (UTB 3210), 2010, p. 112-149; ID., "Gotthold Ephraim Lessing und die Theologie der Aufklärung », in Ch. DANZ (dir.), Schelling und die Hermeneutik der Aufklärung, Tübingen, Mohr Siebeck (Hermeneutische Untersuchungen zur Theologie, 59), 2012, p. 11-28. En français, voir Georges Pons, Gotthold Ephraïm Lessing et le christianisme, Paris, Didier, 1964, p. 246-271 et sur un milieu proche de Lessing, Roger KIRSCHER, Théologie et Lumières. Les théologiens "éclairés » autour de la revue de Friedrich Nicolai, "Allgemeine Deutsche Bibliothek», 1765-1792, Villeneuve d'Ascq, Presses universitaires du Septentrion (Histoire et civilisations), 2001.

163. Cf. Lettre à Karl Lessing, 2 février 1774, WuB 11/2, 546.

164. Cf. AWE, WuB 7, 578.

165. Cf. Ph. BütTGEN, « Lessing et la question du prêche », art. cité, p. 233-234.

166. AWE, WUB 7, 570

167. LES, WUB 7, 478.

168. AWE, WuB 7, 577. Le texte est extrait de la lettre de Leibniz à Friedrich Wilhelm Bierling du 24 octobre 1709, reprise au t. V de Dutens qui contient la correspondance de 1706 avec La Croze citée aussi dans AWE (voir plus haut, n. 80-81 ; cf. dans l'édition Gerhardt, Die philosophischen Schriften von G. W. Leibniz (1875-1890, abr. GP), t. VII, Berlin 1890, réimpr. Hildesheim, Olms, 1996, p. 488-489). Cf. Nicholas JoLLEY, «Leibniz and Locke on Socinianism », Journal of the History of Ideas 39 (1978), p. 233-250. 


\section{Confession et migration}

169. AWE, WuB 7, 577: "Oder ist die nemliche Seichtigkeit des Geistes, welche macht, daß man eben so leicht in der Theologie, als in der Philosophie auf halbem Wege stehen bleibt? "

170. Voir plus haut, n. 161.

171. Voir plus haut, n. 78.

172. Voir plus haut, n. 88-90.

173. AN 165-166/WuB 8, 92/116 : "[...] diejenigen Glaubenslehren, in welchen der kühne aber seinen Grundsätzen getreue Unitarier so viel weiter geht, als der eigentlich genannte Socinianer, der weder kalt noch warm ist, und der, man weiß nicht warum, gern den Namen einer Religion beibehalten möchte, deren innerstes Leben er vernichtet ».

174. Cf. AN 180-181/WuB 8, 103-104/126-127.

175. Comparer AWE, WuB 7, 575: "[...] der uneingenommene, kalte Philosoph [...] » et AN 145/ WuB 8, 76/101 : "Apostat und Mameluke, so vielmal, als man will! Aber der Brief ist doch wahrlich mit einer Kaltblütigkeit und Ruhe geschrieben, die nichts weniger als ein wundes und peinigendes Gewissen verrät [...]»

176. Voir plus haut, n. 173.

177. Voir plus haut, n. 78.

178. Voir plus haut, n. 78 et 171.

179. AN 182/WuB 8, 105/127.

180. AN 189/WuB 8, 110/46: "Also, diese polnische Gemeinde wenigstens, war durch Neusers Schriften so weit gebracht, als nur immer eine solche Gemeinde gehen müßte, wenn sie noch mit einigem Rechte den Namen eine Christlichen Gemeinde führen wollte ».

181. AN 170/WuB 8, 95-96/119.

182. Voir plus haut, n. 80.

183. LES, WuB 7, 482, citation de Johann Jakob Eberhard (1738-1809), alors prédicateur à Berlin, plus tard adversaire de Kant, au t. I (1772) de sa Neue Apologie des Sokrates (cf. HansJoachim KERTSCHER et Ernst StöckMANN (dir.), Ein Antipode Kants? Johann August Eberhard im Spannungsfeld von spätaufklärerischer Philosophie und Theologie, Berlin-New York, De Gruyter (HABEl, 46), 2012); AWE, WuB 7, 573-574.

184. LES, WUB 7, 482.

185. LES, WUB 7, 482-483.

186. LES, WUB 7, 486.

187. Ibid.

188. Pour une lecture des textes des Confessions et de Rousseau juge de Jean-Jacques, je me permets de renvoyer à Ph. BüTTGEN, «Was heisst konfessionelle Eindeutigkeit? Konzeptionelle Überlegungen zum frühneuzeitlichen Begriff der doctrina », in A. PIETSCH et B. STOLLBERGRILINGER (dir.), Konfessionelle Ambiguität. Uneindeutigkeit und Verstellung als religiöse Praxis in der Frühen Neuzeit, Gütersloh, Gütersloher Verlagshaus (SVRG, 214), 2013, p. 27-38.

189. LES, WuB 7, 486 : "Denn das wäre ein wenig zu arg, und ließe sich schlechterdings mit keiner didaktischen Politik, mit keiner Begierde, allen alles zu werden, entschuldigen ».

190. LEIBNIZ, Confessio philosophi. La profession de foi du philosophe, éd. et tr. Y. BELAVAL, Paris, Vrin, 1970². À plusieurs reprises dans la Théodicée et dans sa correspondance, Leibniz indique une datation : 1673.

191. Voir plus haut, n. 108.

192. Voir plus haut, n. 109. 


\section{Adam Neuser}

193. AWE, WuB 7, 574: "Leibnitz hat nichts geglaubt: aber war es ihm darum weniger vergönnt, die verschiednen Meinungen von Christo, als so viel verschiedne Hypothesen zu betrachten, nach welchen die von ihm redenden Stellen der Schrift auf eine übereinstimmende Art zu erklären? Konnte er darum kein gründliches Urteil fällen, welche von ihnen der anderen vorzuziehen sei, weil er im Grunde von keiner überzeugt war? [...] Ja, sollte man sein Urteil nicht eben darum für so viel unparteiischer halten, weil er innerlich nach keiner Seite hing, und weder das eine noch das andere glaubte?»

194. AN 182/WuB 8, 105/127, sur la «natürliche, notwendige Ausdehnung » de la thèse " Jésus n'est pas Dieu » : "il n'a pas à être invoqué ».

195. AWE, WuB 7, 578: "Und nun, auf das Obige zurück zu kommen; auf den Glauben. Mag denn also auch Leibnitz, sagt man, den Socinianern so aufrichtig entgegen gewesen sein, als er will; genug, daß er von der orthodoxen Meinung im Grunde sicherlich gleich weit entfernt war. Er glaubte das eine, eben so wenig als das andere: kurz, er glaubte, von der ganzen Sache nichts ».

196. AWE, WUB 7, 579.

197. Voir plus haut, n. 97 et AWE, WuB 7, 579-580 : "Er [sc. Leibniz] mußte, leider, aus Vorurteilen seiner Jugend sogar dafür halten, daß die christliche Religion, bloß vermöge eines, oder mehrerer, oder auch aller erklärbaren Gründen, glauben, sie eigentlich nicht glauben heiße; und daß das einzige Buch, welches, im eigentlichen Verstande, für die Wahrheit der Bibel, jemals geschrieben worden, und geschrieben werden könne, kein anderes als die Bibel selbst sei ».

198. Voir plus haut, n. 25-27.

199. AN 194/WuB 8, 114/136: "Wem es scheinen möchte, daß ich mich bei einer alten verlegnen Geschichte viel zu viel aufgehalten habe: den bitte ich zu bedenken, wie vieles über den Servetus geschrieben worden; und von Deutschen geschrieben worden! Oder muß man schlechterdings ein Ausländer sein, um unsere Aufmerksamkeit zu verdienen? Leibnitz schrieb irgendwo: "I'ai d'autant plus de compassion du malheur de Seruet, que son merite devoit être extraordinaire puisqu'on a trouvé de nos jours, qu'il avoit une connoissance de la circulation du sang". Nun irrte sich zwar Leibnitz hierin, wie er nachher selbst bemerkte. Aber doch sei es mir erlaubt, in Nachahmung dieser seiner Worte, zu schließen : Ich habe um so vielmehr Mitleiden mit Neusern, da ich finde, daß er doch etwas mehr als ein Antitrinitarier gewesen; daß er auch ein guter mechanischer Kopf gewesen zu sein scheint, indem er an einer Erfindung gearbeitet, die mit der etwas ähnliches haben mußte, die hundert Jahre hernach selbst Leibnitzen einmal durch den Kopf ging. "Neuser", schreibt Gerlach [Note: Beim Heineccius, Anhang S. 27], "hatte sich vorgenommen, einen Wagen zu verfertigen, der sich von selbst bewegen sollte, und durch dessen schnellen Lauf, wenn es angegangen wäre, er große Dinge auszurichten vermeinte". Und was Leibniz leisten wollte, weiß man aus Bechern [Närrische Weisheit S. 49]; oder weiß es vielmehr nicht aus ihm, weil er es mehr zu verspotten, als anzuzeigen für gut fand».

200. Même procédé dans BT, WuB 7, 14-15, où Lessing regrette qu'on ne puisse pas « faire de Béranger un allemand ».

201. AN 178-179/WuB 8, 102-103/125-126.

202. AN 179/WuB 8, 108/126. Le texte cité se trouve dans la lettre de Leibniz à Johann Philipp Schmid du 2 août 1716, reprise dans Dutens V, 534

203. Voir plus haut, p. 28.

204. Sur ce point, voir Ralph BRÖER, «Blutkreislauf und Dreieinigkeit. Medizinischer Antitrinitarismus von Michel Servet (1511-1553) bis Giorgio Biandrata (1515-1588) », Berichte zur Wissenschaftsgeschichte 29 (2006), p. 21-36; cf. aussi ID., "Antiparacelsismus und Dreieinigkeit. Medizinischer Antitrinitarismus von Thomas Erastus (1524-1583) bis Ernst Soner (1572-1605) », ibid., p. 137-153.

205. Le texte de Leibniz a: " J'ai d'autant plus de compassion du malheur de Servet, que son mérite devoit être extraordinaire, puisqu'on a trouvé de nos jours, qu'il avoit une connoissance 


\section{Confession et migration}

de la circulation du sang, qui passe tout ce qu'on en trouve avant lui » (lettre à Mathurin Veyssière de La Croze, 2 décembre 1706, Dutens V, 483). L'élision des derniers mots (soulignés par moi) dans la citation est étrange. Leibniz lui-même établit le rapprochement entre Servet et Neuser. Sur cette lettre à La Croze déjà citée dans Andreas Wissowatius, voir plus haut, n. 80-81 : d'un texte à l'autre des Beiträge, l'effet de série joue à plein.

206. Voir la lettre à Thomas Burnett, 22 novembre 1695, in GP III, 169 et, dans le courant de l'échange, 177, 255, 267: Leibniz oppose au nom de Servet celui d'une autre figure de la dissidence religieuse, le servite Paolo Sarpi (1552-1623), historien du Concile de Trente, patriote vénitien excommunié, source de l'érudition protestante. Voir aussi à Nicaise, 16 juin 1699, GP II, 589. Sur Sarpi et la circulation du sang avant Harvey, cf. Libero Sosı, «Paolo Sarpi, un frate nella rivoluzione scientifica », in C. PIN (dir.), Ripensando Paolo Sarpi. Atti del Convegno Internazionale di Studi nel $450^{\circ}$ anniversario della nascità di Paolo Sarpi, Venezia, Ateneo Veneto (Ricerche Storiche, 6), 2006, p. 183-236, sp. 199-205.

207. Voir plus particulièrement GP III, 267.

208. Essais de Théodicée, Discours préliminaire, § 11, GP VI, p. 57, à propos d'« André Cesalpin, Medecin (auteur de merite, et qui a le plus approché de la Circulation du sang après Michel Servet) ». Pour une mention de la Théodicée dans les Beiträge, cf. LES, WB 7, 484-486.

209. Sur les débats relatifs au leibnizianisme de Lessing dans les années 1770, cf. Ph. BÜTTGEN, "Lessing et la question du prêche », art. cité, p. 214-215.

210. Système nouveau de la nature et de la communication des substances, GP IV, p. 482; $5^{e}$ écrit à Clarke, GP VII, 417-418. Cf. François DUCHESNEAU, Leibniz, le vivant et l'organisme, Paris, Vrin (Mathesis), 2010, p. 85-119, et Justin E. H. SMITH, Divine Machines. Leibniz and the Sciences of Life, Princeton, Princeton University Press, 2011.

211. D. Jo. Heinecii [...] Eigentliche wahrhafftige Abbildung der alten und neuen griechischen Kirche: nach ihrer Historie, Glaubens-Lehren und Kirchen-Gebräuchen [...], Leipzig 1711, p. 27-28, note (a).

212. Stephan Gerlachs des Aelterns Tage-Buch Der [...] Mit wuercklicher Erhalt und Verlaengerung deß Friedens zwischen dem Ottomannischen und Roemichen Kayeserthum [...] Gluecklichst vollbrachter Gesandschaft [...], Frankfurt a. M. 1674, p. 285, col. A. Je traduis l'extrait de récit rapporté par Gerlach: "II a aussi pratiqué des techniques curieuses, commencé à fabriquer une voiture qui devait rouler vite et par elle-même, en a même fait l'essai en miniature, mais cela n'a jamais fonctionné en grand ». Sur une possible origine paracelsiste de ces expériences et sur les essais automobiles à Istanbul autour de 1580, voir M. MuLsow, "Adam Neusers Brief an Sultan Selim II », art. cité, p. 311-312; ID., « Fluchträume und Konversionsräume », art. cité, p. 58.

213. AN 161, n. (p)/Wub 8, 89, n. 16/113 : Lessing mentionne déjà Heineccius, dont le Tableau contient des extraits du journal de Gerlach cités sur le manuscrit original... mais eux aussi traduits en allemand. Le scrupule du philologue est ici mis à nu.

214. AN, 123-125/WuB 8, 59-60/83-84 : la citation s'interrompt quasiment à l'endroit où Lessing la reprend dans le paragraphe final. Voir plus haut, n. 115.

215. Doct. Joh. Joachim Bechers [...] Naerrische Weisheit und Weise Narrheit: Oder Ein Hundert/ so Politische alß Physicalische/ Mechanische und Mercantilische Concepten und Propositionen/ Deren etliche gut gethan/etliche zunichts worden [...], Frankfurt a. M. 1682, p. 148: «28. Leibnizens Postwagen von Hannover nach Amsterdam in sechs Stunden zu fahren. Dieser Leibniz ist durch seine Litteratur bekandt/ ein sehr gelehrter Mann/ hat das Corpus luris wollen reformiren/ hat eine eigene Philosophi und andere Dinge mehr geschrieben/ aber ich weiß nicht/ wer ihn auff diesen Postwagen gesetzt/ darvon er nicht absteigen will/ ohneracht er schon etlich Jahr darauff ist/ ohneracht er siehet/ daß der Wagen nicht fortfahren will/ <[...]». - Sur cet aspect de l'œuvre encyclopédique de Becher, médecin, chimiste, économiste au service des électeurs de Mayence et de Bavière puis de l'empereur Leopold I', cf. Ulrich TRoITZSCH, "Becher als Techniker und Erfinder», 


\section{Adam Neuser}

in G. FrüHSORge et G. F. Strasser (dir.), Johann Joachim Becher (1635-1682), Wiesbaden, Harrassowitz (Wolfenbütteler Arbeiten zur Barockforschung, 22), 1993, p. 85-101.

216. L'information la plus complète se trouve dans la brochure de Gerd VAN DEN HEUVEL, Leibniz im Netz. Die frühneuzeitliche Post als Kommunikationsmedium der Gelehrtenrepublik um 1700, Hameln, C. W. Niemeyer (Lesesaal. Kleine Spezialitäten aus der Gottfried Wilhelm Leibniz Bibliothek - Niedersächsische Landesbibliothek), 2009, sp. p. 22-25, avec plusieurs reproductions de croquis leibniziens (amélioration de roues de chariot, modèles de châssis). - Sur la poste et l'histoire politique du Saint-Empire, voir Wolfgang BEHRINGER, Im Zeichen des Merkur. Reichspost und Kommunikationsrevolution in der Frühen Neuzeit, Göttingen, Vandenhoeck \& Ruprecht (Veröffentlichungen des Max-Planck-Instituts für Geschichte, 189), 2003.

217. Lettre au landgrave Ernst de Hesse-Rheinfels, 14/24 mars 1683, in G. W. LEIBNIz, Sämtliche Schriften und Briefe, éd. Akademie der Wissenschaften der DDR, série I, t. 3, Berlin, AkademieVerlag, 1990, p. 278-279.

218. Voir plus haut, n. 175.

219. La notion est étudiée dans l'ouvrage déjà cité de Jacqueline LAGRÉE, La raison ardente (cf. plus haut, n. 89), qui rappelle (p. 164) que la formule "credo minimum » fut forgée par Madeleine Francès à propos de Spinoza.

220 Je discute ici les propositions d'Étienne BALIBAR à la fin de Saeculum. Culture, religion, idéologie, Paris, Galilée, 2012, p. 100-103 (voir aussi sur le site de Raison publique (janvier 2015), http://www.raison-publique.fr/article739.html). 
G. E. LESSING

ADAM NEUSER 



\section{$[119]<57>$ \\ Adam Neuser, quelques informations authentiques}

[121] Les informations en question sont contenues dans une lettre que ce malheureux unitarien ${ }^{2}$ a écrite de Constantinople à l'un de ses amis. Une copie, très vraisemblablement d'époque, en est conservée parmi les manuscrits modernes de notre bibliothèque $\mathrm{e}^{3}$.

Je ne sache pas qu'elle ait déjà été publiée, cette lettre; ou si jamais cela avait été le cas quelque part, je puis affirmer que c'est tout comme si elle ne l'avait pas été, tant elle s'est obstinément dérobée à mes recherches. On aura en tout cas négligé d'en faire l'usage souhaitable, et récemment encore les falsifications qu'elle réfute de la façon la plus plausible étaient colportées de livre en livre. J'espère donc œuvrer d'une manière qui ne sera ni superflue ni inutile en la reproduisant ici dans son intégralité.

Quant à l'histoire d'Adam Neuser à proprement parler, je puis ici la supposer connue. Toutefois, pour que le lecteur ait à portée de main quelque chose qui lui permette de rafraîchir sa mémoire et de procéder lui-même aux comparaisons nécessaires au moment où il lira cette lettre, on me permettra d'ouvrir pour lui le premier manuel venu, un de ceux qui prétendent en quelques mots expédier le cas des hommes les plus remarquables et des phénomènes les plus étranges de l'univers moral, que ce soit pour les flétrir ou les élever à jamais.

[122] C’est ainsi que Jöcher ${ }^{4}$ écrit: "Adam Neuser, curieux apostat natif de Souabe, fut élevé dans la religion luthérienne mais professa ensuite la religion réformée et se rendit dans le 
Palatinat, où il $<58>$ fut fait prédicateur de l'église Saint-Pierre de Heidelberg ${ }^{5}$. Bien qu'il eût beaucoup de défauts et qu'il fût en particulier très porté sur la boisson, il sut, par l'illusion qu'il donnait d'un zèle dévot, par son éloquence aussi, s'attirer un certain prestige auprès de la population. Lorsqu'il tomba dans la disgrâce de l'électeur palatin Frédéric III $^{6}$, celui-ci le fit retirer de cette église et le transféra à l'église du Saint-Esprit ${ }^{7}$, où l'on ne lui confia que les premières prières du matin. Cette rétrogradation causa chez lui une incroyable frustration; celle-ci lui fit entreprendre de promouvoir le socinianisme ${ }^{8}$, auquel il inclinait secrètement depuis de nombreuses années. Dans ce but, il rallia un certain nombre de pasteurs de la région et s'efforça non seulement d'entrer en correspondance avec le célèbre socinien Georgio Blandrata ${ }^{9}$, à l'époque médecin auprès du voïvode de Transylvanie $^{10}$, mais aussi d'obtenir, pour lui et pour les siens, la protection de l'empereur Selim II $^{11}$. Son principal objectif était de parvenir à un syncrétisme entre la doctrine mahométane et la doctrine photinienne $^{12}$. Il alla jusqu'à écrire une lettre au sultan Selim, mais celle-ci tomba entre les mains de l'électeur; il fut donc [123] emprisonné et conduit jusqu'à Amberg ${ }^{13}$. Sept semaines plus tard cependant, il s'échappa une seconde fois, attint Constantinople, se convertit publiquement à la religion mahométane, ne devenant toutefois rien de plus qu'un chiaus $^{14}$. C'était un libertin, un ivrogne et un complet athée; les Turcs l'en méprisèrent autant que les chrétiens le haïssaient. Sa vie de débauche le précipita dans une honteuse maladie: il fut quasiment dévoré par les vers, empestant au point que plus personne ne voulut s'approcher de lui jusqu'à sa mort, au milieu de terrifiants blasphèmes contre Dieu et toutes les religions, à Constantinople le 15 octobre 1576. Les sociniens de Transylvanie ont acheté ses manuscrits pour cent florins, mais aucun d'entre eux n'a paru. »

$<59$ > Mais Jöcher n'est qu'un pauvre compilateur. Plutôt que des affirmations généralement reçues, on pourrait se contenter de voir dans les circonstances de son récit, dont la lettre qui suit montrera la fausseté, les approximations typiques de ce 
négligent ravaudeur, si elles ne concordaient pas avec d'autres venues d'auteurs plus réfléchis et plus proches des sources, et dont un tout au moins, pour tous les autres, vaudra d'être encore écouté.

Soit donc Heineccius ${ }^{15}$. Dans son Tableau de [124] l'Église grecque ancienne et moderne ${ }^{a}$, il évoque occasionnellement Neuser. "Cet Adam Neuser était au départ prédicateur à Heidelberg, avant d'être déposé en raison d'un conflit avec son collègue, le $\mathrm{D}^{\mathrm{r}}$ Olevian ${ }^{16}$. L'homme en conçut une colère telle qu'il se fit secrètement connaître des sociniens de Transylvanie et qu'il fit sienne leur doctrine de blasphème, vers laquelle il entraîna encore Joh. Sylvan, inspecteur à Ladenbourg ${ }^{17}$, Jacob Suter, pasteur à Weidenheim ${ }^{18}$, et Matthias Vehe, diacre à Lutre ${ }^{19}$, sous le prétexte que le souverain de Transylvanie avait reçu des Turcs un district entier dont les revenus permettraient d'entretenir abondamment les prédicateurs sociniens ${ }^{20}$. Par la suite, lorsqu'un émissaire de Transylvanie vint en 1570 à la diète de Spire $^{21}$, ces sociniens cachés entendirent tirer profit de la situation. Ils ne firent pas que lui rendre visite à Spire: Sylvan écrivit à Georg. Blandrata ${ }^{22}$, le chef des sociniens, médecin personnel du souverain de Transylvanie, et Neuser en fit autant, mais avec l'empereur turc, dans une lettre où il cherche à le dresser contre l'Empire allemand et $<60>$ où il lui indique les moyens d'en prendre possession. Dieu fit cependant ce miracle que l'émissaire remit ces lettres dans les mains de l'empereur Maximilien ${ }^{23}$, qui les transmit aussitôt à l'électeur palatin Frédéric III. On arrêta ces gens et l'on confisqua leurs biens, parmi lesquels se trouvaient des écrits affreux et [125] blasphèmes. Après longue réflexion, Sylvan fut décapité ${ }^{24}$, Suter et Vehe expulsés ${ }^{25}$, cependant que Neuser s'échappait deux fois de ses geôles et parvenait à fuir vers Constantinople, où il se fit circoncire et professa publiquement la foi des mahométans ${ }^{26}$. Peu après il tomba dans l'athéisme, menant une vie affreuse d'épicurien, dans un dérèglement tel que les Turcs eux-mêmes l'appelaient Saitam Ogli ou

a. Annexe, p. 27, note [Les notes appelées par des lettres sont de Lessing (NdT)]. 
fils du diable. Tout cela est exposé plus en détail dans l'Histoire ecclésiastique du Palatinat d'Heinrich Alting ${ }^{27}$ et dans les Monumenta pietatis et litteraria Palatina, p. 206 sqq., ainsi que dans les Actes officiels qui sont partiellement repris p. 318 sqq. ${ }^{28}$ "

Ce qui est vrai, c'est que tout ce qu'Heineccius dit ici est tiré fidèlement d'Alting, dont l'Historia Ecclesiae Palatinae est un maître-livre tant pour l'histoire ecclésiastique du Palatinat en général que pour le cas particulier qui nous occupe. Alting a écrit cette histoire en 1618 , à une époque où l'on disposait encore de renseignements fiables. Elle ne fut cependant publiée qu'en 1701, année où Mieg et Nebel l'intégrèrent à leurs Monumenta pietatis. C'est aussi dans les Monumenta que parurent d'abord les Actes officiels relatifs à Sylvan et Neuser. Ceux-ci toutefois, bien loin de rassembler des Actes judiciaires complets, ne contiennent que la délibération des théologiens et prédicateurs de Heidelberg sur les crimes des prévenus, ainsi que la lettre de Neuser à l'empereur turc. Struve a reproduit cela une nouvelle fois dans son [126] Histoire de l'Église du Palatinat, et n'a augmenté le dossier que d'une seule pièce, peu significative, une lettre de l'électeur $<61>$ Frédéric à l'électeur Auguste de Saxe, qui permettait d'intégrer aussi la délibération des théologiens saxons ${ }^{29}$. Nonobstant tout cela, l'information puisée à ces deux sources, Alting et les Actes, est exacte - mais, j'ose l'espérer, dans la mesure seulement où ces sources elles-mêmes sont exactes ${ }^{30}$ ?

Je prie à présent mes lecteurs de consacrer un moment de leur attention à deux points, qui ne sont pas seulement avancés par Jöcher et Heineccius, ainsi que par tous les compilateurs modernes, mais que l'on trouve aussi expressément affirmés dans Alting.

Le premier point concerne la lettre que Neuser est censé avoir non seulement écrite à l'empereur turc, mais qu'il lui aurait aussi effectivement envoyée, par l'intermédiaire du représentant plénipotentiaire que le souverain de Transylvanie avait dépêché à la diète de Spire en 1570 dans le but de sceller avec l'empereur 
et les États de l'Empire une alliance contre le Turc. "Dum istic versatur ", écrit Alting (il s'agit de l'empereur à la diète), " appulit ibidem Woiwodae Transylvani Legatus, vt cum Imperatore et Ordinibus Imperii ageret de ineundo foedere, mutuae securitatis ac defensionis ergo. Hunc salutatum Spiram excurrunt Neuserus, Sylvanus et Vehe, eique litteras suas in Transyluaniam perferendas commendant, quas Sylvanus ad Giorgium [127] Blandratam, Woiwodae Medicum; Neuserus ad ipsum Imperatorem Turcicum exaranerant, in iis fassi, plures esse in Germania Arrianae factioni addictos, quibus nibil magis in votis esset, quam Turcarum Monarchae viam sternere in Imperio, et cum ipso coniungi $i^{31}$ ».

Le second point concerne la seconde incarcération de Neuser et sa seconde fuite hors de captivité. Là aussi, Jöcher et Heineccius ne font que suivre Alting. Ce dernier, après avoir rapporté que les théologiens et les conseillers laïcs de l'électeur n'avaient pu s'accorder sur les crimes du prévenu non plus que sur le châtiment à lui infliger, continue ainsi: "Dum ita res trabitur, Neuserus fuga elabitur, sed Ambergam < $62>$ retractus die 8. Septembr. eiusdem anni, et carceri mancipatur post sex septimanas custodum seu negligentia seu perfidia, ex turre arcis postica fune se demisit et secunda vice elapsus per Bohemiam et Silesiam in Poloniam ac tandem in Transyluaniam profugit ${ }^{32}$ " - -

On voudra bien, je le disais, garder ces deux points présents à l'esprit au moment de se donner la peine de lire la lettre. Je la reproduis intégralement, telle qu'elle apparaît dans la copie dont nous disposons. J'ai même préféré marquer d'un astérisque les endroits du texte où quelque chose semble manquer, plutôt que de les compléter à mon gré ou d'éveiller le soupçon que la version imprimée aurait seule fait l'objet d'une telle amputation. Sur l'identité de ce "Caspar ", " compatriote " auquel Neuser adresse sa lettre, je ne puis rien dire ${ }^{33}$. L'authenticité du document ne dépend toutefois en rien de ce point. 
[128] La Grâce de Dieu soit avec vous, et avec les vôtres, pour les temps éternels!

Cher Casper, cher compatriote,

La lettre que vous m'avez envoyée m'a fait très plaisir, et d'abord parce que je vois que votre cœur et votre esprit ne se sont pas détournés de moi. Vous vous demandez comment j'ai pu me retrouver en cet endroit (c'est-à-dire à Constantinople), et vous pouvez vous imaginer que les raisons qui expliquent cela ne sont pas minces, mais au contraire fortes et importantes. Vous savez très probablement que j'ai pu échapper à la prison de Frédéric, comte palatin, électeur du Rhin ${ }^{34}$, que Dieu, voyant mon innocence, m'a apporté son secours miraculeux et qu'en Angleterre comme en France il m'a été impossible de trouver refuge. Pour ce qui est de l'Angleterre, je me suis rendu dans la capitale, Londres, auprès des prédicateurs flandrins, ou flamands, ou encore néerlandais, qui ont là-bas une paroisse ou église $^{35}$. Je leur ai proposé mes services, mais sous une fausse identité, et faute de disposer d'un certificat indiquant qui j'étais et d'où je venais, je n'ai pu rien obtenir d'eux, de sorte que le long voyage que j'ai dû faire par mer, jusqu'à Londres, n'aura servi à rien. Pour ce qui est de la France $<63>$ (comme le sait le très savant Theophilus Dasypodius, qui était au même moment précepteur du comte de Solms à Paris ${ }^{36}$ ), je n'ai pu rester à Paris, à cause des gens célèbres qui y étudiaient, et surtout du Dr Bictu, précepteur à Genève du jeune duc et comte palatin Christophe ${ }^{37}$, auprès duquel j'avais été dénoncé comme ennemi de la nouvelle vraie doctrine et de sa chère patrie ${ }^{38}$; s'ils m'avaient reconnu, ils eussent tôt fait de me sacrifier comme sur un étal de boucher.

[129] En Pologne, j'ai rencontré quantité de personnes pieuses, à Cracovie et ailleurs, qui m'eussent volontiers gardé auprès d'elles si ç'eût été possible. Mais mes ennemis, notamment Thretius à qui j'avais été trahi ${ }^{39}$, et surtout l'ordre spécial $\mathrm{du}$ roi, qui ne tolérait plus aucun de ceux qu'on appelle les 
nouveaux ariens, qu'ils vinssent d'Allemagne ou des autres pays $^{40}$, m'avaient poussé dans une grande détresse, au péril de ma vie. Je fus contraint avec le très savant Johann Sumer, recteur à Clausenbourg ou Colosvar en Transylvanie ${ }^{41},{ }^{* 42}$ apprenant mon arrivée et entendant qui je suis, écrit au consistoire de Clausenbourg qui m'avait élu parmi ses pasteurs de ne pas me garder et de me faire partir. Mais le consistoire obtint du souverain de me faire rester, à condition de ne pas introduire de doctrine nouvelle. Entre-temps, j'avais été attaqué par le prédicateur de la cour de Transylvanie, Dipnisius ${ }^{43}$, qui affirmait que j'avais dû fuir ma patrie pour avoir à Heidelberg outragé une jeune fille et commis un adultère. Comme on dit, qui veut noyer son chien l'accuse de la rage ${ }^{44}$, tout le monde afflige et accable celui que son innocence a précipité dans la détresse. À quoi s'ajoutèrent plusieurs affaires avec les autres ministres de Clausenbourg, au motif que je n'adhérais pas en tout point à leur confession, notamment pas sur le de Differentia novi et veteris Testamenti, le de Instificatione coram deo, ou encore le de Interpretatione primi capitis apud Ioannem Evangelistam ${ }^{45}$. Pour couronner le tout, ainsi que me l'écrivit un très savant homme de Pologne, quidam nobilis et magnificus ${ }^{46}$, "statim post tuum discessum a nobis sparsus est rumor, tuum Principem, sc. Palatinum, scripsisse ad nostrum Regem ut te capiat, et vinctum Heidelbergam mittat, quem rumorem a Tretio et ab aliis veritatis hostibus conflatum esse arbitror, sicut et alia multa; jam ut tibi caveas et nomen tuum ne aperias vehementer $\operatorname{rogo}^{47}$ ». Ces affaires et plusieurs autres encore me firent $<64>$ peur au point d'en tomber malade un moment et d'en perdre le sommeil, [130] car je ne pensais qu'à une chose, que j'allais être repris. Et le coup le plus dur fut d'entendre la rumeur que le souverain de Transylvanie avait été renversé par l'empereur turc, qu'il s'était allié à l'empereur romain, et qu'il s'était remis, avec tout son pays, entre les mains de l'empereur ${ }^{48}$. Et cela n'était pas cru par n'importe qui, mais par les plus influents dans le pays, avec aussi la rumeur que tous les ariens du pays allaient être brûlés: tel fut, dis-je, le coup 
le plus dur. Car je pensais à ce que m'avait dit un secrétaire du nom de Magister Stephan ${ }^{49}$ dans ma prison de Heidelberg: si je n'avais pas rebroussé chemin la première fois que j'ai atteint la Hongrie, et si j'avais poussé jusqu'en Transylvanie, j'aurais été capturé et remis à Vienne entre les mains de l'empereur ${ }^{50}$. Je me dis alors ceci: "Déjà dans ta prison de Heidelberg, on n'a cessé de te dire que ce qu'on te faisait, on le faisait au nom de l'empereur. Si tu te retrouves en Transylvanie, dans les terres mêmes de l'empereur ${ }^{51}$, comment l'empereur te traitera-t-il ? " Je fis valoir cela et d'autres choses encore au superintendant de Clausenbourg, Franciscus David ${ }^{52}$. Celui-ci réfléchit à un lieu sûr où je pourrais m'établir pendant deux mois environ avec quelques autres sans crainte d'être inquiété, le temps qu'on voie exactement si je courais ou non un danger à demeurer en Transylvanie. On jugea bon également que je publie un texte dans lequel je dissiperais les calomnies des gens de Heidelberg, en révélant au grand jour mon innocence. Car tous en Transylvanie savaient que j'étais tenu par certains pour un ennemi de la patrie, suite à la découverte d'un texte que j'étais censé avoir écrit. Comme cependant le souverain de Transylvanie, pour éviter la propagation de la doctrine arienne (ainsi qu'on l'appelle) et pour ne pas s'attirer la disgrâce des autres princes chrétiens, nous avait formellement défendu de faire imprimer le moindre texte, le superintendant décida que je devais me rendre pour deux mois en Hongrie, hors des terres du souverain de Transylvanie, dans une ville [131] du nom de Schiman qui dépendait du pacha de Temeşvar $^{53}$. Il y avait là-bas une imprimerie où je devais publier le texte qui réfuterait les attaques de mes adversaires, ainsi que tout ce que pouvais avoir d'utile sur moi. Je fus donc muni d'une lettre ou recommandation officielle $<65\rangle$ du superintendant Franciscus David et envoyé à Schiman chez l'imprimeur, qui s'appelait Paulus et était prédicateur à Schiman même, dans les terres du superintendant. Cette recommandation s'adressait à tous les prédicateurs de Hongrie placés sous l'autorité de cette superintendance et en particulier au sieur Benedict, le 
prédicateur de Temeşvar ${ }^{54}$. Avant même toutefois que je ne sorte des terres du voïvode ou souverain de Transylvanie, alors que je traversais un endroit dénommé Lugusch ${ }^{55}$, je trouve à cet endroit le sieur Paulus, l'imprimeur dont j'ai parlé. Après avoir lu la lettre que lui avait écrite le superintendant, il m'explique qu'il a été chassé de la ville de Schiman par ceux qui professent la foi des Valaques ${ }^{56}$. Ceux-ci, à force de plaintes transmises au pacha, de présents aussi, avaient obtenu son départ, et il demeurait désormais à Lugusch avec ses gens. Il me montra quelques-uns des caractères de son imprimerie qui me plurent beaucoup et me dit qu'ici nous ne pourrions rien imprimer, car ce territoire appartenait encore au souverain de Transylvanie, mais demain, si Dieu voulait, nous irions chez le sieur Benedict à Temeşvar, chez qui nous pourrions très probablement installer l'imprimerie, car il avait une belle et grande maison. Lorsque nous arrivâmes à Temeşvar chez le pasteur, nous le trouvâmes bien mal en point, car il avait la colique; notre plan toutefois lui convint tout à fait et il nous promit de faire tout son possible. Aussitôt que la communauté des Chrétiens Hongrois, ainsi que ceux qu'on appelle les Juges Hongrois ${ }^{57}$, ont vent de mon arrivée, ils me font tous les honneurs. Pour ce qui est de l'imprimerie toutefois, me dit le juge, on ne peut rien faire sans en parler auparavant au pacha, parce que je viens d'Allemagne; car tout juste huit jours auparavant, le pacha lui avait fait jurer sur sa tête de n'autoriser le séjour d'aucun chrétien étranger, pas même pour quelques jours, sans [132] qu'il en ait été prévenu. Pour cette raison, il se proposait de faire part de mes plans au pacha. Mais aussitôt que le pacha apprend que je suis allemand et que je veux faire imprimer des livres à Temeşvar, il dépêche quelqu'un qui me parle durement et me dit que je suis un welche, envoyé par ses ennemis vénitiens pour trahir ce pays ${ }^{58}:$ "Car pourquoi dis-tu que tu n'es pas un welche? Tu as bien parlé welche avec le scribe chrétien. » Nous avions parlé latin, et dans le rapport fait au pacha, cela était devenu du welche. Et il reprend: pourquoi veux-tu imprimer des livres chez nous? Il y a $<66>$ bien des imprimeries en 
Transylvanie. Je réponds que l'actuel souverain ou voïvode ne permet pas qu'on publie sur les matières de religion, ainsi que cela a décidé par le roi ${ }^{59}$. À quoi le pacha répond: si tu dis vrai, alors le voïvode a enfreint le serment qu'il a prêté devant Dieu et notre empereur. Car il a juré qu'il n'interdirait rien, et spécialement pas dans les matières de religion, ainsi que cela a été décidé par le roi. S'il t'a interdit de publier, il a enfreint son serment, ce que je ne crois pas. C'est pourquoi, dit le pacha, je vais écrire au voïvode à ton sujet, pour savoir ce que tu as fait dans son pays et pour lui rapporter ce que tu dis, qu'il n'a pas respecté son serment devant Dieu et l'empereur, puisque tu prétends qu'il t'a interdit de publier. En attendant, tu es mon prisonnier. Si j'apprends du voïvode que tu as menti à son sujet, tu seras à coup sûr un traître et je t'enverrai alors à l'empereur à Constantinople; lui saura bien te faire dire qui tu es, et je vais moi aussi d'ici peu te mettre à la question. ${ }^{* 60}$ Les Juges Chrétiens, d'autres chrétiens encore prirent la parole, me défendirent, j'avais bien été chassé de mon pays pour la cause de la Parole de Dieu, j'avais bien passé trente-cinq semaines en captivité et j'avais bien là-dessus des témoignages écrits que j'avais emmenés de Transylvanie, mais rien n'y fit, je devais être son prisonnier, et il ordonna aux [133] autres chrétiens de se retirer. Je vis alors dans quelle mauvaise passe j'étais, car jamais le souverain de Transylvanie n'écrirait au pacha qu'il avait interdit la publication d'ouvrages, sauf à s'avouer lui-même coupable; il prendrait mes déclarations comme une dénonciation devant le pacha, et à coup sûr sa réponse ne serait pas une chaude recommandation en ma faveur. Et je dis: mon Dieu, je passais en Allemagne pour un ennemi des Allemands et pour un ami des Turcs, et ici parmi les Turcs on me prend pour un ennemi des Turcs et pour un ennemi de ma patrie, tout cela parce que, pour ce qui est de la Trinité, je ne crois qu'en un Dieu, tout comme les Turcs, ce pour quoi on a voulu me tuer. À quoi le pacha répond: s'il est vrai que comme nous tu crois au Dieu unique qui a créé le Ciel et la Terre, et si pour cette raison tu as été pris pour un Turc par 
les tiens, alors prouve-le par le fait, fais-toi Turc, et tu auras ensuite toute liberté pour publier tout ce qui $<67>$ te plaît contre tes ennemis ${ }^{61}$. Mais si tu ne fais pas cela, tu devras t'attendre à courir tous les risques qui t'ont été décrits. Je répondis alors que j'avais lu l'Alcoran, et avec plaisir, raison pour laquelle on m'a pris pour un Turc. À peine le pacha entend-il cela, qu'il déclare qu'il veut m'envoyer à l'empereur à Constantinople; c'est là que je suis encore aujourd'hui, auprès du premier truchement de l'empereur, qui est allemand ${ }^{62}$. Pour le prouver, je vous ai joint la lettre du pasteur d'Alba Julia en Transylvanie ${ }^{63}$. Voilà donc ce que je devais répondre à votre première question, puisque vous désiriez savoir comment et pourquoi je me suis retrouvé à cet endroit.

Tout cela vous fera voir sans peine que malgré le grand nombre de royaumes que j'ai traversés je n'ai pu trouver aucun séjour durable et que c'est par la force des choses qu'il m'a fallu clamer publiquement et par écrit mon innocence. Vous aurez compris ce qu'il est advenu de moi à cause de cette publication ${ }^{64}$. Vous m'exhortez vivement à rebrousser chemin et à [134] retourner dans mon pays, ce qui de mon point de vue reviendrait à me précipiter dans la mort. Car plusieurs personnes dignes de foi m'ont rapporté oralement et par écrit que le prince électeur de Heidelberg a fait couper la tête à Johannes Sylvanus à cause d'un texte que j'étais censé avoir écrit. Voici ce que m'écrit un bon ami: "Gaudebant te, euitato crudeli illo Sylvani iudicio (quem tuae literae ad Turcarum Imperatorem potentissimum scriptae pridie nativitatis Dni. Ao. 72 jugularunt) in tuto esse ${ }^{65}$. "Un autre ami m'écrit ceci: "Sylvanus superioris anni mense Decembri capite plexus est, eiurata prius religione; crimini datum est, quod conscius fuerit tuarum, quas ad Turcas scripseris literarum: ille Deum et homines testatus est, sibi iniuriam fieri. Responsum tandem, Principem non aliter velle; alii dimissi sunt ${ }^{66}$. " Vous pouvez en déduire ce qui m'attendrait si l'idée me venait de partir d'ici. Mais je veux vous faire comprendre en quelques mots ce qu'il en est de cette fameuse lettre qui a coûté la vie à Sylvanus, 
afin que vous sachiez que les allégations de mes adversaires ne sont qu'inventions et mensonges, chose que je vais maintenant rendre aussi claire que le jour. Si quelqu'un pensait: «Eh, qu'astu besoin de parler de tout cela, il est trop tard à présent, tu ne rendras pas la vie à Sylvanus; tu n'as pas à t'excuser, ils ne peuvent $<68>$ plus te faire de mal, et pour les gens chez qui tu es maintenant, les allégations de tes adversaires ne sont pas une honte, mais un grand honneur; reconnais-le, et cesse de parler contre ton honneur ", etc. Mais je ne cherche pas mon honneur, mais la vérité, et je veux à présent parler de ce texte comme si je devais m'expliquer au Jugement dernier devant le Dieu vivant ${ }^{67}$. En premier lieu, l'usage chez les savants anciens, quand on commence un discours ou un texte sur un sujet donné, est d'indiquer quo animo, quo proposito et fine, dans quel esprit, quelle intention et à quelle fin l'on parle ou l'on écrit; qu'on pense à ce que le Siracide enseigne aussi, au chapitre $19^{68}$. Car si [135] l'on ne tient pas compte de l'intention de l'auteur, ou s'il ne la révèle pas lui-même, alors il est impossible de comprendre de quoi il retourne. C'est pourquoi mes adversaires me font du tort et du mal quand ils interprètent ma lettre, dans laquelle je n'ai pas révélé mon propositum, selon leur propre sens et leur bon plaisir. Les choses se présentent de la manière suivante. Voyant que j'errais sur les matières de la Trinité, je décidai à part moi de tout tenter pour apaiser ma conscience inquiète et errante. Comment cela devait-il se faire? De quelle façon? L'usage, quand on doute d'une chose, est de partir et de se rendre sur place, sur les lieux où les choses se sont passées, et d'y explorer la vérité pour être certain des faits. Car nous savons que le pape n'a cessé de nous raconter des mensonges et de fausses histoires et qu'il s'est toujours empressé de bannir la droite vérité par le fer et par le feu. Or où pouvait-on mieux s'enquérir de la vérité sur la Trinité, sinon à l'endroit où la querelle et la controverse se sont d'abord menées? Or cette controverse a commencé à Constantinople, comme le rapportent tous les livres d'histoire. À ce moment, Arius, comme le rapportent ces mêmes histoires, a rallié à son 
opinion l'empereur Constantin et plusieurs de ses descendants ${ }^{69}$; à cause de la Trinité, tous les Grecs ont été mis au ban du pape de Rome, et ils s'y trouvent toujours aujourd'hui ${ }^{70}$. Car ils ne confessent pas que l'Esprit saint procède du Fils, mais seulement qu'il procède du Père. Voici ce que rapporte l'histoire: "Graeci non obediunt Ecclesiae Romanae et habent errores multos, qui sunt condemnati per Ecclesiam sc. Romanam, quia dicunt quod Spiritus sanctus non procedit a Filio, sed a Patre solum; etiam dicunt, quod non est Purgatorium. Haec sunt verba Historiae $^{71}$. » Si donc dans l'opinion < 69 > des Grecs le Saint-Esprit ne procède pas du Fils mais du Père, il s'ensuit que le Christ n'est pas un même Dieu que le Père, car l'Esprit saint procède bien de l'unique Dieu vivant ${ }^{72}$. [136] Or, disent les Grecs, le SaintEsprit ne procède pas du Fils, mais de l'unique Dieu vivant. Plusieurs savants, dont Camerarius à Leipzig, estiment en outre "quod Symbolum Athanasii, non ab ipso Athanasio, sed potius a rancido quodam Monacho compositum sit $^{73}$ ". Ces raisons et d'autres du même genre m'amenèrent fortement à penser ceci: les Grecs ne pensent pas comme le pape sur la Trinité; or les Grecs sont là-bas chez eux; ils connaissent toute l'histoire sur la Trinité, mieux que le pape, et ils n'ont pas la même opinion que lui. C'est pourquoi, pensais-je, il doit y avoir tromperie de la part du Pape, et je décidai donc à part moi, pour le bien de ma conscience et de la vérité, de tout tenter pour apprendre la vérité vraie auprès des Grecs, puisque la vérité de l'histoire ne se trouve chez personne d'autre. Mais puisqu'il est impossible d'accéder à de tels endroits, sinon par force dons et largesses, ou par la connaissance des langues, ou encore par la faveur et recommandation de gros potentats, et qu'il ne m'était permis d'espérer aucune de ces choses-là, richesses, langue ou recommandation, je pris après une longue hésitation exemple sur l'apôtre Paul, qui dans un cas similaire, je veux dire: pour révéler la vérité, est devenu tout pour tous, pour les juifs un juif, pour les païens un païen, et a ordonné de le suivre en ces choses ${ }^{74}$. C'est en suivant le propositum Pauli, et absolument pas pour blesser quiconque, 
ni juif, ni païen, ni chrétien, ni Turc, Dieu m'est témoin, que j'ai écrit cette lettre. J'étais si désireux d'explorer la vérité que j’ai voulu, exactement comme Paul, me faire juif ou païen. Mais mon propositum, qui était bon, a été mal interprété.

À présent, mon cher compatriote, juge de la manière dont j'ai été traité, et vois si elle a été divine ou équitable. Suppose quelqu'un qui aurait fait à Paul le reproche suivant: "Eh Paul, tu as, par écrit et dans tes prêches, voué les juifs et les païens au diable, [137] et te voici devenu toi-même juif et païen. " Auraitce été rendre justice à Paul? Assurément non. Par deux fois, j’ai écrit de Pologne à Heidelberg, à $<70>$ l'électeur en personne, pour lui faire part de mon projet, mais je ne puis croire que mes lettres lui aient été remises ${ }^{75}$ : si elles l'avaient été, il est certain qu'on n'eût pas rendu un tel jugement contre Sylvan. Je parle ici de mon projet d'il y a quatre ans, au moment où j'écrivis la lettre que le comte palatin a découverte parmi mes livres dans mon cabinet de travail ${ }^{76}$. Mais à présent que je n'ai trouvé aucun autre endroit dans le monde entier que Constantinople où, comme vous l'avez vu, je suis arrivé par la miraculeuse Providence de Dieu, à présent que je suis sous la protection et la garde du plus bienveillant des empereurs, mon projet n'est plus du tout ce qu'il avait été alors. Tel est donc le premier argument: mes adversaires ont agi injustement contre moi en me reprochant le contenu de cette lettre, sans comprendre quels étaient exactement mes plans.

À cela j'ajoute que si mes adversaires avaient compris à la lettre ce que dit ce texte, et s'ils l'avaient interprété comme il doit l'être, le droit temporel et le droit divin n'auraient pas permis qu'ils me nuisent comme ils l'ont fait. Car si je demande à mes adversaires: que s'est-il exactement passé? à quels ennemis de l'Allemagne me suis-je allié en écrivant cette lettre? où l'ai-je envoyée?, ils ne pourront pas établir que quelque chose se soit alors réellement passé de facto. Sur mon âme, j'en appelle à tout témoin: jamais personne n'a lu cette lettre, à l'exception de moi-même et de moi seul, jusqu'à 
ce qu'elle tombe entre leurs mains. Supposons que j'aie eu une dette de 100 florins envers l'un de ceux qui ont fouillé ma maison à Heidelberg, et supposons que celui-ci ait trouvé dans mon cabinet une lettre écrite par moi, dans laquelle il serait dit que je veux le rembourser: interprétera-t-il la lettre comme disant qu'il est de facto remboursé? Non bien sûr. Pourquoi alors interprète-t-on ma lettre comme disant que je me serais [138] à l'époque déjà allié à l'ennemi ? Ils diront (car c'est ainsi qu'on m'a répondu dans ma prison): voluntatem malefactionis pro facto reputari ${ }^{77}$, si quelqu'un par exemple a l'intention de voler et qu'on le surprenne avec ce projet, c'est exactement comme s'il avait déjà volé, et il en va de même avec ma lettre: j'ai eu le souhait de me mettre du côté de l'ennemi, de faire du mal à son côté, j'ai été capturé avec cette intention, donc ce texte peut m'être imputé comme si le délit était déjà constitué. $<71>$ Qu'en pensera-t-on? Reste où tu es, Adam, tu ne peux plus répondre. Pour ma part je dis qu'avec de telles déclarations je n'aurais en rien été inquiété, et qu'au contraire on m'aurait affranchi, libéré, innocenté, élargi, car cette lettre dit que j'ai voulu me mettre avec leurs ennemis, et c'est dans cette intention que j'ai été capturé. Car lorsque j'apprends que Sylvan a été pris au motif que nous sommes allés voir le légat du voïvode, je m'enfuis, je vais jusqu'à Presbourg ${ }^{78}$, fais la connaissance de marchands de Debrecen ${ }^{79}$. Cependant, comme je vois que je ne peux arriver en Transylvanie, je réfléchis et décide de faire à nouveau demi-tour, de retourner à Heidelberg, pour ne plus jamais de ma vie me mêler de ce qui concerne la foi ou autres affaires, mais au contraire tout laisser tomber et laisser les choses là où elles sont. C'est dans cette intention que je fais demi-tour; je parcours presque cent miles dans la direction inverse, je ne me mets pas du côté des ennemis du comte palatin, mais de ses amis, avec son chancelier à Amberg ${ }^{80}$, je m’y présente, il m’invite au cloître, j’y vais, je ne vois rien venir, et dans la même nuit il me fait capturer. Comment peuvent-ils dire que j'ai été capturé à cause de l'intention qui était dans 
ma lettre de fuir chez leurs ennemis? Si donc ils devaient parler selon la vérité: faut-il imputer à quelqu'un son intention ou sa volonté comme on lui imputerait ses actes? Quelqu'un qui aurait l'intention de tuer son prochain mais qui, en y allant, se raviserait, se dirait que c'est mal, rebrousserait chemin, navré d'avoir eu une telle intention — à celui-là faudrait-il imputer sa volonté [139] comme on imputerait ses actes ? Assurément non. Or que les choses aient pris pour moi cette tournure et cette signification, le Seigneur Dieu le sait très bien. Le fait d'avoir fait par moi-même demi-tour, d'être allé voir le prédicateur de l'électeur, Melchior Potter, à Neubourg ${ }^{81}$; de m'être avec lui rendu à Amberg et de m'y être présenté au chancelier du comte palatin: tout cela ne veut pas dire que j'aie été capturé à cause de l'intention qui était dans ma lettre. Le roi David a un jour voulu tuer Saül, son seigneur. Il rentre cependant en lui-même et dit: Dieu me garde (1 Samuel $24^{82}$ ) de tuer mon seigneur le roi. Cette intention qu'a eue David vient à être connue de Saül, mais ce n'est pas pour lui une raison de tenir David pour un assassin. Si donc Saül, malgré son émotion, a pu voir cela, alors même qu'il en voulait nuit et jour à la vie de David, des gens aussi sages qu'eux n'auraient-ils pas dû le voir aussi, si leurs passions ne les en avaient pas empêchés?

$<72>$ En outre, quand bien même ils m'eussent capturé au moment où je partais pour la Transylvanie, sur le chemin du départ donc et non pas du retour, en vérité cela ne m'aurait pas davantage porté tort. Car si je suis parti pour la Transylvanie, c'est parce que j'étais allé voir le légat du voïvode à Spire et que j'avais promis de me mettre à son service, et ce n'est donc pas à cause de cette lettre que je suis parti, mais parce que je voulais me rendre auprès du prince de Transylvanie. Quant à savoir si celui-ci, à l'époque, était tenu pour un ami ou un ennemi de la patrie, cela est connu de tous; le secrétaire de Spire nous l'avait dit dans la maison du potier où nous étions ${ }^{83}$ : le voïvode était devenu un ami de l'Allemagne ${ }^{84}$, et toutes les vieilles inimitiés étaient déposées. On en déduira ce que je pensais de cette lettre 
dont on parle tant, dès lors que j'avais moi-même, re ipsa, changé de fond en comble mon propositum.

Et pourtant mes ennemis me chargent de cet opprobre et de cette injustice. Il en va de moi comme de quelqu'un qui a dénoncé, annulé [140] et détruit un testament ou une lettre de créance; voilà qu'on retrouve cette lettre et qu'on veut la faire entrer en vigueur. Tout le monde dira que cette lettre n'a plus de valeur, puisque son auteur l'a déclarée sans valeur. Faut-il beaucoup insister? Qu'on laisse parler cette lettre (celle que j'ai écrite ou celle qui a été retrouvée ${ }^{85}$ ), pour laquelle on a voulu me faire perdre la vie; elle m'innocentera et me libérera.

Je dis donc: si, en suivant la lettre de ce texte, ${ }^{* 86}$, à qui je l'avais écrite, je la relus, elle me déplut et je me dis alors: "S'il arrivait, par un malheur particulier, que ceux qui ne t'aiment pas tombent sur cette lettre, ils pourraient te causer bien du malheur; personne ne te croira quand tu diras que tu l'as écrite in proposito et fine, c'est-à-dire pour connaître la vérité; fautil te donner tant de peine pour la religion et partir pour des pays lointains et inconnus? " Je décidai de laisser reposer toute l'affaire, de ne rien entreprendre, et pour en laisser un témoignage j'écrivis à côté de la lettre, dans la marge: "Hoc potest omitti i. e hoc negotium, hoc meum propositum potest omitti ", c'est-à-dire: " mon projet, cette lettre, cette affaire peuvent être oubliés ». Tels sont les derniers mots que j'ai écrits sur cette lettre, après l'avoir relue.

$\mathrm{Si}$ maintenant mes adversaires veulent tout faire reposer sur la lettre $<73>$ de ce texte dont on parle tant, il faut qu'ils le lisent tout entier, en ne laissant rien de côté. Imaginons quelqu'un qui aurait écrit les dix commandements, et notamment: "Je suis le Seigneur ton Dieu, qui t'ai fait sortir du pays d'Égypte; tu ne te feras pas d'idole; tu ne voleras point, tu ne tueras point, tu ne commettras pas l'adultère ${ }^{87}$ ", et qui, ayant écrit tout cela et l'ayant relu, voudrait écrire au bas de la lettre, ou sur la page: "Ces commandements peuvent être oubliés, on a le droit de ne pas les suivre, droit d'avoir d'autres dieux, 
on peut voler " - quelle valeur cet homme accorderait-il aux dix commandements? Assurément aucune. Or c'est exactement comme cela, de ma propre initiative et seul dans mon cabinet de travail, que j'ai signé de ma main au bas de cette lettre [141] dont il est tellement question, pour dire qu'elle n'était rien, ne valait rien et qu'elle pouvait être oubliée. C'est pourquoi, comme je l'ai dit, ce qui m'arrive avec cette lettre s'apparente à ce qui arriverait à quelqu'un à qui on présenterait un testament déchiré ou rayé par son auteur, en lui disant: "Vois, c'est dans la lettre; c'est ta volonté, ton propositum! ", sans tenir compte du fait que le testament est déchiré ou rayé et que cette déchirure et cette rature anéantissent la volonté de l'auteur.

Par conséquent, lorsque mes adversaires disent: "C'est dans la lettre, tu l'as écrit, tu as voulu faire ceci ou cela ", il faudrait qu'ils ajoutent immédiatement: "Hoc potest omitti ${ }^{88}$ ". Imaginons quelqu'un qui écrirait, seul dans son cabinet de travail, qu'il veut incendier une ville ou un village mais qui le regretterait ensuite et écrirait au bas de la lettre: "Je ne veux pas faire ce que j'ai écrit "; imaginons ensuite qu'il se mette au service de l'ami d'une ville ou d'un village qui voudrait faire la guerre à un autre et pour cela voudrait incendier la ville ou le village dont j'ai parlé d'abord - pourrait-on interpréter sa lettre comme exprimant toujours l'intention d'incendier cette ville ou ce village? Non bien sûr, les mots et les actes manifesteraient le contraire. L'intention est la même ici. Cette lettre, je l'ai détruite et effacée de ma main, avec ce "Hoc potest omitti ", et je me suis mis ensuite au service du voïvode, qui était un ami de l'Allemagne; à ce moment, j'ai prouvé, en parole et en acte, le contraire de ce qu'il y avait dans la lettre. Cela suffira, à présent, pour me justifier de l'opprobre dont on veut me charger. Car où suis-je, à l'heure où j'écris ces lignes? À Constantinople, et non pas dans les prisons de l'électeur du Rhin ${ }^{89}$, où la peur, ou bien $<74>$ le souci de sauver ma vie, pourraient guider mon propos. Quel intérêt ai-je à présent d'écrire tout ceci? Aucun, hormis, comme je l'ai écrit, celui de la vérité. 
[142] Dernièrement j'ai eu vent de ce qu'affirment mes adversaires: j'aurais volé le sceau de l'électeur de Heidelberg, et celuici figurerait sur la lettre qu'on a retrouvée. Il en va toutefois de cette accusation comme de la précédente. Voici ce qu'il en est. Après avoir écrit cette fameuse lettre, y ayant mis mon nom pour dire qui j'étais et quelles étaient mes fonctions et attributions à Heidelberg, je me suis dit: personne, dans les pays lointains où tu veux partir, ne croira que tu as exercé ces fonctions, à moins que tu n'aies le papier et le sceau de ton prince. Or l'électeur, au moment du ban de Genève ${ }^{90}$, avait adressé en propre à chacun des théologiens les plus éminents, comme le docteur Poquinus ${ }^{91}$, le docteur Zanchius ${ }^{92}$, ainsi qu'à moi-même, une lettre qu'il avait, selon l'usage, revêtue de son sceau. Et comme cette lettre de l'électeur portait l'en-tête "À notre cher Adam Neuser, prédicateur et serviteur de l'Église ici à Heidelberg ", je me suis dit: cette lettre, en pays étranger, témoignera suffisamment que tu es celui que tu dis être. Car l'électeur, auquel je m'étais opposé à propos du ban de Genève ${ }^{93}$, ne risquait pas de m'envoyer encore beaucoup de lettres et de sceaux. Je me suis donc dit que je pourrais envoyer la lettre de l'électeur avec l'autre, de façon à ce qu'on croie bien que j'étais celui que je disais être, et j'ai donc écrit dans cette fameuse lettre: "Ut intelligas me sc. talem esse, qualem me esse praedico, mitto tibi literas sigillo Principis munitas $^{94}$." De ce passage mes adversaires concluent que j'aurais volé le sceau de l'électeur ou que j'en aurais fabriqué un portant son nom. C'est ce genre de choses que je subis; ce sont les accusations de mes adversaires. Si ce qu'ils affirment est vrai, je pose la question: l'électeur, ou bien un de ses secrétaires, a-t-il perdu son sceau? Car si je m'étais emparé de ce sceau électoral, on en aurait constaté la perte. Or personne [143] à cette époque ne s'est plaint de la perte de ce sceau, pas même lorsque j'étais en prison. En outre, quel orfèvre, quel artisan aurait été autorisé à fabriquer pour moi ce sceau électoral, quand bien même $<75>$ j'en eusse exprimé le désir ? Et où est celui qui l'a fabriqué ? Pourquoi n'ai-je écrit aucune lettre au nom de l'électeur? 
Où a-t-on retrouvé ce sceau ${ }^{95}$ ? Si j'étais coupable, je n'aurais pas à en rougir, là où je suis maintenant; je pourrais narguer mes adversaires. Mais Dieu qui est aux cieux en est témoin: dans cette affaire, mes adversaires me font du tort et du mal. Si j'ai eu en ma possession un sceau contrefait de l'électeur, alors il faut que ce soit lui qui me l'ait envoyé, car je ne connais ni ne mentionne aucune lettre porteuse du sceau, à l'exception de celle qu'il m'a écrite sur la question du ban ${ }^{96}$. Mon Dieu, quelle iniqua interpretatio ${ }^{97}$. Car imaginons un maire qui aurait écrit une lettre à quelqu'un et l'aurait revêtue de son sceau; et à supposer que le destinataire eût envoyé cette lettre du maire à quelqu'un d'autre encore, en écrivant en marge "Mitto tibi literas sigillo consulis munitas $^{98} "$ : si l'on interprétait ce passage comme voulant dire: j’ai dérobé le sceau du maire, son cachet, et l'ai utilisé, ou encore: je t'envoie le cachet du maire — ne serait-ce pas une action et une interprétation malveillantes? Mais Dieu, qui l'a vu et qui le sait, les en châtiera.

Par ailleurs, cher compatriote, vous m'exhortez à chercher consolation dans la grâce et la miséricorde de Dieu, là où je me serais trompé sur la doctrine. Sur ce point, vous devez savoir que je ne manque de rien, Dieu soit loué. Car je connais mon Dieu et je sais qu'après m'avoir sauvé de tant de tourments, il le fera encore. Rien ne me réjouit davantage que de savoir que devant Dieu mon cœur est resté pur et mon esprit ferme; je suis certain que je suis un ami et non un ennemi de Dieu. Car ma conscience, comme l'enseigne [144] Jean I, $3^{99}$, est pour moi plus forte et plus grande que le témoignage du monde entier. Mon souhait de Heidelberg, à propos de la doctrine d'Arius, et notamment sur la Trinité, s'est grâce à Dieu réalisé. J'ai aussi envoyé en Transylvanie des vetustissima Exemplaria Novi Testament $i^{100}$ en manuscrit, dont j'aimerais que vous les regardiez. Je pense que ces Exemplaria ont été rédigés peu après la naissance du Christ.

En ce qui concerne ces liens naturels d'amour dont vous me parlez, vous devez savoir - et vous pouviez vous en douter 
— que je suis un homme; je ne suis pas de bois ou de pierre. C'est pourquoi une chose pareille (le fait d'avoir dû quitter les miens) $<76>$ ne préoccupe personne plus que moi. Mais en quoi cela aurait-il aidé les miens si j'étais resté auprès d'eux et si je m'étais fait tuer à Heidelberg? Car il n'auraient plus pu se faire le moindre espoir. Je vous en prie, au nom de nos liens déjà anciens, aidez-moi et faites en sorte que mon fils soit libéré de prison, et dites-lui de n'essayer en aucun cas de me rejoindre ${ }^{101}$. Cela lui serait impossible; il serait pris et vendu, et ne pourrait être libéré. Car ici, ce n'est pas un pays où l'on peut voyager comme en Allemagne. Je tiens aussi à vous remercier vivement de votre souhait, que je déduis de votre lettre, de me manifester amitié et affection. Si vous pouviez vous informer sur les miens à Heidelberg, voir comment ils se portent, cela m'importerait de le savoir. Sur quoi je vous recommande au bon Dieu, avec les vôtres. Fait à Constantinople le mercredi d'avant Pâques de l'an de grâce 1574 .

Votre compatriote

Saluez pour moi le Dr. Crato ${ }^{102}$, qui, si je comprends bien, a transmis votre lettre.

Adam Neuser

[145] En tête de notre exemplaire se trouve cette mention ajoutée par une main plus récente: "Infelicissimi terque quaterque Apostatae et Mamelucae Adami Neuseri scriptum, in quo pessima fide et conscientia leprosa suam historiam narrat ${ }^{103}$. " Je ne saurais pour ma part juger de la sorte. Apostat et mamelouk, autant qu'on voudra! Mais en vérité, cette lettre est écrite avec un sangfroid et une tranquillité qui trahit tout sauf une conscience meurtrie et pénitente. Et pour ce qui est de la "pessimam fidem ${ }^{104}$ ", j'affirmerai exactement le contraire. Certes Neuser s'autorise quelques enjolivements pour décrire le pas qu'il a franchi: qui les lui reprocherait? En revanche, les faits qu'il relate ont tous l'apparence parfaite de la crédibilité; ils concordent entièrement avec ce que l'on sait, par d'autres sources, des réalités politiques 
de ce temps; et ils sont même considérablement renforcés par ce qu'affirment ses adversaires - à leur insu certes et contre leur gré: au point que la "pessima fides » risquerait $<77>$ bien plutôt de retomber sur eux, si tous les récits inexacts devaient reposer sur la "pessimam fidem » et si les hommes, même avec la ferme volonté de dire la vérité, ne pouvaient pas, plus souvent qu'à leur tour, tromper le monde et se tromper eux-mêmes.

Pour éviter de dire tout cela en l'air, je reviens sur les deux points auxquels j'avais demandé à mes lecteurs de prendre particulièrement garde. Je commence par le second, parce que c'est [146] le moins important mais aussi le moins sujet à controverse et qu'on pourra donc le concéder d'abord à l'auteur.

Combien de fois Neuser a-t-il été capturé? Personne ne peut mieux le savoir que Neuser lui-même. Et de la même façon, personne ne peut mieux savoir que lui combien de fois il a fui sa captivité. Si donc il raconte qu'il n'a été capturé qu'une seule fois ou plutôt que même cette fois-là il n'a pas été capturé ${ }^{105}$, mais qu'il s'est rendu à la captivité; s'il déclare qu'apprenant l'incarcération de ses compagnons, il a pris la fuite et est allé jusqu'à Presbourg; s'il indique les causes et les circonstances qui l'ont poussé à faire demi-tour; s'il donne les noms des personnes encore en vie à qui il a d'abord jugé bon de s'adresser à son retour $^{\mathrm{b}}{ }^{106}$ : quels scrupules aura-t-on de le croire entièrement sur tous ces points qui, au bout du compte, ne changent rien au fond de l'affaire, et au sujet desquels on ne verrait pas du tout pourquoi le récit qu'il en fait devrait différer de ce qu'il s'est réellement passé ? Et à qui raconte-t-il cela ? À quelqu'un qui n'y connaîtrait rien et n'y pourrait rien connaître? Au hasard d'une postérité à qui des détails de ce genre n'importent pas assez pour les soumettre à un examen approfondi ? Pas du tout: il les raconte à un compatriote qui compatit à ses malheurs, et aux yeux de qui son récit $<78>$ d'événements lointains deviendrait très suspect s'il cherchait à le tromper sur des faits qui se sont

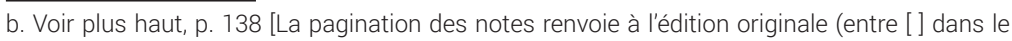
texte) (NdT)] 
produits dans sa [147] propre patrie et dont la réalité peut être vérifiée sur le champ. Si nous y regardons de près, nous trouverons jusque dans les Actes que nous mentionnions plus haut un passage très favorable aux affirmations de Neuser. Dans la délibération des théologiens de Heidelberg ${ }^{107}$, et plus précisément dans le paragraphe qui concerne Matthias Vehe ${ }^{c}$, on trouve une citation d'une lettre écrite de la main de Neuser, disant que Sylvanus et Vehe, sur le chemin de la prison, l'avaient fait avertir par un étudiant du nom de Mader ${ }^{108}$. Neuser à ce moment-là n'était donc pas encore incarcéré. Il a fait bon usage de l'avertissement reçu: quoi de plus crédible que cela?

Et pourtant, comme je l'ai dit, ce point importe si peu qu'on ne se formalisera pas de considérer le récit que Neuser en fait comme le plus véridique. "Si peu » - mais tout de même, pas si peu! Car peut-on contester que ce retour volontaire, auquel Neuser s'était décidé alors qu'il savait que ces compagnons avaient été capturés, ne témoigne pas, c'est le moins qu'on puisse dire, de la mauvaise conscience que ses crimes supposés auraient dû faire naître? Et puis quelle défiance un détail manifestement forgé peut jeter sur tous les autres détails de la même histoire! Qui ne connaît pas celui-ci ne peut connaître les autres. Et qui a jugé bon de détourner et falsifier un détail au gré de ses intentions peut très bien se l'être permis avec tous les autres.

[148] Avec cette méfiance, abordons donc le point principal, la lettre à l'empereur turc. Cette lettre, comme je l'ai déjà noté, se trouve effectivement dans les Actes et son contenu est des plus compromettants; en outre, Neuser reconnaît $<79>$ l'avoir écrite. Plus encore, ce qu'il allègue pour son excuse semble en partie relever du pur et simple enjolivement: je parle de ce qu'il dit de l'intention dans laquelle il a écrit cette lettre. L'exemple de saint Paul est très manifestement maltraité.

Mettons toutefois de côté cette intention douteuse et concédons même que son intention a été visiblement, non pas de rechercher la vérité, mais, dans la certitude d'une vérité déjà

c. Dans Struve, p. 227. 
recherchée et déjà trouvée, d'inspirer notre pire ennemi contre les adversaires de celle-ci, et de faire cause commune avec lui. Il lui reste néanmoins pour se justifier un argument qui à lui seul fait si nettement pencher la balance de son côté que je ne vois pas ce qu'il y a à répondre ${ }^{109}$.

Je l'ai écrite, dit Neuser, cette malheureuse lettre, si incomprise; mais je ne l'ai jamais envoyée; je ne l'ai donnée à lire à personne; par une clause ajoutée de ma main, je l'ai pour ainsi dire anéantie; et j'ai fait en réalité le contraire de ce que j'avais l'intention de faire.

C'est cela que dit Neuser, et selon toute vraisemblance il ne dit là que la pure vérité; ou alors ce [149] serait un singulier malheur pour ses adversaires s'il n'avait pas dit la vérité, alors qu'à présent, sous les yeux d'une postérité froide et impartiale, leurs propres allégations ne font que vérifier et renforcer ses dires!

Qu'on y réfléchisse. À qui Neuser est-il censé avoir confié, pour transmission à l'empereur turc, sa lettre de traître "in qua fassus ", selon Alting, "plures esse in Germania Arianae factioni addictos, quibus nibil magis in votis esset, quam Turcarum Monarchae viam sternere in Imperio, et cum ipso coniungi $i^{110}$ "; cette lettre dans laquelle, comme disent les théologiens de Heidelberg dans leur mémoire ${ }^{\mathrm{d}}$, il ourdit une conspiration féroce contre la chrétienté entière? $<80>$ À l'émissaire de Transylvanie? À celui qui avait été envoyé par son maître à Spire pour négocier "de ineundo foedere " (ce sont à nouveau les termes d'Alting) "cum Imperatore et Ordinibus Imperii, mutuae securitatis ac defensionis ergo" contre le Turc ${ }^{11}$ ? À celui-là? Il aurait fallu être fou furieux! À celui qui vient en Allemagne pour chercher de l'aide contre le Turc, confier une lettre dans laquelle le Turc est exhorté à frapper aussi vite que possible? Dans laquelle les plus grands espoirs sont placés dans les armes turques? Dans laquelle l'auteur écrit expressément à l'empereur turc: "Pour ma part, je n'épargnerai aucun effort,

d. Dans Struve, p. 218. 
d'écriture et d'exhortation, pour que [150] les chrétiens idolâtres soient convertis à la vraie foi, pour que la gloire de Dieu augmente et pour que l'Empire de Votre Majesté (l'Empire turc) s'étende $e^{112}$ "? Confier une lettre pareille à un ennemi du Turc! Encore une fois: Neuser aurait dû être fou, il aurait dû être furieux. Ou si ce n'est pas cela, dira-t-on que Dieu a pu autant aveugler un homme qui l'avait renié une fois et que dans cet aveuglement il a pu le laisser agir de cette façon totalement insensée $^{113}$ ? En vérité, ce serait une jolie fleur de rhétorique mais pour la chaire seulement ${ }^{114}$. L'historien exige la vérité, ou tout au moins la vraisemblance. Tout cela pourrait encore être écouté s'il s'agissait de dire que Neuser ne connaissait pas les véritables dispositions de l'émissaire de Transylvanie. Le prince de Transylvanie s'étant si longtemps tenu au côté du Turc, Neuser n'aurait pu deviner qu'il s'en détourne soudain. Mais Neuser lui-même réfute cela en écrivant dans sa lettre que les volontés de l'émissaire de Transylvanie étaient très généralement connues, et en mentionnant des endroits et des individus où et auprès de qui il avait pu s'en enquérir ${ }^{\text {e }}{ }^{115}$. D'une manière générale aussi bien, comment $<81>$ le mandat de l'émissaire pouvait-il être un secret pour quiconque, puisqu'il s'en était auparavant ouvert à l'empereur à Prague et que ce mandat, comme l'écrit Isthuanfius ${ }^{\mathrm{f}}$, avait été reçu "vbique a Caesarianis summa laetitiae significatione, quacunque iter [151] fecerit, exquisitisque honoribus ${ }^{116}$ ". Certes celui-ci ajoute à la suite: "Isthic demum ", à Spire où l'émissaire avait dû suivre l'empereur, "Caesar legationis seriem et capita ita discussit, vt eam quam secretissimam esse vellet; nec vllum alium praeterquam Ioannem Trautsonium, aulae suae praefectum, ac Ioannem Baptistam Weberum Iurisconsultum et Romani Imperii Vicecancellarium, ex Vngaris vero Iohannem Listhium Episcopum Besprimiensem et Vngaricum Cancellarium consiliis adhiberet, iisque serio interdiceret, ne ea vllo modo panderentur ${ }^{117}$ ". Il faut toutefois

e. Voir plus haut, p. 139 .

f. Hist. lib. XXIII, p. 157. 
comprendre - aucun doute là-dessus — que cette négociation secrète a porté sur les seules conditions de l'alliance et non sur l'alliance même.

Mais continuons: comment l'électeur palatin est-il censé être tombé sur cette lettre que Neuser aurait si inconsciemment confiée à des mains aussi peu sûres? C'est ce que raconte Alting à la suite du passage cité plus haut: "Quum igitur Maximilianus Imperator sese excusaret Oratori Transyluano de foedere, negaretque cum iis pacisci se posse, qui deitatem Christi, et diuinam Personarum Trinitatem non agnoscerent: atqui, respondit ille, non est quod tantopere abhorreas ab illa fide, quam una nobiscum tenent ac tuentur magni in Imperio Principes, eorumque Theologi. Et cum dicto, vt assertioni suae fidem faceret, depromsit litteras Neuseri ac Syluani, et Caesari in manus tradidit. Is porro resignatas et lectas Friderico III. Palatino Electori communicauit; eumque commotum rei insoli [152] tae indignitate, ne nimium turbaretur monuit; cum ipse in suis ditionibus, quanquam ignarus foueret id genus hominum; in quos tamen detectos secundum leges animaduerti Magistratus $<82>$ esset $^{118}$. " Quelle médiocrité! Oh le pédant empereur! Oh le brave et maladroit émissaire! C'est cela qui aurait dû choquer l'empereur? Par amour de l'orthodoxie, il aurait fallu refuser de s'engager avec un prince qui était prêt à faire pour lui dévolution de son royaume, ou tout au moins à renoncer à son titre et à ses droits sur ce royaume, et qui voulait précisément s'allier avec lui contre son plus épouvantable ennemi? Si Maximilien a réellement eu cette pieuse faiblesse, pourquoi n'en a-t-il pas fait part tout de suite, à Prague? Pourquoi s'est-il épargné un tel scrupule jusqu'à Spire? jusqu'au moment où, comme par hasard, l'émissaire avait en poche la lettre de Neuser? En quoi enfin, dès lors que l'émissaire l'eut informé que des ariens se trouvaient aussi en Allemagne ${ }^{119}$, et même parmi les princes de l'Empire et leurs théologiens, en quoi les ariens de Transylvanie en devenaient-ils meilleurs à ses yeux ? Et comment pouvaient-ils devenir soudain à ce point meilleurs que non seulement il conclut 
le pacte avec joie, mais qu'il promit aussi l'une de ses nièces en mariage au prince hérétique? Et qu'il promit de l'accueillir sur ses terres, au cas où le Turc le chasserait de Transylvanie ${ }^{\mathrm{g}} 120$ ? Était-ce, dans les deux cas, à la condition que le prince de Transylvanie renonçât préalablement à son erreur arienne? L'histoire n'en dit rien. Aussi bien eût-il été [153] difficile de se risquer à faire ne serait-ce qu'une allusion à une exigence aussi grotesque devant l'émissaire. Car qui était donc cet émissaire? C'était, nous le savons, Caspar Bekes ${ }^{121}$, l'ami le plus proche du prince Jean Sigismond, et lui-même arien. Sandius le montre ${ }^{\text {h }}{ }^{122}$, pour le cas où la confiance que le prince lui faisait ne suffirait pas à le prouver. C'est donc à cet homme, arien lui-même, qu'on aurait dit, les yeux dans les yeux, que les ariens n'étaient pas des gens avec qui un honnête chrétien pouvait faire alliance? Arien luimême, il n'aurait trouvé rien d'autre $<83>$ à répondre, sinon qu'il y avait des ariens jusque parmi les princes de l'Empire et leurs théologiens? Arien lui-même, il aurait pu sans scrupule trahir la clandestinité de ses frères allemands devant l'empereur? Il se peut très bien qu'il n'ait pas su qui parmi les princes de l'Empire était arien. En revanche, ce qu'il pouvait et devait savoir, c'est que les théologiens qui lui étaient connus étaient exposés par sa dénonciation à la plus inévitable des persécutions, et que pour l'éviter ces hommes s'étaient précisément adressés à lui. Et même sans tenir compte de cela, les aurait-il sacrifiés sans nécessité, sans bénéfice en vue ? - Celui qui pourra comprendre des choses pareilles comprendra aussi tout ce que les théologiens pourront et voudront bien raconter au cours de l'histoire pour justifier les cruautés qu'ils commettent!

J'ai jusqu'ici admis que la lettre à l'empereur turc que Neuser reconnaît lui-même avoir esquissée est [154] la même que celle qui, nous l'avons dit, se trouve dans les Actes. Je ne nie non plus qu'il en soit ainsi en réalité. Mais je ne peux pas m'abstenir de faire remarquer que l'on aurait des raisons de considérer que

g. Isthuanfius, loc. cit., p. 517.

h. Enucl. Hist. Lib. III. p. 430. 
l'authenticité de cette dernière version n'est pas totalement hors de doute. Ce qui est en tout cas certain, c'est que nous ne l'avons pas dans la langue dans laquelle Neuser l'a rédigée. Neuser l'avait écrite en latin, ainsi qu'on le voit dans le passage qu'il cite lui-même ${ }^{123}$. On ne peut la lire ici qu'en allemand, dans une traduction qu'il semble difficile d'attribuer à l'auteur. De fait, si l'on compare le passage cité avec l'allemand, il apparaît clairement que le traducteur, quel qu'il ait été, ne s'est pas tenu à l'original avec une exactitude excessive. Et ce n'est pourtant là que le plus petit de mes scrupules quant au crédit que l'on peut accorder à cette version allemande qui subsiste. Bien plus important est celui qui se rapporte à un passage de celle-ci que je ne parviens absolument pas à faire concorder avec d'autres données historiques fournies aussi bien par Neuser que par $<84>$ ses ennemis. Neuser dit lui-même dans sa lettre datée de Pâques 1574 qu'il a rédigé sa lettre à l'empereur turc il y a quatre ans ${ }^{\mathrm{i}}{ }^{124}$, c'est-à-dire à Pâques 1570, avant la diète de Spire, à un moment où personne ne le soupçonnait d'arianisme et où aucun danger lié à ce soupçon ne pouvait le pousser à fuir le pays. Ses ennemis eux-mêmes admettent n'avoir eu cette lettre entre les mains que lors de la [155] diète de Spire; eux-mêmes disent que ce n'est qu'au vu de cette lettre, le 15 juillet 1570, qu'a été émis, contre lui et ses compagnons, l'ordre d'emprisonnement auquel il eut la chance d'échapper. Et pourtant dans cette même lettre, telle qu'on la trouve aujourd'hui dans les Actes, il est expressément fait mention de sa première fuite. Comment une chose pareille est-elle possible? Comment Neuser peut-il être contraint à la fuite par une lettre dans laquelle il relate cette fuite? Comment l'effet a-t-il pu précéder sa cause? Ou bien faut-il comprendre qu'il s'agit de sa première fuite, bien que dès le départ il écrive à l'empereur turc ${ }^{j}$ ? " En premier lieu, sa Majesté doit me croire: si c'est chez elle que je cherche asile, ce n'est pas, comme le font certains chrétiens, parce que leurs mauvaises actions - vol,

i. Voir plus haut, p. 137.

j. Dans Struve, p. 230. 
meurtre ou adultère - les empêchent de rester plus longtemps chez eux. Car il y a un an de cela j'avais eu le projet de fuir auprès de vous; j'étais arrivé jusqu'à Presbourg, mais je ne pus aller plus loin, faute de connaître la langue hongroise, et je suis pour cette raison retourné auprès des miens, où j'ai séjourné encore presque une année, ce qui n'aurait pas été possible si j'avais été fugitif à la suite d'un délit, etc. » De quelle fuite s'agitil ? Ni lui ni ses ennemis ne nous avaient dit qu'il avait une fois déjà pris la fuite pour la Hongrie, avant d'être capturé $<85>$ en raison de sa lettre à l'empereur turc. En revanche, cette fuite [156] qu'il mentionne ici à l'empereur et celle dont il parle plus haut dans sa lettre, p. $138^{125}$, se ressemblent tellement qu'il faut tout simplement considérer qu'il s'agit de la même. À partir de là, deux solutions seulement restent envisageables. Soit Neuser a écrit sa lettre à l'empereur turc après son retour volontaire, pendant sa captivité à Amberg. Et pour cette seule raison il ne peut déjà plus être vrai que ce soit à cause de cette lettre qu'il ait été d'emblée incarcéré avec les autres; pas plus qu'il est vrai que l'électeur ait pu la recevoir des mains de l'émissaire de Transylvanie, via l'empereur. Soit Neuser l'a écrite avant son voyage pour Spire, qu'il l'ait ou non confiée à l'émissaire. Dans ce cas la copie, telle qu'on la trouve encore dans les Actes, est un faux, ou elle est à tout le moins interpolée à l'endroit cité, qui se rapporte très visiblement à une époque plus tardive. La première solution ne peut m'apparaître comme la plus vraisemblable, puisque l'indication de Neuser, selon laquelle il aurait écrit la lettre quatre années plus tôt, va contre elle; et parce qu'il dit expressément que le brouillon en a été retrouvé dans son cabinet de travail, parmi ses livres, alors qu'on aurait dû le retrouver en prison s'il l'avait écrit en prison. On retombe donc tout naturellement sur la deuxième solution: c'est là que je voulais en venir. Certes le reste de la lettre ne contient rien que Neuser n'aurait pu réellement écrire. Toutefois le propre des faux est qu'il est plus facile d'y [157] imiter une tournure de pensée que de se prémunir contre toute atteinte aux données de l'histoire. Aussi 
bien je ne soutiens pas que la lettre tout entière ait été inventée. J'affirme seulement que le passage cité ne peut être exact tant que l'on entend croire Neuser et que ses adversaires refusent de se battre avec leurs propres armes. C'est en partie ce que semble avoir déjà $<86>$ ressenti Struve lorsqu'il écrit: "En Transylvanie, où il s'était retiré, Neuser fut également poursuivi par l'empereur et par l'électeur palatin; lorsqu'il ne s'y sentit pas plus en sécurité que dans le reste de la chrétienté, il s'adressa, dans le courrier qui suit, à l'empereur turc ${ }^{126}$. » Ainsi donc selon lui, c'est seulement depuis la Transylvanie que Neuser aurait fait partir à l'attention de l'empereur turc ce courrier à partir duquel on a pris l'habitude de démontrer ses dispositions hostiles envers l'Allemagne et la chrétienté entière, alors même qu'il s'y trouvait encore? N'est-ce donc pas, selon lui, le même courrier que celui que l'émissaire de Transylvanie transmit à l'empereur? N'est-ce donc pas le même courrier que celui qui provoqua la persécution voulue par l'électeur? Pas le même que celui auquel il renvoie dans le récit qui précède, en y voyant le plus grand crime de Neuser? Pas le même que celui que tous les auteurs qui traitent de l'affaire Neuser considèrent comme le même? -

Voilà donc, provisoirement, pour nos deux points. Tous les éléments que j'aurais encore à apporter pour les éclaircir et d'une manière générale pour éclaircir la lettre que j'ai reproduite, on me permettra de les faire tenir, sans ordre ni [158] ornement, dans une série de remarques. Elles seront faites une bonne fois, ces remarques; et quand bien même elles ne devraient pas en elles-mêmes se révéler d'une grande importance, elles pourront toujours épargner à celui qui travaille dans une petite parcelle de ce domaine, tantôt un petit effort, tantôt une petite erreur. Que ne faut-il pas produire de mauvais, dans la discipline historique, avant d'écrire quelque chose de bon!

1. Que Neuser ait fui chez les Turcs et qu'il soit mort chez eux, cela est incontestable et depuis toujours incontesté. Mais que pour autant il se soit lui-même fait turc, qu'il ait embrassé la foi turque selon toutes les formes requises ${ }^{127}$, c'est ce dont 
plusieurs, comme on sait, continuent de douter; c'est le cas de Sandius $^{128}$, Arnold $^{129}$, Gerber ${ }^{130}$ et d'autres. Mais comme Gerber a suivi Arnold, comme Arnold $<87>$ a suivi Sandius, et comme celui-ci se réfère exclusivement à Mart. Ruarus ${ }^{131}$, il me faut à propos de ce dernier relever quelque chose que G. H. Götze ${ }^{\mathrm{k} 132}$, qui a jugé utile de réfuter expressément ces sceptiques, aurait dû relever avant toutes choses. À savoir qu'il n'est pas vrai que Ruarus, vers qui tous en fin de compte ramènent, ait douté du passage formel de Neuser à la religion turque; et que Sandius a mal compris ce qu'il expose. Ruarius en effet écrit à $\operatorname{Calov}^{13}{ }^{133}$ : "Ignosce, Vir clarissime, quod iure tui monendi vtar, quod ipse mibi dedisti, in historico [159] praecipue genere. Eo pertinet et illud, quod Paulus Alciatum perinde atque Neuserum ad Turcas se proripuisse, et eiurata religione Christiana Alcoranum professum, nimium aliorum relationi credens, affirmas; quorum nomina satius fuisset allegare, ne fides tua accusari posset ${ }^{134}$." Que signifie cela? Ruarius veut-il dire que Calov a été injuste envers les deux, Alciatus et Neuser? Pas du tout: il ne le critique qu'au nom du seul Alciatus ${ }^{135}$, dont Calov a affirmé que, tout comme Neuser, "perinde ac Neuserus ${ }^{136}$ ", il serait passé à la religion turque. S'il avait voulu le nier des deux, il aurait plus probablement relié les deux noms par un simple et. Mais puisqu'il emploie la formule "perinde atque $e^{137}$ ", il le concède de Neuser et s'interdit seulement de mettre Alciatus dans la même catégorie que lui. Que telle soit la bonne interprétation, nous le voyons aussi au fait que dans la suite Ruarius ne s'attache qu'à l'apologie d'Alciatus ${ }^{138}$, sans plus avoir le moindre mot pour Neuser. D'Alciatus il assure, à partir de témoignages familiaux crédibles, qu'il serait mort à Danzig; sur Neuser, il lui a fallu avouer qu'il était mort à Constantinople; et qu'auraitil pu avancer pour démontrer qu'il n'y est pas mort turc? S'il fallait absolument $<88>$ objecter quelque chose à cela, le plus plausible serait encore que Neuser lui-même n'en dit rien dans

k. Praef. ad Meletemata Annaebergensia.

I. Epist. Cent. I, 47. 
sa lettre. Il dit seulement ${ }^{\mathrm{m}}{ }^{139}$ : « $\mathrm{A}$ peine le pacha entend-il cela (à savoir sa confession [160] du Coran ${ }^{140}$ ) qu'il dit qu'il veut m'envoyer à l'empereur à Constantinople; c'est là que je suis encore aujourd'hui, auprès du premier truchement de l'empereur, qui est allemand ». Mais devait-il en dire plus? Qui raconterait une comédie qu'il a dû laisser jouer avec lui-même? Pour un homme qui n'est pas totalement dépourvu de sentiment et de pudeur, s'y soumettre coûte les plus grands efforts: quoi d'étonnant qu'il évite toute nouvelle occasion de s'en souvenir? Il est très bien que les religions se soient compliqué le passage au point de rendre difficile à un honnête homme d'aller de l'une à l'autre! On n'aura donc pas le droit de mettre en doute ce que Neuser ne fait ici que taire sur lui-même, dès lors que la chose est confirmée par d'autres personnes crédibles qui ont pu en recueillir l'information sur place.

2. Un mot toutefois de ces personnes crédibles. J'aurais peine à y inclure Michael Heberer ${ }^{\text {n } 141}$, qui ne vint qu'en 1588 à Constantinople, douze ans donc après la mort de Neuser, et qui à la vérité n'a pas eu ses informations de personnes très fiables. Mieux vaudra encore laisser place au baron de Bohême Wenceslas Budowecz von Budowa ${ }^{142}$, qui se trouvait vers 1579 dans la légation romaine impériale à Constantinople ${ }^{143}$. Il n'a donc pas connu Neuser personnellement, ce qui ne l'a pas empêché, quelque trente ans plus tard, d'écrire sur lui les pires choses [161] du monde ${ }^{\circ}$, dont $<89>$ quelques-unes sont visiblement inventées. Le seul auteur pur de reproches est donc Stephan Gerlach, qui fut prédicateur de la légation impériale de Constantinople dans les années 1573-78 et fréquenta beaucoup Neuser ${ }^{144}$. Ce qu'il dit de lui - en partie dans les textes polémiques qui ont été publiés par la suite en Allemagne, en partie dans son journal - est la source principale, à l'aune de laquelle toutes

m. Voir plus haut, p. 133.

n. Dans son Aegyptiaca servitus, imprimée en 1610 à Heidelberg, in-4

o. Voir la Genealogia Socinianorum annexée aux Horologii lunaris et solaris etc. Hanoviae 1616, in- $4^{\circ}$, p. 234. 
les informations doivent être vérifiées; sans oublier cette source elle-même, à vérifier aussi par elle-même. Car les eaux qu'on y puise ne sont pas toutes également pures, notamment dans le journal, dont l'original ne nous a pas été transmis ${ }^{\mathrm{p}}$ : les humeurs variables de l'auteur semblent avoir joué un rôle non négligeable sur ce qu'il a jugé bon de noter à propos de cet homme.

[162] 3. Pour revenir à ce qui précède: bien que ce journal ne dise nulle part explicitement que Neuser s'est fait circoncire et qu'au contraire on y voie Neuser y déclarer à plusieurs endroits ne pas appartenir à la religion turque; bien que Gerlach luimême parle d'un welche devenu turc, mais non circoncis $^{\mathrm{q}}{ }^{145}$; d'autres données attestent indiscutablement que Neuser ne s'en est pas sorti comme cela. Les Turcs lui confiaient par exemple à $<90>$ déchiffrer et à traduire des lettres de l'émissaire impérial qu'ils avaient pu intercepter ${ }^{\mathrm{r}}$, ce qu'ils auraient difficilement pu faire s'ils n'avaient eu toutes les raisons de le considérer comme l'un des leurs. Gerlach n'a pas douté une minute de la circoncision de Neuser: je peux encore le prouver à partir d'une de ses lettres conservées dans notre bibliothèque. Cette lettre a été écrite de Constantinople le 11 octobre 1573 au Dr Heerbrand de Tübingen ${ }^{146}$. Je veux à plus d'un titre faire entrer en ligne de compte le passage qui concerne Neuser. — "Memini adbuc, ornatissime Vir, R. V. D. mihi mandasse, vt de Adamo Neusero, quondam pastore Heidelbergensi, inquirerem. Comperi autem a ludi rectore Gommorensi (cui familiaris fuit) quod Neuserus solum, vt dicitur, vertens, Gomorram peruenerit, ibique se in dolium cum aliis multis Budam transferendum includi curauerit, verum cuiusdam mercatoris proditione latere [163] non potuisse.

p. Ce n'est qu'en 1674 qu'un petit-fils de l'auteur en a révélé l'existence au public, à partir de ses papiers manuscrits. Bien qu'il n'ait pas indiqué que ces papiers avaient été rédigés en latin et qu'il ne faisait donc que livrer une traduction, on en trouvera suffisamment de traces dans le texte même ; des traces qui démontrent qu'il s'agit non seulement d'une traduction, mais malheureusement aussi d'une très misérable traduction. Une copie de l'original latin se trouvait entre les mains de Joh.[ann] Pet.[er] Ludewig. Elle a été utilisée par Heineccius (cf. annexe de l'Abbildung der griechischen Kirche, p. 16).

q. Journal, p. 80.

r. Ibid., p. 175. 
Hac fraude detecta, aliam comminiscitur, et habitum Vngaricum assumens totum se more Turcarum radi voluit, vt tutius et securius inter Budense ingredi possit. Sed ne hoc quidem cessit ei consilium. Nam ad supremum Capitaneum castrorum Gomorrensium D. Kielmannum Greppingensem tanquam transfuga et explorator delatus, in vincula coniectus est. Ex quibus tandem, precibus dicti ludi moderatoris aliorumque, hominis vesaniam, ex assiduis studiis et lucubrationibus contractam, mentientium, liberatus, per Poloniam Septem castra adiit, indeque comitem assumens (vt audio, virum doctum) ante annum Constantinopolin venit, mox cum comite infausto circumcises, non Mophti i. e. Turcarum patriarcha aut Papa, sed Spachii factus est ${ }^{147}$." D'un curé, on avait fait un cavalier solitaire! "Sunt enim Spachii Turcici Imperatoris gregarii equites. Sed tantum stipendii non habet, $v$ t equum alere possit. Vitam agit miseram et contemptam. Socios habet Germanos quosdam in bello captos, cum his quotidie fere in tabernis et tonsdrina quadam potat; profana et obscena, non < $91>$ numquam de masculorum (salva R.V.) concubitu (qui in Turcia vsitatissimus est), tractat: a suis sceleratus Pfaffus et transfuga quouis supplicio dignus audit, quod abiurata religione nostra ad Turcas sponte transierit; regerit ille conuitia, sicque tempus fallunt. Sed nec ipsum interim terrores et pugnae (illae foris et a conterraneis) desistunt. Nam a familiaribus ipius intelligo, quod pessima conscientia vtatur: attonitus et meditabun[164]dus assideat: subinde ingemiscat vocesque desperationis plenas interdum edat, quod nimirum maiestatem Dei scrutans in hunc errorem et tenebrarum gurgitem demersus sit. Mox rursum se colligens, blasphemiis et mendaciis religionem nostram incessit. Nunquam tamen manifestis verbis Turcicam probare visus est. Et cum ipsi a sociis (nam hic religio omnis libera est) Apostasia obiicitur, non se fidem mutasse, sed pristinam adhuc in corde alere, respondet. Circumcisioni vero exemplo, nescio corde populorum, a Diuo Matthaeo conuersorum, patrocinatur, qui antiquitus et baptismum et circumcisionem retinerent. Omnem pecuniam, quam secum 
ex Germania et Transyluania abstulit, Constantinopoli amisit, eamque per Magos recuperare frustra tentauit. Ita miser homo a Satana vbique deluditur. Nouis rebus et magicis artibus ipsum studere familiares perbibent. Primo Octobris colloquium meum per tonsorem quendam Germanicum petiit, sed quia concioni opera danda erat, conuentum in aliud tempus distuli. Vxorem iam ducere cogitat, interpretis nostri vicinam, sed quia nummis, quos vnice spectant Turcae, non turget, metuo ne nuptiis istis excidat. Sed plus satis de isto ${ }^{148}$. $»-$ Le sophisme de la circoncision ne peut pas avoir été une invention des abrutis dépravés qui tenaient compagnie à Neuser; il n'a pas non plus été une invention de Gerlach, qui reconnaît lui-même que les faits qui le justifient lui sont inconnus. On peut donc raisonnablement estimer qu'il vient de Neuser lui-même et qu'il démontre plus que toute autre chose que l'opération que Neuser a voulu enjoliver par ce sophisme a réellement été [165] pratiquée sur lui. Ce sont les chrétiens d'Éthiopie qui, comme chacun le sait désormais, $<92>$ ont les deux choses, circoncision et baptême. Neuser en a sans aucun doute eu connaissance parmi les Grecs ${ }^{149}$. L'ignorance de Gerlach sur ce point montre que la chose semblait encore totalement incroyable dans l'Allemagne de l'époque. Du reste, je note que ce n'est qu'en 1574 que nos compatriotes ont pris connaissance de la Confession de foi éthiopienne, telle que transmise en 1534 par Zaga Zabo au Portugal ${ }^{150}$. — Sur le reste du passage cité, voir plus bas.

4. L'authenticité de la lettre de Neuser n'est pas peu renforcée par le fait que son contenu concorde parfaitement avec le récit que Neuser avait déjà fait oralement de ses destinées à Gerlach. On ne raconte pas des contre-vérités avec autant de cohérence. Voyons ce récit dans Wolf ${ }^{\mathrm{s}}{ }^{151}$, ainsi que dans le journal de Gerlach, à la date du 21 octobre $1573^{152}$. Lorsque par exemple dans notre lettre il déclare qu'il est volontairement retourné en Palatinat, il dit ici la même chose, "sponte in Palatinum reuersus ${ }^{153}$ ".

s. Lect. Memorab. Centenario XVI. p. 901. Wolf l'aura emprunté à I'Antidanaeus de Gerlach, où je n'en ai cependant trouvé (p. 35) que la dernière section. 
Lorsqu'il dit dans la lettre qu'il est entré en conflit avec les prédicateurs de Clausenbourg, il le dit également ici, sauf que j'ai l'impression de voir plus nettement encore quels étaient les points disputés. Il s'agit d'articles de foi à propos desquels l'audacieux [166] unitarien, fidèle à ses principes, va beaucoup plus loin que le socinien à proprement parler, lequel n'est ni froid ni chaud et qui, sans qu'on sache pourquoi, aimerait bien conserver le nom d'une religion dont il anéantit pourtant la vie intérieure ${ }^{154}$. "Dum ibi haereo », c'est-à-dire à Clausenbourg, "inter Fratres Poloniae et Transyluaniae disputatur de articulo Instificationis: et res eo deducitur, quod Christus sua morte et passione genus humanum non redemerit, nec illud suo sanguine justificare et saluare possit, siquidem nudus homo sit ${ }^{155}$ ", etc. On devine facilement de quel côté Neuser a été dans cette querelle: du côté de Franciscus David < 93 > à n'en pas douter, lui dont, à ce qu'il me semble, on ne répétera jamais assez ni assez fort par les temps qui sont les nôtres que lui-même finit par devenir le persécuteur ${ }^{156}$. Tant il est vrai que les sectaires, pour le peu qu'ils croient encore, peuvent à l'occasion, envers ceux qui refusent de croire ce "peu ", être aussi enclins à l'intolérance que le plus superstitieux des orthodoxes peut l'être envers eux. Dans notre lettre, Neuser raconte qu'il n'a jamais eu la moindre intention de se convertir à la religion turque en partant pour la Hongrie, mais simplement celle d'y publier une réfutation de ses adversaires, ou toute autre chose utile, et que seule une nécessité majeure, celle de ne pas aussi se retrouver persécuté par les Turcs, l'a poussé à franchir le pas ultime ${ }^{157}$. Ici, il ne raconte rien d'autre. "Haec ", dit-il à propos des controverses mentionnées plus haut, "cum agitarentur, et ego quaedam de vno vero Deo contra Trinitatem publicare constituerem, eiusque gratia in [167] vicum quendam nobilem Turciae patrocinio gaudentem, ad Typographum ibi commorantem profectus essem, Bassae Themeswarensi proditus fui, qui me Constantinopolim misit nibil reluctantem, sed potius de eo gratulantem mibi ipsi: quod Alcoranum a veritate non alienum esse, et in omnibus 
capitibus religionis mecum sentire cognonissem ${ }^{158}$ ", etc. $\mathrm{La}$ seule différence porte sur la lettre à l'empereur, sur laquelle il est si prolixe dans sa lettre et dont il ne dit rien ici, probablement parce que l'accusation à laquelle elle a donné lieu ne lui était pas encore revenue aux oreilles et parce qu'il n'en avait pas été question pendant sa captivité. Mais si tel est le cas, alors cette lettre n'a été découverte qu'après sa fuite d'Amberg; ce qui souligne une nouvelle fois la fausseté de l'affirmation selon laquelle l'empereur l'aurait reçue de l'émissaire de Transylvanie. Certes Neuser n'oublie pas complètement l'empereur, lorsqu'il écrit ici: "Hoc ", c'est-à-dire ses dispositions ariennes, "cum in comitiis Spirensibus de me et Syluano Imperatori Maximiliano, et per eum meo Principi innotuis < 94 > set, fuga mibi consu$l u i^{159}$. » Faut-il pour autant que l'empereur en ait eu révélation par l'émissaire de Transylvanie en personne? Faut-il que ce soit par la lettre à l'empereur turc qu'il ait découvert de quel genre d'esprit Neuser était l'engeance? Neuser lui-même reconnaît qu'il a rendu visite à l'émissaire de Transylvanie à Spire avec ses amis. Et si l'empereur, ayant eu vent de cette information, avait cherché à savoir, par pur soupçon - celui qu'on a envers tous les émissaires étrangers —, ce qu'il en était de [168] cette visite? Et si donc il avait fait saisir les lettres parvenues à l'émissaire? Et si par conséquent le secret n'avait été trahi à l'empereur que par cette saisie des lettres de Neuser à l'émissaire? Cette hypothèse est tellement vraisemblable qu'on ne s'étonnera pas de voir Sandius la tenir pour vraie ${ }^{t}$, et de le voir citer la lettre de Neuser " ad illustrem Dn. Bekesium, Ioannis Sigismundi Transyluaniae Principis Legatum ad Maximilianum II. Imperatorem ${ }^{160}$ ", à l'époque encore disponible sous sa forme manuscrite, avec cet ajout: "qua epistola Caesar intercepta, procuranit, vt Neuserus cum Syluano in vincula coniiceretur ${ }^{161}{ }$. La date de 1571 indiquée par Sandius est une coquille, et cela peut se comprendre. Mais on comprend de la même façon que là où il y a coquille, il ne peut y avoir en même temps mensonge. Il est certain qu'une

$\overline{\text { t. Biblioth. Antitrini. p. } 61 .}$ 
lettre de Neuser à Békés a été saisie. Mais est-ce l'empereur qui l'a saisie? C'est une autre question. Car n'aurait-il pas été facile à l'électeur palatin de la saisir? À lui moins qu'à tout autre, le voyage de Neuser n'avait pu rester caché. Auprès de lui, Neuser n'avait de toute façon déjà pas le bon signalement. Neuser avait déjà à plusieurs reprises sollicité de lui de pouvoir partir. Quoi d'étonnant alors à ce qu'il ait d'emblée soupçonné le pire de cet homme et qu'il ait cherché à accéder à ses lettres? Et une fois celles-ci entre ses mains, pourquoi n'aurait-il pas pu $<95>$ affirmer les avoir reçues de l'empereur, afin de dissimuler l'intensité et la profondeur de [169] ses recherches? Neuser le dit bien: il avait toujours entendu dire en prison que ce qu'on lui faisait, on le faisait au nom de l'empereur ${ }^{162}$. Qu'il ait lui-même fini par le croire: est-ce vrai pour autant? N'est-il pas plutôt toujours hautement invraisemblable que l'empereur se soit rendu coupable d'un comportement si contradictoire en faisant d'un côté durement poursuivre une poignée de malheureux ecclésiastiques dont il avait découvert l'arianisme d'une façon discutable et en cherchant d'autre part à faire alliance et à entrer dans un lien de parenté avec un arien déclaré ? Pourquoi c'est bien plutôt l'électeur que je crois capable d'un subterfuge, la raison en sera dite plus tard ${ }^{163}$.

5. Lorsque les Actes dont il a été plusieurs fois question parurent pour la première fois, avec la lettre de Neuser à l'empereur turc, dans les Monumenta Palatina en $1701^{164}$, les éditeurs réformés ne purent se retenir dans leur préface de quelques piques contre les théologiens luthériens, lesquels, certes à tort, avaient voulu attribuer l'apostasie de Neuser à son calvinisme et avaient jugé trop dure la condamnation de Syl$\operatorname{van}^{165}$. "Bene est ", ajoutent-ils, " quod saltem nil in gratiam Neuseri scripserint, qui ebrius abiit in locum suum, et cuius Epistola, quam publicamus, et notae, quas Alcorani sui margini alleuit, quasque penes nos asseruamus, qualis fuerit indicant. Sed nec in Syluano supplicio furor erga errantes (Wüterei gegen die Irrenden) exercebatur, siquidem ille aeque ac Neuserus 
cum Turcis commercium [170] habuit, et blasphemiae eius tam horrendae fuerint, $v$ t priores esse non potuerint ${ }^{166}$. " Pour autant, on le voit, je ne me laisse pas détourner de faire toujours ce que ces Messieurs pensaient si bon de n'avoir jamais fait. "Bene est, quod saltem nil in gratiam Neuseri scripserint ${ }^{167}$ ! " "Bene"? Je dis qu'il est grave qu'une telle chose ne soit pas arrivée! Grave d'être le premier, au bout de deux cents ans, à faire entendre la voix d'un malheureux devant la postérité! Un malheureux qu'à force de poursuites on a $<96>$ chassé de la chrétienté! Ou bien, s'il était en tort, qui s'en est laissé chasser: a-t-il pour autant tort en tout? Ses persécuteurs ont-ils eu pour autant contre lui, je ne veux pas dire: partie gagnée - celle-là, ils l'avaient, hélas! - , mais en tout les cas beau jeu, jeu honnête, au prétexte de l'avoir finalement amené à franchir un pas assurément indéfendable? Si la fin doit être l'âme de l'histoire, si par elle doit être jugé tout ce qui est venu avant, alors il serait aussi bien de n'avoir pas d'histoire du tout. Suffit-il de faire imprimer les réflexions assoiffées de sang de théologiens hargneux à côté d'une lettre nulle et non avenue, le tout sous le titre d'Actes, et cela contre un condamné, de façon à débouter d'avance et pour toujours ses défenseurs? La meilleure pièce qui manque à ces Actes, l'interrogatoire, c'est-à-dire les déclarations des accusés eux-mêmes, est dans une certaine mesure remplacée par la lettre de Neuser; et à présent, je demande la révision du procès. Cette lettre au Turc pourrait être aussi vraie qu'on voudra, et même au mot près authentique; elle pourrait n'avoir été ni raturée, ni reniée par son auteur; elle pourrait avoir été vraiment envoyée [171] par lui et contenir autant de crimes civils qu'on voudra: en quoi la lettre d'un autre homme concernerait-elle Sylvan? L'avait-il signée? Pas du tout. Il assure n'en rien savoir; et il meurt. Neuser aussi assure que Sylvan ne l'a pas plus lue que quiconque au monde; il ne se fait pas faute de l'écrire par deux fois, de Pologne, à l'électeur à Heidelberg ${ }^{168}$. Rien n'indique ce qui pourrait faire que Sylvan soit convaincu du contraire. Et pourtant! Et pourtant: ne sommes-nous pas en droit de dire 
que l'exécution de ce dernier releva purement et simplement de la rage contre les égarés ${ }^{169}$ ?

6. Une autre preuve invincible que cette exécution n'a rien été d'autre que cela a été donnée par un homme qu'on ne pourra pas soupçonner d'avoir voulu favoriser un antitrinitaire; et il l'a donnée dans un texte qui ne vise à rien moins qu'à louer ce parti : $<97>$ je veux parler d'E. S. Cyprian, dans sa dissertation De Mortibus Socinianorum ${ }^{\mathrm{u}}{ }^{170}$. Au neuvième chapitre, qui traite en particulier de Sylvan, il dit de lui: "An et perduellonis conuictus sit, quod volunt Pareus, Altingius, Hoornbeckius, Spanhemius et Reformati communiter, valde dubium est. Mibi ob solam doctrinam et in Christum dicteria interemtus videtur. Habeo autem huius meae sententiae longe firmissimum argumentum, quod nulla arte elusum iri [172] existimo. Nimirum, forte et melior consiliariorum pars noluit eum capitali supplicio affectum, quare ipsemet elector sententiam ferre coactus est, vt supra ex Altingio percepimus. At si Syluanus criminis laesae maiestatis convictus fuisset, consiliarii mortis sententiam sine omni circuitione in eum tulissent. Deinde adeo non est probatu, Syluano cum Turcis literarum commercium fuisse, $v t$ id ne dicere audeant Reformati ${ }^{171}$. " L'argument a sa justesse. Toutefois Cyprian - ou plutôt Alting, qu'il suit ici — n'est pas assez précis pour indiquer exactement entre qui et qui il y a eu désaccord au sujet de la peine à infliger à Sylvan. Ce désaccord n'a pas tant opposé les conseillers de l'électeur (encore qu'entre eux aussi il ait existé) que les conseillers aux théologiens. Les théologiens voulaient du sang et encore du sang. Les conseillers politiques au contraire se prononçaient en grande majorité pour une peine plus clémente. Tout cela ressemblerait beaucoup à de la calomnie contre les théologiens si l'électeur ne l'avait pas lui-même déclaré dans sa lettre à l'électeur Frédéric de Saxe. "Après que j'eus, écrit-il", consulté à la fois mes théologiens et mes conseillers [173] politiques sur la peine à infliger à ce

u. On la trouvera parmi ses Dissertationes varii argumenti, éditées par Fischer.

v. Dans Struve, p. 228. 
blasphémateur, une partie, à savoir les théologiens, conclurent leur délibération en disant non seulement que de tels blasphèmes devaient être châtiés en toute rigueur, capitaliter ${ }^{172}$, mais que $<98>$ du point de vue politique aussi il s'était rendu coupable, au point de lui mériter une sévère peine corporelle. Mes conseillers politiques au contraire avaient en majorité délibéré que le droit impérial permettait de réduire cette peine, et quod Ecclesia non claudat gremium redeuntibus ${ }^{173}$, etc. ". - Par malchance pour eux, la délibération des théologiens existe toujours: à elle seule, comme on l'a vu ${ }^{174}$, elle constitue la quasi-totalité de nos Actes. Et quelle délibération! À faire se dresser les cheveux sur la tête de n'importe qui, cette délibération! Depuis qu'il existe dans ce monde des procès pour hérésie, jamais il n'en est sorti un texte aussi sophistique et aussi cruel! Car que peut-il y avoir de plus sophistique que de statuer en permanence sur le seul motif du blasphème? Comme si les accusés avaient reconnu ce blasphème! Comme si les accusés ne leur avaient pas plutôt retourné cette accusation! Comme si les accusés, s'ils en avaient eu le pouvoir, n'eussent pas plutôt réclamé leur tête pour ce motif même! Et que peut-il y avoir de plus cruel que de refuser de se laisser fléchir par l'expression d'un repentir ou la promesse de s'amender ? Étaient-ils des hommes, ceux qui pouvaient écrire ${ }^{\mathrm{w}}$ : "Car ils (ces hommes épouvantables qui confessent le Dieu seulement un et non trine) promettent de s'amender au moment même où ils font leurs aveux. Il faudrait leur souhaiter que Dieu veuille bien leur accorder une conversion sincère. Mais de même qu'il dépend de Dieu seul de faire miséricorde à qui il veut faire miséricorde, il convient que l'homme qui a expressément prescrit et ordonné ces jugements contre eux les exécute avec fermeté $^{175}$. » Par conséquent, coupez-leur d'abord [174] la tête, et pour ce qui est de s'amender, on verra après, si Dieu veut! Quel bonheur que les temps soient révolus où des dispositions pareilles étaient appelées religion et piété! Ou du moins qu'ils soient révolus sous nos cieux! Mais quelle pensée humiliante

$\overline{\text { w. Dans Struve, p. } 223 .}$ 
que d'imaginer < 99 > qu'ils puissent un jour revenir sous ces mêmes cieux!

7. Toutefois, dans la lettre que j'ai citée, l'électeur Frédéric ne sollicite l'électeur de Saxe qu'en vue d'une délibération de ses conseillers politiques, et il s'interdit de le faire pour une délibération de ses théologiens, au motif qu' "elle aurait, comme les siens, sans doute conclu en faveur du droit divin ${ }^{176}$ ». On peut affirmer avec certitude que, sans doute, ce "sans doute » aurait alors abouti à tout autre chose, et que si l'électeur considère ici comme acquis quelque chose qui était tout sauf acquis, c'est parce qu'il voulait éviter de s'exposer de ce côté-là à de nouvelles objections, dans une affaire où, selon toute apparence, il avait depuis longtemps pris sa décision. Car il était impossible que des théologiens luthériens acceptent le principe genevois qui impose de punir de mort tout ce que la loi de Moïse ordonne de punir de mort; c'est là-dessus qu'est construite toute la délibération des Heidelbergeois. Quelle direction la délibération des conseillers saxons a prise, on ne peut certes pas le dire avec une parfaite certitude, puisque cette délibération n'a jamais été rendue publique. Il est néanmoins [175] probable qu'elle ait concordé en grande partie avec la délibération des conseillers palatins, car sinon l'électeur s'y serait référé et il n'aurait pas été obligé de se présenter comme s'il rendait une sentence prise selon son seul bon vouloir, avec cet étonnant ajout, "il croit aussi avoir à son côté le Saint-Esprit, qui dans cette affaire est un maître et professeur de vérité177 ». "Elector autem ", écrit Alting, "cunctantibus et haerentibus Conciliariis, ne iretur in infinitum, et sua manu sententiam conscripsit (cui hoc epiphonema subiunxerat, putare se, quod et ipse Spiritum Sanctum habeat, hac in parte magistrum et doctorem veritatis), eamque die 11. Aprilis 1572 octo mensibus ante quam executioni mandaretur, Consiliariis suis communicauit ${ }^{178}$." Si ce furent là vraiment les paroles de l'électeur, alors on y trouvera la raison que je promettais tout à l'heure pour expliquer pourquoi je crois qu'il ne s'est pas estimé au-dessus d'un recours à de petits subterfuges. $<100>$ Car 
y a-t-il subterfuge plus éclatant que cette invocation de l'Esprit saint, que lui aussi veut avoir? Qui s'était opposé à lui, sinon ses conseillers politiques, lesquels très probablement ne se réclamaient pas de l'inspiration immédiate du Saint-Esprit? À leur Saint-Esprit il aurait eu besoin d'opposer le sien? Ceux qui se targuaient de l'illumination du Saint-Esprit étaient déjà de son avis; ou plutôt lui du leur. Quel Saint-Esprit avait-il donc lui aussi, sinon celui qui soufflait depuis Genève ${ }^{179}$ ?

8. Je reviens à notre Neuser. Cyprian fait, à son sujet aussi, quelques bonnes remarques, et il est loin de prendre pour vérités établies tout ce que ses adversaires ont pu lui [176] attribuer. "Datae porro ad Selimum II Neuseri literae, de quibus non satis exploratum habeo, num consilia subuertendi imperii Romani suggesserint, quae procul dubio risu a Turcis fuissent excepta $^{180}$. "Cyprian n'avait pas encore lu la lettre de Neuser, telle qu'elle figure dans les Actes. Il déclare même plus loin qu'il pense que cette lettre n'a jamais été rendue publique. Pourtant sa dissertation n'a été publiée qu'en 1703, deux ans après la parution de la lettre dans les Monumenta Palatina ${ }^{181}$. Se peut-il qu'il n'ait pas connu ces Monumenta? Il ne les connaissait que trop, puisqu'il cite l'Hist. Eccl. Palat. d'Alting, qui y était parue d'abord elle aussi ${ }^{182}$. C'est là un mystère pour moi, je l'avoue. À moins qu'il n'ait considéré, comme plus tard Struve, que la lettre qu'on trouve dans les Monumenta constitue un courrier plus tardif, que Neuser aurait écrit à l'empereur turc depuis la Transylvanie et qui serait donc sans rapport avec la plainte engagée contre lui? Dans ce cas, j'imagine qu'il se serait exprimé plus clairement à son sujet. Quoi qu'il en soit, il ne la connaissait pas ou ne voulait pas la connaître. Il écrit encore: "Scripsit ad Turcarum Imperatorem Neuserus, fateor, sed quia literae, quod ego sciam, nunquam publici iuris factae sunt, incertum est, num suffecerint probando perduellionis proposito. Quid si Neuserus hoc solum scripserit, se ex cinitate sua in Turciam migraturum, vbi loqui < $101>$ liberius liceret. Sane id scribi non vetat ius naturae, ceu Grotius docuit secundo de iure belli, capite V. $\mathbb{S} 24$. 
Dicamus autem, iure ciuili id interdictum fuisse; num [177] quid sola voluntatis transeundi significatio illico capitale supplicium meruerit? Et contineant tandem Neuseri literae perduellionis indicia; quid hoc ad Syluanus ${ }^{183}$ ? " Difficile de juger de façon plus clémente la lettre de Neuser sans l'avoir lue. Et ce jugement était des plus plausibles: car quels conseils un misérable prédicateur de Heidelberg pouvait-il bien donner à l'empereur turc? Mais même sans cela, il est néanmoins possible de juger cette lettre plus sévèrement après l'avoir lue, en considérant que la version qu'on en lit dans les Actes est parfaitement authentique. Certes Neuser en dit ceci ${ }^{184}$ : "C'est en suivant le propositum Pauli, et absolument pas pour blesser quiconque, ni juif, ni païen, ni chrétien, ni Turc, Dieu m'est témoin, que j'ai écrit la lettre. "Il n'en reste pas moins que plusieurs passages semblent très clairement viser à blesser les chrétiens. Comme celui-ci: "Par conséquent, si Sa Majesté voulait mener les chrétiens idolâtres à la connaissance du Dieu unique, étendre Son Empire et répandre la gloire du Dieu unique dans le monde entier, le temps est venu de le faire, car les curés et prédicateurs chrétiens sont divisés, les peuple des simples commence à douter de sa foi, les évêques et les autorités pressurent et oppriment les pauvres gens si durement que ceux-ci souhaitent ouvertement l'arrivée de Sa Majesté, qui permettra à Sa Majesté de prendre possession de l'Empire allemand et d'affranchir les pauvres ${ }^{185}$. » - Plus loin: "Ce qu'il est nécessaire de savoir sur l'état des [178] chrétiens, j'en ferai, si Dieu le permet, oralement le rapport à Sa Majesté $^{186}$. »- Ces passages, si, comme je le disais, ils ne sont pas interpolés, entreront difficilement sous la protection de Grotius qui, à l'endroit que j'ai cité, se contente de $<102>$ reconnaître qu'il est de droit pour les sujets de choisir d'échanger contre un autre État l'État dans lequel il ne leur convient plus de vivre ${ }^{187}$. En revanche, que l'État en question puisse être un État ennemi de celui dont ils veulent émigrer, et que cette émigration puisse se faire dans l'intention de porter assistance à l'État ennemi,

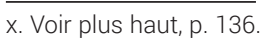


Grotius est bien loin de l'affirmer. Aussi bien ne s'agit-il pas de justifier Neuser sur ce point. Il se peut bien qu'il y ait dans sa lettre autant de haute trahison qu'une lettre peut en contenir! Peu importe: il n'a l'a pas envoyée et, après mûre réflexion, il l'a lui-même condamnée. C'est cela que ses adversaires nous ont tu, en voulant nous convaincre du contraire.

9. Même Leibniz, qui avait tout lu, devait n'avoir pas encore lu la lettre de Neuser au Turc dans la version des Actes, lorsqu'il écrit à La Croze ${ }^{188}$ : " C'est un bonheur pour le Christianisme que les Turcs n'ayent pas eu l'esprit de profiter des avis des gens faits comme Adam Neuser, ministre du Palatinat, qui vouloit établir une intelligence entre eux et les Chretiens Anti-Trinitaires ${ }^{189}$. " Car à en [179] juger par cette lettre, le projet de Neuser n'allait pas aussi loin. Il a voulu se jeter dans les bras du Turc avec femme et enfants; il a demandé à l'empereur de l'accueillir parmi ses sujets; a juré, comme tout nouveau sujet, de l'assister en paroles et en actes dans son combat contre les chrétiens; il a assuré qu'il y avait parmi les chrétiens des hommes disposés comme lui, en nombre suffisant pour se ranger du côté de l'empereur aussitôt que celui-ci paraîtrait en Allemagne avec son armée. Mais de là à penser qu'il a souhaité mettre en place une entente en bonne et due forme entre ces hommes et les Turcs, qu'il leur a ouvert de réelles perspectives à ce sujet et que les Turcs n'ont juste pas été assez intelligents pour exploiter ces ouvertures: rien, pas plus cette lettre qu'autre chose, ne permettra de le montrer. Comme à Cyprian, il m'apparaît à moi aussi très vraisemblable que des ouvertures de ce genre, $<103>$ faites par un curé inconnu du fin fond de l'Allemagne, n'étaient vouées qu'à s'attirer le sarcasme et le mépris, quand bien même il eût été possible de les porter à la connaissance du Divan ${ }^{190}$. - Plus tard encore (1716), Leibniz écrit quelque part: "Autrefois un certain Adam Neuser, qui de ministre réformé s'étoit rendu Turc, avoit aussi eu la pensée de cabaler dans la Chrétienté en faveur des Turcs. Il est sûr que les Turcs y trouveroient des partisans, s'ils agissoient d'une manière moins barbare; car les Sociniens, 
les Anabaptistes et les Fanatiques pourroient leur être favorables ${ }^{191}$. " Si le premier point est certain, il n'est, tout aussi certainement, jamais venu à l'esprit de Neuser de comploter contre la chrétienté. [180] Il ne cherchait rien d'autre qu'à s'en sortir de la meilleure manière. Si Leibniz n’a pas été abusé par son propre génie, celui qui lui faisait penser toutes choses dans leurs dimensions les plus vastes, en voyant des plans et des intentions partout où il y en a (et où il peut y en avoir), il faut penser qu'il a déduit l'idée qu'il se faisait de Neuser de la sévérité dont on avait fait preuve envers ses compagnons. Il avait peine à mettre cette sévérité en rapport avec la simple intention de fuir chez les Turcs, et a donc complété les raisons qui apparaissaient à son imagination par des faits réels, pensant, selon son habitude, de façon très concise, sinon tout à fait exacte.

10. Mon intention n'est en rien de blâmer toutes les petites erreurs que les uns et les autres ont pu commettre en relatant les destinées de Neuser. Je ne dis donc par exemple rien du fait que Lauterbach fait de Jean Sigismond - celui qui a envoyé son émissaire à Spire en 1570 - un Báthory ${ }^{\text {y }}{ }^{192}$; et tant d'autres inexactitudes qu'il recopie, ou commet le premier. Il n'y en a qu'une que je ne peux me retenir de relever, même si elle n'est pas du tout à mettre au compte de cet auteur: celle qui $<104>$ en permanence pousse à faire de Neuser un socinien. Si l'on fait cela dans l'intention de rendre les sociniens plus détestables encore, alors c'est de la méchanceté. Si c'est tout simplement pour indiquer de qui l'on estime que [181] Neuser fut l'élève et le disciple, c'est de l'ignorance. Car ce qui est certain, c'est que Neuser était mort depuis longtemps lorsque Faust Socin commença à se rendre célèbre; et rien n'avait été publié des écrits de Lélius ${ }^{193}$. La concordance de leurs doctrines ne permet absolument pas de justifier cette appellation. Les sociniens protestent contre elle, et ils ont raison de se plaindre de ce qu'on mette sous ce nom toutes les variantes des unitariens; de

y. Voir son Polnischer Arianischer Socinianismus, 1728 , in-8 ${ }^{\circ}$. 
la même façon qu'il y en a quelques-uns parmi ces derniers qui refusent qu'on les affuble du nom de sociniens.

11. Il faut toutefois que j'indique en particulier ce que Samuel Crell dit de ce point, car il contient une donnée très importante au sujet de Neuser ${ }^{194}$. "Iam vero scis ", écrit-il à La Croze ${ }^{\mathrm{z}}$, "me Socinum, qua Socinus fuit, id est, ab aliis diversa excogitauit, plane deserere. In dogmate de vno Deo Patre constanter persisto. Quoad alia diuersarum partium orthodoxis communia, cum orthodoxis sentio, aut ad eos propius accedo. Mahometis doctrinam non ego tantum, verum etiam qui Socinum stricte sequebantur, semper sunt detestati et abominati. Nec video, quomodo ii, qui Christum non prophetam solummodo aliis excellentiorem, sed dominum coeli et terrae, Deo patri, quantum fieri potest, coniunctum, imperiique eius reapse participem, credunt, magis quam alii Christiani Mahometismo obnoxii fieri possint. Fateor, illa Vnitariorum monstra, quae Chri[182]stum invocandum inficiantur, aut tantum pro propheta fere in regno demum millenario regnaturo habent, facilius eo insaniae delabi posse. Parente, inquam: Franciscus enim Dauidis eo adhuc tempore, quo cum Georgio Blandrata < $105>$ Georgium Maiorem professorem Wittenbergensem refutabat, dominum Iesum inuocandum esse statuebat, vt ex isto opere non vno iudicio contat. Neuserus vero non obscure sibi dogmatis huius intentionem adscribit, adeoque etiam Franciscum illum seduxisse videtur ${ }^{195}$." Cela a très certainement été l'opinion de Neuser: aucune prière ni invocation n'est due au Christ, à qui il contestait la divinité. Car dès lors qu'il sacrifiait la divinité de l'Écriture, en plaçant l'Alcoran à son côté, et dès lors que de ce côté-là plus aucune difficulté exégétique ne pouvait le retenir, qu'est-ce qui pouvait le retenir de faire ce second pas, que toute saine raison exige de faire aussitôt qu'on a fait le premier? "Il n'est pas Dieu ", " il n'a pas à être invoqué " sont pour la raison des propositions identiques. Tout cela, concernant Neuser, est certain, je le dis. Qu'il ait en revanche été le premier à avoir donné à sa doctrine

z. Thes. Epist. Lacroziani T. I. p. 111. 
cette extension naturelle et nécessaire, qu'il ait entraîné Franciscus David vers la même position, et qu'il se soit clairement targué d'être l'inventeur de cette position, c'est ce dont je doute et dont j'aurais souhaité que Samuel Crell l'eût non seulement affirmé, mais aussi démontré. Je n'ai pas encore eu l'occasion de regarder dans l'ouvrage de Fr. David [183] contre Georg Major ce qui est dit de l'invocation du Christ ${ }^{196}$. Très vraisemblablement il ne s'y sera pas autrement exprimé qu'il ne l'avait fait en 1568 lors du colloque de Weissenburg ${ }^{197}$. À ce moment, je le sais, sa position était déjà celle qu'il est censé n'avoir reçue que de Neuser. En effet, s'il ne rejetait pas expressément l'invocation du Christ, tout son propos allait dans ce sens, dès lors qu'il affirmait qu'une invocation était due au Christ, mais pas la même que celle qui est réservée au Père. Il lui concédait donc une invocation de la même manière qu'il lui concédait une divinité, c'est-à-dire qu'il lui concédait une invocation qui n'en était pas une aa ${ }^{198}$. Avec le temps, il ne fit que s'exprimer de manière plus aride sur cette question. $<106>$ Cela a tenu, non pas du tout à la capacité d'entraînement de Neuser, mais uniquement aux contradictions de Socin, qui parmi les nouveaux unitariens fut le premier à emprunter cette étrange voie médiane, osant donner rien de moins qu'une démonstration "quod Christo, licet rei creatae, tamen inuocatio et adoratio, seu cultus diuinus conueniat $^{\text {ab } 199}$ ». Tous les unitariens avant lui, quand on les obligeait à dire leur fait, partageaient l'opinion de David, ou en tout cas comprenaient l'invocation du Christ comme quelque chose de tout autre que l'invocation de Dieu. Et il est même si peu vrai que David ait d'abord enseigné en Transylvanie selon ce qu'il avait appris de Neuser, comme le dit Crell, que Socin [184] lui-même en nomme plusieurs qui l'avaient précédé sur ce point. "Videbam enim ", dit-il dans la dédicace de sa Disputatio de Iesu Christi inuocatione, "ad falsas et valde perniciosas planeque Iudaicas quasdam de Christo opiniones, quas

aa. Voir Disputatio in causa sacrosanctae Trinitatis etc. Claudiopoli 1568.

ab. Voir F. Socini Epistolae p. 143. Racoviae 1618. 
praeter vel etiam ante Franciscum Dauidis, Iacobus Palaeologus, Iohannes Sommerus, Matthias Glirius, et alii in Transiluania disseminauerant, ex multorum animis radicitus extirpandas tractatione ista opus esse, in qua nimirum tota ferme Christianae religionis ratio explicaretur ${ }^{200}$. " Et plus loin, il nomme tout particulièrement Matthias Glirius, "Symmistam et ex parte praeceptorem »de David ${ }^{201}$.

12. Ce Glirius va facilement nous ramener très près de Neuser. Car je ne peux ici résister à la tentation de dévoiler une petite découverte que je crois avoir faite sur Glirius. Sandius dit en effet ${ }^{\text {ac }}$ que ce Matthias Glirius semble être le même que celui que Possevinus désigne sous le nom de Matthias Polonus, et dont il rapporte qu'il avait succédé à Joh. Sommer au rectorat de Clausenbourg ${ }^{202}$. Il se refuse seulement à le considérer comme polonais, au motif qu'il a été le compagnon de Joh. Sylvan et de Neuser et qu'il a subi avec eux $<107>$ la persécution en Palatinat: "fuit enim Ioannis Syluani et Adami Neuseri socius, ac persecutionis eorum particeps ${ }^{203}$ ". Or nous savons, et nous savons de source sûre, que personne n'a été mêlé à l'affaire Neuser en Palatinat, à l'exception de Sylvanus, [185] qui s'en est le plus mal sorti ${ }^{204}$, et encore de Jacob Suter et Matthias Vehe. Par conséquent, soit les informations de Sandius sont complètement fausses, soit Matthias Glirius n'est autre que Matthias Vehe. Je crois en la dernière hypothèse. Je crois que Matthias Vehe, au moment de quitter le Palatinat et l'Allemagne, crut bon de changer son nom et de se faire appeler Glirius au lieu de Vehe. La raison qui me fait croire cela est que " Glirius " ne me semble être rien d'autre que la traduction de «Vehe ». Car "Vehe » désignait - et dans certaines parties de l'Allemagne désigne encore - une précieuse fourrure, ou plutôt le petit animal dont la peau produit cette fourrure, et qui en latin est désigné par le nom générique de " glis $^{205}$ ». De sorte que l'adjectif «Glirius » pourrait très bien désigner quelqu'un qui croirait tenir son nom d'un tel «Vehe».

$\overline{\text { ac. Biblioth. Antitrinit. p. } 60}$ 
13. Si donc, comme on l'a dit, Glirius nous ramène à Neuser et si par conséquent les deux, David et Glirius, ont puisé leur erreur à une seule et même source, il reste néanmoins un certain nombre d'individus dont Socin reconnaît qu'ils ont conçu et répandu la même erreur "praeter vel ante Franciscum Davidis ${ }^{206}$ ". C'est contre l'un d'entre eux, Joh. Paleologus ${ }^{207}$, que Socin avait consacré un ouvrage qui combattait cette erreur, à un moment où il n'était pas encore établi que David y adhérait aussi ${ }^{208}$. Je le vois à sa réponse à Marcellus Squarcialupus, qui le soupçonnait de s'en être pris à Paleologus sur ce point comme sur d'autres moins [186] importants ${ }^{209}$. C'est même à lui, Paleologus, que Socin, dans la réponse que j'ai mentionnée, attribue l'honneur dont Crell avait voulu accabler Neuser. "Nec sane quemquam futurum puto, qui modo < $108>$ Palaeologi librum legerit, quin fateatur, vix aliter, quam ego feci, ei responderi potuisse, aut mitius aliquanto cum eo agi debuisse. Quid si cognitum haberet, ut quidem ego habeo, quot malorum causa, non isthic tantum in Transylvania, sed in Vngaria quoque, in Lithuania, et aliis in locis, Palaeologi auctoritas et scripta fuerint? An non ipse primus omnium in provincia ista, sententiam illam maxime inpiam et detestandam de non adorando neque invocando Christo, una cum aliis compluribus pestilentissimis erroribus docuit et scriptum reliquit? Nonne eius doctrina hodie, quae a quibusdam Francisci Davidis esse creditur, integrae eaeque non paucae Ecclesiae in Vngaria foedissime sunt corruptae ${ }^{210}$ ? " Et pourtant il est tout à fait certain que Paleologus n'a pas pu être l'instigateur, le fondateur pour lequel Socin veut le faire passer. Tout au plus se peut-il qu'il ait été le premier à s'être formellement opposé à ceux qui voulaient rendre au Christ d'une main ce qu'ils lui avaient pris de l'autre, et qui croyaient bien mériter du christianisme - qui sait à quel point - en le purifiant d'un mystère inintelligible, c'est-à-dire en le rabaissant au niveau de toutes les fausses religions qui invoquent ni plus ni moins que des êtres finis, alors que ses premiers maîtres se donnèrent tant de mal pour repousser ces religions. 
[187] 14. Pour autant, je ne veux pas nier que l'enseignement oral et les écrits de Neuser, quand bien même ils seraient innocents des maux dont Crell les charge, aient été par ailleurs très préjudiciables à l'Église unitarienne. Je veux même, pour le prouver, compléter une information donnée par Gerlach, et la compléter à partir de Gerlach lui-même. L'information se trouve dans le passage bien connu de son Antidanaeus. "Exhibuit mibi ", écrit Gerlach, "ipse Neuserus Constantinopoli, anno Domini 1574 literas, eodem anno, 2. Iulii ad se ex Polonia a primario quodam Antitrinitariae haeresis propugnatore datas, (quas bona fide transscipsi) cuius inter cetera, haec quoque verba sunt: Quaeso, mi Adame, diligenter interroga, an Alcoranus $<109>$ iste, quem Bibliander Tiguri edidit, sit authenticus, et veritati Arabicae conueniat. Nam isto libro nos valde delectamur, et diuinum esse asserimus. Deinde peto etiam nomine fratrum, vt omnes vetustos Graecos libros inspicias, et si disputationem aliquam de vno Deo inuenies, tecum apportato. Si veneris ad nos, nullo modo impediemus, quin ad tuos redeas, sed summopere curabimus, vt tuto discedere Constantinopolin possis. Nam talem virum, sicut tu es, optamus Constantinopoli habitare, vt quo ad libros istos praedictos, vtilitas quaedam Ecclesiae accedat. Afferto etiam tecum, si potes inuenire libellum Porphyrii de autoritate s. scripturae, contra quem Cyrillus Alexandrinus scripsit. Nam nos ex tuis literis, quas scripsisti, intelligimus, multas esse contradictiones in sacris literis, igitur de multis locis dubitamus, et te magna [188] cum auiditate exspectamus, te amplectimur, ex ore tuo verba dinina audire petimus. Noli ergo propter Deum tuos fratres in hac deserere etc. ${ }^{211}$ " - C'est précisément cet extrait de la lettre d'un Arien polonais à Neuser que Gerlach avait transmis dès le $1^{\text {er }}$ novembre au Dr Jacob Andreae de Tübingen ${ }^{212}$, dans un courrier qui se trouve également parmi les lettres non éditées de Gerlach dans notre bibliothèque. Puisque j'y trouve non seulement le nom de cet Arien polonais, auteur de la lettre à Neuser, mais aussi quelques passages qui ont été supprimés à l'endroit que j'ai cité, 
je vais donc compléter à partir de cette version. Andreae avait averti Gerlach contre Neuser; Gerlach reçoit avec reconnaissance ce paternel avertissement mais ajoute que Neuser est loin de se trouver dans une situation telle qu'il puisse donner lieu à beaucoup d'inquiétudes; c'est à lui, au contraire, d'avoir peur d'eux, pour des raisons qu'il n'est pas simple d'exposer. (Ceci se rapporte sans doute au fait que Neuser avait été assez brave pour tirer l'émissaire du Saint-Empire, le baron von Ungnad, d'une très pénible affaire, d'une manière qui ne le rendit pas très digne de la confiance que les Turcs avaient placée en lui, mais qui montrait que sa bienveillance envers $<\mathbf{1 1 0}>$ ses compatriotes et anciens frères en religion ne s'était pas le moins du monde éteinte - chose qu'on peut voir, avec d'autres indices encore, dans le journal de Gerlach, p. 175-177 ${ }^{213}$.) Là-dessus, Gerlach continue: "Religionem nostram damnare desinit, disputationem de Deo respuit, Turcicismum tanquam fabulas ridet, reditum [189] cum occasione, et quidem ad Protestantes, non dissimulat. Sed quod nequam plurimorum errorum monstra in corde alat, non prorsus inficior. Scripsit ad eum 2. Iulii ex Polonia Petrus Witrousk, Superintendens Generalis Ecclesiarum recte de Deo sentientum, (sic se appellat) omnium fratrum nomine petens, $v t$ ad ipsos venire et de omnibus articulis religionis cum ipsis conferre velit; se enim ipsius scriptis, quae in Polonia reliquerit, motos esse, $v t$ pedibus in ipsius sententiam irent. Deinde inter cetera sic scribit: Quaeso, mi Adame ${ }^{214}$," etc. Comme dans l'Antidanaeus, à ceci près que la suite n'est pas disposée dans le même ordre et qu'après les mots "Te cum apportato" le passage suivant y a été supprimé: "Frustra enim non facies et annuum stipendium dabimus tibi honestum. Adhaec tua scripta, quae de omnibus religionis capitibus collegisti, tecum fer. Nam imprimi curabimus, vt aduersarii pudore suffundantur ${ }^{215}$. " - Il y a donc au moins une paroisse polonaise que les écrits de Neuser ont entraînée aussi loin qu'une paroisse unitarienne pouvait aller, c'est-à-dire plus loin qu'une telle paroisse n'aurait dû aller si elle voulait garder un certain droit à porter le nom d'une 
paroisse chrétienne. Car le fait est que même Franciscus David n'est pas allé aussi loin, non plus que ceux qui avec lui, en plus de la divinité du Christ, lui contestaient le droit d'être invoqué: ils continuaient de voir dans l'Ancien et le Nouveau Testament des livres divins, rien d'autre, et en tiraient même leurs démonstrations, de sorte que la morale chrétienne, tout au moins, leur semblait confirmée au-delà de tout [190] doute par ces livres inspirés par Dieu. En revanche, ces unitariens polonais, pour qui le Coran était lui aussi divin, n'étaient rien d'autre que soit des Turcs non circoncis soit, si « divin » ne $<111>$ signifie ici que «bon » et "édifiant », des déistes, et si toutes les paroisses unitariennes polonaises ont été d'accord avec eux, on ne pourra pas dire que ce sont des chrétiens qui ont été chassés de Pologne en 1658 et $1660^{216}$.

15. Parmi les manuscrits que Neuser a laissés derrière lui en Pologne ou parmi ceux qui après sa mort sont passés dans d'autres mains, il faut que Crell en ait possédé ou lu au moins une partie, car il peut dire plus haut: "Neuserus non obscure sibi dogmatis huius [de non adorando et inuocando Christo] inuentionem adscribit ${ }^{217}$. " De Neuser en effet d'après Sandius, rien n'a été publié, à l'exception d'un Scopus septimi capitis ad Romanos où il aurait eu peine à jouer sur cette corde ${ }^{218}$. Il n'en eût été que plus nécessaire que Crell nous cite des extraits de Neuser lui-même, s'il avait voulu que nous puissions voir dans ses allégations plus qu'une hypothèse qui semble par trop contredire la nature de l'affaire. Que les Argumenta philosophica cuiusdam semi Ariani, que H. Zanchius avait dû réfuter sur ordre de l'électeur - cette réfutation se trouve dans les lettres de Zanchius $^{\text {ad }}$ — soient de Neuser, il n'y a pas lieu d'en douter ${ }^{219}$. Mais il a été malveillant de placer cette réfutation à l'endroit que j'ai dit, sans les Argumenta eux-mêmes, qu'on ne devine pas sans peine à partir de la réfutation. Peut-être s'agit-il [191] d'un essai trouvé dans les papiers de Neuser après sa fuite. Car lui-même ne s'en sera pas ouvert, ayant tant de raisons de garder le secret

$\overline{\text { ad. Op. Tom. VIII. p. } 114 .}$ 
le plus strict, au point de n'oser les confier, comme il le dit à Gerlach, qu'à "Erasto suo intimo ${ }^{220}$ ". Mais quand on voit que dans le journal de Gerlach ces mots sont traduits par "son très proche et cher ami ", et qu'à cela est ajouté: "qui fut peut-être Sylvan ${ }^{221}$ ", il est impossible que cette dernière mention soit de Gerlach, et ces deux choses montrent la négligence et l'ignorance avec laquelle on a glané pour ce $<\mathbf{1 1 2}>$ journal les papiers latins de l'auteur ${ }^{222}$. Celui-ci devait bien savoir qui était Thomas Erastus $^{223}$ : il avait été au côté de Neuser dans la querelle sur la discipline de l'Église et avait entretenu avec lui une amitié si étroite que beaucoup par la suite le soupçonnèrent d'arianisme. C'est lui sans conteste que Neuser avait en vue et il n'y avait pas lieu de penser à la signification étymologique du $\operatorname{mot}^{224}$. Bien entendu Neuser avait plusieurs confidents et ce qu'il dit ici ne prouve rien contre Éraste. Car une chose est d'être le confident d'opinions fausses, une autre est de les cultiver soi-même. Je ne puis qu'admirer cet Éraste à qui Neuser pouvait confier ses pensées les plus secrètes et qui de son côté pouvait vivre en toute amitié, sans s'en formaliser, auprès d'un strict orthodoxe, au point que cet orthodoxe lui-même n'hésita pas à devenir son plus zélé défenseur. [192] Car c'est lui l'ami à propos duquel Zanchi écrit à Lavater: "In hac autem causa Arianismi, cuius suspectum habuerunt amicum permulti, propter arctissimam amicitiam cum $N$. defendi et defendam usque ad sanguinem, quia fit illi iniuria, quantum ego potui ex familiaribus iisque permultis cum eo sermonibus colligere ${ }^{\text {ae } 225}$. "

16. Avant de conclure, il me faut encore dire un mot du caractère moral de Neuser. On a sans doute été enclin à le dépeindre sous un jour si noir et repoussant, et à le croire tel, parce qu'on a posé deux choses comme tout à fait incontestables et nécessaires. La première est que seul un homme aux mœurs aussi répréhensibles pouvait franchir le pas que Neuser a franchi. La seconde est que celui qui a échangé la religion chrétienne contre la turque, quand bien même celle-ci ne lui aurait procuré

ae. Zanchii Epist. lib. II. Op. VIII. p. 402. 
aucun apaisement, n'avait d'autre solution que de se précipiter dans l'incroyance la plus extrême, celle qui justifie la vie la plus débauchée et qui conduit inévitablement au désespoir. Que $<113>$ l'exemple de beaucoup de renégats, et même de la plupart d'entre eux, justifie ces présupposés, c'est ce que je ne veux pas contester; à condition qu'on veuille bien reconnaître, en sens inverse, qu'il peut exister des exceptions et que Neuser peut en avoir fait partie. Et il en a vraiment fait partie, s'il faut en croire les témoignages plus que les racontars. Je parle de témoignage quand l'émissaire impérial écrit à sa cour: "C'est face à Dieu seul qu'il lui faut rendre des comptes de sa conscience, [193] pour le reste il n'est ni un méchant homme ni un ennemi des chrétiens $^{226}$. " Je parle de témoignage quand un personne digne de foi assure à Gerlach: "Neuser est paisible et travailleur, et il a un logement retiré, de sorte qu'aucun Allemand ne sait où le trouver $^{227}$. " En revanche, j'appelle racontar ce que l'on traîne pendant des années derrière soi et que les gens traînent pour des raisons que l'on ne voit que trop facilement. C'est le cas de ce que Gerlach, on l'a vu plus haut, a écrit en Allemagne au sujet de Neuser, avant de l'avoir vu en personne et de lui avoir parlé. C'est le cas des choses que Heberer et Budowecz ${ }^{228}$, longtemps après sa mort, ont entendues à son sujet, les entendant d'une façon telle que celui qui les racontait voyait bien qu'ils les attendaient et même les appelaient de leurs vœux. Gerlach, dont la présence à Constantinople coïncide avec la mort de Neuser, dit que celui-ci est mort d'hémorragie dysenterique, et qu'il est mort parmi ses amis, bien que ce ne fût pas dans la meilleure des occupations: au milieu d'une beuverie, sans le moins $d u$ monde parler d'affaires de foi. Cette information n'est pas flatteuse, mais elle est suffisamment fiable pour qu'un Gerlach ait pu et voulu l'introduire le jour même dans son journal. Certes les Jöcher et Heineccius ${ }^{229}$ prennent toujours plaisir à ne pas s'en tenir là et préfèrent recopier les histoires de Budowecz et Heberer, que Gerlach < $114>$ permet de convaincre ouvertement de mensonge. La dysenterie devient peste chez Heberer et 
chez Budo[194]wecz, pour le dire d'un mot, c'est une syphilis telle que la puanteur est censée avoir empêché tout le monde de rester auprès du malade, alors même qu'on le disait mourir dans le plus grand désespoir. Qu'on juge du reste! Cela me dégoûte de me quereller avec de vieilles bonnes femmes.

17. À qui trouverait que j'ai passé bien trop de temps dans une vieille histoire confuse, je demanderai de réfléchir à tout ce qui a été écrit sur Servet ${ }^{230}$, et ce par des Allemands! Ou bien faut-il être étranger pour mériter notre attention? Leibniz a écrit quelque part: "I'ai d'autant plus de compassion du malheur de Seruet, que son mérite devoit être extraordinaire puisqu'on a trouvé de nos jours, qu'il avoit une connoissance de la circulation du sang ${ }^{231}$. »Certes Leibniz se trompait, ainsi qu'il l'a relevé plus tard. Mais on m'autorisera à conclure, en imitant ses paroles: j'ai d'autant plus de compassion pour Neuser, qu'il me semble avoir été encore quelque chose de plus qu'un antitrinitaire: une bonne tête mécanique, qui a travaillé à une découverte assez similaire à celle qui cent ans plus tard traversa l'esprit de Leibniz. "Neuser ", écrit Gerlach ${ }^{\text {af }}$, "avait entrepris de fabriquer une voiture qui devait se déplacer toute seule; il se promettait de grandes choses de sa vitesse, une fois mise en route ${ }^{232}$. " Ce que Leibniz voulait obtenir, on le sait par Becher ${ }^{\text {ag } 233}$; ou plutôt c'est par lui qu'on ne le sait pas, puisqu'il a jugé meilleur de s'en moquer que de dire de quoi il s'agissait.

af. Dans Heineccius, Annexe, p. 27.

ag. Närrische Weisheit, S. 149. 


\section{Notes de la traduction}

1. Les crochets [] indiquent la pagination dans l'édition originale: Von Adam Neusern, einige authentische Nachrichten, in Zur Geschichte und Literatur. Aus den Schätzen der Herzoglichen Bibliothek zu Wolfenbüttel, Dritter Beitrag, XVII, Braunschweig 1774, p. 119-194; les chevrons $<>$ renvoient à la pagination de l'édition d'Arno SCHILSON: G. E. LESSING, Werke und Briefe (abr. WuB), éd. W. BARNER et alii, Frankfurt a. M., Deutscher Klassiker Verlag (1985-2003), t. 8, 1989, p. $55-114$

Abréviations utilisées dans les notes: ADB = Allgemeine Deutsche Biographie, Leipzig 18751911; BBKL = Biographisch-bibliographisches Kirchenlexikon, Hamm, Bautz, 1975-2015; EÆ = Encyclopaedia Aethiopica, Wiesbaden, Harrassowitz, 2003-2014; El2 = The Encyclopaedia of Islam, New Edition, Leiden, Brill/London, Luzac, 1960-2005. Suivent les indications de tome, d'année, de page et, entre parenthèses, les noms des auteurs des notices. TOB = Traduction œuménique de la Bible.

2. Les unitariens défendent l'unicité de Dieu en niant les dogmes de la Trinité et de la divinité de Jésus-Christ. Selon les diverses variantes de cette croyance, Jésus peut être ou non vénéré comme maître et prophète, mais en aucun cas comme Fils de Dieu. Ce mouvement se veut le continuateur moderne de l'arianisme défait lors des grands conciles des $\mathrm{IV}^{\mathrm{e}}$ et $\mathrm{V}^{\mathrm{e}}$ siècles, Nicée (325), Constantinople (381), Chalcédoine (451). Adam Neuser constitue un document sur les débuts de l'unitarisme moderne dans l'un de ses berceaux, la Transylvanie (voir plus bas, n. 10). L'ouvrage de référence reste celui d'Earl Morse WILBUR, A History of Unitarianism, t. I: Socinianism and Its Antecedents, t. II: In Transylvania, England, and America, Cambridge (Mass.), Harvard University Press, 1946-1952, plusieurs fois réédité.

3. Wolfenbüttel, HAB, Cod. Guelf. 32.1.B Extrav., f. 248r-261r. La bibliothèque ducale de Wolfenbüttel, fondée en 1572 par le duc Jules de Brunswick-Lunebourg (1528-1589) et enrichie par Auguste le Jeune (1579-1666), était considérée au XVII siècle comme la plus grande bibliothèque au nord des Alpes. Ses collections sont aujourd'hui partie intégrante de la Bibliothèque nationale allemande. Après notamment un mandat de Leibniz entre 1691 et 1716, sa direction fut confiée à Lessing en 1770 (voir introduction, n. 2 et Richard DAUNICHT, Lessing im Gespräch. Berichte und Urteile von Freunden und Zeitgenossen, München, Fink, 1971, n 495496, p. 292-294). On peut toujours consulter l'ancienne monographie de Friedrich Karl Otto von HeInEMANN, Die Herzogliche Bibliothek zu Wolfenbüttel. Ein Beitrag zur Geschichte deutscher Büchersammlungen, Wolfenbüttel 1894², réimp. Amsterdam, Van Heusden, 1969, ainsi que Georg RuPPELT et Sabine Solf (dir.), Lexikon zur Geschichte und Gegenwart der Herzog-AugustBibliothek Wolfenbüttel, Wiesbaden, Harrassowitz (Lexika europäischer Bibliotheken, 1), 1992 et Mechthild RAABE, Die fürstliche Bibliothek in Wolfenbüttel und ihre Leser. Zur Geschichte des institutionellen Lesens in einer norddeutschen Residenz 1664-1806, Wolfenbüttel, Steuber, 1997. Sur Lessing bibliothécaire, les meilleurs travaux sont ceux de ses successeurs : Wolfgang MILDE, "Studien zu Lessings Bibliothekariat in Wolfenbüttel (1770-1781). Bücherausleihe und Büchererwerbung », Lessing Yearbook 1 (1969), p. 99-125 et 2 (1970), p. 162-180; Paul RAABE, "Lessing und die Gelehrsamkeit. Bemerkungen zu einem Forschungsthema ", in E. P. HARRIS et R. R. SCHADE (dir.), Lessing in heutiger Sicht. Beiträge zur Internationalen Lessing-Konferenz, Cincinnati, Ohio, 1976, Bremen etc., Jacobi, 1977, p. 65-88. Voir aussi Bernd REIFENBERG, Lessing und die Bibliothek, Wiesbaden, Harrassowitz (Wolfenbütteler Schriften zur Geschichte des Buchwesens, 23), 1995; Wilfried BARNER, «Lessing zwischen Bürgerlichkeit und Gelehrtheit », in R. VIERHAUS (dir.), Bürger und Bürgerlichkeit im Zeitalter der Aufklärung, Heidelberg, Schneider (Wolfenbütteler Studien zur Aufklärung, 7), 1987, p. 165-204. Pour un point de vue d'histoire régionale, cf. Gerd BIEGEL, "Eigentlich ist es der Erbprinz, welcher mich hierher gebracht hat". Wolfenbüttel und Braunschweig: Lessing zwischen Herzog, Hof und Bibliothek », in ID., "Liebhaber der Theologie ». Gotthold Ephraim Lessing - Philosoph - Historiker der Religion, Frankfurt a. M. etc., Lang (Braunschweiger Beiträge zur Kulturgeschichte, 3), 2012, p. 11-35. 


\section{Adam Neuser}

4. Christian Gottlieb Jöcher (1694-1758), docteur en théologie en 1735, dirige à partir de 1742 la bibliothèque de Leipzig : Lessing se tourne ici vers un confrère décédé, qu'il estime peu. Le texte cité est extrait d'une vaste encyclopédie biographique des savants depuis le commencement du monde, Allgemeines Gelehrten-Lexikon, 4 vol., Leipzig 1750-1751, t. III, col. 887-888. Voir par ex. Ulrich Johannes SCHNEIDER, " Jöcher's Anthropology of Scholars », in A. HOLENSTEIN, H. SteInKE et M. Stuber (dir.), Scholars in Action. The Practice of Knowledge and the Figure of the savant in the 18th Century, Leiden-Boston, Brill (Scientific and Learned Cultures and their Institutions), 2013, t. 1, p. 195-204.

5. L'église Saint-Pierre (Peterskirche) de Heidelberg, construite au XII ${ }^{\mathrm{e}}$ siècle, est de fondation au moins aussi ancienne que la ville elle-même. À partir de 1400, elle est paroisse de l'université. Voir Anneliese SEeliger-ZeIss, Die Peterskirche, Universitätskirche Heidelbergs, Regensburg, Schnell \& Steiner (Kleine Kunstführer, 1595), $2006^{2}$.

6. L'électeur Frédéric III dit le Pieux (1515-1576), fils de Jean II de Palatinat-Simmern (14921557) et de Béatrix de Bade (1492-1535), règne sur le Palatinat à partir de 1559 et mène d'emblée son territoire du luthéranisme à la religion réformée (voir introduction, p. 11, 14). Sur ses intérêts théologiques, voir Andreas WIRSCHING, "Ob ich gleych ein armer eynfeltiger lay bin". Kurfürst Friedrich III von der Pfalz und das konfessionelle Zeitalter », in E. AXMACHER et K. SCHWARZWÄLlER (dir.), Belehrter Glaube. Festschrift für Johannes Wirsching zum 65. Geburtstag, Frankfurt a. M. etc., Lang, 1994, p. 373-399 et les études sur la confessionnalisation du Palatinat citées en introduction, n. 32. - Au Xvl ${ }^{e}$ siècle, la composition du collège des sept princes-électeurs (Kurfürsten) investis de la fonction d'élire le « roi des Romains » avant son couronnement par le pape est encore celle qui avait été définie par la Bulle d'Or de 1356 : les archevêques de Mayence, Trèves et Cologne, le roi de Bohême, le duc de Saxe, le margrave de Brandebourg et le comte palatin du Rhin, « haut-sénéchal » de l’Empire.

7. Construite entre 1398 et 1515, l'église du Saint-Esprit (Heiliggeistkirche) de Heidelberg est le plus grand édifice religieux de la ville. Elle fut conçue comme collégiale de l'université et paroisse pour la vieille ville. Sur le modèle de l'université de Wittenberg, elle abrita la Bibliothèque palatine jusqu'au transfert de celle-ci à Rome pendant la guerre de Trente Ans. Les électeurs palatins et leurs familles y furent enterrés de 1410 à 1685. Voir Mathias KöHLER, Heiliggeistkirche Heidelberg, Regensburg, Schnell \& Steiner (Kleine Kunstführer, 1184), $2006^{4}$.

8. Le socinianisme est la branche de l'unitarisme née des efforts doctrinaux et militants de Lelio Sozzini (1525-1562) et de son neveu Fausto Sozzini (1539-1604), ou Socin. Ces efforts les conduisirent via Genève et Bâle du patriciat siennois à la Petite Église polonaise, antitrinitaire (voir plus bas, n. 155). Le rejet de la pluralité des personnes en Dieu s'allie chez eux au respect pour l'enseignement moral de Jésus. Voir Jean-Pierre OSIER, Faust Socin ou le christianisme sans sacrifice, Paris, Cerf (Patrimoines), 1996, ainsi que les études historiques citées en introduction, n. 77, avec la réédition de l'étude de 1939 de Delio CANTIMORI, Eretici italiani del Cinquecento e altri scritti, éd. A. Prosperi, Torino, Einaudi (Biblioteca di cultura storica, 193), 1992.

9. Le médecin piémontais Giorgio Biandrata (ou Blandrata, 1515-1588), formé à Montpellier, rejoint la Pologne après un séjour infructueux à Genève et devient médecin de la cour. En 1563, il passe en Transylvanie, où avec Ferenc Dávid (voir plus bas, n. 52) il publie un De falsa et vera unius Dei Patris, Filii et Spiritus Sancti cognitione (Albae Iuliae 1568, réimp. Utrecht etc., Bibliotheca Unitariorum (Foundation Bibliotheca Unitariorum, 2), 1988), largement inspiré de la Christianismi restitutio de Michel Servet (1553, voir plus bas, n. 230). II serait revenu peu avant sa mort à la foi catholique. Avec Faust Socin, il compte parmi les tenants d'une ligne unitarienne modérée (cf. BBKL 1 (1975), 611 (Friedrich Wilhelm BAUTz)).

10. Le terme "voïvode », qui désigne dans le monde slave une sorte de préfet ou de gouverneur militaire, s'applique au prince de Transylvanie, dans les conditions de souveraineté limitée qui régissent ce territoire d'environ un million d'habitants à la fin du Xvi siècle. La Transylvanie couvre alors $100000 \mathrm{~km}^{2}$ de la partie occidentale de l'actuelle Roumanie, mais relève historiquement aussi de la Hongrie: les conflits de mémoire restent vivaces dans la région 
(cf. Olivier GILLET, «L'histoire de la Transylvanie. Le différend historiographique entre Hongrois et Roumains », Revue belge de philologie et d'histoire 75 (1997), p. 457-485). Après une phase de flou consécutive à sa victoire à Mohács (1526), l'empereur Soliman le Magnifique règle entre 1541 et 1547 le partage de la Hongrie: le centre passe sous administration turque directe, l'ouest revient aux Habsbourg contre le versement d'un tribut annuel, et la Transylvanie est une principauté administrée par un voïvode payant lui aussi tribut aux ottomans. En 1542, trois « Nations » sont distinguées pour définir la composition de la diète qui élit le voïvode: "Saxons » (germanophones), Hongrois et Sicules. Pour une introduction, voir Harald RotH, Kurze Geschichte Siebenbürgens (1996), Köln-Weimar-Wien, Böhlau, $2007^{3}$, et sur les aspects religieux les études citées en introduction, $n$. 36. À l'époque désignée dans le texte, le voïvode de Transylvanie est le roi de Hongrie Jean II (Jean-Sigismond) Szapolyai, qui accepte de régner sous tutelle turque. Au moment où Neuser y séjourne, d'importants changements sont en cours : par le traité de Spire (août 1570), l'empereur Maximilien II (voir plus bas, n. 23) reconnaît Jean-Sigismond comme "prince de Transylvanie », en contrepartie de l'abandon par celui-ci du titre de « roi de Hongrie »: voir Teréz OBORNI, « Le royaume des Szapolyai, du royaume de Hongrie orientale à la principauté de Transylvanie (1541-1571)», in O. CHALINE et M.-F. SAUDRAIX-VAJdA (dir.), La Hongrie ottomane, $X V l^{e}-X V I I^{e}$ siècles = Histoire, économie et société, 3/2015, p. 65-77. Voir en outre Gerald VoLKMER, Das Fürstentum Siebenbürgen 15411697. Außenpolitik und völkerrechtliche Stellung, Kronstadt, Aldus/Heidelberg, Arbeitskreis für Siebenbürgische Landeskunde, 2002; István KEUL, Early Modern Religious Communities in East-Central Europe. Ethnic Diversity, Denominational Plurality and Corporative Politics in the Principality of Transylvania (1526-1591), Leiden-Boston, Brill (Studies in Medieval and Reformation Traditions, 143), 2009.

11. Selim II, né en 1524, succéda en 1566 à son père Soliman le Magnifique comme sultan de l'Empire ottoman. II est connu sous les surnoms de l'« Ivrogne » et du « Blond ». II mourut quelques mois après Neuser en décembre 1574. Sous son règne, assez peu personnel, l'Empire s'agrandit de Chypre (1571) et de la Tunisie (1573). Pour un portrait placé sous le signe de la "décadence", voir dans la somme de Nicolae IORGA, Geschichte des Osmanischen Reiches. Nach den Quellen dargestellt (1908-1913), t. III, Gotha 1910, réimp. Darmstadt, Wissenschaftliche Buchgesellschaft, 1997, p. 137-161.

12. L'appellation provient de Photin, évêque de Sirmium en Pannonie (actuelle Hongrie), mort en 376. Sa doctrine d'inspiration adoptianiste, selon laquelle Jésus aurait été un homme élevé par Dieu au rang divin, fut plusieurs fois condamnée à partir de 344. Voir D. H. WILLIAMS, "Monarchianism and Photinus of Sirmium as the Persistent Heretical Face of the Fourth Century ", The Harvard Theological Review 39 (2006), p. 187-206.

13. Amberg, dans le Haut-Palatinat, aujourd'hui en Bavière, entre 1329 et 1620 sur le territoire de l'électorat palatin. Une prison s'y trouve toujours.

14. "Chiaus », « tchavouch » (en turc actuel çavus) est un titre employé pour désigner différentes catégories de personnages remplissant des tâches d'intermédiaire: transmission d'ordres, maintien de la discipline, protocole. Les çavus du divan impérial, ou de la Sublime Porte, étaient deux cents sous le règne de Mehmed II (mort en 1581). Ils assuraient la garde du divan, précédaient le souverain lors des processions et l'accompagnaient lorsque celui-ci partait en campagne. Ils veillaient à l'exécution des ordres du sultan ou du grand vizir, qu'ils portaient à leurs destinataires, dans la capitale, en province et à l'étranger. Encore de nos jours, çavus désigne le grade militaire correspondant à celui de sergent. Je remercie Frédéric Hitzel de ces informations.

15. Johann Michael Heineccius (Heinecke, 1674-1722), théologien, historien et poète spirituel actif à Halle (cf. ADB 11 (1880), 603 (Jacob FrANK)). Le texte cité est extrait de son histoire de I'Église grecque, Eigentliche und wahrhafftige Abbildung der alten und neuen griechischen Kirche, nach ihrer Historie, Glaubens-Lehren und Kirchen-Gebräuchen [...], 3 vol., Leipzig 1711, Appendice II, p. 27, n. (2). 


\section{Adam Neuser}

16. Caspar Olevianus (Olevian, 1536-1587), figure importante de la "seconde Réforme» calvinienne dans l'Empire. Né catholique à Trèves, il est formé en droit en France (Paris, Bourges, Orléans), où il a ses premiers contacts avec des communautés réformées. II séjourne en 1558 à Genève, Lausanne, Zurich auprès de Calvin, Bullinger et Pierre Martyr Vermigli. Expulsé en 1560 de Trêves, il passe à Heidelberg à l'invitation de l'électeur Frédéric III, est élu contre Neuser professeur de théologie mais préfère se consacrer à la formation pastorale. II joue un rôle décisif dans l'élaboration du nouveau règlement ecclésiastique du Palatinat. De nouveau chassé en 1577 après le retour du Palatinat au luthéranisme, il quitte Heidelberg et fonde à Herborn, à la demande du comte Jean VI de Nassau-Dillenbourg, I'une des principales académies réformées de l'Empire. Voir la brève monographie d'Andreas MüHLING, Caspar Olevian 1536-1587. Christ, Kirchenpolitiker und Theologe, Zug, Achius (Studien und Texte zur Bullingerzeit, 4), 2008, et sur les années à Heidelberg l'étude plus fouillée de Robert C. WALTON, "Der Streit zwischen Thomas Erastus und Caspar Olevian über die Kirchenzucht in der Kurpfalz in seiner Bedeutung für die internationale reformierte Bewegung », Monatshefte für evangelische Geschichte des Rheinlandes 37-38 (1988-1989), p. 205-246.

17. Johann Sylvan (Holzer?, Sylvanus, ?-1572), natif du Tyrol, étudie la théologie à Vienne et devient chapelain du prince-électeur de Wurtzbourg, au côté duquel il prend part à la diète de Ratisbonne en 1556. II rompt avec l'Église et rejoint en 1559 le Württemberg luthérien, où il publie sa confession de foi (1560). Son rapprochement avec les thèses réformées est rapide. En 1563, sa trace est retrouvée à Kaiserslautern, qui se trouve sous la juridiction de l'électeur palatin. II participe assez activement à la réforme du territoire sous l'impulsion de Frédéric III et d'Olevian (voir plus haut, n. 6 et 16), ce qui lui vaut d'être nommé en 1567 superintendant du district de Ladenbourg, où des violences iconoclastes, dans l'esprit calvinien, avaient éclaté les années précédentes. Son évolution vers l'unitarisme est favorisée par la volonté du princeélecteur de faire administrer la discipline ecclésiastique, et notamment l'excommunication, à l'échelon des paroisses (voir introduction, p. 11), mais aussi par un approfondissement de sa théologie sacramentelle qui lui fait rejeter comme encore trop idolâtre la thèse calvinienne de la présence spirituelle du Christ dans l'Eucharistie. La prise de distance s'opère en outre à travers une étude de l'éthique d'Aristote, qui aux yeux de Sylvan redonne sens à la doctrine du libre-arbitre, condamnée par les réformés comme par les luthériens. Ses premiers projets de fuite datent comme pour Neuser de l'été 1569. La rupture définitive se produit quand, invité à réfuter la confession De regno Christi de Giorgio Biandrata (voir plus haut, $n$. 9), il se découvre en plein accord avec ses thèses. II organise avec Neuser la prise de contact avec les émissaires de Transylvanie à la diète de Spire pendant l'été 1570. Capturé et torturé à Heidelberg, il abjure sa doctrine antitrinitaire, mais l'embarras causé par l'affaire prolonge sa détention. Son jugement est prononcé en décembre 1572, alors que l'échafaud est déjà installé. La décapitation a lieu le 31 décembre, les restes de Sylvan sont brûlés et dispersés dans le Neckar. Les sources et la bibliographie sont rassemblées dans Christopher J. BURCHILL, The Heidelberg Antitrinitarians. Johann Sylvan, Adam Neuser, Matthias Vehe, Jacob Suter, Johann Hassler, Baden-Baden/ Bouxwiller, Koerner (Bibliotheca dissidentium. Répertoire des non-conformistes religieux des $X V I^{e}$ et $X V I I^{e}$ siècles, $\left.X I\right), 1989$, p. 107-156.

18. Jakob Suter (Sauter, vers 1545-vers 1614), né dans le Württemberg luthérien, étudie à Heidelberg où il entre en contact avec plusieurs étudiants suisses qui favorisent son évolution vers le protestantisme réformé. Membre du premier cercle d’Erastus (voir plus bas, n. 223), il devient pasteur près de Darmstadt puis à Feudenheim (plutôt que Weidenheim, toponyme mentionné dans le texte), non loin de Heidelberg. Le ministère pastoral le rapproche de Sylvan, et comme Sylvan il se tourne vers les thèses antitrinitaires à la lecture du De regno Christi de Biandrata (voir n. préc.). Absent à Spire, il est néanmoins informé du projet et pour cette raison arrêté, avec Vehe. Une rétractation tardivement consentie permet aux deux hommes d'être libérés en août 1572. II semble que Suter ait été à l'initiative des contacts pris avec la communauté juive de Grünsfeld, dans l'actuel Württemberg (voir n. suiv.). Suter et Vehe passent en Transylvanie au début de l'année 1574 mais ils rebroussent rapidement chemin. 
À Ingolstadt, Suter se convertit au catholicisme. L'évêque de Constance lui procure une rapide carrière universitaire, d'abord à la faculté des arts de Fribourg-en-Brisgau puis à la faculté de médecine dont il devient docteur en 1579. Ses succès de praticien le conduisent à la cour du prince-évêque de Passau. Sa date de décès n'est pas connue; la date d'entrée en fonction de son successeur dans la charge de médecin de cour, 1614, peut fournir un indice. Sources et bibliographie se trouvent également dans Ch. J. BURCHILL, The Heidelberg Antitrinitarians, op. cit., p. 211-233.

19. Matthias Vehe (alias Nathanael Elias, Matthias Glirius, Theodosius Schimberg, Dietrich Dorsch, vers 1545-1590), au terme d'une formation confessionnellement composite à Heidelberg mais aussi dans des places-fortes luthériennes comme Rostock et Tübingen, fait le choix de la seconde Réforme et commence une carrière pastorale comme ministre-assistant de Sylvan à Ladenbourg (voir plus haut, n. 17). Chez lui aussi, l'imposition de la discipline ecclésiastique à l'échelon presbytéral marque un tournant. Vehe, après d'âpres luttes contre le conseil ecclésiastique de Heidelberg au côté d'Erastus, s'implique dans le voyage de Neuser et Sylvan à Spire à l'été 1570, qui provoque son arrestation. Libéré avec Jacob Suter en 1572 et revenu comme lui de Transylvanie en 1574 (voir n. préc.), il va plus loin dans le rapprochement avec le judaïsme, dans lequel il finit, contrairement aux autres antitrinitaires du groupe de Heidelberg, par voir l'Église véritable. À Cologne, sous la direction du converti Johannes Isaac, il se forme à l'hébreu et à la science rabbinique, avant de s'installer en 1577 près de Bonn, dans le ghetto de Königswinter. Le Mattanjah (Mattaniah, das ist [...] die wahre Christliche Religion [...] aus der Bibel grundlich tractirt, Cologne 1578, sous le pseudonyme de Nathanael Elias) est le produit de cette synthèse judéo-chrétienne, ou judéo-unitarienne, vécue en première personne. Revenu en Transylvanie, il enseigne à Clausenbourg (Cluj) et s'implique dans les conflits internes des antitrinitaires au côté de Ferenc Dávid et des unitariens stricts (voir plus bas, n. 52). II mène par la suite, sous différentes identités, une existence errante en Pologne et Lituanie, sans pouvoir établir de contacts durables avec les groupes antitrinitaires. Un nouveau retour dans le Saint-Empire lui sera fatal : vu à Marbourg en 1589, il est ensuite emprisonné dans la partie réformée de la Frise orientale, qui cherche à l'extrader vers Heidelberg. L'action judiciaire s'éteint avec la mort de Vehe en captivité en décembre 1590. Voir Ch. J. BURCHILL, The Heidelberg Antitrinitarians, op. cit., p. 157-209 et Robert DÁN, Matthias Vehe-Glirius. Life and Work of a Radical Antitrinitarian with his Collected Writings, Budapest, Akadémiai Kiadó (Studia Humanitatis, 4), 1982, qui reproduit notamment l'édition de Cologne du Manttajah.

20. Le texte de Heineccius cité ici se fait l'écho de la compréhension peu précise que les antitrinitaires de Heidelberg avaient des évolutions religieuses récentes de la Transylvanie. Leur intérêt pour ce territoire fait suite à la décision du voïvode Jean-Sigismond (voir plus haut, n. 10) d'étendre à tous ces sujets l'édit de tolérance adopté en 1557 pour les catholiques et les luthériens. L'édit de Torda (Thorenburg en allemand, ou Turda en roumain, 1568) confère le statut de « religion acceptée » (recepta religio) aux quatre confessions catholique, luthérienne, réformée et antitrinitaire (les chrétiens orthodoxes ne sont pas mentionnés dans l'édit mais sont reconnus de fait). Les antitrinitaires entrent ainsi en régime de confessionnalisation et se constituent la même année en Église unitarienne, sous l'autorité de Ferenc Dávid (voir plus bas, n. 52). En 1569, Neuser tente une première fuite (voir introduction, p. 12) et Sylvan envisage aussi l'émigration pour la Transylvanie (voir plus haut, n. 17).

21. L'émissaire à la diète est Gáspár Bekes (1520-1579), trésorier du voïvode de Transylvanie Jean-Sigismond Szapolyai (voir plus haut, n. 10) et unitarien. Désigné par Jean-Sigismond comme son successeur, il échoue cependant, la noblesse hongroise à la diète préférant élire le catholique Étienne Báthory. Ses efforts pour organiser la rébellion contre Báthory, avec le soutien de l'empereur Maximilien II (voir plus bas, n. 23), n'aboutissent pas. Après l'élection de Báthory comme roi de Pologne et grand-duc de Lituanie en 1576, il se rallie. - La diète mentionnée ici est la diète d'Empire tenue en 1570 dans la cité épiscopale de Spire, lieu habituel, avec Augsbourg et Ratisbonne, de ces "parlements" mobiles du Saint-Empire romain germanique à l'époque moderne. Les diètes désignent les réunions des États de 


\section{Adam Neuser}

I'Empire (Ordines Sacri Romani Imperii), convoqués (sous certaines conditions après 1519) par l'empereur pour délibérer sur les affaires publiques. Sur les institutions de l'Empire germanique à l'époque moderne, voir la présentation synthétique d'Axel GoTTHARD, Das Alte Reich 14951806 (2003), Darmstadt, Wissenschaftliche Buchgesellschaft (Geschichte Kompakt), 20135 , et pour une approche d'anthropologie culturelle Barbara STOLLBERG-RILINGER, Des Kaisers alte Kleider. Verfassungsgeschichte und Symbolsprache des Alten Reiches (2008), München, Beck, $2013^{2}$, tr. fr. Ch. DuHAMELLE, Les Vieux habits de l'empereur. Une histoire culturelle des institutions du Saint-Empire à l'époque moderne, Paris, Éditions de la Maison des Sciences de l'Homme (Bibliothèque allemande), 2013. Les documents relatifs à la diète de 1570 sont édités: Der Reichstag zu Speyer 1570, éd. M. LANZINNER, Göttingen, Vandenhoeck \& Ruprecht (Deutsche Reichstagsakten, 4. Reichsversammlungen 1556-1662), 2 vol., 1988.

22. Voir plus haut, n. 9.

23. L'empereur Maximilien II (1527-1576), fils de Ferdinand Ier, neveu de Charles Quint, règne à partir de 1564. Moins hostile au protestantisme que ses prédécesseurs, il doit cependant renoncer à son rêve de réunification des confessions et mène une politique de compromis, s'attachant à maintenir les acquis de la Paix d'Augsbourg entre catholiques et luthériens (1555). Son règne est marqué par le passage du Palatinat dans le camp réformé et par le traité d'Andrinople de 1568, qui inaugure une période de vingt-cinq ans de paix avec l'Empire ottoman. Voir Paula SUTTER FICHTNER, Emperor Maximilian II, New Haven, Yale University Press, 2001 et sur les rapports avec le Palatinat en particulier Andreas EdEL, Der Kaiser und Kurpfalz. Eine Studie zu den Grundelementen politischen Handelns bei Maximilian II (1564-1576), Göttingen, Vandenhoeck \& Ruprecht (Schriftenreihe der Historischen Kommission bei der Bayerischen Akademie der Wissenschaften, 58), 1997.

24. Voir plus haut, n. 17.

25. Voir plus haut, n. 18-19.

26. Comme chez Jöcher plus haut, la description met l'accent sur l'acte de confession publique lié à la conversion de Neuser. La récitation de la formule de shahâda (" attestation », "témoignage ") est l'un des piliers de l'islam. Dans la perspective de la conversion, et à condition d'être effectuée en connaissance de cause et devant témoins, elle marque l'entrée de l'individu dans la communauté des croyants (" Shahada », El2 9 (1997), 201 (Daniel GIMARET)). Les auteurs protestants cités par Lessing se pensent en terrain connu et rapprochent spontanément la shahâda d'une formule de confession de foi. Voir introduction, p. 30-34.

27. Sur le théologien réformé Heinrich Alting, voir Pierre-Olivier LÉcHOT, «Entre irénisme et controverse. La réécriture historique de la différence confessionnelle chez le théologien palatin Heinrich Alting (1583-1644)», in B. FORCLAZ (dir.), L'Expérience de la différence religieuse dans l'Europe moderne (XVI -XVIII $^{e}$ siècles), Neuchâtel, Alphil, 2013, p. 649-369; Thomas KLÖCKNER, "Heinrich Alting (1583-1644). Erste Einblicke in eine Biographie (zugleich ein Beitrag zur Netzwerktätigkeit der Reformierten im ausgehenden 16. Jahrhundert) », in A. EUSTERSCHULTE et H. WäLzHolz (dir.), Anthropological Reformations - Anthropology in the Era of Reformation, Göttingen, Vandenhoeck \& Ruprecht (Refo500 Academic Studies, 28), 2015, p. 459-478. Originaire de Frise orientale, il étudie à Heidelberg, où il devient professeur de dogmatique (1613), avant d'en être chassé pendant la guerre de Trente Ans et de fuir aux Provinces-Unies. Son Histoire ecclésiastique du Palatinat (1644) est éditée en 1701 dans les Monumenta de Mieg et Nebel (voir n. suiv.). Sur l'historiographie ecclésiastique réformée en Palatinat, voir Gustav Adolf BENRATH, Reformierte Kirchengeschichtsschreibung an der Universität Heidelberg im 16. und 17. Jahrhundert, Speyer, Zechner (Veröffentlichungen des Vereins für Pfälzische Kirchengeschichte, 9), 1963.

28. Lessing décrit ici le contenu de la première partie des Monumenta pietatis et literaria virorum in re publica illustrium selecta édités à Francfort en 1701 par Ludwig Christian Mieg (16681740), alors professeur de théologie à Marbourg, à partir de 1705 à Heidelberg (cf. ADB 21 (1885), 712 (Heinrich HoltzmanN)) et Daniel Nebel (1664-1733), professeur de médecine, 
recteur de l'université de Marbourg en 1697 et 1705, à Heidelberg à partir de 1708 (cf. Hessische Biographie, en ligne, texte du 20.07.2016, consulté le 18.10.2016). Ce recueil de documents historiques, principalement consacré à I'histoire ecclésiastique du Palatinat aux $X V I^{e}-X V I I^{e}$ siècles, contient entre autres un catalogue des manuscrits grecs de la Bibliothèque palatine (p. 1-128), I'Historia Ecclesiae Palatinae d'Alting (p. 129-250, voir n. préc.), les Actes du procès des antitrinitaires de Heidelberg (p. 318-336) et la lettre de Neuser au sultan Selim II (p. 337-344), dans la version allemande, assez douteuse, décrite dans l'introduction, p. 16-17.

29. Voir Burkhard Gotthelf STRUVE, Ausführlicher Bericht von der Pfältzischen Kirchen-Historie [...], [Jena] 1721, qui retrace I'histoire de l'Église en Palatinat « du début de la Réforme au temps présent ». Struve (1671-1738), juriste et bibliothécaire de l'université d'léna à partir de 1697, conseiller et historiographe de la cour ernestine (cf. ADB 36 (1893), 671-676 (Paul MıTZSCHKE)), est comme Jöcher (voir plus haut, n. 4) un confrère et prédécesseur de Lessing dans ce monde érudit de l'Allemagne moyenne qui relie la bibliothèque de Wolfenbüttel à celles des principautés thuringeoises et saxonnes (léna, Leipzig, Gotha, voir plus bas, n. 170). - Sur la lettre de Frédéric III à l'électeur Auguste de Saxe (1526-1586, règne à partir de 1553), reproduite par Struve (p. 227-228), et qui constitue en effet la seule pièce supplémentaire par rapport au dossier des Monumenta, voir plus bas, n. 173.

30. Première mise en cause par Lessing de la sincérité des sources, à travers le constat des liens qui existent entre l'historiographie ecclésiastique palatine et la publication des pièces officielles du procès Neuser.

31. Alting, Historia Ecclesiastica Palatinae, in Monumenta pietatis et literaria [...], op. cit., p. 207 : "Alors qu'il séjournait là [à Spire, NdT], arriva un émissaire du voïvode de Transylvanie pour conclure un pacte de sécurité et de défense mutuelles avec l'empereur et les États de l'Empire. Pour le saluer, accourent à Spire Neuser, Sylvan et Vehe, qui lui confient des lettres à transmettre en Transylvanie. Sylvan en avait écrit une à Giorgius Blandrata, médecin du voïvode, et Neuser à l'empereur turc lui-même. Il y était dit que beaucoup en Allemagne s'étaient attachés à la faction arienne, et que ceux-là ne désiraient rien de plus que d'ouvrir le chemin vers l'Empire au roi des Turcs, et de faire alliance avec lui ».

32. Ibid., p. 209: "L'affaire traînant ainsi en longueur, Neuser prit la fuite mais fut ramené à Amberg le 8 septembre de la même année [1570, NdT] et gardé au cachot. Six semaines plus tard, par une négligence ou une trahison de ses gardiens, il se laissait glisser le long d'un fil depuis une tour arrière de la forteresse et, fugitif une seconde fois [Lessing souligne, NdT], s'échappa en Pologne à travers la Bohême et la Silésie, pour finalement rejoindre la Transylvanie».

33. Depuis Lessing, cet interlocuteur a été identifié : il s'agit de Kaspar Baumann, alors à Schintau (Šintava, actuelle Slovaquie) et prédicateur auprès du comte Jules I $^{\text {er }}$ de Salm et Neubourg (1531-1595). Ces informations sont contenues dans la lettre de Baumann en date du 17 janvier 1574, à laquelle Neuser répond (texte reproduit dans WuB 8, 789-792).

34. II s'agit de l'électeur Frédéric III (voir plus haut, n. 6).

35. La Dutch Church de Londres fut fondée en 1550, sur le site de l'ancien couvent des frères augustins (Austin Friars), pour accueillir les réformés réfugiés peu avant la formation des PaysBas espagnols. Voir Johannes LINDEBOOM, Austin Friars. A History of the Dutch Reformed Church in London 1550-1950, The Hague, Nijhoff, 1950. Son premier superintendant fut le polonais Johannes a Lasco (Jan Łaski, 1499-1560), qui avait auparavant réformé la Frise orientale (voir Judith BECKER, Gemeindeordnung und Kirchenzucht. Johannes a Lascos Kirchenordnung für London (1555) und die reformierte Konfessionsbildung, Leiden-Boston, Brill (Studies in Medieval and Reformation Traditions, 122), 2007). Au moment où Neuser arrive à Londres, vers 1570, les "Flamands" sont, en nombre, la plus importante communauté expatriée de Londres. II n'y a aucun hasard à ce que Neuser dans sa fuite se soit dirigé vers ce qui a constitué historiquement l'une des premières stations de l'exil réformé. 


\section{Adam Neuser}

36. On sait peu de choses sur ce Theophilus Dasypodius. L'éd. Schilson d'Adam Neuser (voir plus haut, n. 1) suppose qu'il fut précepteur à Paris d'un des fils du comte de Salm et Neubourg, dont le correspondant de Neuser, Caspar Baumann, fut le prédicateur. L'erreur est manifeste: il est question ici d'une autre maison, celle de Solms. Les Dasypodius sont une lignée d'érudits helvéto-alsaciens. Petrus Dasypodius (Peter Rauchfuss, 1559), fut professeur de grec à Strasbourg; son fils Conrad (1531-1601), professeur de mathématiques, éditeur d'Euclide et de Théodose, conçut l'horloge astronomique de la cathédrale (cf. Nouveau Dictionnaire de biographie alsacienne, fasc. 7, Strasbourg, Fédération des sociétés d'histoire et d'archéologie d'Alsace, 1986, p. 582-583, notices de Jean RoTT). Théophile est mentionné comme éditeur d'un volume de Lettres de Cicéron plusieurs fois réédité par l'imprimeur strasbourgeois Rihel entre 1572 et 1582 . II semble avoir fait partie du cercle de l'humaniste Johannes (Jean) Sturm. Les raisons pour lesquels Neuser en appelle à son témoignage nous sont inconnues.

37. Ce « Doctor Bictu » nous est plus inconnu encore. Il est présenté ici comme précepteur d'un des fils de l'électeur palatin Frédéric III (voir plus haut, n. 6), Christophe (1551-1574), tombé à la bataille de Mook contre les Espagnols.

38. La « nouvelle vraie doctrine » (rechte neue Lehre) désigne, dans un vocabulaire typique des orthodoxies confessionnelles, la doctrine réformée à laquelle Frédéric III avait entrepris de convertir le Palatinat. La reprise de la formule, de la part de Neuser, peut avoir un caractère ironique.

39. Christoph Thretius (mort vers 1590), après un passage à Wittenberg mentionné en 1556 et d'abondants voyages qui le rapprochent des réformateurs helvétiques (Calvin, Bullinger), devient en 1564 recteur du Gymnase réformé de Cracovie et s'affirme comme l'un des principaux adversaires des unitariens polonais. Voir Theodor WOTSCHKE, « Christoph Thretius. Ein Beitrag zur Geschichte des Kampfes der reformierten Kirche gegen den Antitrinitarismus in Polen », Altpreussische Monatsschrift 44/1, p. 1-42 et 44/2 (1907), p. 151-210, part. 185, n. 3. Ironiquement, il semble que Neuser et Sylvan se soient laissés gagner à l'antitrinitarisme par les documents que Thretius leur envoyait de Pologne à des fins de réfutation. Thretius prend connaissance de ce tournant chez ses alliés en mai 1570 au cours d'un séjour à Heidelberg. La présence de Neuser en Pologne dans l'hiver 1571-1572 ne pouvait que l'alarmer.

40. La doctrine d'Arius (256-336), prêtre d'Alexandrie, soutient le caractère créé du logos johannique et nie donc l'égalité de condition divine du Père et du Fils. Condamnée au concile de Nicée (voir plus haut, n. 2), elle est utilisée depuis lors comme dénomination hérésiologique et s'applique à l'époque de Neuser aux unitariens et à tous les négateurs du dogme trinitaire. Lors de la diète de Partzow en août 1564, le roi de Pologne Sigismond II Auguste (1520-1572, règne à partir de 1548) bannit du territoire tous les non-catholiques étrangers. L'interdiction est expressément notifiée aux antitrinitaires et anabaptistes en novembre de la même année. Thretius (voir n. préc.) obtient en avril 1572 que cette interdiction soit réaffirmée à propos de Neuser. Un récit détaillé se trouve dans Curt HoRN, Der Kampf zwischen Calvinismus und Zwinglianismus in Heidelberg und der Prozess gegen den Antitrinitarier Johann Sylvan. Ein Beitrag zur pfälzischen Reformationsgeschichte, Heidelberg 1913, p. 38. Voir aussi Th. WOTSCHKE, "Christoph Thretius », art. cité, p. 38-40.

41. Johann Sommer ou Sumer (1542-1574), natif de Saxe, immatriculé en 1561 à l'université de Francfort-sur-l'Oder, occupe divers postes de directeur d'école en Moldavie et en Transylvanie avant de diriger l'Académie unitarienne fondée en 1557 à Clausenbourg, en lien étroit avec le superintendant unitarien Ferenc Dávid (voir plus bas, n. 52), dont il fut peut-être le gendre. La ville de Clausenbourg (Klausenburg en allemand, Kolozsvár en hongrois, Cluj en roumain) reçoit le statut de ville royale libre en 1405 de Sigismond I ${ }^{\text {er }}$, alors roi de Hongrie et futur empereur germanique; le futur roi Matthias Corvin y naît en 1443. Après la conquête ottomane, Clausenbourg fait partie du territoire de la Transylvanie. Sa bourgeoisie, hongroise et allemande magyarisée, passe à l'antitrinitarisme au milieu du XVI siècle. Voir p. ex. Konrad GÜNDISCH, 
« Cluj [-Napoca] », in H. ROTH (dir.), Siebenbürgen, Stuttgart, Kröner (Handbuch der historischen Stätten, 330), 2003, p. 57-63.

42. L'astéristique, comme indiqué plus haut par Lessing (voir p. $85=[127] /<62>$ ), correspond à un passage corrompu dans la copie de la lettre de Neuser.

43. Coquille dans l'éd. originale : il s'agit de Dionysius Alesius (1577), superintendant luthérien de Transylvanie. Voir Martin ARMGART, « Territoriale Kirchenleitungsmodelleim multikonfessionellen Territorium - Fürstentum Siebenbürgen », in J. WISCHMEYER (dir.), Zwischen Ekklesiologie und Administration. Modelle territorialer Kirchenleitung und Religionsverwaltung im Jahrhundert der europäischen Reformationen, Göttingen, Vandenhoeck \& Ruprecht (Veröffentlichungen des Instituts für europäische Geschichte Mainz, 100), 2013, p. 225-249, sp. 234, n. 38.

44. Je transpose librement une expression proverbiale dans l'allemand de Neuser: «wenn der Wagen faellt, so hat er fuenf Raeder ", littéralement: "Quand le chariot se renverse, c'est qu'il a cinq roues ». Peu après Lessing, un dictionnaire de 1825 rapproche la formule d'un proverbe: "Arbore dejecta quivis ligna colligit», et paraphrase encore, en allemand: "Le monde entier marche sur celui qui est tombé » (Ferdinand PHILIPPI, Kleines lateinisches Conversationslexikon, t. I, Dresden 1825, p. 38).

45. «De la différence entre Nouveau et Ancien Testament », « De la justification devant Dieu », «De l'interprétation du premier chapitre de Jean l'évangéliste»: ce sont des rubriques de controverse, présentées de manière scolaire pour lister les points de désaccord entre Neuser et les (ou des) antitrinitaires de Clausenbourg. Elles recouvrent en partie ce que l'on sait des sujets traités dans les œuvres manuscrites perdues de Neuser (cf. Ch. J. BURCHILL, The Heidelberg Antitrinitarians, op. cit., p. 151-152). Sur les confessions de foi en Transylvanie, voir Ludwig BINDER, "Theologie und Bekenntnis auf Synode der evang.-sächsischen Kirche 1545-1578 », in U. A. WIEN (dir.), Reformation, Pietismus, Spiritualität. Beiträge zur siebenbürgischsächsischen Kirchengeschichte, Köln-Weimar-Wien, Böhlau (Siebenbürgisches Archiv, 41), 2011, p. 37-122.

46. « Un homme noble et illustre », dont l'identité n'est pas connue.

47. « Aussitôt après ton départ s'est répandue la rumeur que ton prince, c'est-à-dire le [électeur] Palatin, avait écrit à notre roi pour lui demander de t’appréhender et de te ramener enchaîné à Heidelberg. Je suppose que cette rumeur, comme beaucoup d'autres, a été forgée par Thretius et d'autres ennemis de la vérité. Je te demande instamment de prendre garde et de ne pas faire connaître ton nom ». Sur Thretius, voir plus haut, n. 39.

48. L'« empereur romain » renvoie au Saint-Empire romain germanique, qui se voit comme la continuation de l'Empire romain. Le passage reflète la compréhension confuse qu'a Neuser de la situation politique en Transylvanie. Allusion est faite au traité signé à la diète de Spire, par lequel l'empereur Maximilien II reconnaît Jean-Sigismond comme " prince de Transylvanie », en même temps que celui-ci renonce au titre de « roi de Hongrie » (voir plus haut, n. 10). Le traité consacre ainsi le rapprochement de la Transylvanie avec le Saint-Empire.

49. II s'agit peut-être de Stephan Cirler, secrétaire privé de l'électeur Frédéric III. Voir Volker PRESS, Calvinismus und Territorialstaat. Regierung und Zentralbehörden in der Kurpfalz 1559-1619, Stuttgart, Klett (Kieler historische Studien, 7), 1970, p. 240.

50. Vienne est la ville de résidence des empereurs de la dynastie des Habsbourg.

51. Neuser semble croire que la Transylvanie est devenue partie intégrante du Saint-Empire.

52. Ferenc Dávid (ou Dávid Ferenc selon l'usage hongrois, sous forme latinisée Franciscus Davidis, 1520-1579) est une figure-clé de l'antitrinitarisme transylvanien, qui a parcouru le spectre entier des confessions dans ce territoire, occupant à chaque fois des positions ecclésiastiques éminentes. Né catholique à Clausenbourg, il étudie à Wittenberg, devient luthérien en 1554, est nommé l'année suivante superintendant (évêque) de la ville, passe en 1564 au protestantisme réformé, dans laquelle il conserve le même grade de superintendant, 


\section{Adam Neuser}

devenant en outre pasteur à la cour du roi Jean-Sigismond (voir plus haut, n. 10). Après la promulgation en 1568 de l'édit de Torda qui reconnaît la coexistence des quatre confessions de Transylvanie, il devient superintendant unitarien, en charge avec Johann Sommer (voir plus haut, n. 41) de l'Académie de Clausenbourg. L'élection au royaume du catholique Étienne Báthory en 1571 entraîne son emprisonnement. II meurt en captivité en 1579. À la fin de la décennie 1560, il prend part aux controverses internes des antrinitaires et soutient la thèse considérée comme rigoriste selon laquelle le Christ n'a pas à être invoqué dans les prières à Dieu. Voir Mihály BALÁZs, Ungarländische Antitrinitarier IV. Ferenc Dávid, Baden-Baden/Bouxwiller, Koerner (Bibliotheca dissidentium, XXVI), 2008 et les travaux cités en introduction, n. 36.

53. « Schiman », Şimand (Schimand en allemand, Alsósimánd en hongrois), ville de Roumanie, sur l'actuelle frontière hongroise, alors placée sous administration directe de l'Empire ottoman. Dans l'édition originale, la première occurrence a "Sochiman ». Le pacha est gouverneur de Temeşvar (actuellement Timişoara en Roumanie, Temesvár en hongrois, Temeswar en allemand; par convention, j'adopte dans la traduction l'actuelle orthographe turque), devenue province (eyâlet) ottomane en 1552 (pour un aperçu en français, voir Jean-Paul BLED, «Le Banat. Un panorama historique », Études Germaniques 67/3 (2012), p. 415-419). - Sur le titre de pacha, conféré par le sultan, voir art. «Pasha », El2 8 (1995), 279-281 (Jean DENY).

54. On ne sait rien de cet imprimeur «Paulus » et de ce prédicateur « Benedict ». Le texte laisse entendre que Ferenc Dávid, comme superintendant des unitariens de Transylvanie, aurait autorité spirituelle sur les prédicateurs unitariens dans le territoire de la province ottomane de Temeşvar (voir n. préc.).

55. Lugusch, actuellement ville de Lugoj en Roumanie. Neuser n'est pas très au clair sur les frontières qu'il traverse : au moment où il s'y trouve, la ville se trouve bien en territoire ottoman.

56. La «foi des Valaques » est grecque orthodoxe. L'éd. Schilson (WuB 8, 806) suggère qu'il s'agit de ressortissants de la principauté de Valachie, au sud de la Transylvanie, placée elle aussi, depuis 1415, sous suzeraineté ottomane. Les événements rapportés ici se déroulent cependant dans la province ottomane de Temeşvar, à l'ouest de la Transylvanie. Plus vraisemblablement, il est question ici d'une communauté de langue romane orientale installée à Temeşvar, comme en plusieurs autres endroits des Balkans (les Grecs parlent des B $\lambda$ áxoı). L'étude la plus éclairante est celle de Minhea BERINDEI et Gilles VEINSTEIN, L'Empire ottoman et les pays roumains, 1544-7545. Études et documents, Paris, Éditions de l'École des Hautes Études en Sciences Sociales (Documents et recherches sur le monde byzantin, néohellénique et balkanique, 14)/Cambridge, Mass., Harvard Ukrainian Research Institute (Studies in Ottoman Documents Pertaining to the Ukraine and the Black Sea Countries, 1), 1987.

57. Schilson (WuB 8, 807) suppose qu'il s'agit de réformés magyars, qui composent de fait une des principales communautés de Transylvanie. Étant donné l'accueil favorable qu'ils réservent à Neuser, ces « Juges Hongrois » de Temeşvar sont plus vraisemblablement antitrinitaires.

58. "Welsch» désigne en allemand, de manière de plus en plus nettement péjorative, les locuteurs de langues latines et romanes. II se peut que Neuser reprenne le terme de la bouche du pacha, car sur la même racine que " welsche », "iflak » (eflak) en turc désigne la Valaquie, région de langue roumaine mentionnée peu avant dans sa lettre. Avant tout cependant, le pacha se fait l'écho des préoccupations géopolitiques de l'Empire ottoman. En 1570 avait éclaté la quatrième guerre entre l'Empire ottoman et la République de Venise et la Sainte-Ligue pour le contrôle de Chypre et de la Crète. La bataille de Lépante, perdue sur mer par les Turcs en octobre 1571 (cf. Alessandro BARBERO, Lepanto. La battaglia dei tre imperi (2010), Roma, Laterza, $2011^{4}$, tr. fr. La Bataille des trois empires. Lépante 1571, Paris, Flammarion (Champs), 2012) marque les consciences, mais la mort du pape Pie v en mai 1572 affaiblit la Sainte-Ligue et un traité de paix est signé l'année suivante. Le soupçon d'une implication de Neuser dans ce conflit n'a pas de fondement, mais quelques années plus tard, à Istanbul, le fuyard jouera bien un petit rôle dans les relations diplomatiques entre les puissances du temps (voir plus bas, n. 213). 
59. S'agit-il de l'empereur Maximilien II, dont le voïvode de Transylvanie cherchait à se rapprocher? Ici encore le propos de Neuser trahit une compréhension confuse de la situation, et la titulature « roi » est peu claire. On comprend cependant que le pacha prenne l'affaire au sérieux: cette interdiction édictée unilatéralement par le voïvode, si elle était attestée, marquerait sa volonté de s'affranchir de la tutelle ottomane.

60. Nouveau signalement par Lessing d'un passage corrompu dans le texte de Neuser.

61. Pour un commentaire de ce passage du dialogue, où les confessions de foi s'échangent à cadence accélérée entre Neuser et le pacha, voir introduction, p. 31-32. La formule du pacha sur le « Dieu unique qui a créé le Ciel et la Terre » est parfaitement coranique: voir Coran XXXIX (Troupes), 5 ; XL (Le croyant), 59; XLII (La délibération), 9; LXV (Le divorce), 12.

62. De 1551 à sa mort en 1571, le poste d'« interprète en chef » (terdjuman bachi, terme qui donnera en français «truchement " ou Dolmetscher en allemand) est occupé par Ibrahim bey, un noble polonais dont le nom d'origine est Joachim Strasz (voir Josef MATUz, "Die Pfortendolmetscher zur Herrschaftszeit Süleymāns des Prächtigen », Südost-Forschungen 34 (1975), p. 26-60). II semblerait qu'un Bavarois, d'origine noble également, lui succède sous le nom de Mahmud: voir Gilles VEINSTEIN, "L'administration ottomane et le problème des interprètes », in B. MARINO (dir.), Études sur les villes du Proche-Orient, XVI ${ }^{e}-x I x^{e}$ siècle. Hommage à André Raymond, Damas, Institut français d'études arabes de Damas (Études arabes, médiévales et modernes), 2001, p. 65-79. Je remercie de nouveau Frédéric Hitzel pour ces informations et références.

63. Alba Iulia (Gyulafehérvár en hongrois, Karlsburg ou Weissenburg en allemand), depuis 1541 capitale de la principauté de Transylvanie.

64. Référence est faite au projet inabouti d'apologie dans laquelle Neuser aurait voulu rendre compte de ses agissements à Heidelberg. Neuser fait comprendre que sa volonté de publier ce texte est à l'origine de son transfert à Istanbul.

65. « Ils se sont réjouis que tu aies échappé en lieu sûr au jugement cruel qui a frappé Sylvan (auquel ta lettre écrite au très-puissant empereur des Turcs à la veille de la Naissance du Christ, dans l'année 1572, a coûté la vie) ». Ce texte et le suivant sont extraits de lettres à Neuser qui n'ont pas été conservées.

66. « Sylvanus a été décapité en décembre de l'année dernière, après qu'il eut abjuré sa religion ; son crime était d'avoir eu connaissance de la lettre que tu as écrite au Turc. Il en a appelé à Dieu et aux hommes de l'injustice qui lui était faite. La réponse définitive qu'il avait reçue est que le prince en avait décidé ainsi; l les autres ont été libérés ».

67. Réminiscence biblique, cf. Ps 42, 2 (TOB) : « J'ai soif de Dieu, du Dieu vivant: Quand pourraije entrer et paraître face à Dieu? »

68. Adaptation libre du livre biblique du Siracide, Si 19, 13-17: «Interroge ton ami, peut-être n'a-t-il rien fait, et s'il l'a fait, qu'il ne recommence plus. Interroge ton prochain, peut-être n'a-t-il pas dit cela, et s'il l'a dit, qu'il ne le répète pas! Interroge ton ami, car la calomnie est fréquente, ne te fie pas à tout ce qu'on dit. Tel glisse sans mauvaise intention : qui donc n'a jamais péché en paroles? Interroge ton prochain avant de le menacer, et laisse la Loi du Très Haut suivre son cours ».

69. Le récit de Neuser est pour le moins tendancieux. La doctrine d'Arius (voir plus haut, n. 40) est condamnée en 325 par le concile de Nicée convoqué par l'empereur Constantin (272-337), qui s'était converti au christianisme une quinzaine d'années auparavant (récit légendaire de la victoire du pont Milvius en 312 et de l'apparition survenue à l'empereur : "In hoc signo vinces »). Le souci de l'unité de l'Église et de l'Empire explique le ménagement avec lequel les Ariens sont traités par la suite. Constantin est même baptisé, peu avant sa mort, par l'évêque Eusèbe de Nicomédie, certes arien mais signataire du credo de Nicée. Si le processus de christianisation de l'Empire fait toujours l'objet de discussions parmi les historiens, il est en revanche impossible de considérer, comme le fait Neuser, qu'Arius «a rallié à son opinion l'empereur 


\section{Adam Neuser}

Constantin ». L'absence dans son récit de toute mention du concile de Nicée relève du tour de force en matière de refoulement de la réalité historique.

70. Neuser veut bien sûr parler d'excommunication. La formule «mettre au ban » porte la trace des combats menés par Neuser à Heidelberg : elle renvoie au « ban de Genève », comme il désigne plus bas (p. $99=[142] /<74>$ ) la polémique qui éclata en Palatinat au milieu de la décennie 1560 à propos des nouvelles règles d'excommnication, inspirées de Calvin (voir introduction, p. 11).

71. «Les Grecs n'obéissent pas à l'Église romaine; ils ont beaucoup d'erreurs, qui sont condamnées par l'Église, c'est-à-dire l'Église romaine, car ils disent que l'Esprit saint ne procède pas du Fils, mais du Père seulement. De même ils disent qu'il n'y a pas de Purgatoire. Voilà ce que dit l'histoire ». II n'a pas été possible de retrouver l'origine du texte cité ici par Neuser.

72. Neuser mêle dans son enquête grecque deux épisodes bien distincts de l'histoire de l'Église: d'une part la querelle trinitaire des $I V^{e}-v^{e}$ siècles, ponctuée par les grands conciles œcuméniques, dont celui de Nicée (voir plus haut, n. 2), d'autre part l'épisode du schisme de 1054 entre l'Église d'Occident et l'Église d'Orient, aboutissement de la querelle du Filioque dont Neuser résume ici les termes doctrinaux (procession de l'Esprit saint à partir du Père et du Fils pour l'Église latine, du seul Père pour les orientaux). S'il est vrai que des continuités peuvent être observées dans la rivalité entre Rome et Constantinople du $\mathrm{V}^{\mathrm{e}}$ au $\mathrm{XI}^{\mathrm{e}}$ siècle, la présentation très particulière que donne Neuser témoigne d'une vision de l'histoire de l'Église dans laquelle tout est prétexte à marteler la thèse de la subordination du Fils créé au Père éternel, « unique Dieu vivant ». Il va de soi que l'Église grecque n'est pas antitrinitaire.

73. «[...] que le Symbole d'Athanase n'a pas été composé par Athanase lui-même, mais par un quelconque moine puant». Le Symbole (confession de foi ou credo) d'Athanase, désigné aussi par son premier mot, Quicumque, est mentionné pour la première fois en 670. Le début du texte contient une forte affirmation trinitaire, anti-arienne. Son attribution à Athanase le Grand, évêque d'Alexandrie (295-373), fut cependant contestée à plusieurs reprises à l'époque moderne, notamment par Joachim Camerarius (Liebhard, 1500-1574), philologue, professeur à Wittenberg, Nuremberg, Tübingen, Leipzig, très lié à Melanchthon dont il fut le biographe (voir Stephan KUNKLER, Zwischen Humanismus und Reformation. Der Humanist Joachim Camerarius (1500-1574) im Wechselspiel von pädagogischem Pathos und theologischem Ethos, Hildesheim-New York, Olms (Theologische Texte und Studien, 8), 2000 ; Rainer KössLING et Günther WARTENBERG (dir.), Joachim Camerarius, Tübingen, Narr (Leipziger Studien zur klassischen Philologie, 1), 2003). Le texte se trouve par ex. dans le Denzinger (Enchiridion symbolorum, definitionum et declarationum de rebus fidei et morum (1854), Freiburg i. B., 2014 $\left.4^{44}, n^{\circ} 75-76\right)$. Il est reconnu au nombre des confessions de foi des Églises catholique, luthérienne et réformée, mais son usage liturgique est limité. On estime aujourd'hui qu'il constitue un collage tardif de formules patristiques, issues en particulier d'Augustin: voir Volker Henning DRECOLL, «Das Symbolum Quicumque als Kompilation augustinischer Tradition », Zeitschrift für antikes Christentum 11 (2007), p. 30-56 et Annette von Stockhausen et Hanns Christoph BREnNECKE (dir.), Von Arius zum Athanasium. Studien zur Edition der "Athanasius Werke », Berlin-New York, De Gruyter (Texte und Untersuchungen zur Geschichte der altchristlichen Literatur, 164), 2010.

74. Neuser paraphrase les ch. 9-11 de la première épître aux Corinthiens, 1 Co 9, 19-23: "Oui, libre à l'égard de tous, je me suis fait l'esclave de tous, pour en gagner le plus grand nombre. J'ai été avec les juifs comme un juif, pour gagner les juifs, avec ceux qui sont assujettis à la loi, comme si je l'étais - alors que moi-même je ne le suis pas -, pour gagner ceux qui sont assujettis à la loi ; avec ceux qui sont sans loi, comme si j'étais sans loi - alors que je ne suis pas sans loi de Dieu, puisque Christ est ma loi -, pour gagner ceux qui sont sans loi. J'ai partagé la faiblesse des faibles, pour gagner les faibles. Je me suis fait tout à tous pour en sauver sûrement quelques-uns. Et tout cela, je le fais à cause de l'Évangile, afin d'y avoir part. » ; 10, 33: "C'est ainsi que moi-même je m'efforce de plaire à tous en toutes choses, en 


\section{Adam Neuser}

ne cherchant pas mon avantage personnel, mais celui du plus grand nombre, afin qu'ils soient sauvés. »; 11, 1: "Soyez mes imitateurs, comme je le suis moi-même du Christ. »

75. Les lettres envoyées par Neuser de Pologne à l'électeur palatin sont aujourd'hui perdues.

76. II s'agit de Louis VI (1539-1583), comte palatin (Pfalzgraf), fils de l'électeur Frédéric III (voir plus haut, n. 6), resté luthérien à la différence de son père. Une fois électeur, à partir de 1576, il fut l'artisan de la reluthérisation du Palatinat.

77. «La volonté de mal agir vaut mauvaise action », maxime inspirée du droit romain, même si elle ne semble se trouver nulle part dans le code justinien, du moins sous la forme qu'elle prend ici. Max RADIN, dans sa recension de l'ouvrage de Hermann KANTOROWICZ, Tat und Schuld (Zürich-Leipzig 1933, cf. Journal of Criminal Law and Criminology 25 (1935), p. 816-818), se méfie de la formule. Je remercie Frédéric Gabriel de cette indication et de l'ensemble des vérifications auxquelles il s'est livré.

78. Presbourg, actuelle Bratislava, capitale aujourd'hui de la Slovaquie, désignée en 1536, devant l'avance ottomane, comme capitale de la Hongrie. La ville est baignée par le Danube, dont Neuser a dû suivre le cours à partir de Heidelberg.

79. Debrecen, aujourd'hui deuxième ville de Hongrie, à l'est du pays, alors à la frontière de la Transylvanie, que Neuser ne put franchir lors de cette tentative de fuite. À partir de 1536, sous l'influence notamment de ses riches marchands (ils sont mentionnés ici par Neuser), la ville devient le centre du calvinisme hongrois. Debrecen est prise en 1555 par les Turcs, mais achète son autonomie contre paiement d'un tribut.

80. Voir plus haut, n. 13.

81. II s'agit peut-être de Melchior Petri, prédicateur réformé du Palatinat, auteur au milieu des années 1560 de deux écrits polémiques contre le superintendant luthérien de Strasbourg, Johannes Marbach (1521-1581). Neubourg-sur-le Danube se trouve dans le Haut-Palatinat.

82. Voir 1 S 24, 7, David épargne Saül, roi d'Israël, son prédécesseur, après l'avoir provoqué: " Il dit à ses hommes: "Que le Seigneur m'ait en abomination si je fais cela à mon seigneur, le messie du Seigneur. Je ne porterai pas la main sur lui, car il est le messie du Seigneur" ».

83. Ce "secrétaire de Spire» (Secretarius zu Speyer) est difficile à identifier. S'agit-il de l'émissaire du voïvode de Transylvanie à la diète de Spire, Gáspár Bekes, mentionné juste auparavant? (Voir plus haut, n. 21).

84. Neuser rend compte en ces termes des travaux préparatoires à la conclusion du traité de Spire entre le Saint-Empire et la principauté de Transylvanie (voir plus haut, n. 10).

85. Comme Lessing après lui (voir plus haut, p. 107-110 = [153-157]/<83-86>), Neuser doute de l'authenticité de la version de la lettre au sultan produite à charge par les autorités de l'électorat palatin.

86. Nouveau signalement par Lessing d'un passage corrompu dans le texte de Neuser.

87. Dt 5, versets $6,8,17,18$.

88. "Cela peut être oublié », voir plus haut dans le texte la traduction proposée par Neuser.

89. L'électeur palatin : "Kurfürst am Rhein » est une partie de sa titulature.

90. Neuser fait allusion aux controverses sur le droit de l'excommunication qui, au milieu des années 1560, agitèrent l'Église du Palatinat, dans le sillage de la nouvelle discipline réformée introduite par l'électeur : voir introduction, p. 11.

91. Pierre Bouquin (Boquin, Boquinus, vers 1510/1515-1582), né en Saintonge, docteur en théologie de Bourges (1539), d'abord carmélite, passe définitivement à la Réforme en 1555. Nommé professeur à Heidelberg en 1558 , il est actif dans la rédaction du nouveau catéchisme réformé (voir introduction, p. 11 et la réédition de la traduction française de 1986, Le Catéchisme de Heidelberg. Au cœur de l'identité réformée, éd. P.-O. LÉCHOT, Genève, Labor et Fides, 2013). 


\section{Adam Neuser}

La reluthérisation du Palatinat sous l'électeur Louis VI le fait fuir à Lausanne, où il devient professeur en 1578. Voir BBKL 1 (1975), 718-719 (F.-W. BAUTZ) et la notice dans La France protestante, éd. E. et É. HAAG, t. 2, Paris $1879^{2}$, col. 875-880.

92. Girolamo Zanchi (1516-1590), né près de Bergame, fuit l'Italie en 1551, devient professeur d'Ancien Testament à Strasbourg, entre en conflit avec les autorités luthériennes de la ville et est nommé professeur à Heidelberg en 1568, où il devient un maître de la théologie scolaire réformée. Voir Stefan LINDHOLM, Jerome Zanchi (1516-1590) and the Analysis of Reformed Scholastic Christology, Göttingen, Vandenhoeck \& Ruprecht (Reformed Historical Theology, 37), 2016.

93. Le «ban de Genève » désigne la doctrine calvinienne de l'excommunication (exclusion temporaire de la cène ou exclusion définitive de l'Église) et de son administration à l'échelon paroissial : voir plus haut, n. 90.

94. «Pour qu'on comprenne que je suis celui que je dis être, je t'envoie cette lettre revêtue du sceau du Prince ».

95. Littéralement: « où ai-je laissé ce sceau? »

96. Voir plus haut, n. 93.

97. « interprétation injuste».

98. Voir traduction plus haut, n. 94.

99. La citation de Neuser est imprécise. Peut-être s'agit-il de 1 Jn 3, 21 : «Mes bien-aimés, si notre cœur ne nous accuse pas, nous nous adressons à Dieu avec assurance ».

100. « exemplaires très anciens du Nouveau Testament ».

101. Le fils de Neuser, également prénommé Adam, était retenu en otage à Vienne, preuve supplémentaire de la dimension impériale qu'avait prise l'affaire de Heidelberg. Voir M. MuLSow, «Fluchträume und Konversionsräume zwischen Heidelberg und Istanbul. Der Fall Adam Neuser », in ID. (dir.), Kriminelle - Freidenker - Alchemisten, Köln-Weimar-Wien, Böhlau, 2014, p. 33-60, sp. 55-57.

102. L'intermédiaire salué ici est une figure dont l'importance montre l'étendue des relations de Neuser: Johannes Crato (Kraft) von Krafftheim (1519-1585), natif de Breslau, étudie la théologie à Wittenberg auprès de Luther et Melanchthon, puis la médecine à Padoue. À partir de 1560, il est médecin des empereurs Ferdinand I'r, Maximilien II (dont il autopsie le cadavre) et Rodolphe II à Vienne et Prague. À la fin de sa vie, il fonde une paroisse réformée sur sa terre natale. II noue des liens autant avec les réformés de Heidelberg (Erastus, voir plus bas, n. 223) qu'avec les milieux antitrinitaires. Voir Ralf BRöER, "Friedenspolitik durch Verketzerung. Johannes Crato (1519-1585) und die Denunziation der Paracelsisten als Arianer », Medizinhistorisches Journal 37 (2002), p. 139-182.

103. « Écrit d'Adam Neuser, trois fois et quatre fois apostat, malheureux mamelouk, dans lequel, avec la pire mauvaise foi et une conscience lépreuse, il raconte son histoire ».

104. «mauvaise foi », voir n. préc.

105. Jeu de mots à partir de la construction idiomatique "gefangen nehmen », «capturer ». L'italique de Lessing sur «nehmen» (prendre) permet d'insister sur la passivité de la capture, par opposition au choix attribué à Neuser de se constituer prisonnier ("sich selbst der Gefangenschaft überliefer[ $n]$ »).

106. Voir plus haut, p. 95-96 (= [138-139]/<71>).

107. Dans les notes infrapaginales qui suivent, Lessing renvoie toujours aux Actes du procès des antitrinitaires de Heidelberg, cette fois dans le texte donné par l'Ausführlicher Bericht de Struve (voir plus haut, $n$. 29).

108. Theophil Mader (1541-1604), à l'époque étudiant à Heidelberg après quelque temps à Bâle. II deviendra professeur de logique à Altdorf (1583), puis médecin à Amberg (1585), enfin 
professeur de médecine à Heidelberg. Voir Dagmar DRÜLL, Heidelberger Gelehrtenlexikon 13861657, Berlin/Heidelberg, Springer, 2002, p. 363-364.

109. Léger jeu de mots sur le paradigme d'Antwort, la réponse: Verantwortung, la justification; antworten, répondre.

110. Alting, Historia Ecclesiae Palatinae, in Monumenta pietatis et literaria, op. cit., pars prior, p. 207: « [...] dans laquelle il est dit qu'il y en a beaucoup en Allemagne, partisans de la faction arienne, qui ne souhaiteraient rien de plus que de paver la voie du monarque des Turcs dans l'Empire et de s'allier avec lui ».

111. Ibid. : "sur un pacte de sécurité et de défense mutuelles à conclure avec l'empereur et les États de l'Empire».

112. "Adami Neuseri, gewesenen Predigers zu Heydelberg Schreiben an den Türckischen Kayser Selym dieses Namens den Andern », in Monumenta pietatis et literaria, op. cit., pars prior, p. 343. Voir la traduction de la lettre au sultan par Veyssière de La Croze plus bas, p. 169-176.

113. Réminiscence de Rm 9, 14-18, dans une parodie d'argumentation biblique: "Qu'est-ce à dire? Y aurait-il de l'injustice en Dieu? Certes non! II dit en effet à Moïse : Je ferai miséricorde à qui je veux faire miséricorde et je prendrai pitié de qui je veux prendre pitié [Ex 33, 19]. Cela ne dépend donc pas de la volonté ni des efforts de l'homme, mais de la miséricorde de Dieu. C'est ainsi que l'Écriture dit au Pharaon: Je t'ai suscité précisément pour montrer en toi ma puissance et pour que mon nom soit proclamé par toute la terre [Ex 9, 16]. Ainsi donc il fait miséricorde à qui il veut et il endurcit qui il veut ». Lessing se hâte de qualifier cette argumentation de « fleur de rhétorique ».

114. La rhétorique de la prédication, les facilités qu'elle s'octroie, font l'objet d'une réflexion profonde de Lessing, dans laquelle l'identité d'écrivain s'éprouve dans l'opposition aux pratiques d'Église : voir Ph. BüTTGEN, « Lessing et la question du prêche. Philosophie, théologie, pastorat », Les Études philosophiques, 2/2003, p. 213-243, sp. 218-234.

115. Voir plus haut, p. $96(=[139] /<72>)$. Dans les notes de Lessing, je maintiens les renvois à la première édition d'Adam Neuser.

116. Nicolai Isthuanfi Pannoni Historiarum de rebus ungaricis libri triginta quatuor, Coloniae Agrippinae 1622, p. 517: «[...] partout avec les plus grandes expressions de joie par les impériaux et, partout où il passait, avec les honneurs les plus recherchés ». Nicolaus Isthuanfius (Miklós Istvánffy, 1535-1608), étudie à Bologne et Padoue, devient secrétaire puis chancelier de la chancellerie hongroise à la cour de l'empereur Maximilien II et enfin vice-palatin de Hongrie, administrateur de la cour royale. Son histoire moderne de la Hongrie depuis la mort du roi Matthias Corvin (1490) est citée par Lessing dans sa première édition.

117. Ibid. : «Là enfin, l'empereur exposa la marche à suivre et les points à soulever; il les voulait aussi secrets que possible. À ces discussions, il ne fit participer que Johannes Trautsonius, préfet de sa cour, et Johann Baptist Weber, juriste et vice-chancelier de l'Empire romain, ainsi que, pour les Hongrois, Johann Listhius, évêque de Veszprém et chancelier de Hongrie ; à tous ceux-ci, il interdit fermement de s'ouvrir d'une quelconque manière de ces sujets ». - Johann von Trautson (vers 1507-1589), noble du Tyrol, se mit au service des empereurs Maximilien II, Ferdinand II et Rodophe II (cf. ADB 38 (1894), p. 519-520 (Franz VON KRONES)). Johann Baptist Weber (1526-1593), professeur de droit à Ingolstadt, fut entre 1570 et 1577 vice-chancelier impérial (voir Andreas EDEL, "Johann Baptist Weber (1526-1584). Zum Lebensweg eines gelehrten Juristen und Spitzenbeamten im 16. Jahrundert », Mitteilungen des Österreichischen Staatsarchiv 45 (1997), p. 111-185). János Liszthy (Johannes List(h)ius, 1532-1578), fut évêque de Vészprem de 1568 à 1573 (cf. Magyar Katolikus Lexikon, lexikon. katolikus. hu).

118. Alting, Historia Ecclesiae Palatinae, loc. cit., p. 207-208: "Alors que l'empereur Maximilien s'expliquait avec le négociateur de Transylvanie au sujet de l'alliance, en disant qu'il ne pouvait conclure de pacte avec des gens qui ne reconnaissaient ni la divinité du Christ ni la divine Trinité des Personnes, son interlocuteur lui répondit : la raison n'est pourtant pas que tu craignes cette 


\section{Adam Neuser}

foi, que de grands princes de l'Empire, avec leurs théologiens, soutiennent et défendent avec nous. Et en disant cela, pour prouver ses déclarations, il sortit les lettres de Neuser et Sylvan et les remit entre les mains de l'empereur. Celui-ci rompit leur sceau, les lut et, tout en l'exhortant à ne pas trop s'en tourmenter, il les transmit à Frédéric III, qui fut ému par l'indignité de ce procédé peu commun. Lui-même, certes à son insu, avait laissé prospérer ce genre d'individus sur ses territoires; mais il relevait de sa charge de les sanctionner selon les lois. »

119. Sur la dénomination « arien », voir plus haut, n. 40.

120. Lessing suit toujours le récit d'Istvánffy (voir plus haut, n. 116), auquel il renvoie en note. Voir ISTHuANFIUS, Historiarum de rebus ungaricis libri, op. cit., p. 517 : "Quod si Turcarum armis Transsiluania pelleretur, tum ei ad Oppolitani principatus iura, quem olim cum Isabella matre tenuerat, reuertit integrum foret. Hostes atque amici iidem vtrique forent: \& cum necessitas exigeret, \& Turcae bellum Transssiluano mouerent, Maximilianus ei omnibus viribus praesto esset: sic tamen, vt quamdiu fieri posset lohannes Sigismundus, suppressa atque occulta huius pacis mentione, Selimum pristinis officiis in quiete \& ocio omnibus artibus construare niteretur. Promittebat etiam Caesar, ad confirmandas nouo affinitatis vinculo faederis conditiones se illi alteram ex neptibus suis Alberti Bauariae, aut Gulielmi lulacensis principis filiam matrimonio iuncturum. »

121. Sur Cáspár Bekes, voir plus haut, n. 21.

122. Christoph Sand (Christof Van Der Sand, Christophorus Sandius, 1644-1680), natif de Königsberg, émigre à Amsterdam en raison de ses convictions antitrinitaires. II devient un proche de Spinoza, qu'il défend contre Pierre-Daniel Huet (cf. Lech SzczUckI, «In the Spinozian Circle (Christopher Sandius Jr)», Przeglad Filozoficzno-Literacki 6 (2007), p. 289-311). Son œuvre inclut un catalogue posthume de textes antitrinitaires, la Bibliotheca Antitrinitariorum, Freistadii 1684, réimpr. Varsoviae, Panstwowe Wydawnictwo Naukowe (Biblioteka Pisarzy Reformacyjnych, 6), 1958. Le texte mentionné par Lessing est le Nucleus historiae ecclesiasticae, exhibitus in historia Arianorum (1669), Coloniae 1676 dans la seconde édition revue par l'auteur, p. 430 : «A. 1561. Obiit Joannes Sigismundus princeps Transsylvaniae Arianus, qui fuit filius Joannis Scepusii Regis. Dicti Joannis Sigismundi temporibus etiam floruit Transsylvaniae regulus Gaspar Beckessius, itidem Arianus ».

123. Voir plus haut, p. $99(=[142] /<74>)$, la phrase citée par Neuser : « Ut intelligas me sc. talem esse, qualem me esse praedico, mitto tibi literas sigillo Principis munitas » (traduction plus haut, ก. 94).

124. Voir plus haut, p. $94(=[137] /<70>)$.

125. Voir plus haut, p. $95(=[138] /<71>)$.

126. StRuve, Ausführlicher Bericht von der Pfältzischen Kirchen-Historie, op. cit., p. 230.

127. Ces « formes » requises pour la conversion à l'islam sont, principalement, la profession ou attestation du Dieu unique et de son prophète (shahâda, voir plus haut, n. 26), secondairement la circoncision. La question de la confession de foi de Neuser est essentielle pour Lessing : voir introduction, p. 30-34.

128. Christoph Sand: voir plus haut, n. 122.

129. Gottfried Arnold (1666-1714), prédicateur et superintendant dans le Harz et en Prusse, historiographe de l'électeur de Brandebourg Frédéric III, le maître de l'hérésiologie luthérienne, traditionnellement rangé dans l'aile radicale du piétisme. Lessing renvoie ici à son ouvrage principal, I'Unpartheyische Kirchen- und Ketzerhistorie parue à Francfort en 1699-1700 (réimpr. Genschmar, Gruber, 2004), qui contient une brève mention de Neuser (t. I, I. XVI, ch. XXXI, § 24, p. 384, col. B). Le doute d'Arnold quant à la conversion de Neuser est du reste formulé avec discrétion. Au sein d'une production abondante depuis une vingtaine d'années, voir le recueil d'Antje MissfeldT (dir.), Gottfried Arnold, radikaler Pietist und Gelehrter. Jubiläumsgabe von und für Dietrich Blaufuß und Hanspeter Marti, Köln-Weimar-Wien, Böhlau, 2011, ainsi que Dietrich Blaufuss, Friedrich NiewÖHneR et Hans SchneIder (dir.), Gottfried Arnold (1666-1714), 
Wiesbaden, Harrassowitz (Wolfenbütteler Forschungen, 61), 1995 et Andreas Urs SommER, " Geschichte und Praxis bei Gottfried Arnold », Zeitschrift für Religions- und Geistesgeschichte 54 (2002), p. 210-243; C. Scott DIxON, «Faith and History of the Enlightenment. Ernst Salomon Cyprian, Gottfried Arnold, and the History of Heretics », The Journal of Ecclesiastical History 57 (2006), p. 33-54

130. Christian Gerber (1660-1731) étudie à Leipzig et Wittenberg avant de devenir pasteur dans des localités de Saxe (ADB 8 (1878), 718-719 (Jacob FRANK)). Le cas de Neuser est examiné dans la Fortsetzung der unerkannten Sünden der Welt [...], Frankfurt 1705², p. 81, cité par Georg Heinrich Götze dans le texte que Lessing mentionne un peu plus loin (voir plus bas, n. 132).

131. Martin Ruarus (Ruar, 1589-1657) étudie à Rostock puis à l'Académie d'Altdorf, où il se rapproche d'un cercle socinien formé autour du médecin Ernst Soner et du théologien Johann Crell (voir plus bas, n. 194 et Siegfried WoLLGAST, Philosophie in Deutschland zwischen Reformation und Aufklärung 1550-1650, Berlin, Akademie-Verlag, 1988, ch. VI. 2, p. 366-409). À partir de 1614, il est en Pologne, actif dans l'Église des Frères polonais à Raków puis Danzig (voir plus bas, n. 155). Dans les années 1640, il conseille les rois de Pologne Ladislas IV Vasa et Jean II Casimir (voir Janusz TAZBIR, art. "Ruarus, Martin », in Biographisches Lexikon für Schleswig-Holstein und Lübeck, t. 9, Neumünster, Wachholtz, 1991, p. 319-325). Un an après sa mort, en 1658, le libre exercice des religions antitrinitaires est interdit en Pologne. Sur le texte cité de Ruarus, voir plus bas, n. 134.

132. Georg Heinrich Götze (1667-1728), après des études à Leipzig, sa ville natale, léna et Wittenberg, devient superintendant luthérien d'Annaberg, en Saxe, puis de Lübeck, où il officie pendant vingt-six ans. Voir, dans la banque de données des mss. des Franckesche Stiftungen de Halle, la notice à l'adresse http://192.124.243.55/cgi-bin/gkdb.pl? x=u \& sart = p \& t_multi = x \& v_0 = TIT \& q_0 = 100818633 (consulté le 8 décembre 2016)). Lessing renvoie en note à la préface des Meletemata Annaebergensia varii argumenti, Lubecae $1707^{2}$, ici p. 5.

133. Abraham Calov (Calovius, Kalau, 1612-1686), figure de l'orthodoxie luthérienne, professeur à Wittenberg à partir de 1650, est connu notamment pour sa prise de position intransigeante pendant la querelle syncrétiste, contre Georg Calixt à Helmstedt. Une présentation d'ensemble est fournie par Kenneth G. APPOLD, «Abraham Calov als Vater der spätlutherischen Orthodoxie », in E. KocH et J. WALLMANN (dir.), Ernst Salomon Cyprian (1673-1745). Zwischen Orthodoxie, Pietismus und Frühaufklärung, Gotha, Forschungs- und Landesbibliothek Gotha (Veröffentlichungen der Forschungs- und Landesbibliothek Gotha, 34), 1996, p. 49-58. Une thèse non publiée traite de sa controverse contre les sociniens: Olaf REESE, Lutherische Metaphysik im Streit. Berichte von Calovs antisozinianische Feldzüge, Diss., Univ. Göttingen, 2009, accessible par https ://ediss. uni-goettingen. de.

134. L'opinion de Ruarus sur Neuser se trouve dans l'édition posthume de sa correspondance, Martini Ruari [...] aliorumque virorum doctorum [...] ad ipsum Epistolarum selectarum centuria, t. 1, Amstelodami 1677, lettre 47, M. Ruarus A. Calovio, p. 225 : "Pardonne, homme illustre, que je fasse usage d'un droit que toi-même m'as donné, celui de te critiquer notamment dans le domaine historique. À cela se rapporte aussi ton affirmation selon laquelle Paulus Alciatus, tout comme Neuser, se serait précipité chez les Turcs et aurait professé le Coran après avoir abjuré la religion chrétienne. Tu accordes ici trop de foi au récit d'autres auteurs dont il aurait été préférable que tu donnes les noms afin d'éviter que ta crédibilité ne soit mise en cause ». Voir aussi la lettre 46 de Ruarus au même Calov, ibid., p. 217, sur Matthias Vehe (cf. plus haut, n. 19) et les antitrinitaires de Transylvanie. - Giovanni Paolo Alciati della Motta (vers 1520-vers 1586) est un antitrinitaire natif du Piémont, qui a suivi la voie menant de Genève à la Pologne antitrinitaire. Médecin, lié à Biandrata (voir plus haut, n. 9), il doit fuir la Pologne après l'édit de Partzow de 1564 (voir plus haut, n. 40). Cf. Domenico SELLA, art. « Alciati della Motta, Giovanni Paolo ", in Dizionario biografico degli Italiani, t. 2, Roma, Istituto dell'Enciclopedia Italiana, 1960, p. 68-69 et D. CANTIMORI, Eretici italiani del Cinquecento, op. cit., p. 214-215, 222-223.

135. Sur Giovanni Paolo Alciati della Motta, voir n. préc. 


\section{Adam Neuser}

136. « tout comme Neuser».

137. «tout comme».

138. On relèvera le terme pour " apologie », Ehrenrettung, qui renvoie à l'un des plus anciens projets intellectuels de Lessing, celui des Rettungen (voir introduction, p. 8-10).

139. Voir plus haut, p. $91(=[133] /<67>)$.

140. Les paroles confuses de Neuser devant le pacha de Temeşvar sont interprétées comme une confession de foi musulmane en bonne et due forme. Sur ce passage important, voir introduction, p. 31-32.

141. Michael Heberer (1560-1623), apparenté par sa mère à Philipp Melanchthon, entreprend en 1582 un voyage en Méditerranée au cours duquel il est fait prisonnier par les Turcs. Après trois ans dans les galères, il est libéré et entre au service de l'électeur palatin Frédéric IV. Lessing renvoie en note à son récit de voyage Aegyptiaca servitus, paru à Heidelberg en 1610, réimp. Graz, Akademische Druck- und Verlagsanstalt (Frühe Reisen und Seefahrten in Originalberichten, 6), 1967, tr. fr. O. V. VolkofF, Voyages en Égypte de Michael Heberer von Bretten, 1585-1586, Le Caire, Institut français d'archéologie orientale du Caire (Collection des voyageurs occidentaux en Égypte, 18), 1976). Voir Claudia ULBRICH, " "Hat man also ein solches Blutbad, Würgen und Wüten in der Stadt gehört und gesehen, daß mich solches jammert wider zu gedencken..." Religion und Gewalt in Michael Heberer von Brettens Aegyptiaca servitus von 1610 », in K. vON GREYERZ (dir.), Religion und Gewalt. Konflikte, Rituale, Deutungen (15001800), Göttingen, Vandenhoeck \& Ruprecht (Veröffentlichungen des Max-Planck-Instituts für Geschichte, 215), 2006, p. 85-108.

142. Václav Budovec z Budova (en allemand Wenzel Wilhelm Freiherr Budowecz von Budowa, 1547 ou 1551-1621), après des voyages qui le firent connaître de plusieurs figures protestantes dont Théodore de Bèze, accompagne de 1577 à 1581 l'émissaire impérial Joachim von Sinzendorf (1544-1594) à Constantinople. À son retour, il joue un rôle dirigeant dans le mouvement des Frères tchèques, continuateurs de l'œuvre de Jean Hus, et prend en 1618 la tête du soulèvement de la Bohême, à l'origine de la guerre de Trente Ans. II est exécuté à Prague en 1621. En 1614, il avait fait paraître un Anti-Alkoran en tchèque, pour prouver que le Coran « vient du Diable » (rééd. Praha, Odeon, 1989). Lessing renvoie en note à une lettre sur la «Généalogie des sociniens » destinée par Budovec à son fils, datée de 1612 et placée par lui à l'intérieur d'un ouvrage d'emblématique, le Circulus horologi Lunaris et solaris (Hanoviae 1616), qui figure en images la « série des principaux changements intervenus dans l'Église et dans le monde ». Le bref passage sur Neuser (p. 234) mentionné par Lessing consigne toute la légende noire: athéisme, mauvaises mœurs, mort atroce. L'ouvrage comporte aussi plusieurs sections anti-musulmanes. Voir la biographie de Noemi REJCHTRovÁ, Václav Budovec z Budova, Praha, Melantrich, 1984.

143. Au sens du Saint-Empire romain germanique.

144. Stephan Gerlach (1546-1612) est de 1573 à 1578 prédicateur luthérien de l'émissaire impérial à Constantinople, David Ungnad (voir plus bas, n. 213). De retour dans l'Empire, il devient professeur de théologie à Tübingen. Son journal de Turquie est publié plus de soixante ans après sa mort: Stephan Gerlachs deß Aeltern Tage-Buch der [...] an die Ottomannische Pforte zu Constantinopel abgefertigten und durch [...] Hn. David Ungnad [...] mit würcklicher Erhalt- und Verlängerung deß Friedens zwischen dem Ottomannischen und Römischen Käyserthum [...] glücklichst-vollbrachter Gesandtschafft, Frankfurt am Main, 1674. II existe une traduction turque (Stephan GERLACH, Türkiye günlüğü, éd. et tr. K. BEYDILlı et T. NOYAN, Istanbul, Kitapyayınevi, 2007). Voir Matei CAZACU, «Le patriarcat de Constantinople dans la vision de Stephan Gerlach (1573-1578) », in P. OdoRICo (dir.), Le Patriarcat œcuménique de Constantinople aux $x I V^{e}-X V l^{e}$ siècles, Paris, École des Hautes Études en Sciences Sociales (Centre d'études byzantines, néo-helléniques et sud-est européennes, Dossiers byzantins, 7), 2007, p. 369-386 ; Michael KLEIN, «Zwei Lutheraner an der Hohen Pforte. Leben, Reisen und religionspolitisches 
Wirken der Tübinger Theologen Stephan Gerlach und Salomon Schweigger », in F. SCHWEITZER (dir.), Kommunikation über Grenzen. Kongressband des XIII. Europäischen Kongresses für Theologie, 27.-25. September 2008 in Wien, Gütersloher Verlagshaus (Veröffentlichungen der Wissenschaftlichen Gesellschaft für Theologie, 33), 2009, p. 533-552. - Plus loin, la note ${ }^{p}$ de Lessing fait le point sur la transmission du texte du journal. Sur Heineccius, voir plus haut, n. 15. Johann Peter von Ludewig (1668-1743) fut recteur de l'université de Halle (1722), successeur sur la chaire de droit de Christian Thomasius (1729).

145. Sur les « welsches », voir plus haut, n. 58.

146. Jacob Heerbrand (1521-1600), docteur en théologie à Tübingen en 1550, devient professeur dans cette université en 1557 et y atteint des positions éminentes (cf. Wolfram ANGERBAUER, Das Kanzleramt an der Universität Tübingen und seine Inhaber 1590-1817, Tübingen, Mohr (Contubernium, 4), 1972, p. 19-20). Son Compendium theologiae de 1571 résume une théologie d'inspiration melanchthonienne (BBKL 2 (1990), 638 (F.-W. BAUTZ)).

147. Lettre de Stephan Gerlach à Jacob Heerbrand, 11 octobre 1573, ms. Wolfenbüttel, HAB, Cod. Guelph. 15 III Aug. 2 f. 265-267: " J'ai bien en tête, homme très illustre, que Sa Très Honorable Majesté m'avait chargé d'enquêter sur Adam Neuser, ancien pasteur de Heidelberg. Le recteur de l'école de Komorn, qui l'a bien connu, m'a appris que Neuser, tournant, comme on dit, le dos à son pays, alla à Komorn. De là, il essaya de passer à Buda en se faisant enfermer avec plusieurs autres dans un tonneau, mais la trahison d'un marchand ne lui permit pas d'y rester caché. Cette ruse éventée, il en machina une autre: il revêtit l'habit des Hongrois et voulut se faire intégralement raser, à la façon des Turcs, pour prendre en toute sécurité la route de Buda. Mais ce plan ne réussit pas non plus. Dénoncé comme transfuge et espion au commandant suprême de la place de Komorn, le sieur Kielmann de Greppingen, il fut mis aux fers. Libéré à la demande du directeur d'école dont j'ai parlé et de plusieurs autres qui alléguèrent la folie d'un homme égaré par les veilles d'étude nocturne, il atteignit la Transylvanie par la Pologne. Moins d'un an plus tard, ayant pris avec lui un compagnon (un homme savant, à ce qu'on me dit), il vint à Constantinople, se fit vite circoncire avec son infortuné compagnon, devenant, non pas un muphti, c'est-à-dire un patriarche ou un pape des Turcs, mais un spahi ». - La «Très Honorable Majesté » nommée ici est probablement le duc Louis VI de Württemberg (1554-1593), dont Gerlach et Heerbrand étaient les sujets. Komorn (en hongrois Komárom) se situe sur la rive droite du Danube, sur l'actuelle frontière ungaro-slovaque. Buda avait été jusqu'en 1541 la capitale du royaume de Hongrie ; l'unification avec Pest et Óbuda, pour former Budapest, ne fut définitive qu'en 1873. On ne sait rien du commandant de la forteresse de Komorn, le sieur Kielmann, probablement souabe, à en juger par l'indication de sa ville d'origine. - Neuser est qualifié de "spahi », du nom des troupes à cheval (sipahi), le corps d'armée le plus important de l'Empire ottoman avec les janissaires: on comptait environ 40000 cavaliers ottomans au début du Xvi ${ }^{e}$ siècle, chacun d'eux devant acheter son cheval. L'opposition avec le titre religieux de « muphti » est ici assez étrange et repose sur la prise en considération de la condition pastorale qui était celle de Neuser avant sa fuite de Heidelberg.

148. Ibid. : "Car les Spahis sont les cavaliers de base de l'empereur turc. Lui cependant n'a pas suffisamment de revenus pour nourrir un cheval. II mène une vie misérable et méprisée. Il a pour amis quelques Allemands prisonniers de guerre. Avec eux il va boire presque tous les jours dans des tavernes ou dans la boutique d'un barbier; il y parle de choses impies et obscènes, assez souvent (sauf le respect de Sa Majesté) de l'accouplement entre hommes, qui est très courant en Turquie. Auprès de ces gens il passe pour un infâme cureton, un transfuge digne de tous les supplices, parce qu'après avoir abjuré notre religion il est de son plein gré passé chez les Turcs. II leur rend leurs insultes et c'est ainsi qu'ils passent le temps, sans que ne s'arrêtent contre lui les menaces et les coups de poing, qu'ils viennent de l'extérieur ou de ses compatriotes. Car par ses proches je vois bien qu'il a très mauvaise conscience; il est là, hébété, perdu dans ses pensées. De temps à autre il pousse des soupirs et laisse échapper des exclamations de pur désespoir, pour s'être noyé dans l'erreur et dans un gouffre 


\section{Adam Neuser}

de ténèbres à force de scruter la majesté de Dieu. Quand ensuite il se reprend, il accable notre religion de blasphèmes et de mensonges. Et quand ses amis lui reprochent son apostasie (car ici toute religion est libre), il répond qu'il n'a pas changé de foi et qu'il nourrit dans son cœur celle qu'il a toujours eue. De sa circoncision, il se justifie en invoquant l'exemple de certains peuples convertis par saint Matthieu - je ne sais desquels il s'agit -, qui de toute antiquité ont maintenu à la fois le baptême et la circoncision. Tout l'argent qu'il avait amené avec lui d'Allemagne et de Transylvanie, il l'a perdu à Constantinople et il a tenté en vain de le récupérer avec l'aide de magiciens. De sorte que Satan se joue en tout de ce malheureux. Ses proches rapportent qu'il s'adonne à des choses étranges et aux arts magiques. Le premier octobre, il a sollicité un entretien avec moi par l'intermédiaire d'un barbier allemand, mais parce que je devais donner ma prédication, j'ai reporté la rencontre à un autre moment. II envisage à présent de prendre femme en la personne de la voisine de notre interprète, mais puisqu'il ne roule pas sur l'or, qui est la seule chose que les Turcs regardent, j'ai peur qu'il ne sorte rien de ce mariage. Mais j'en ai dit plus qu'assez à son sujet ».

149. Allusion aux recherches que Neuser, dans sa lettre à Baumann, disait vouloir entreprendre à Constantinople (voir plus haut, p. 91-94 = [134-136]/<68-69>).

150. Le texte de Lessing pose plusieurs difficultés de chronologie, déjà soulignées par A. SCHILSON (WuB 8, 823) et qu'il faut expliciter encore. La "confession de foi éthiopienne » n'est probablement pas celle qui figure aujourd'hui dans le Denzinger (voir plus haut, n. 73) sous le $n^{\circ} 1$, extrait des traditions apostoliques apocryphes du Sēnodos, recueil parvenu en Éthiopie au milieu du XIV ve siècle (II Sēnodos etiopico. Canoni pseudoapostolici: Canoni dopo l'Ascensione, Canoni di Simone Cananeo, Canoni Apostolici, Lettera di Pietro, éd. A. BAUsı, Lovanii, Peeters (Corpus scriptorum christianorum orientalium, 552, 553 [Scriptores aethiopici, 101, 102]), 1995 et Alessandro BAUSI, «Alcune considerazioni sul Sēnodos etiopico », Rassegna di studi etiopici 34 (1992), p. 5-73). En dépit de la date indiquée par Lessing (1534), il s'agit plus probablement de la Confessio Claudii, composée en 1555 à l'initiative du souverain Gelawdéwos (Claude, Atsnaf Sagad Ir), vraisemblablement en réponse aux attaques jésuites sur la supposée dérive judaïsante de l'Église d'Éthiopie (voir Edward ULLENDORF, "The Confessio Fidei of King Claudius of Ethiopia », Journal of Semitic Studies 32 (1987), p. 42-50). Ce texte, comme le Fet a Nagaśt (Livre des Rois, en usage aussi depuis le Xvi siècle), mentionne la circoncision des enfants mâles le huitième jour comme une coutume, qui correspond de fait à la pratique de plusieurs peuples de la Corne de l'Afrique (cf. art. "Circumcision », EAE 1 (2003), 748-749 (Steven KAPLAN)). Cette question de la circoncision avait très tôt été intégrée au débat avec les missionnaires européens : voir E. ULLENDORF, Ethiopia and the Bible, London, Oxford University Press, 1968; Paolo MARRASSINI, «Sul problema del giudaismo in Etiopia », in B. CHIESA (dir.), Correnti culturali e movimenti religiosi del giudaismo, Roma, Carucci (Associazione Italiana per lo Studio del Giudaismo, Testi e Studi, 5), 1987, p. 175-183 et aujourd'hui Andreu MARTINEZ D'Alòs-MONER, "Paul and the Other. The Portuguese Debate on the Circumcision of the Ethiopians », in V. BöLL, S. KAPLAN, A. MARTINEZ D'Alòs-MONER et E. SOKOLINSKAIA (dir.), Ethiopia and the Missions. Historical and Anthropological Insights, Münster etc., Lit (Afrikanische Studien, 25), 2005, p. 31-51. De ce débat, Lessing évoque un acteur majeur, Șaggā Za'āb, liqa kāhenāt (chef des prêtres) et moine, chargé par le roi David II (Lebna Dengel, 1508-1540) de deux missions diplomatiques, la première auprès des Portugais en Éthiopie (1520-1527), au cours de laquelle il rencontre le chapelain Francisco Álvares (vers 1465-1541), confesseur du roi Manuel Ier, la seconde en Europe entre 1527 et 1533 (cf. "Ṣaggā Za'āb », EAE 4 (2010), 455-456 (Michael KLEINER), ainsi que Kate LowE, "Representing" Africa. Ambassadors and Princes from Christian Africa to Renaissance Italy and Portugal, 1402-1608, Cambridge, Cambrige University Press (Transactions of the Royal Society, VI, 17), 2007). En 1533, Șaggā Za'āb rencontre I'humaniste Damião de Góis (1502-1574). Leur collaboration donne lieu à la rédaction du Fides, religio moresque Æthiopium, publié en 1540 avec l'ouvrage d'Álvares, Verdadeira informação das terras do Preste João das Índias : on peut voir aujourd'hui la traduction allemande par S. UHLIG et G. BüHRING, Damian de Góis'Schrift über Glaube und Sitten der Äthiopier, Wiesbaden, Harrassowitz 
(Aethiopistische Forschungen, 39), 1994. On s'est souvent plus intéressé au texte d'Álvares, très vite traduit en latin (1540), en français (1558) et en allemand (Wahrhafftiger Bericht von den Landen [...] des mechtigen Königs von Ethiopien, den wir Priester Johan nennen, Eisleben 1566) qu'à celui traduit par Góis, défense et une illustration de la foi éthiopienne censurée au Portugal et attaquée par les jésuites, mais qui attint l'Europe protestante. Je remercie Olivia Adankpo pour l'ensemble de ces informations.

151. Johann Wolf (Wolff, 1537-1600), formé en théologie à Wittenberg et en droit à Bourges, s'employa comme juriste et administrateur auprès de deux souverains de l'Empire, Wolfgang de Palatinat-Deux-Ponts et Charles II de Bade-Durlach. Lessing mentionne en note ses immenses Lectiones memorabiles (Lauingen 1600, ici t. II, p. 902), 2200 pages en deux volumes, auxquelles la recherche a commencé à s'intéresser: voir Sabine SCHMOLINSKY, "Prophetia in der Bibliothek? Die Lectiones memorabiles des Johannes Wolf », in K. BERGDOLDT et W. LUDWIG (dir.), Zukunftsvoraussagen in der Renaissance, Wiesbaden, Harrassowitz (Wolfenbütteler Abhandlungen zur Renaissanceforschung, 23), 2005, p. 89-130; EAD., «Im Angesicht der Endzeit? Positionen zur den Lectiones memorabiles des Johannes Wolf (1600) », in W. BRANDES et F. SCHMIEDER (dir.), Endzeiten. Eschatologie in den monotheistischen Weltreligionen, Berlin-New York, De Gruyter (Millenium-Studien 16), 2008, p. 369-417. La note de Lessing mentionne un texte de controverse de Gerlach (cf. plus haut, n. 144), I'Antidanaeus (Tübingen 1580, ici p. 39), contre le théologien réformé Lambert Daneau: "Et huc iam res in Polonia \& Transyluania apud vestrae sodalitatis homines redijt, vt de merito Christi iam dudum disputare coeperint, an illud sufficiens sit pro peccatis totius mundi, cum Christus, vt nudus homo, passus sit ».

152. GERLACH, Tage-Buch, op. cit., p. 34-37.

153. Wolf, Lectiones memorabiles, op. cit., t. II, p. 902 : « rentré volontairement en Palatinat ». En allemand, voir GERLACH, Tage-Buch, op. cit., p. 35.

154. Sur ce passage, voir introduction, p. 45.

155. Wolf, Lectiones memorabiles, op. cit., t. II, p. 902 : «À l'époque où je séjournais là-bas, il y eut une controverse entre les frères de Pologne et de Transylvanie au sujet de l'article de la justification. La discussion fut menée jusqu'au point d'affirmer que le Christ n'a pas racheté le genre humain par sa mort et sa passion et qu'il ne peut le justifier ni le sauver par son sang, dès lors qu'il n'est qu'un homme ». Gerlach n'a pas ce développement. - Les « Frères polonais » (Bracia Polscy) désignent le mouvement organisé à partir de la fin des années 1550 par Giorgio Biandrata (voir plus haut, n. 9), et qui se donna en 1565, au synode de Bełżyce, le nom d'« Église des Frères de Pologne et de Lituanie qui ont rejeté la Trinité ». Entre les antitrinitaires polonais et transylvaniens, les rapports ne furent pas d'emblée conflictuels, comme l'atteste le passage de Biandrata en Transylvanie, mais la montée en puissance de Faust Socin en Pologne (voir plus haut, n. 8) aggrava les divergences doctrinales. Lessing peut ainsi mettre en scène un désaccord de fond entre sociniens polonais et unitariens de Transylvanie. Outre l'étude de Wilbur mentionnée plus haut, n. 2, voir George Hunston WILLIAMS, « Unterschiede zwischen dem polnischen und dem siebenbürgisch-ungarischen Unitarismus und ihre Ursachen », in W. DEPPERT, W. ERDT, A. DE GROOT (dir.), Der Einfluß der Unitarier auf die europäisch-amerikanische Geistesgeschichte, Frankfurt a. M. etc., Lang, 1990, p. 33-57.

156. Le "côté de Franciscus David » désigne l'orientation unitarienne qui, en niant comme Neuser le caractère rédempteur de la mort du Christ (voir n. préc.), refuse aussi que le Christ soit vénéré d'une quelconque façon, y compris par voie d'invocation dans la prière. Voir en Faust Socin un persécuteur de Dávid, comme Lessing le suggère ici, prolonge l'interprétation dure des relations entre sociniens et « davidiens » proposée notamment par Jacob Palaeologus (voir plus bas, n. 207). En 1572, Faust Socin fut chargé par Biandrata d'une médiation auprès de Dávid pour le convaincre d'adopter une vue moins intransigeante. Ses efforts échouèrent, la controverse s'exacerba et Dávid mourut dans sa captivité de Déva (Diemrich), où l'avait placé Étienne Báthory (voir plus haut, n. 21). 


\section{Adam Neuser}

157. Sur la thématique importante du «pas » (Schritt) franchi par Neuser, voir introduction, n. 179.

158. Wolf, Lectiones memorabiles, t. II, p. 902: « Au moment où ces controverses faisaient rage, j'avais pris moi aussi la décision de publier quelque chose sur l'unicité de Dieu contre la Trinité et je m'étais dans ce but rendu dans un village assez connu qui jouissait de la protection de la Turquie, chez un imprimeur qui s'était établi là. C'est à ce moment que je fus livré au pacha de Temeşvar, qui m'envoya à Constantinople sans que je ne m'y oppose en rien, et bien plutôt en m'en félicitant moi-même. Car j'avais vu que l'Alcoran n'était pas étranger à la vérité et que sur tous les chapitres de religion ses opinions étaient les miennes ».

159. Ibid. : "Lorsque ceci, à mon sujet et sur Sylvan, fut révélé publiquement à l'empereur et à travers lui à mon prince, je me décidai à prendre la fuite ».

160. «à l'illustre M. Bekes, émissaire du prince Jean Sigismond de Transylvanie auprès de l'empereur Maximilien II ». Lessing renvoie en note à la Bibliotheca Antitrinitariorum de Sand, op. cit., p. 61, qui intègre de fait la lettre à Bekes dans la très courte liste des écrits de Neuser.

161. SAND, Bibliotheca Antitrinitariorum, loc. cit. : « une fois que l'empereur eut intercepté cette lettre, il fit en sorte que Neuser fût mis aux fers avec Sylvan ».

162. Voir plus haut dans la lettre de Neuser à Baumann, p. $88(=[64] /<130>)$.

163. Voir plus bas, p. 122-123 (= [175]/<99-100>).

164. Sur le recueil des Monumenta de Mieg et Nebel, voir plus haut, n. 28.

165. Sur ce passage, voir introduction, p. 26-27.

166. Monumenta pietatis et literaria, op. cit., préface, f. * $\left.{ }^{0}\right)(4 \mathrm{v}]$ : « II est bon au moins qu'ils n'aient rien écrit en faveur de Neuser, cet ivrogne qui a rejoint le lieu qu'il mérite. Sa lettre, que nous publions, les notes qu'il a portées en marge de son Alcoran, que nous gardons par-devers nous, montrent l'homme qu'il fut. Pourtant, même dans l'exécution de Sylvan, ce n'est pas la rage contre les égarés qui s'est exprimée, puisque celui-ci, comme Neuser, avait eu des contacts avec les Turcs et que ses blasphèmes avaient été épouvantables, au point qu'il ne pouvait y en avoir de pires. »

167. Ibid. : " Il est bon au moins qu'ils n'aient rien écrit en faveur de Neuser. »

168. Sur les lettres perdues de Neuser à l'électeur palatin, voir introduction, n. 54.

169. Lessing reprend ici la formule bilingue, "furor erga errantes ", "Wüterei gegen die Irrenden ", contenue dans le passage qu'il vient de citer de la préface aux Monumenta de Mieg et Nebel. Voir plus haut, n. 166.

170. Ernst Salomon Cyprian (1673-1745), docteur de Wittenberg, l'un des derniers grands théologiens de l'orthodoxie luthérienne, enseigne à Helmstedt et Cobourg puis devient directeur de la bibliothécaire ducale de Gotha - à nouveau un confrère et prédécesseur de Lessing. Voir E. Koch et J. Wallmann (dir.), Ernst Salomon Cyprian (1673-1745), op. cit. et E. KocH, Kirchenleitung in Überganszeiten. Zum Lebenswerk von Ernst Salomon Cyprian (1673-1745), Groß Oesingen, Verlag der Lutherischen Buchhandlung Harms, 1997. Sur le texte cité par Lessing, voir note qui suit.

171. Ernst Salomon CYPRIAN, «Dissertatio V historico-ecclesiastica de morte Socinianorum », in Dissertationes varii argumenti, Coburg 1755, p. 94 : « Quant à savoir s'il fut convaincu de haute trahison, comme le veulent Pareus, Alting, Hoornbeck, Spanheim et tous les réformés, c'est là une chose extrêmement douteuse. À mes yeux, c'est seulement à cause de sa doctrine et de ses blasphèmes contre le Christ qu'il a été mis à mort. J'ai à l'appui de cette opinion un argument des plus solides, qu'aucun procédé ne permettra à mon avis d'éluder. À coup sûr, la plus grande partie, et peut-être aussi la meilleure partie des conseillers refusa pour lui la peine capitale, raison pour laquelle l'électeur en personne fut contraint de rendre cette sentence, comme nous l'avons vu plus haut dans Alting. Mais si Sylvan avait été convaincu du crime de lèse-majesté, 
les conseillers auraient sans détour prononcé la peine de mort contre lui. Il est, par suite, si peu démontré que Sylvan ait eu des contacts par lettres avec les Turcs que pas même les réformés n'osent l'affirmer. » Cyprian renvoie à plusieurs auteurs réformés: Daniel PAREUS (Wängler, 1605-1635, philologue palatin, professeur à Neustadt an der Weinstraße puis Kaiserslautern), Historia Palatina, Francoforti 1633; ALTING, Historia Ecclesiae Palatinae, in Monumenta pietatis et literaria, op. cit. (voir plus haut, n. 27) ; Johannes HORNBEEK (1617-1666, professeur de théologie à Utrecht puis Leyde), Summa controversiarum religionis cum infidelibus, haereticis, schismaticis (1653), Trajecti ad Rhenum 1658; Friedrich SPANHEIM le Jeune (1632-1701, historien de l'Église, professeur à Heidelberg puis Leyde), Summa Historiae Ecclesiasticae, Lugduni Batavorum 1689.

172. «par la peine capitale».

173. "et que l'Église ne referme pas son sein à ceux qui retournent vers elle». La note de Lessing indique la référence: STRUVE, Ausführlicher Bericht von der Pfältzischen Kirchen-Historie, op. cit., p. 228. La formule latine "Ecclesia non claudat gremium redeuntibus » se trouve à la fin du De summa Trinitate qui ouvre le code de Justinien (livre I, titre I). Voir dans l'édition du juriste réformé Denys Godefroy (1549-1622), très diffusée à l'époque moderne, Corpus luris civilis in IIII. partes distinctum, t. II : Codicis libri XII., Genevae 1583, p. 12: «Sed quia gremium suum nunquam redeuntibus claudit Ecclesia ». Je remercie de nouveau Frédéric Gabriel pour cette identification.

174. Voir plus haut, p. $84(=[125] /<60>)$.

175. La note de Lessing indique aussi la référence: STRUVE, Ausführlicher Bericht von der Pfältzischen Kirchen-Historie, op. cit., p. 223. Le passage se trouve aussi dans les Monumenta pietatis et literaria, op. cit., p. 330.

176. Ibid., p. 228.

177. Voir n. suiv.

178. Alting, Historia Ecclesiae Palatinae, in Monumenta pietatis et literaria, op. cit., pars prior, p. 209: « Voyant ses conseillers temporiser et tenir sur leur position, l'électeur, pour éviter que l'affaire ne s'étire à l'infini, rédigea de sa main la sentence (à laquelle il avait joint l'exclamation suivante: il pensait avoir l'Esprit Saint, en cette affaire maître et professeur de vérité) et la communiqua à ses conseillers le même jour, le 11 avril 1572, huit mois avant que l'exécution en fût ordonnée. » La citation est mal abrégée. II faut lire : « [...] consilium ex se petiit, et sua manu sententiam conscripsit. »

179. Sur l'« Esprit » soufflant depuis Genève, voir introduction, p. 15-16. Lessing fait allusion à la rigueur de la discipline ecclésiastique genevoise, dont Frédéric III entendait s'inspirer.

180. E. S. CYPRIAN, «De morte Socianianorum », loc. cit., p. 89 : «Une lettre de Neuser fut en outre donnée à Selim II; je n'ai pas pu assez l'examiner pour établir si elle fournissait des conseils pour renverser l'Empire romain, auquel cas les Turcs l'eussent sans doute accueillies par le rire ». " Empire romain » se comprend de nouveau au sens de "romain germanique » (voir plus haut, n. 48).

181. Voir plus haut, n. 28.

182. Voir plus haut, n. 27.

183. CYPRIAN, « De morte Socianorum », loc. cit., p. 94 : « Neuser, je l'avoue, a écrit à l'empereur des Turcs, mais parce que sa lettre, pour ce que j'en sais, n'a jamais été rendue publique, il n'est pas sûr qu'elle suffise à démontrer l'intention de haute trahison. Qu'en serait-il si Neuser avait seulement écrit qu'il allait émigrer de sa ville vers la Turquie, où il aurait la possibilité de s'exprimer plus librement? Assurément, le droit naturel n'interdit pas d'écrire cela, comme Grotius l'a enseigné au second livre du Droit de la guerre, chapitre V, § 24. Supposons toutefois qu'une telle chose ait été interdite par le droit de l'État: est-ce à dire que la simple expression de sa volonté de passer les frontières lui aurait valu sur le champ la peine capitale? Et quand bien même, en fin de compte, la lettre de Neuser eût contenu des indices de haute trahison: quel rapport avec Sylvan?» Le raisonnement juridique de Cyprian inclut un passage par 


\section{Adam Neuser}

le droit naturel, avec sa part tactique: contre les historiens et théologiens réformés qu'il réfute plus haut (voir passage cité plus haut, p. $120(=[171] /<97>$ et $n .171)$, il se réclame du réformé Grotius, dont les convictions arminiennes, au sein du monde calvinien (cf. p. ex. F. Leroy Forlines, Classical Arminianism. A Theology of Salvation, Nashville, Tenn., Randall House, 2011), administrent une leçon de tolérance juridique. Le contexte heidelbergeois est en outre présent, à travers le lien entre Grotius et Erastus: voir Charles D. GUNNOE, Jr., «The Evolution of Erastianim: Hugo Grotius's Engagement with Erastus », Grotiana 34 (2013), p. 41-61. - Sur le texte de Grotius cité par Cyprian, voir plus bas, n. 187.

184. Voir plus haut, p. 93-94 (= [136]/<69>).

185. Je renvoie toujours à l'édition de la lettre à Selim II dans les Monumenta de Mieg et Nebel: "Adami Neuseri, gewesenen Predigers zu Heydelberg Schreiben an den Türckischen Kayser Selym dieses Namens den Andern », in Monumenta pietatis et literaria, op. cit., pars prior, p. 343. Voir aussi la traduction française par Veyssière de La Croze en Annexe, p. 174-175.

186. Ibid., p. 344. Voir Annexe, p. 176.

187. Hugo Grotius, De jure belli ac pacis libri tres, Parisiis 1625, tr. fr. P. Pradier-Fodéré, éd. D. Alland et S. Goyard-Fabre, Paris, PUF, 2012², I. II, ch. V, \&XXIV, p. 243-244: "On demande ici s'il est permis aux citoyens de se séparer de l'État dont il font partie, sans en avoir obtenu l'autorisation. [...] Mais nous demandons ce qui doit avoir lieu naturellement, dans le cas où il n'a été rien convenu sur ce point; et nous parlons de ceux qui sortent, non d'une partie de l'État, mais de tout l'État, ou de ce qui est compris dans les limites d'une même souveraineté. Or, que l'on ne puisse sortir en masse de l'État, cela est suffisamment démontré par la nécessité du but, qui tient lieu de loi dans les choses morales; car si c'était permis, la société civile ne pourrait subsister. Quant à la sortie des individus isolés, il semble qu'il doive en être autrement, de même que c'est tout autre chose de puiser de l'eau d'un fleuve, ou d'en détourner le cours dans un canal. [...] II faut cependant observer une règle d'équité naturelle, que les Romains ont suivie dans la dissolution des sociétés particulières, savoir: que cela ne doit pas être permis, si l'intérêt de la société s'y trouve engagé. [...] En dehors de ces cas, il y a lieu de croire que les peuples consentent à la libre sortie des citoyens, parce qu'ils n'éprouvent pas par l'effet de cette liberté un avantage moindre d'un autre côté. »

188. Mathurin Veyssière (de) La Croze (1661-1739), s'enfuit de l'abbaye de la congrégation de Saint-Maur à Saint-Germain-des-Prés, passe à Bâle et embrasse la foi réformée. En 1697, il devient bibliothécaire du prince-électeur de Brandebourg, fonction qu'il cumule à partir de 1725 avec celle de professeur de philosophie au Collège français de Berlin. Les fréquentes mentions de son nom dans les Beiträge de Lessing s'expliquent, d'une part, par son intense correspondance savante, avec Leibniz notamment (voir introduction, p. 23-24), d'autre part, par son érudition dans le domaine des langues orientales. La relation ambivalente qu'il a entretenue avec les hérésies antitrinitaires reste un sujet d'enquête pour les spécialistes de la littérature clandestine des Lumières. Voir M. MuLsow, Die drei Ringe. Toleranz und clandestine Gelehrsamkeit bei Mathurin Veyssière La Croze (1667-1739), Tübingen, Niemeyer (Hallesche Beiträge zur europäischen Aufklärung, 16), 2001. On peut voir aussi Sylvia MURR, « Indianisme et militantisme protestant. Veyssière de La Croze et son Histoire du protestantisme des Indes », Dix-Huitième Siècle 18 (1986), p. 303-331.

189. Lettre à Mathurin Veyssière de La Croze, 2 décembre 1706, in LEIBNIZ, Opera omnia, Genevae 1768 (réimpr. Hildesheim-New York, Olms, 1990, abr. Dutens), t. V, p. 484, en français dans le texte.

190. Le Divan désigne ici l'administration impériale ottomane, par laquelle la lettre de Neuser a dû transiter. Voir art. « Dīwān. - The Caliphate », El2 2 (1965), 323-327 (Abd al-Aziz DuRI).

191. Lettre à Johann Philipp Schmid, 2 août 1716, Dutens V, 534, en français dans le texte.

192. Samuel Friedrich Lauterbach (1662-1728), natif de Fraustadt (Wschowa), pasteur luthérien, senior général des Églises de Grande-Pologne (Wielkopolska), connu pour ses 
travaux historiques. Voir Christian-Erdmann SCHOTT, "Der erste polnische Historiograph in deutscher Sprache. Samuel Friedrich Lauterbach (1662-1728)», Beiträge zur ostdeutschen Kirchengeschichte 4 (2001), p. 12-27. Lessing renvoie en note à son histoire de l'antitrinitarisme polonais, Ariano-Socinismus olim in Polonia. Der ehmahlige Polnische Arische Socinismus, Wie er sich in diesen Landen eingeschlichen, und ausgebreitet [...], Frankfurt-Leipzig 1725, p. 88. Les Báthory sont une grande famille hongroise originaire de Souabe: voir plus haut, n. 21 sur Étienne Báthory, élu prince de Transylvanie à la succession de Jean-Sigismond en 1571.

193. Sur Lelio Sozzini (Lelio Socin) et son neveu Fausto (Faust), voir plus haut, n. 8.

194. Samuel Crell (1660-1747), né à Kreuzburg (Kluczbork) en actuelle Pologne, fils d'un pasteur de l'Église des Frères polonais (voir plus haut, n. 155), prédicateur en Silésie et en Prusse, auteur d'un important catéchisme socinien (Kurzer Unterricht in der christlichen Religion nach der Lehre der Unitarier, Amsterlodami 1717), réfugié en 1727 à Amsterdam. Voir BBKL 1 (1975), 1158 (F.-W. BAUTZ) et Herbert JAUMANN, Handbuch Gelehrtenkultur der Frühen Neuzeit, t. I: Biobibliographisches Repertorium, Berlin-New York, De Gruyter, 2004, p. 202. Lessing renvoie en note à une lettre conservée dans la correspondance de Mathurin Veyssière de La Croze (voir plus haut, n. 188) éditée en 1742-1746 par le juriste Johann Ludwig Uhl (1714-1790), voir note qui suit.

195. Thesaurus epistolici Lacroziani, t. I, Lipsiae 1742, p. 111 : « Tu sais déjà que j'ai totalement abandonné Socin en tant qu'il est Socin, c'est-à-dire en tant qu'il a développé des conceptions divergentes des autres. Sur le dogme de l'unique Dieu et Père, je campe avec constance. Pour ce qui est des autres conceptions communes aux orthodoxes des différents partis, je suis en accord avec les orthodoxes ou je me rapproche d'eux. Je ne suis pas le seul à avoir toujours repoussé et conjuré la doctrine de Mahomet; tous ceux qui ont suivi strictement Socin l'ont fait aussi. Et je ne vois pas comment ceux qui croient que le Christ n'est pas seulement un prophète d'un rang plus élevé que les autres, mais le maître du ciel et de la terre, lié à Dieu le Père d'aussi près qu'il se peut et prenant part réellement à Son Empire, comment ces gens pourraient davantage pencher vers l'islam que les autres chrétiens. J'avoue que ces monstres unitariens qui nient l'obligation d'invoquer le Christ, ou qui le considèrent seulement comme un prophète qui finira par régner sur le royaume de mille ans, peuvent encore plus facilement sombrer dans cette folie, ainsi qu'on le rapporte de Neuser, le père de ce dogme impie. Le père, dis-je: car Franciscus David, à cette époque où avec Giorgio Blandrata il réfutait Georg Major, professeur à Wittenberg, estimait encore que le Christ doit être invoqué, comme plusieurs indices le laissent voir dans cette œuvre. Neuser s'attribue sans ambiguitté l'invention de ce dogme, et il semble même avoir entraîné Franciscus. » Sur Biandrata et Franciscus (Ferenc) Dávid, voir plus haut, n. 9 et 52. Sur Georg Major, voir note qui suit.

196. Lessing renvoie ici à la Refutatio scripti Georgii Maioris, in quo deum trinum in personis, et unum in essentia [...] probare conatus est (s.I. 1569), dans laquelle Biandrata et Dávid répliquaient à la Commonefactio [...] de fugiendis \& execrandis blasphemijs Samosatenicis, Arianis, Eunomianis [...] (Wittenbergae 1569) de Georg Major (Meier, 1502-1574), figure importante de la théologie wittenbergeoise du second $\mathrm{XVI} \mathrm{e}^{\mathrm{e}}$ siècle, proche de Melanchthon (cf. I. DINGEL, G. WARTENBERG et M. BEYER (dir.), Georg Major (1502-1574). Ein Theologe der Wittenberger Reformation, Leipzig, Evangelische Verlags-Anstalt (Leucorea-Studien zur Geschichte der Reformation und der Lutherischen Orthodoxie, 7), 2005). Major réagissait au De falsa et vera unius Dei Patris, Filii et Spiritus Sancti cognitione de Biandrata et Dávid (Albae luliae 1568), déjà mentionné plus haut, ก. 9.

197. II s'agit de la dispute publique tenue entre le 8 et le 18 mars 1568 à Alba lulia (cf. plus haut, n. 63) en présence du prince de Transylvanie Jean-Sigismond (voir plus haut, n. 10) entre les antitrinitaires Dávid et Biandrata et l'un de leurs adversaires les plus acharnés, le réformé Peter Méliusz (vers 1536-1572). L'issue des débats convainquit le prince d'embrasser la cause antitrinitaire. Voir Philip BENEDICT, Christ's Churches Purely Reformed. A Social History of Calvinism, New Haven-London, Yale University Press, 2002, p. 278-279. 


\section{Adam Neuser}

198. La note de Lessing renvoie aux Actes de la dispute d'Alba lulia (voir n. préc.) publiés par le parti réformé : Disputatio in causa sacrosanctae et semper benedictae Trinitatis [...] inter nouatores D. Georgium Blandratam, Franciscum Dauidis, eorumque asseclas et pastores ministroscumque Ecclesiae Dei catholicae, ex Hungaria \& Transyluania, qui diuinam veritatem ex scriptis Propheticis \& Apostolicis, iuxta continuum Ecclesiae sanctae catholice consensum, defendam susceperunt, per decem dies, Albae Iuliae in Transyluania Habita, Claudiopoli 1568. Les antitrinitaires publièrent aussi leur compte rendu, attribué à Ferenc Dávid: Brevis enarratio disputationis Albanae de Deo trino et Christo duplici coram serenissimo principe et tota ecclesia decem diebus habita anno domini MDLXVIII 8. Martii, Claudiopoli 1568.

199. Lessing cite un recueil posthume de lettres de Faust Socin (voir plus haut, n. 8), Fausti Socini senensis ad amicos epistolae, Racoviae 1618, troisième lettre à Matthaeus Radecius, p. 143: " [...] qu'au Christ, bien qu'être créé, sont dues néanmoins invocation et adoration, autrement dit culte divin. »

200. Lessing cite ici la De lesu Christi invocatione disputatio (s.l. 1595) que Faust Socin eut par écrit avec Ferenc Dávid peu avant la mort de celui-ci en captivité en 1578-1579 (voir plus bas, n. 156). Le passage se trouve p. 709 de l'éd. Irenopoli 1656: " Je voyais en effet que pour extirper entièrement de nombreux esprits les opinions fausses, très pernicieuses et absolument judaïques qui, en plus de Franciscus David et même avant lui, avaient été répandues en Transylvanie par Jacobus Paleologus, Johannes Sommerus, Matthias Glirius et d'autres, le présent traité était nécessaire, dans lequel presque toute la religion chrétienne est exposée. » Sur Johann Sommer, voir plus haut, n. 41, sur Glirius et Paleologus plus bas, n. 202 et 207.

201. De lesu Christi invocatione, éd. citée, p. 711 : «frère en initiation et en partie maître. »

202. La note de Lessing renvoie à SAND, Bibliotheca Antitrinitariorum, op. cit., p. 60, notice "Matthias Glirius ». Antonio Possevino (1533-1611), jésuite impliqué dans plusieurs missions diplomatiques au service du pape en Pologne et Transylvanie dans les années 1580, est mentionné par Sand pour son De sectariorum nostri temporis atheismis liber, Coloniae 1586. L'erreur dénoncée par Lessing se trouve dans la Transiluania de Possevinus (1584), éd. A. Veress, Budapest 1913, p. 104-105, 136-145. Voir Alberto CASTALDINI (dir.), Antonio Possevino. I gesuiti e la loro eredità culturale in Transilvania, Roma, Institutum historicum Societatis lesu (Bibliotheca Instituti historici S. I., 67), 2009.

203. SAND, Bibliotheca Antitrinitariorum, op. cit., p. 60 : « « Il fut en effet le compagnon de Johannes Sylvanus et d'Adam Neuser, et il a subi avec eux la persécution ».

204. C'est peu dire: sur l'exécution de Sylvan en 1572 à Heidelberg, voir plus haut, n. 17.

205. Le latin glis désigne le loir.

206. « [...] en plus de Franciscus David et même avant lui [...] » : voir plus haut, n. 200.

207. Jacob Palaeologus, né Giacomo da Chio (vers 1520-1585), l'une des figures de l'unitarisme le plus radical, né sur l'île grecque de Chios alors sous domination génoise, embrasse au couvent dominicain de Péra, à Constantinople, les vues antitrinitaires de Michel Servet (voir plus bas, n. 230). Pourchassé par l'Inquisition, brièvement protégé par l'empereur Maximilien II à Prague, il rejoint la Transylvanie en 1573 et se range résolument au côté de Ferenc Dávid et de ses vues anti-adorationnistes contre Faust Socin et les Frères polonais (voir plus haut, n. 52, 8 et 155). Extradé à Rome en 1582, il abjure l'année suivante à la vue du bûcher mais refuse toujours de coopérer avec le pape Grégoire XIII contre ses anciens alliés antitrinitaires et est décapité en 1583. Sa théologie est une bataille sur trois fronts, contre Rome, les réformés et les sociniens polonais. Elle s'en prend aux dogmes fondamentaux: Trinité, mais aussi prédestination et péché originel. Voir l'introduction à lacobus PALAEOLOGUS, Disputatio scholastica, éd. J. DOMAŃSKI et L. SzCZUCKI, Utrecht, Bibliotheca unitariorum (Bibliotheca unitariorum, 3), 1994, p. VII-LIV, ainsi que Massimo FIRPO (éd.), Antitrinitari nell'Europa orientale del '500. Nuovi testi di Szymon Budny, Niccolò Paruta e lacopo Paleologo, Firenze, La Nuova 
Italia (Pubblicazioni del Centro di studi del pensiero filosofico del Cinquecento e del Seicento in relazione ai problemi della scienza del Consiglio Nazionale delle Richerche, 1), 1977. Palaeologus rapporte une visite à Neuser à Istanbul en 1573: Epistola lacobi Palaeologi, de rebus Constantinopoli et Chii cum eo actis, lectu digna. Anno 1573, s.l. 1591 (voir M. Mulsow, "Fluchträume und Konversionsräume », art. cité, p. 46, n. 61).

208. Contre Palaeologus (voir n. préc.), Faust Socin avait fait paraître un Ad lac. Palaelogus librum, cui titulus est, defensio verae sententiae de magistratu [...] pro Racoviensibus responsio, s.l., 1581.

209. Marcello Squarcialupi (Squarcialupus, ?-1599), médecin antitrinitaire né à Piombino, après des études à Bâle, vit en Pologne puis, à partir de 1588, en Transylvanie et rédige divers ouvrages de médecine, géologie et astronomie. Voir Claudio MADONIA, "Marcello Squarcialupi », in A. Gordon KINDER (dir.), Alumbrados of the Kingdom of Toledo. Jacobus Acontius, Baden-Baden/Bouxwiller, Koerner (Bibliotheca dissidentium, XVI), 1994, p. 119-170. II n'a pas été possible d'identifier le texte auquel Lessing fait ici allusion.

210. Faust Socin, Defensio verae sententiae de magistratu, p. 323 (je cite encore d'après l'édition Irenopoli 1656) : «Et je ne pense vraiment pas qu'il vienne quelqu'un pour dire, si tant est qu'il ait lu le livre de Paleologus, qu'on aurait pu lui répondre ne serait-ce qu'un peu autrement que je ne l'ai fait, ou qu'on aurait dû procéder avec lui avec un tant soit peu plus de douceur. Et qu'en serait-il si l'on savait, comme je le sais, combien de maux le prestige et les écrits de Paleologus ont pu causer non seulement ici en Transylvanie, mais aussi en Hongrie, en Lituanie et en d'autres endroits ? N'est-ce pas lui qui, le premier dans cette province, a enseigné et mis par écrit cette opinion hautement impie et abominable sur le Christ qu'on n'adore ni n'invoque, ainsi que de nombreuses autres erreurs des plus malsaines? N'est-ce pas par sa doctrine, que certains croient être celle de Franciscus David, que des églises entières en Hongrie, et pas en petit nombre, ont été ignominieusement corrompues? »

211. GeRLACH, Antidanaeus, op. cit., p. 38-39: « Neuser en personne, en l'an de grâce 1574 à Constantinople, m'a montré une lettre qui lui avait été envoyée de Pologne le 2 juillet de la même année par un des principaux défenseurs de l'hérésie antitrinitaire (je l'ai consciencieusement recopiée). On y trouve, entre autres, les phrases suivantes: "Je te demande, cher Adam, de vérifier très soigneusement si le Coran, tel que Bibliander l'a édité à Zurich, est authentique et correspond à la vérité arabe. Car nous nous délectons de ce livre et affirmons qu'il est divin. Deuxièmement je te prie, en mon nom et au nom de nos frères, d'examiner tous les anciens livres grecs et, si tu y trouves une controverse sur le Dieu unique, de l'apporter avec toi. Si tu viens chez nous, nous ne t'empêcherons en aucun cas de revenir auprès des tiens, et nous ferons notre possible pour que tu puisses quitter Constantinople en toute sécurité. Car nous souhaitons qu'un homme tel que toi puisses habiter à Constantinople afin que l'Église trouve son utilité dans les livres dont il a été question. Apporte aussi avec toi, si tu peux le trouver, le livre de Porphyre sur l'autorité de la Sainte Écriture, que Cyrille d'Alexandrie a réfuté. Car en ce qui nous concerne, nous avons retenu des lettres que tu nous as écrites qu'il y a beaucoup de contradictions dans les Saintes Écritures. Par conséquent, nous doutons de nombreux passages et t'attendons avec impatience. Nous t'embrassons et demandons à entendre de ta bouche les paroles de Dieu. Pour l'amour de Dieu, n'abandonne pas tes frères dans cette affaire, etc. "». - Sur cette lettre du superintendant des antitrinitaires polonais Piotr Witrousk et sur la traduction du Coran par Theodor Bibliander (1543), voir introduction, n. 76. La notion de « vérité arabe » imite celle d'hebraica veritas, qui désigna d'abord, au Moyen Âge, les traductions de la Bible hébraïque faites sur l'original, à commencer par celle de Jérôme. Pour la période ultérieure, voir Allison P. COUDERT et Jeffrey S. SHOULSON (dir.), Hebraica veritas? Christian Hebraists and the Study of Judaism in Early Modern Europe, Philadelphia, University of Pennsylvania Press (Jewish Culture and Contexts), 2004. - II n'existe pas d'ouvrage du philosophe Porphyre de Tyr (243-vers 305) spécialement consacré à la réfutation de l'Écriture. Witrousk peut faire allusion à un ou plusieurs des fragments contre les chrétiens édités en 


\section{Adam Neuser}

1916 en 1921 par Adolf von Harnack (cf. Sébastien MORLET (dir.), Le Traité de Porphyre contre les chrétiens. Un siècle de recherches, nouvelles questions, Paris, Institut d'études augustiniennes (Collection d'études augustiniennes, série Antiquité), 2011), ou bien à un passage mal compris de l'Historia philosophica. La réfutation de Porphyre par Cyrille, évêque d'Alexandie (372-444) contient bien une discussion sur la Trinité : " Il faut, je pense, ajouter à ce qu'il a dit ce que ces gens disent sur l'Esprit Saint. Porphyre, en effet, dit, exposant la doctrine de Platon, que la substance du divin procède jusqu'à trois hypostases; le Dieu le plus éminent est le Bien, après lui, en deuxième, est le Démiurge, en troisième l'âme du monde; car la divinité procède jusqu'à l'âme » (CYrille d'AleXANdrie, Contre Julien I, 47, 3-9, éd. P. Burguière et P. ÉVIEuX, Paris, Cerf (Sources chrétiennes, 322), 1985 ; traduction de Marwan Rashed, que je remercie de m'avoir signalé ce texte).

212. Jacob Andreae (Andreä, 1528-1590), artisan de l'unification doctrinale des luthériens dans la deuxième moitié du $x v I^{e}$ siècle, organisateur de l'Église dans son duché natal de Württemberg mais aussi en Brunswick-Wolfenbüttel, prit une part importante dans l'adoption de la Formule de concorde (1577), l'un des écrits "symboliques" de l'Église luthérienne. Son autobiographie a été éditée en version bilingue: Leben des Jakob Andreae Doktor der Theologie, von ihm selbst mit großer Treue und Aufrichtigkeit beschrieben bis auf das Jahr 1562, éd. H. EHMER, Stuttgart, Calwer Verlag (Quellen und Forschungen zur württembergischen Kirchengeschichte, 10), 1991. Voir Christoph WEISMANN, "Auf Kanzeln, Kathedern und in Kutschen. Jakob Andreae als Universitäts- und Kirchenpolitiker », in U. KöPF, S. LORENZ et D. R. BAUER (dir.), Die Universität Tübingen zwischen Reformation und Dreißigjährigem Krieg, Thorbecke, Ostfildern (Tübinger Bausteine zur Landesgeschichte, 14), 2010, p. 119-140. Gerlach écrit ici à l'un de ses collègues les plus éminents de l'université de Tübingen : Andreae y devient professeur, chancelier et chanoine en 1561. II faut souligner l'activité diplomatique d'Andreae et sa tentative pour rapprocher les Églises luthérienne et orthodoxe à travers la correspondance qu'il entretint avec le patriarche Jérémie II de Constantinople (vers 15301595) : voir Dorothea WENDEBOURG, Reformation und Orthodoxie. Der ökumenische Briefwechsel zwischen der Leitung der Württembergischen Kirche und Patriarch Jeremias II. von Konstantinopel in den Jahren 1573-7581, Göttingen, Vandenhoeck \& Ruprecht (Forschungen zur Kirchen- und Dogmengeschichte, 37), 1986.

213. À partir du journal de Gerlach (Tage-Buch, op. cit., p. 176-177), Lessing reconstitue ce que l'on savait en son temps de l'activité d'agent double de Neuser, au service du sultan et de l'Empire. Dans le cadre de l'ambassade de David Ungnad von Sonnegg (vers 1538-1600) dépêchée en 1573 à Istanbul, Neuser communiqua des informations à la partie impériale et empêcha le décodage de lettres chiffrées : voir introduction, n. 103.

214. Lettre de Stephan Gerlach à Jacob Andreae, 11 octobre 1573 (même jour que la lettre à Heerbrand citée par Lessing, voir plus haut, n. 145), ms. Paris, BSG, Epistolae Haereticorum 1458, 143v-144v, publiée dans M. FIRPO (éd.), Antitrinitari nell'Europa orientale del '500, op. cit., p. 89-90: " II a cessé de maudire notre religion, rejette toute controverse sur Dieu, raille le Turquicisme comme on le fait d'une fable et ne dissimule pas sa perspective d'un retour quand l'occasion s'en présentera - et un retour chez les protestants. Mais que ce vaurien nourrisse en son cœur plusieurs erreurs monstrueuses, je ne le contesterai nullement. Le 2 juillet, Petrus Witrousk, superintendant général des Églises de ceux qui de Dieu jugent bien (ainsi qu'il s'intitule), lui a écrit de Pologne pour lui demander au nom de tous ses frères de venir auprès d'eux et de discuter de tous les articles de religion. Ils sont en effet tellement bouleversés par les écrits qu'il a laissés en Pologne qu'ils rallieraient sur le champ sa position. À la suite, il écrit, entre autres choses: Je te demande, cher Adam, etc. » Sur la lettre de Witrousk à Neuser, voir Ch. J. BuRCHILL, The Heidelberg Antitrinitarians, op. cit., p. 155-156.

215. Lettre de Stephan Gerlach à Jacob Andreae, 11 octobre 1573, loc. cit. : " Tu ne le feras pas pour rien, et nous te donnerons un honnête salaire à l'année. Pour ce qui est des écrits que tu as rassemblés sur toutes les grandes questions de religion, apporte-les avec toi. Car nous nous 
occuperons de les faire imprimer, et nos adversaires en seront couverts de honte. » Lessing compare avec le texte de l'Antidanaeus de Gerlach, op. cit., ici p. 38 (voir plus haut, n. 151).

216. En juillet 1658, la diète de Pologne interdit l'Église des Frères polonais (voir plus haut, n. 155) et donne trois ans à ses membres pour se convertir au catholicisme. La plupart des Frères cherchent refuge en Transylvanie, dans l'Empire et aux Provinces-Unies. Voir G. H. WILLIAMS, The Polish Brethren. Documentation of the History and Thought of Unitarianism in the Polish-Lithuanian Commonwealth and in the Diaspora 1607-1685, Missoula, Mont., Scholars Press (Harvard Theological Studies, 30), 1980, t. I, p. 40.

217. Thesaurus epistolici Lacroziani [..., loc. cit., voir plus haut, n. 195: « Neuser s'attribue sans ambiguiité l'invention de ce dogme [du Christ qu'on n'adore ni n'invoque]. »

218. Adam NeUSER, Scopus septimi capitis ad Rom. Anno 1572, in Tractatus aliquot Christianae religionis, Ingolstadii (en fait: Cracovie) 1583, f. 81v-89v. Le recueil contient des textes de Johann Sommer (voir plus haut, n. 41), Adam Neuser et Matthias Vehe alias Theodosius Schimberg, son éditeur (voir plus haut, n. 19 et SAND, Bibliotheca Antitrinitariorum, op. cit., p. 88). Sur le texte de Neuser, qui conteste l'interprétation de $\mathrm{Rm} 7$ comme doctrine de la régénération, voir Ch. J. BURCHILL, The Heidelberg Antitrinitarians, op. cit., p. 148-150.

219. Sur Girolamo (Hieronymus) Zanchi, voir plus haut, n. 92. Lessing renvoie en note aux H. Zanchii epistolarum libri duo repris au t. VIII des Opera, Genevae-Parisiis 1619, p. 52-60, où « N. » désigne le «semi-arien » auteur des « thèses philosophiques » réfutées par Zanchi.

220. GERLACH, Tage-Buch, op. cit., p. 35 : « son Éraste, un très proche ».

221. Ibid.

222. Sur la fiabilité douteuse du texte allemand édité de Gerlach, voir plus haut, n. 85 .

223. II a déjà été question du cercle heidelbergeois du médecin et théologien Thomas Erastus (1524-1583), au centre de l'opposition à la discipline ecclésiastique introduite par Frédéric III: voir plus haut, n. 18-19, ainsi que Ruth WESEL-ROTH, Thomas Erastus. Ein Beitrag zur Geschichte der reformierten Kirche und zur Lehre von der Staatssouveränität, Lahr/Baden, Schauenburg (Veröffentlichungen des Vereins für Kirchengeschichte in der Evangelischen Landeskirche in Baden, 15), 1954 et Ch. D. GunNoE, Jr., Thomas Erastus and the Palatinate. A Renaissance Physician in the Second Reformation, Leiden-Boston, Brill (Brill's Studies in Church History, and Religious Culture, 48), 2011.

224. «Éraste », grec épaotńs, l'amant, l'ami.

225. H. Zanchii epistolarum libri duo, loc. cit., p. 186 (lettre à Johann Ludwig Lavater, 20 septembre 1570) : « Dans cette affaire d'arianisme, où beaucoup soupçonnèrent mon ami à cause de son amitié très étroite avec $\mathrm{N}$., je l'ai défendu et je défendrai jusqu'au sang car on lui fait du tort, pour autant que j'aie pu m'en rendre compte dans les conversations très nombreuses et familières que j'ai eues avec lui. » - (Johann) Ludwig Lavater fut pasteur et antistes de l'Église de Zurich (cf. Dictionnaire historique de la Suisse, http://www.hls-dhs-dss.ch/textes/f/F10728.php (Hans Ulrich BÄCHTOLD), consulté le 07.01.2017).

226. GERLACH, Tage-Buch, op. cit., p. 322.

227. Ibid., p. 249.

228. Sur Michael Heberer et Wenzel Budowecz von Budowa, voir plus haut, n. 141-142.

229. Sur Christian Gottlieb Jöcher et Johann Michael Heineccius, voir plus haut, n. 4 et 15.

230. Michel Servet (Miguel Servet(o), 1511-1553), figure tutélaire de l'antitrinitarisme, médecin né en Aragon et brûlé à Genève sur ordre de Calvin, auteur de la Christianismi restitutio (Vienne 1553), source d'inspiration pour les antitrinitaires de Transylvanie (voir plus haut, n. 9). Dans une littérature abondante, voir p. ex. Valentine ZUBER (dir.), Michel Servet, 1517-1553. Hérésie et pluralisme du XVI au XXI siècle, Paris, Champion (Colloques, congrès et conférences sur la Renaissance européenne, 56), 2007. 


\section{Adam Neuser}

231. Lettre à Mathurin Veyssière de La Croze, 2 décembre 1706, Dutens V, 483.

232. HEINECCIUS, Eigentliche und wahre Abbildung der alten und neuen griechischen Kirche [...], op. cit., Appendice II, p. 28.

233. Johann Joachim Becher (1635-1682), docteur en médecine de Mayence en 1661, converti au catholicisme en 1657, médecin, chimiste, économiste au service des électeurs de Mayence et de Bavière puis de l'empereur Leopold ler. Voir Gotthardt FRÜHSORGE et Gerhard F. STRASSER (dir.), Johann Joachim Becher (1635-1682), Wiesbaden, Harrassowitz (Wolfenbütteler Arbeiten zur Barockforschung, 22), 1993; Michael LORBER, « Alchemia oeconomica - Johann Joachim Bechers (1635-1682) Sozialutopismus am Schnittpunkt von Projektemacherei, Staatsräson und Universalwissenschaft », in P.-A. ALT, J. EMING, T. RENZ et V. WELS (dir.), Magia daemoniaca, magia naturalis, zouber. Schreibweisen von Magie und Alchemie in Mittelalter und Früher Neuzeit, Wiesbaden, Harrassowitz (Episteme in Bewegung, 2), 2015, p. 339-375. Sur le texte de Becher, voir introduction, p. 52. 
ANNEXE

LA LETTRE AU SULTAN 



\section{Lettre d'Adam Neuser au sultan Selim II (1570)}

Source: [Mathurin Veyssière de La Croze], DISSERTATIONS | HISTORIQUES | SUR | DIVERS SUJETS. | TOME PREMIER, | A RotTERDAM, | chez REINIER LEERS, | MDCcViI. [1707], « Réflexions historiques et critiques sur le mahométisme \& sur le socinianisme ", p. 105-121 [ex. Berlin, Staatsbibliothek, Bibl. Diez oct. 1266]

Traduction française de " ADAMI NEUSERI, gewesenen Predigers zu Heydelberg Schreiben an den Türckischen Kayser Selym dieses Namens den Andern ", in ANTIQUITATES | Quædam Palatinæ. Ex Johannis Agrico-|lae Ruperti Imp. Cam. Secretarii Viridario \& aliis | MSS. Collectae per Jacobum Beyrlin, in MONUmenTA | PIETATIS \& LITERARIA | VIRORUM | IN RE PUBLICA \& LITERARIA | ILLUSTRIUM, SELECTA [...]| Francofurti ad Moenum, | Apud JOHANNES MAXIMILIANUM à SANDE, | Anno MDCCI. [1701], p. 337-344 (ex. Berlin, Staatsbibliothek, Ag 1000').

Sur l'authenticité de ce texte, voir introduction, p. 16-17.

TRES INVICIBLE ET TRES-PUISSANT MONARQUE.

Moi Adam Neuser, né Chretien en Allemagne, \& promù à la di-[106]gnité de Predicateur du peuple à Heidelberg, ville où se trouvent aujourd'hui les plus savans hommes de toute l'Allemagne, je me refugie avec une profonde soumission vers Vôtre 
Majesté, vous conjurant pour l'amour de Dieu, \& de vôtre Prophete, sur lequel soit la paix de Dieu, de me recevoir an nombre de vos sujets, \& de ceux de vôtre peuple, qui croient en Dieu. Car par la grace du Dieu Tout-puissant, je vois, je reconnois, \& je crois de tout mon cœur que vôtre doctrine \& votre religion sont pures, nettes \&o agreables à Dieu. Je suis très-persuadé que ma retraite d'entre les Chretiens idolatres engagera plusieurs personnes de consideration à embrasser vôtre Religion; vîu sur tout, que plusieurs des plus savans \& des plus considerables d'entre eux sont en cela du même sentiment que moi, comme je le ferai connoître de bouche à Vôtre Majesté.

Pour ce qui est de moi, je suis as-[107]sûrement un de ceux, dont il est parlé en ces termes dans le XIII. Chapitre de l'Alcoran: Les Chretiens nous font paroître beaucoup plus de bienveillance, que les Juifs. Et quand leurs Prêtres \& leurs Evêques, pourvu qu'ils ne soient point impudens ni opiniâtres, entendent le commandement que fait le Prophete de Dieu, \& que par là ils reconnoissent la verité, ils disent les larmes aux yeux: Ah Dieu! nous esperons de nôtre cœur, que puisque nous croions la même chose que les gens de bien, tu nous feras aussi entrer dans leur communion. Car pourquoi ne croirions-nous pas en Dieu, \& en celui qui est manifesté par la verité?

Certainement, ô Empereur! je suis un de ceux qui lisent l'Alcoran avec joie: je suis un de ceux qui desirent d'être de vôtre peuple; \& je rens temoignage devant Dieu, que la doctrine de vôtre Prophete, sur lequel soit la paix de Dieu, est d'une veri[108] té indubitable. C'est pourquoi je supplie très-humblement Vôtre Majesté, pour l'amour de Dieu, \& de vôtre Prophete, de vouloir me faire la grace de m'écouter, \& d'entendre de quelle manière le Dieu de misericorde m'a revelé sa verité.

Mais premierement, Vôtre Majesté doit être entierement persuadée que je n'ai pas recours à sa protection, comme quelques Chretiens ont accoûtumé de le faire, qui à cause de leurs crimes, de leurs larcins, meutres ou adulteres, ne sauroient demeurer en sûreté, parmi les gens de leur Religion. Car j'avois resolu, il y a 
plus d'un an, de me refugier vers vous: je m'etois même avancé jusqu'à Presbourg; mais comme je n'entends pas la langue Hongroise, je ne pus aller plus avant, \& contre mon gré je fus contraint de revenir en mon païs, ce que je n'aurois eu garde de faire, si j'avois fui pour quelque crime. De plus rien ne me contraint à embrasser vôtre Religion, car qui pourroit m'y [109] forcer, inconnu que je suis à vos gens, si fort éloigné d'eux?

Ainsi Vôtre Majesté ne doit pas me mettre au nombre de ces Chretiens, qui aiant été vaincus, \& faits prisonniers par vos sujets, embrassent vôtre Religion, mais non pas de bon cour, \& qui d'abord qu'ils en trouvent l'occasion, s'enfuient \& renoncent à la vraie foi. C'est pourquoi je supplie derechef Vôtre Majesté de prêter de l'attention à ce que je vais dire, \& de reconnoître la veritable cause de ma retraite dans vos Etats.

Aiant été promî̀ à la dignité de Predicateur dans la celebre Université de Heidelberg, par l'Electeur Palatin, qui après l'Empereur, est le plus puissant Prince de toute l'Allemagne, je commençai à pezer mûrement en moi-même les diverses dissenssions \& les divisions de nôtre Religion Chretienne. Car autant de personnes qu'il y a parmi nous, autant y a-t-il de divers sentimens. Je [110] commençai par faire abstraction de tous les Docteurs \& de tous les Interpretes de l'Ecriture, qui ont écrit ou enseigné depuis le Prophete Jesus-Christ. Je m'attachai aux seuls commandemens de Moïse, ơ à l'Evangile. Ensuite, j'invoquai Dieu interieurement avec une application religieuse, \& je le priai de me montrer la voie droite, afin que je ne fusse pas en danger de me devoier moi \& mes auditeurs. Alors il plut à Dieu de me reveler l'article de l'invocation d'un seul Dieu; article, sur lequel j'ai composé un livre, dans lequel je prouve, \& je fais voir par l'Evangile, que la Doctrine de JEsus-CHRIST n'a point consisté à assûrer qu'il fût lui-même un Dieu, comme les Chretiens l'avancent faussement; mais qu'il n'y a qu'un seul Dieu, qui n'a point de fils, qui lui soit consubstantiel. J'ai adressé ce livre à Vôtre Majesté, \& je suis très-certain que les plus habiles gens d'entre les Chretiens ne sont [111] pas capables 
de le refuter. Et pourquoi voudrois-je associer à Dieu un autre Dieu qui lui fût semblable? Mö̈se l'a defendu, \& J. CHRIst ne l'a jamais enseigné.

Dans la suite me fortifiant de jour en jour par la grace de Dieu, \& reconnoissant que les Chretiens abusent de tous les bienfaits de JEsus-CHRIST, comme autrefois les Juifs abuserent du serpent d'airain, [sur quoi j'ai écrit un traité particulier que j'ai par devers moi] j'ai conclû qu'il ne se trouve rien de pur parmi les Chretiens, \& que tout ce qu'ils ont, est falsifié. Car ils ont perverti par leurs fausses interpretations presque tous les écrits de Moïse \& de l'Evangile, comme je le fais voir dans un livre que j'ai écrit de ma propre main, \& que je presenterai à Vôtre Majesté.

Ce que je dis que les Chretiens ont falsifié les commandemens de Moïse \& de JESUS-CHRIST, je ne l'entends que des paroles \& $d u$ [112] sens: car la doctrine de Moïse, de Jesus \& de Mahomet conviennent en tout, \& ne sont contraires en aucune chose, comme je vais le prouver par des textes de l'Alcoran.

On trouve ces mots dans le second Chapitre de ce Livre: De même que Dieu a donné un livre à chacun des autres Prophetes, il en a aussi donné un à Jesus-Christ, fils de Marie, auquel l'Esprit de Dieu a rendu temoignage, \& l'a assisté. Quelle raison avez-vous de contredire les Prophetes, qui vous sont envoiez? Peut-être ne disent-ils pas des choses qui vous soient entierement agreables, $\left({ }^{\mathrm{a}}\right) \& \mathrm{c}$.

Ces passages font voir clairement que l'Alcoran rend un temoignage avantageux à Mö̈se \&o à Jesus-Christ. Mais il insiste princi-[113]palement sur ce que les Chretiens, par leurs fausses interpretations, ont corrompu les commandemens de Moïse, \& de l'Evangile de Jesus-CHRIst. En effet, si la parole de Dieu étoit fidellement interprétée, il n'y auroit aucune difference entre les Juifs, les Chretiens \& les Turcs. Ainsi ce que l'Alcoran

(a) II y a en cet endroit une longue tirade de passages de l'Alcoran. Mais comme Neuser les a tirez de l'ancienne version Latine, qui est fort infidelle, \& d'ailleurs qu'il les a traduits d'une manière peu intelligible, je náai pû me resoudre à les mettre en nôtre langue. [Note de Veyssière de La Croze]. 
repete si souvent, est vrai. La doctrine de Mahomet annulle toutes les fausses interpretations de l'Ecriture, \& enseigne le vrai sens de la parole de Dieu.

Mais pourquoi m'etendre davantage? Vôre Majesté sait tout cela. J'en reviens à ce qui me concerne.

Après que par la grace de Dieu, j'eus reconnu qu'il n'y avoit qu'un seul Dieu; que j'eus remarqué que la Doctrine de JESUSCHRIST n'étoit point enseignée, comme elle le devoit être; que toutes les ceremonies de Chretiens s'étoient fort éloignées de leur premiere institution, je commençai à croire que dans tout le reste du monde j'étois le seul de cette opi-[114]nion. Je n'avois point encore vî l'Alcoran, \& parmi nous autres Chretiens on a repandu de tous cotez des bruits si infames \& si scandaleux contre tout ce qui concerne la doctrine de Mahomet, que le pauvre peuple, à qui on fait croire ces choses comme autant de veritez, est frappé d'horreur, \&o devient hors de lui-même au seul nom de l'Alcoran. Mais pourtant par un effet de la Providence, ce livre m'est tombé entre les mains: j'en rends graces à Dieu, à Dieu, dis-je, qui fait que dans mes prieres je l'invoque pour Vôtre Majesté, ¿o pour tous ceux qui vous appartiennent. J'ai cherché toute sorte de voies pour donner la connoissance de ces veritez à mes auditeurs, \&o en cas qu'ils ne voulussent pas recevoir cette doctrine, j'avois resolû de demander mon congé à l'Electeur, d'abandonner ma charge, \&o de me retirer vers Vous.

J'ai commencé à attaquer par manière de dispute dans les Eglises, $6[115]$ dans les Ecoles, quelques points de notre doctrine, \& j'ai obtenu ce que je souhaitois: car j'ai conduit la chose à un point, que cela a été connu de tous les Etats de l'Empire, \& que j'ai attiré plusieurs Savans dans mon parti. Quelle étoit cette doctrine que j'attaquois, Vôtre Majesté le pourra voir par un écrit que je lui envoie, qui vient de l'Electeur même, \& qui est scellé de son propre sceau.

Mes sentimens \& l'interpretation que je donne à l'Ecriture, n'étant conformes à la doctrine d'aucun des Savans qui ont vêcu dans le Christianisme, depuis la naissance de J. CHRIsT, 
l'Electeur craignant que cette bonne doctrine ne deplùt à l'Empereur Maximilien, qui suit les dogmes \& les interpretations du Pape; étant d'ailleurs menacé d'une invasion de l'Empereur \& des Etats de l'Empire, parce qu'il a abandonné le Papisme, \& changé de Religion, il m'a deposé de ma charge, qui etoit celle d'un des principaux Predicateurs de l'E-[116]glise, jusqu'à ce qu'il se pût trouver quelque voie d'union entre moi \& ses autres Theologiens. Depuis ce tems-là il s'est donné beaucoup de mouvemens pour me reconcilier avec eux: mais tous ses soins ont été inutiles; car j'ai defendu la verité avec tant de force, tant par ecrit que de vive voix même en presence de l'Electeur, que des personnes de premier rang, or des principaux d'entre eux se sont enfin rendus à mon sentiment.

Aiant pressenti par la resistance que nos Theologiens, \& l'Electeur même faisoient à ces commencemens d'introduction à la verité, le peu que j'avois pour le reste, je n'eus point de peine à conclure qu'ils n'admettroient jamais des dogmes plus relevez ¿o beaucoup plus excellens. C'est pourquoi j'ai dejà renoncé au service de l'Electeur, \& je me donne à Vôtre Majesté, dans l'esperance où je suis, que je combattrai les Chretiens idolatres avec plus de fruit o moins de danger, \& dans la confiance que [117] j'ai de leur causer par là plus de chagrin, que si je demeurois parmi eux.

En effet d'abord que les Chretiens seront informez que la croiance de Vôtre Majesté est fondée sur leur Evangile, ils ne resisteront plus, car personne ne peut se resoudre à combattre contre Dieu, \& à faire violence aux lumieres de sa conscience en agissant contre ce qu'il croit. Et quand les Chretiens viendront à reconnoître que le regne de Vôtre Majesté est certainement le règne, dont il est parlé dans Daniel au second \&o au septiéme chapitre; regne qui doit subjuguer tous les peuples du monde, \& soumettre tous les Empereurs \& tous les Rois; ils ne seront pas desobeissans; ils plieront d'eux-mêmes sous vôtre autorité.

C'est pourquoi, si Vôtre Majesté veut reduire les Chretiens idolâtres à la connoissance d'un seul Dieu, agrandir son Empire, 
¿ étendre le culte de Dieu par toute la terre, il [118] est à present tems d'agir. Les Prêtres, \& les Predicateurs des Chretiens sont divisez entre eux: le peuple commence à douter de sa foi: les Evêues \& les Magistrats foulent \& oppriment avec tant de cruauté les pauvres peuples, que ces mêmes peuples soubaitent hautement que Vôtre Majesté puisse triompher de l'Empire d'Allemagne, \& decharger les pauvres du fardeau, dont ils sont accablez. On les entend se plaindre tous les jours, que les Prêtres ne leur debitent que des faussetez \& des mensonges.

Pour ce qui est de moi, je travaillerai de tout mon pouvoir, de bouche \& par écrit, je n'epargnerai aucun de mes soins, pour faire en sorte que les Chretiens idolâtres se convertissent à la vraie foi; que le culte de Dieu soit avancé, \& que le regne de Vôtre Majesté s'étende de plus en plus. Car je veux preferer la verité \&o le culte de Dieu, à ma patrie, à mes freres, à mes sours, [119] \& à tout ce que j'ai d'amis, \& de parens sur la terre.

Je me recommande donc avec une profonde soûmission à Dieu \& à Vôtre Majesté, \& je ne doute point que Vôtre Majesté ne me reçoive favorablement moi \& mes enfans, que j'amenerai avec moi. Car, comme dit le Prophete au XviII. Chapitre de l'Alcoran: Soiez de bonne foi à l'égard de ceux qui se jettent pacifiquement entre vos mains; \& dans le Xv. Chapitre: dis à tous ceux qui viennent à la foi, \& qui suivent nos commandements: Le salut de Dieu soit sur vous.

Que Vôtre Majesté ne doute point de ma fidelité \&o de ma constance dans vôtre Religion. Je crains Dieu, \& je fais ce que dit le Prophete: Ceux qui abandonnent les voies de Dieu, \& qui s'opposent au Prophete, après qu'ils ont connû la droite voie, nuisent à eux-mêmes, \& non à Dieu (b) \& c.

[120] J'invoque Dien le Createur du Ciel \& de la Terre, qui a envoié Moïse, Jesus-Christ, \& le Prophete, je l'invoque, dis-je, afin qu'il soit temoin à mon ame que toutes mes paroles sont sinceres, \& que je parle du fonds du cour, que j'embrasse votre

(b) Il y a encore là quelques passages de l'Alcoran que j'ai omis dans ma traduction. (Note de veyssière de la Croze). 
Religion, comme elle est contenuë dans l'Alcoran, \& que je la tiens pour la loi \& la doctrine du Dieu Tout-puissant.

Pour ce qui regarde une connoissance plus etenduë de l'état $d u$ Christianisme, j'espere avec le secours de la grace de Dieu, d'en informer de bouche Vôtre Majesté, laquelle je recommande à la protection du Tout-puissant.

Je dis devant Dieu avec l'Alcoran, qu'aucune force ni contrainte ne me portera jamais à mentir à Dieu, à abandonner ses preceptes, ni à m'attacher à un autre, duquel il m'a delivré.

Je me soumets de tout mon cour à cette loi, \&o je prie Dieu instam-[121]ment que mon moien il fasse connoître la verité aux Chretiens. Il est le Dieu veritable, à qui toutes choses sont connuës.

ADAM NEUSER. 
BIBLIOGRAPHIE 



\section{Euvres de Lessing}

Zur Geschichte und Literatur. Aus den Schätzen der Herzoglichen Bibliothek zu Wolfenbüttel, Braunschweig, im Verlage der Fürstl. WaysenhausBuchhandlung, 6 vol., 1773-1781 (abr. ZGuL).

LESSING Gotthold Ephraim, Werke und Briefe, éd. W. BARNER et alii, Frankfurt a. M., Deutscher Klassiker Verlag, 12 t. en 14 vol., 1985-2003 (abr. WuB).

—, Sämmtliche Schriften, éd. K. LACHMANn et W. MunCKER, Stuttgart, Göschen, 23 t., 1886-1924³ , réimp. Berlin, De Gruyter, 1968 (abr. LM).

Von Adam Neusern, einige authentische Nachtrichten, in ZGuL, Dritter Beitrag, XVII, Braunschweig, im Verlage der Fürstl. Waysenhaus-Buchhandlung, 1774, p. 119-194.

Von Adam Neusern, einige authentische Nachtrichten, in LM, t. 12 (1897), p. 199-290.

Von Adam Neusern, einige authentische Nachrichten, éd. A. ScHILson, in WuB, t. 8 (1989), p. 55-114.

\section{Sources}

ABBADIE Jacques, Traité de la vérité de la religion chrétienne (1684), Rotterdam, R. Leers, $1689^{3}$.

—, Traité de la divinité de notre Seigneur Jésus-Christ, Rotterdam, R. Leers, 1689.

ÁLVARES Francisco, Wahrhafftiger bericht von den landen, auch geist und weltlichem Regiment des mechtigen Königs in Ethiopien, den wir Priester Johan nennen [...] in das deutsche gebracht, [Eisleben], Joachim Heller, [1566].

[ANDREAE Jacob] Leben des Jakob Andreae Doktor der Theologie, von ihm selbst mit großer Treue und Aufrichtigkeit beschrieben bis auf das Jahr 
1562, éd. H. EHMER, Stuttgart, Calwer Verlag (Quellen und Forschungen zur württembergischen Kirchengeschichte, 10), 1991.

Antitrinitari nell'Europa orientale del '500. Nuovi testi di Szymon Budny, Niccolò Paruta e Iacopo Paleologo, éd. M. FIRPo, Firenze, La Nuova Italia (Pubblicazioni del Centro di studi del pensiero filosofico del Cinquecento e del Seicento in relazione ai problemi della scienza, I, 8), 1977.

ARNOLD Gottfried, Unpartheyische Kirchen- und Ketzerhistorie vom Anfang des Neuen Testaments bis auff daß Jahr 1688, 2 vol., Frankfurt a. M., Fritsch, 1699-1700, réimp. Genschmar, Gruber, 2004.

[BECHER, Johann Joachim] Doct. Joh. Joachim Bechers [...] Naerrische Weisheit und Weise Narrheit: Oder Ein Hundert so Politische alß Physicalische Mechanische und Mercantilische Concepten und Propositionen/Deren etliche gut gethan/etliche zunichts worden [...], Frankfurt, Zubrod, 1682.

[BIANDRATA Giorgio et DÁvid Ferenc] De falsa et vera unius Dei Patris, Filii, et Spiritus Sancti cognitione, libri duo, authoribus ministris ecclesiarum consentientum in Sarmatia, \& Transyluania, Albae Iuliae 1568, réimp. Utrecht etc., Bibliotheca Unitariorum (Foundation Bibliotheca Unitariorum, 2), 1988.

-, Refutatio scripti Georgii Maioris, in quo deum trinum in personis, et unum in essentia [...] probare conatus est, s. l., s. n., 1569.

[Budovec z Budova Václav] Circulus horologi Lunaris et solaris, Hoc est, Brevissima Synopsis, Historica, Typica, et Mystica, Hanoviae, Aubrius, 1616.

Le Catéchisme de Heidelberg. Au cœur de l’identité réformée, éd. P.-O. LÉcHOT, Genève, Labor et Fides, 2013 (cf. Die Bekenntnisschriften der reformierten Kirche in authentischen Texten [...], éd. E. F. K. MüLLER, Leipzig, Deichert, 1903, réimp. Walltrop, Spenner (Theologische Studien-Texte, 5), 1999).

Cyrille D’AleXANdrie, Contre Julien, t. 1 (Livres I et II), éd. P. Burguière et P. Évieux, Paris, Cerf (Sources chrétiennes, 322), 1985.

[DÁvID Ferenc] Brevis enarratio disputationis Albanae de Deo trino et Christo duplici coram serenissimo principe et tota ecclesia decem diebus habita anno domini MDLXVIII 8. Martii, Claudiopoli, apud viduam Raphaelis Hoffhalteri, 1568.

[DE GóIs Damião] Damian de Góis’Schrift über Glaube und Sitten der Äthiopier, G. BÜHRING, Wiesbaden, Harrassowitz (Aethiopistische Forschungen, 39), 1994.

Enchiridion symbolorum, definitionum et declarationum de rebus fidei et morum, éd. H. DENZINGER, Freiburg i. B., Herder, 2014 ${ }^{44}$.

GERBER Christian, Fortsetzung der unerkannten Sünden der Welt. Aus Gottes heiligen [sic] Wort, zu der Ruchlosen Bekehrung, und derer, die den Herrn suchen wollen, Bewahrung, vorgestellet, Frankfurt, Winckler, $1705^{2}$. 
[GERLACH Stephan] Stephan Gerlachs deß Aeltern Tage-Buch der [...] an die Ottomannische Pforte zu Constantinopel abgefertigten und durch [...] Hn. David Ungnad [...] mit würcklicher Erhalt- und Verlängerung deß Friedens zwischen dem Ottomannischen und Römischen Käyserthum [...] glücklichst-vollbrachter Gesandtschafft, Frankfurt a. M., Zunner, 1674, éd. et tr. turque K. BEYDILli et T. NoYAN, Türkiye günlüğü, Istanbul, Kitapyayınevi, 2007.

-, Antidanaeus, sive responsio, qua Lamberti Danaei figmenta et calumniae, quas Antisturmium D. D. Osiandri, in causa Coena Dominica, et Maiestatis Christi Hominis, impotenter evomuit, ex verbo Dei deteguntur et refutantur [...], Tubingae, Gruppenbach, 1580.

[GöTZE Georg Heinrich] Georgii Henrici Goetzii [...] Meletemata Annaebergensia varii argumenti, Lubecae, Wiedemaier, $1707^{2}$.

[Grotius Hugo] Hugonis Grotii de jure belli ac pacis libri tres, Parisiis, N. Buon, 1625, tr. fr. P. Pradier-FodÉré, éd. D. Alland et S. Goyard-Fabre, Paris, PUF, $2012^{2}$.

[HEBERER, Michael] Aegyptiaca servitus. Das ist Wahrhafte Beschreibung einer dreyjährigen Dienstbarkeit, so zu Alexandrien in Egypten ihren Anfang und und zu Constantinopel ihr Ende genommen [...], Heidelberg, Vögelin, [1610], réimp. Graz, Akademische Drucks und Verlagsanstalt (Frühe Reisen und Seefahrten in Originalberichten, 6), 1967, tr. fr. O. V. VoLKoff, Voyages en Égypte de Michael Heberer von Bretten, 1585-1586, Le Caire, Institut français d'archéologie orientale du Caire (Collection des voyageurs occidentaux en Égypte, 18), 1976

[HEINECCIUS Johann Michael] D. Jo. Heinecii [...] Eigentliche wahrhafftige Abbildung der alten und neuen griechischen Kirchewahrhafftige: nach ihrer Historie, Glaubens-Lehren und Kirchen-Gebräuchen [...], Leipzig, Gleditsch, 1711.

[Heltus Caspar (éd.)] Disputatio in causa sacrosanctae et semper benedictae Trinitatis [...] inter nouatores D. Georgium Blandratam, Franciscum Dauidis, eorumque asseclas et pastores ministroscumque Ecclesiae Dei catholicae, ex Hungaria \& Transyluania, qui diuinam veritatem ex scriptis Propheticis \& Apostolicis, iuxta continuum Ecclesiae sanctae catholice consensum, defendam susceperunt, per decem dies, Albae Iuliae in Transyluania Habita, Claudiopoli, Caspar Heltus, 1568.

[LA CROze Mathurin Veyssière de] Thesaurus epistolici Lacroziani [...] ex Bibliotheca Iordaniana ed. Io. Ludovicus Uhlius, 3 vol., Lipsiae, Gleditsch, 1742-1746.

[LAUTERBACH Samuel Friedrich] Ariano-Socinismus olim in Polonia. Der ehmahlige Polnische Arische Socinismus, Wie er sich in diesen Landen eingeschlichen, und ausgebreitet, welches ihre vornehmsten und 
bekandtesten Lehrer gewesen, deren 50. an der Zahl nach ihrem Leben, und ausgegangenen Schrifften, beschrieben werden, und wie er endlich völlig daraus vertilget worden, in einer Historischen Erzehlung gezeuget, [...], Frankfurt-Leipzig, Knoch, 1725.

[LEIBNIZ Gottfried Wilhelm] Gothofredi Guilielmi Leibnitii [...] opera omnia nun primum collecta, in classes distributa [...] studio Ludovici Dutens, Genevae, De Tournes, 1768.

-, Sämtliche Schriften und Briefe, Reihe 1: Allgemeiner historischer und politischer Briefwechsel, éd. Preußische Akademie der Wissenschaften/Akademie der Wissenschaften der DDR/Leibniz-Forschungsstelle Hannover der Akademie der Wissenschaften zu Göttingen beim Leibniz-Archiv der Gottfried Wilhelm Leibniz Bibliothek Hannover, Berlin, AkademieVerlag, 1923-.

-, Confessio philosophi. La profession de foi du philosophe, éd. et tr. Y. BELAVAL, Paris, Vrin, $1970^{2}$

[MAJOR Georg] Commonefactio [...] de fugiendis \& execrandis blasphemijs Samosatenicis, Arianis, Eunomianis, \& alijs, quae hoc tempore a Francisco Dauidis, \& quodam Italo Georgio Blandrata, [...] sparguntur [...], Wittenbergae, Hans Lufft, 1569.

[MIEg Ludwig Christian et NeBEL Daniel (éd.)], Monumenta pietatis et literaria virorum in re publica illustrium selecta [...], Francoforti ad Moenum, Sand, 1701.

[NEUSER Adam] Scopus septimi capitis ad Rom. Anno 1572, in Tractatus aliquot Christianae religionis, Ingolstadii, s. n., 1583

Palaeologus Iacobus, Disputatio scholastica, éd. J. Domański et L. SzCZucki, Utrecht, Bibliotheca unitariorum (Bibliotheca unitariorum, 3), 1994.

PHILIPPI Ferdinand, Kleines lateinisches Conversationslexikon, Dresden, Hilscher, 1825.

Der Reichstag zu Speyer 1570, éd. M. LANZINNER, Göttingen, Vandenhoeck \& Ruprecht (Deutsche Reichstagsakten, 4. Reichsversammlungen 15561662), 2 vol., 1988.

Possevino Antonio, Transiluania (1584), éd. A. VEREss, Kolosvár, Fontes rerum Transylvanicarum/Budapest, Tipografia artistica Stephaneum, 1913.

[RUAR Martin] Martini Ruari [...] aliorumque virorum doctorum [...] ad ipsum Epistolarum selectarum centuria, 2 vol., Amstelodami, Ruarus, 1677-1681.

Il Sēnodos etiopico. Canoni pseudoapostolici: Canoni dopo l'Ascensione, Canoni di Simone Cananeo, Canoni Apostolici, Lettera di Pietro, éd. A. BAusI, Lovanii, Peeters (Corpus scriptorum christianorum orientalium, 552, 553 [Scriptores aethiopici, 101, 102]), 1995. 
[SAND Christoph] Nucleus historiae ecclesiasticae, exhibitus in historia Arianorum, Coloniae, Nicolai, $1676^{2}$.

—, Bibliotheca Antitrinitariorum, Freistadii, Johannes Aconius, 1684, réimpr. Varsoviae, Panstwowe Wydawnictwo Naukowe (Biblioteka Pisarzy Reformacyjnych, 6), 1958.

[Socin Faust] Ad Iac. Palceologi librum, cui titulus est, Defensio verce sententice de magistratu politico, \& c., pro Racoviensibus responsio [...] (s. l. [Kraków], Adamides, 1581), Irenopoli, s. n., 1656.

-, De Iesu Christi invocatione disputatio, quam Faustus Socinus per scripta habuit cum Francisco Davidis anno 1578, et 1579 [...] (s. l., Radekius, Valentinus, 1595), Irenopoli, s. n., 1656.

_, Fausti Socini senensis ad amicos epistolae [...], Racoviae, Sternacius, 1618.

[STRUVE Burkhard Gotthelf] Burcard Gotthelf Struvens Ausführlicher Bericht von der Pfältzischen Kirchen-Historie: In sich fassend die verschiedenen Religions-Veränderungen und den Kirchen-Staat in der Chur-Pflatz von Beginn der Reformation an bißs auf gegenwärtige Zeiten [...], s. l. [Jena], Hartung, 1721.

[VeHE Matthias] Mattaniah, das ist [...] die wahre Christliche Religion [...] aus der Bibel grundlich tractirt (1578), réimp. in R. DÁN, Matthias Vehe-Glirius. Life and Work of a Radical Antitrinitarian with his Collected Writings, Budapest, Akadémiai Kiadó (Studia Humanitatis, 4), 1982.

Wissowatius Andreas, Religio rationalis, s. l., s. n., 1685, éd. Z. OGonowSKI, Religio rationalis. Editio trilinguis, Wolfenbüttel, Herzog-August-Bibiothek (Wolfenbütteler Forschungen, 20), 1980.

[ZANCHI Girolamo] H. Zanchii epistolarum libri duo, in Clariss. viri D. Hie. Zanchii Omnium operum theologicorum tomi octo, t. VIII, s. l. [Genevae], Crispinus, 1619.

\section{III. Études}

AGETHEN Alfred, "Bekehrungsversuche an Juden und Judentaufen in der frühen Neuzeit ", Aschkenas. Zeitschrift für Geschichte und Kultur der Juden 1 (1991), p. 65-94.

AL-Shammary Zahim M. M., Lessing und der Islam, Berlin, Schiler, 2011.

ALMOND Ian, History of Islam in German Thought. From Leibniz to Nietzsche, New York, Routledge, 2011.

ANER Karl, Die Theologie der Lessingzeit, Halle, Niemeyer, 1929, réimpr. Hildesheim, Olms, 1964.

ANGERBAUER Wolfram, Das Kanzleramt an der Universität Tübingen und seine Inhaber 1590-1817, Tübingen, Mohr (Contubernium, 4), 1972, p. 19-20. 
ANTOGnazZA Maria Rosa, Trinità e incarnazione. Il rapporto tra filosofia e teologia rivelata nel pensiero di Leibniz, Milano, Vita e Pensiero (Pubblicazioni dell'Università Cattolica del Sacro Cuore, 64), 1999, tr. angl. Leibniz on Trinity and the Incarnation. Reason and Revelation in the Seventeenth Century, New Haven, Yale University Press, 2007, p. 137-149.

APPoLD Kenneth G., " Abraham Calov als Vater der spätlutherischen Orthodoxie ", in E. Косн et J. WallmanN (dir.), Ernst Salomon Cyprian (16731745). Zwischen Orthodoxie, Pietismus und Frühaufklärung, Gotha, Forschungs- und Landesbibliothek Gotha (Veröffentlichungen der Forschungs- und Landesbibliothek Gotha, 34), 1996, p. 49-58.

Arberry A. J., Oriental Essays. Portraits of Seven Scholars, London, Allen \& Unwin, 1960.

ARMGART Martin, "Territoriale Kirchenleitungsmodelle im multikonfessionellen Territorium - Fürstentum Siebenbürgen ", in J. WISCHMEYER (dir.), Zwischen Ekklesiologie und Administration. Modelle territorialer Kirchenleitung und Religionsverwaltung im Jahrhundert der europäischen Reformationen, Göttingen, Vandenhoeck \& Ruprecht (Veröffentlichungen des Instituts für europäische Geschichte Mainz, 100), 2013, p. 225-249.

Asche Matthias, "Von Konfessionseiden und gelehrten Glaubensflüchtlingen, von Konvertiten und orthodoxen Gelehrten. Mobilitätsphänomene konfessionell devianter Professoren zwischen obrigkeitlicher Duldung, Landesverweis und freiwilligem Abzug ", in H. P. JüRGENS et Th. WELLER (dir.), Religion und Mobilität. Zum Verhältnis vom raumbezogener Mobilität und religiöser Identitätsbildung im frühneuzeitlichen Europa, Göttingen, Vandenhoeck \& Ruprecht (Veröffentlichungen des Instituts für Europäische Geschichte Mainz, Beiheft 81), 2010, p. 375-400.

AtTIAs Jean-Christophe (dir.), De la conversion, Paris, Cerf (Patrimoines. Religions du Livre), 1997.

BÄBLER Balbina et NESSELRATH Heinz-Günther (dir.), Christian Gottlob Heyne. Werk und Wirkung nach zweihundert Jahren, Berlin-New York, De Gruyter (Abhandlungen der Akademie der Wissenschaften zu Göttingen, Neue Folge, 32), 2015.

BAER Marc, "Islamic Conversions of Women. Social Change and Gendered Religious Hierarchy in Early Modern Ottoman Istanbul ", Gender \& History 16 (2004), p. 425-458.

BAHLCKE Joachim et STROHMEYER Arno (dir.), Konfessionalisierung in Ostmitteleuropa. Wirkungen des religiösen Wandels im 16. und 17. Jahrhundert, Stuttgart, Steiner (Forschungen zur Geschichte und Kultur des östlichen Mitteleuropa, 7), 1999.

BAHLCKE Joachim (dir.), Glaubensflüchtlinge. Ursachen, Formen und Auswirkungen frühneuzeitlicher Konfessionsmigration in Europa, Berlin etc., 
Lit (Religions- und Kulturgeschichte in Ostmittel- und Südosteuropa, 4), 2008.

BALÁzs Mihály, Early Transylvanian Antitrinitarianism (1566-1571). From Servet to Palaeologus, Baden-Baden/Bouxwiller, Koerner (Bibliotheca dissidentium, VII), 1996.

—, Ungarländische Antitrinitarier IV. Ferenc Dávid, Baden-Baden/Bouxwiller, Koerner (Bibliotheca dissidentium, XXVI), 2008.

Balibar Étienne, Saeculum. Culture, religion, idéologie, Paris, Galilée, 2012.

BARBERO Alessandro, Lepanto. La battaglia dei tre imperi, Roma, Laterza, $2011^{4}$, tr. fr. La Bataille des trois empires. Lépante 1571, Paris, Flammarion (Champs), 2012.

BARNER Wilfried, "Lessing zwischen Bürgerlichkeit und Gelehrtheit ", in R. VIERHAUS (dir.), Bürger und Bürgerlichkeit im Zeitalter der Aufklärung, Heidelberg, Schneider (Wolfenbütteler Studien zur Aufklärung, 7), 1987, p. 165-204.

- (dir.), Lessing. Epoche - Werk - Wirkung, München, Beck (Arbeitsbücher zur Literaturgeschichte), $1998^{6}$.

—, " Lessing im Streit um das geistige Eigentum. Gelehrtenexistenz, Medialität, neues Publikum », in K. BREMER et C. SPOERHASE (dir.), Gelehrte Polemik II = Zeitsprünge 19 1/4 (2015), p. 189-238.

BAUSI Alessandro, "Alcune considerazioni sul Sēnodos etiopico ", Rassegna di studi etiopici 34 (1992), p. 5-73.

BEck Philippe et THOuARD Denis (dir.), Popularité de la philosophie, Fontenayaux-Roses, ENS Éditions (Theoria), 1995.

BECKER Judith, Gemeindeordnung und Kirchenzucht. Johannes a Lascos Kirchenordnung für London (1555) und die reformierte Konfessionsbildung, Leiden-Boston, Brill (Studies in Medieval and Reformation Traditions, 122), 2007

BEHRINGER Wolfgang, Im Zeichen des Merkur. Reichspost und Kommunikationsrevolution in der Frühen Neuzeit, Göttingen, Vandenhoeck \& Ruprecht (Veröffentlichungen des Max-Planck-Instituts für Geschichte, 189), 2003.

BENEDICT Philip, Christ's Churches Purely Reformed. A Social History of Calvinism, New Haven-London, Yale University Press, 2002.

BENNASSAR Bartolomé et BENNASSAR Lucile, Les Chrétiens d'Allah. L'histoire extraordinaire des renégats, $X V I^{e}$ et XVII ${ }^{e}$ siècles (1989), Paris, Perrin (Tempus, 115), $2006^{2}$.

BENRATH Gustav Adolf, Reformierte Kirchengeschichtsschreibung an der Universität Heidelberg im 16. und 17. Jahrhundert, Speyer, Zechner (Veröffentlichungen des Vereins für Pfälzische Kirchengeschichte, 9), 1963. 
BERINDEI Minhea et VEINSTEIN Gilles, L'Empire ottoman et les pays roumains, 1544-1545. Études et documents, Paris, Éditions de l'École des Hautes Études en Sciences Sociales (Documents et recherches sur le monde byzantin, néohellénique et balkanique, 14) Cambridge, Mass., Harvard Ukrainian Research Institute (Studies in Ottoman Documents Pertaining to the Ukraine and the Black Sea Countries, 1), 1987.

BERNARDINI Michele, Costantinopoli nella relatione di Domenico Gierosolimitano (1611), Napoli, Istituto universitario orientale, 1995.

BERnARdini Michele, Borrelli Clara, CERbo Anna, SÁnchez GARCÍA Encarnación (dir), Europa e Islam tra i secoli XIV e XVI, 2 vol., Napoli, Istituto universitario orientale (Collana « Matteo Ripa », XVIII), 2002.

BEUTEL Albrecht, Kirchengeschichte im Zeitalter der Aufklärung. Ein Kompendium, Göttingen, Vandenhoeck \& Ruprecht (UTB 3210), 2010.

-, "Gotthold Ephraim Lessing und die Theologie der Aufklärung ", in Ch. DANZ (dir.), Schelling und die Hermeneutik der Aufklärung, Tübingen, Mohr Siebeck (Hermeneutische Untersuchungen zur Theologie, 59), 2012, p. 11-28.

BIEGEL Gerd, « "Eigentlich ist es der Erbprinz, welcher mich hierher gebracht hat”. Wolfenbüttel und Braunschweig: Lessing zwischen Herzog, Hof und Bibliothek ", in ID., "Liebhaber der Theologie ". Gotthold Ephraim Lessing - Philosoph - Historiker der Religion, Frankfurt a. M. etc., Lang (Braunschweiger Beiträge zur Kulturgeschichte, 3), 2012, p. 11-35.

BINDER Ludwig, "Theologie und Bekenntnis auf Synode der evang.-sächsischen Kirche 1545-1578 ", in U. A. WIEN (dir.), Reformation, Pietismus, Spiritualität. Beiträge zur siebenbürgisch-sächsischen Kirchengeschichte, Köln-Weimar-Wien, Böhlau (Siebenbürgisches Archiv, 41), 2011, p. 37-122.

BLAUfuss Dietrich, NIEWÖHNER Friedrich et SchNEIDER Hans (dir.), Gottfried Arnold (1666-1714), Wiesbaden, Harrassowitz (Wolfenbütteler Forschungen, 61), 1995.

BLED Jean-Paul, « Le Banat. Un panorama historique ", Études Germaniques 67/3 (2012), p. 415-419.

Bobzin Hartmut, Der Koran im Zeitalter der Reformation. Studien zur Frühgeschichte der Arabistik und Islamkunde in Europa, Stuttgart, Steiner, 1995, réimp. Würzburg, Ergon (Beiruter Texte und Studien, 42), 2008.

Bock Heike, « Konversionen und Säkularisierung? Untersuchungen zum Wandel konfessioneller Repräsentation im frühneuzeitlichen Zürich », in M. PoHLIG (dir.), Säkularisierungen in der Frühen Neuzeit. Methodische Probleme und empirische Fallstudien, Berlin, Duncker \& Humblot (Zeit für historische Forschung, Beiheft, 41), 2008, p. 159-199. 
-, Konversionen in der frühneuzeitlichen Eidgenossenschaft. Ein Vergleich von Zürich und Luzern, Epfendorf/Neckar, Bibliotheca Academica (Frühneuzeit-Forschungen, 14), 2009.

BÖDEKER Hans Erich, BÜtTGEn Philippe et EsPagne Michel (dir.), Die Wissenschaft vom Menschen in Göttingen. Wissenschaftliche Praktiken, institutionelle Geographie, europäische Netzwerke, Göttingen, Vandenhoeck \& Ruprecht (Veröffentlichungen des Max-Planck-Instituts für Geschichte, 237), 2008, p. 23-46.

BREMER Kai, « Conversus, confirma fratres tuos. Zum "Ich” in Konversionsberichten in den ersten Jahrzehnten nach der Reformation ", zeitenblicke 1 (2002), URL http://www.zeitenblicke.de/2002/02/bremer/index.html

-, "Konversion und Konvertiten auf dem Theater der Frühen Neuzeit ", in U. Lotz-Heumann, J.-F. Missfelder et M. Pohlig (dir.), Konversion und Konfession in der Frühen Neuzeit, Gütersloh, Gütersloher Verlagshaus (Schriften des Vereins für Reformationsgeschichte, 205), 2007, p. 431446.

-, " Der Conversus und sein Bekenntnis. Zur Performanz der Bekehrung auf dem deutschen Theater um 1600 ", in Ch. MEIER, B. RAMAKERS et H. BEYER (dir.), Akteure und Aktionen. Figuren und Handlungstypen im Drama der Frühen Neuzeit, Münster, Rhema (Symbolische Kommunikation und gesellschaftliche Wertesysteme 23), 2008, p. 485-508.

—, « Konversionalisierung statt Konfessionalisierung? Bekehrung, Bekenntnis und das Politische in der Frühen Neuzeit ", in H. JaumanN (dir.), Diskurse der Gelehrtenkultur in der Frühen Neuzeit. Ein Handbuch, BerlinNew York, de Gruyter, 2010, p. 369-408.

BRÖER, Ralph, « Friedenpolitik durch Verketzerung. Johannes Crato (15191585) und die Denunziation der Paracelsisten als Arianer ", Medizinhistorisches Journal 37 (2002), 139-182.

-, « Blutkreislauf und Dreieinigkeit. Medizinischer Antitrinitarismus von Michel Servet (1511-1553) bis Giorgio Biandrata (1515-1588), Berichte zur Wissenschaftsgeschichte 29 (2006), p. 21-36.

-, "Antiparacelsismus und Dreieinigkeit. Medizinischer Antitrinitarismus von Thomas Erastus (1524-1583) bis Ernst Soner (1572-1605) ", Berichte zur Wissenschaftsgeschichte 29 (2006), p. 137-153.

BÜTTGEN Philippe, «Lessing et la question du prêche. Philosophie, théologie, pastorat ", Les Études Philosophiques, 2/2003, p. 213-243.

- et Duhamelle Christophe (dir.), Religion ou confession? Un bilan francoallemand sur l'époque moderne (XVI $I^{e}-X V I I I^{e}$ siècles), Paris, Éditions de la Maison des Sciences de l'Homme (Colloquium), 2010.

- , « Portrait d'autrui en groupe. Premières recherches sur la sémantique de la confession dans le Saint-Empire ", in Ch. BERNAT et H. Bost (dir.), Énoncer, dénoncer l'autre. Discours et représentations du différend 
confessionnel à l'époque moderne, Turnhout, Brepols (Bibliothèque de l’École des Hautes Études, Sciences Religieuses, 151), 2012, p. 173-184.

—, "L'Orient des conversions. Johann David Michaelis, Gotthold Ephraim Lessing ", in M. EsPagne et P. Simon-NAHUM (dir.), Passeurs d'Orient. Les Juifs dans l'orientalisme, Paris, Éditions de l’Éclat (Bibliothèque des Fondations), 2013, p. 29-48.

—, " La raison de sang-froid. Sur une page de Lessing ", in M. MalPangotTo, V. Jullien et E. Nicolaidis (dir.), L'Homme au risque de l'infini. Mélanges d'histoire et de philosophie des sciences offerts à Michel Blay, Turnhout, Brepols (De diversis artibus, 93), 2013, p. 359-366.

—, « Was heisst konfessionelle Eindeutigkeit? Konzeptionelle Überlegungen zum frühneuzeitlichen Begriff der doctrina ", in A. PIETSCH et B. STOLLBERG-RILINGER (dir.), Konfessionelle Ambiguität. Uneindeutigkeit und Verstellung als religiöse Praxis in der Frühen Neuzeit, Gütersloh, Gütersloher Verlagshaus (Schriften des Vereins für Reformationsgeschichte, 214), 2013, p. 27-38.

—, " Confession de foi et survie du serment », Droits 60 (2014), p. 39-52.

—, "Philosophie et religion en Allemagne. Le droit des confessions ", Études germaniques 70 (2015), p. 659-670.

BultMann Christoph et VollHaRdT Friedrich (dir.), Gotthold Ephraim Lessings Religionsphilosophie im Kontext. Hamburger Fragmente und Wolfenbütteler Axiomata, Berlin-New York, de Gruyter (Frühe Neuzeit, 159), 2011.

Bultmann Christoph et Siwcyk Birka (dir.), Tolerant mit Lessing. Ein Lesebuch zur Ringparabel, Leipzig, Evangelische Verlags-Anstalt, 2013.

Burchill Christopher J., The Heidelberg Antitrinitarians. Johann Sylvan, Adam Neuser, Matthias Vehe, Jacob Suter, Johann Hassler, Baden-Baden/ Bouxwiller, Koerner (Bibliotheca dissidentium. Répertoire des nonconformistes religieux des $\mathrm{XVI}^{\mathrm{e}}$ et XVII ${ }^{\mathrm{e}}$ siècles, XI), 1989.

CANTIMORI Delio, Eretici italiani del Cinquecento e altri scritti, éd. A. PROSPERI, Torino, Einaudi (Biblioteca di cultura storica, 193), 1992.

CARL Gesine, " Das Ich am Ende des Schreibens? Die Konversionserzählung Malachia Ben Samuels als Medium der Identitätsbildung (1621) ", in M. RHEINHEIMER (dir.), Schriftlichkeit und Identität in der Neuzeit, Neumünster, Wachholtz (Studien zur Wirtschafts- und Sozialgeschichte Schleswig-Holsteins, 38), 2004, p. 45-59.

CARLEbach Elisheva, Divided Souls. Converts from Judaism in Germany 15001750, New Haven, Yale University Press, 2001.

CASTAldini Alberto (dir.), Antonio Possevino. I gesuiti e la loro eredità culturale in Transilvania, Roma, Institutum historicum Societatis Iesu (Bibliotheca Instituti historici S. I., 67), 2009. 
CAZACU Matei, "Le patriarcat de Constantinople dans la vision de Stephan Gerlach (1573-1578) ", in P. OdoRICo (dir.), Le Patriarcat oecuménique de Constantinople aux $X I V^{e}-X V I^{e}$ siècles, Paris, École des Hautes Études en Sciences Sociales (Centre d'études byzantines, néo-helléniques et sud-est européennes, Dossiers byzantins, 7), 2007, p. 369-386.

CHRIST Günter, " Fürst, Dynastie, Territorium und Konfession. Beobachtungen zu Fürstenkonversionen des ausgehenden 17. und beginnenden 18. Jahrhunderts ", Saeculum 24 (1973), p. 384-387.

CLARK Christopher M., The Politics of Conversion. Missionary Protestantism and the Jews in Prussia, 1728-1941, Oxford, Clarendon Press, 1995.

COUDERT Allison P. et SHOULSON Jeffrey S. (dir.), Hebraica veritas? Christian Hebraists and the Study of Judaism in Early Modern Europe, Philadelphia, University of Pennsylvania Press (Jewish Culture and Contexts), 2004.

Courcelles Dominique de, "Un lieu pour la raison des "Lumières": la conversion à l'islam d'Adam Neuser au XVI ${ }^{\mathrm{e}}$ siècle ", in M. GARCÍA ARENAL (dir.), Conversions islamiques. Identités religieuses en Islam méditerranéen - Islamic Conversions. Religious Identities in Mediterranean Islam, Paris, Maisonneuve et Larose (Individu et société dans le monde méditerranéen musulman), 2001, p. 141-148.

CRĂCIUN Maria, « Implementing Catholic Reform. The Jesuits and Traditional Religion in Early Modern Transylvania ", in A. OHLIDAL et S. SAMERSKI (dir.), Jesuitische Frömmigkeitskulturen. Konfessionelle Interaktion in Ostmitteleuropa 1570-1700, Stuttgart, Steiner (Forschungen zur Geschichte und Kultur des östlichen Mitteleuropa, 28), 2006, p. 37-62.

-, " The Construction of Sacred Space and the Confessional Identity of the Transylvanian Lutheran Community ", in E. WETTER (dir.), Formierungen des konfessionellen Raumes in Ostmitteleuropa, Stuttgart, Steiner (Forschungen zur Geschichte und Kultur des östlichen Mitteleuropa, 28), 2008, p. 97-124.

—, Deventer Jörg, Elbe Martin, "Confession and Conversion. Transcending Religious Boundaries in Central and Eastern Europe, 1560-1700 ", Bohemia. Zeitschrift für Geschichte und Kultur der böhmischen Länder 48 (2008), p. 192-202.

Dagron Tristan, Leibniz et Toland. L'invention du néo-spinozisme, Paris, Vrin (Bibliothèque d'histoire de la philosophie), 2009.

DAKHLIA Jocelyne, KAISER Wolfang et VINCENT Bernard (dir.), Les Musulmans et l'histoire de l'Europe, 2 vol., Paris, Seuil, 2011-2013.

DÁN Róbert et PIRNÁT Antal (dir.), Antitrinitarianism in the Second Half of the Sixteenth Century, Budapest-Leiden, Akademiai Kiadó (Studia Humanitatis, 5), 1976. 
DÁN Róbert, Matthias Vehe-Glirius. Life and Work of a Radical Antitrinitarian with his Collected Writings, Budapest, Akadémiai Kiadó (Studia Humanitatis, 4), 1982.

DANIEL Norman, Islam and the West. The Making of an Image, Edinburgh, Edinburgh University Press, 1966.

DANNEBERG Lutz, "Der Fragmentenstreit als Streit um die hermeneutica sacra und das testimonium divium der Heiligen Schrift ", in K. BREMER et C. SPOERHASE (dir.), Gelehrte Polemik II = Zeitsprünge 19 1/4 (2015), p. 239-264.

Daugirdas Kestutis, Die Anfänge des Sozinianismus. Genese und Eindringen des historisch-ethischen Religionsmodells in den universitären Diskurs der Evangelischen in Europa, Göttingen, Vandenhoeck \& Ruprecht (Veröffentlichungen des Instituts für Europäische Geschichte Mainz, 240), 2016.

DAUNICHT Richard, Lessing im Gespräch. Berichte und Urteile von Freunden und Zeitgenossen, München, Fink, 1971.

DE BRujJ J. T. P., " The Persian Studies of Adriaan Reland (1676-1718) », in Ch. VAN RuYMBEcke (dir.), Mais "comment peut-on être persan? ». Éléments persans en Orient et Occident. Liber amicorum Annette Donckier de Donceel, Leuven, Peeters, 2003, p. 37-50.

DEFLERS Isabelle, « Die Einführung der Kirchenzuchtordnung von 1570 in der Pfalz - Ein Beispiel für Kompetenzstreitigkeiten um die geistliche Strafgerichtsbarkeit ", Zeitschrift der Savigny-Stiftung für Rechtsgeschichte 124 (2007), p. 393-405.

DEVENTER Jörg, " “Confessionalization”. A Useful Theoretical Concept for the Study of Religion, Politics and Society in Early Modern East-Central Europe? ", European Review of History 11 (2004), p. 403 - 425.

-, " Konversion und Konvertiten im Zeitalter der Reformation und Konfessionalisierung. Stand und Perspektiven der Forschung ", Aschkenas. Zeitschrift für Geschichte und Kultur der Juden 15 (2005), p. 257-270.

- (dir.), Konfessionelle Formierungsprozesse im frühneuzeitlichen Ostmitteleuropa. Vorträge und Studien, Leipzig, GWZO (Berichte und Beiträhe des Geisteswissenschaftlichen Zentrums Geschichte und Kultur Ostmitteleuropas an der Universität Leipzig, 2006, 2), 2006.

-, " Konversionen zwischen den christlichen Konfessionen im frühneuzeitlichen Europa », in M. KURZ et Th. WINKELBAUER (dir.), Glaubenswechsel = Wiener Zeitschrift zur Geschichte der Neuzeit 7/2 (2007), p. 8-24.

-, " "Zu Rom übergehen”. Konversion als Entscheidungshandlung und Handlungsstrategie. Ein Versuch ", in R. LEEB, S. Cl. PILS et Th. WINKELBAUER (dir.), Staatsmacht und Seelenheil. Gegenreformation und Geheimprotestantismus in der Habsburgermonarchie, Wien-München, Oldenbourg (Veröffentlichungen des Instituts für Österreichische Geschichtsforschung 47), 2007, p. 168-180. 
—, " Nicht in die Ferne - nicht in die Fremde? Konfessionsmigration im schlesisch-polnischen Grenzraum im 17. Jahrhundert ", in J. BAHLCKE (dir.), Glaubensflüchlinge. Ursachen, Formen und Auswirkungen frühneuzeitlicher Konfessionsmigration in Europa, Berlin etc., Lit (Religions- und Kulturgeschichte in Ostmittel- und Südosteuropa, 4), 2008, p. 95-118.

-, Po-Chia Hsia Ronnie, Lotz-Heumann Ute, Luria Keith, Pörtner Regina, SIEBENHÜNER Kim et WALShAM Alexandra, " Conversions in Early Modern Europe. A Discussion ", Colloquia. Journal of Central European History 15 (2008), p. 104-127.

Dingel Irene, WARTENBERG Günther et BeYer Michael (dir.), Georg Major (1502-1574). Ein Theologe der Wittenberger Reformation, Leipzig, Evangelische Verlags-Anstalt (Leucorea-Studien zur Geschichte der Reformation und der Lutherischen Orthodoxie, 7), 2005.

DIXoN C. Scott, "Faith and History of the Enlightenment. Ernst Salomon Cyprian, Gottfried Arnold, and the History of Heretics ", The Journal of Ecclesiastical History 57 (2006), p. 33-54.

DöRING Heinrich, " Franz Anton Knittel ", in ID., Die deutschen Kanzelredner des achtzehnten und neunzehnten Jahrhunderts, Neustadt a. d. Orla, Wagner, 1830, p. 171-175.

DreColL Volker Henning, "Das Symbolum Quicumque als Kompilation augustinischer Tradition ", Zeitschrift für antikes Christentum 11 (2007), p. 30-56.

DRÜLL Dagmar, Heidelberger Gelehrtenlexikon 1386-1651, Berlin/Heidelberg, Springer, 2002.

DUCHESNEAU François, Leibniz, le vivant et l'organisme, Paris, Vrin (Mathesis), 2010.

DuHAMELle Christophe, "Le rêve du corail. La controverse vue par ellemême dans les récits de conversions princières allemandes au catholicisme, $\mathrm{XVI}^{\mathrm{e}}$-XVIII ${ }^{\mathrm{e}}$ siècles ", in P. SCHÖTTLER, P. VEIT et M. WERNER (dir.), Plurales Deutschland - Allemagne plurielle. Festschrift für Étienne François - Mélanges Étienne François, Göttingen, Wallstein, 1999, p. 103-109.

—, « La conversion princière au catholicisme dans le Saint-Empire: conséquence ou remise en cause de la paix de Westphalie? ", in J.-P. KINTZ et G. LIVET (dir.), $350^{e}$ anniversaire des Traités de Westphalie. Une genèse de l'Europe, une société à reconstruire, Strasbourg, Presses universitaires de Strasbourg, 1999, p. 299-310.

- (dir.), Les Espaces du Saint-Empire à l'époque moderne = Histoire, Économie et Société, 2004/1.

-, La Frontière au village. Une identité catholique allemande au temps des Lumières, Paris, Éditions de l'École des Hautes Études en Sciences Sociales (En Temps \& Lieux, 20), 2010. 
-, "Confession, confessionnalisation ", Histoire, Monde et Cultures religieuses 26 (2013), p. 159-174.

EBERT Hans-Georg et HANSTEIN Thoralf (dir.), Johann Jacob Reiske. Ein Leipziger Byzantinist und Begründer der Orientalistik im 18. Jahrhundert, Leipzig, Evangelische Verlags-Anstalt (Beiträge zur Leipziger Universitäts- und Wissenschaftsgeschichte, 6), 2005.

EDEL Andreas, Der Kaiser und Kurpfalz. Eine Studie zu den Grundelementen politischen Handelns bei Maximilian II (1564-1576), Göttingen, Vandenhoeck \& Ruprecht (Schriftenreihe der Historischen Kommission bei der Bayerischen Akademie der Wissenschaften, 58), 1997.

—, «Johann Baptist Weber (1526-1584). Zum Lebensweg eines gelehrten Juristen und Spitzenbeamten im 16. Jahrundert", Mitteilungen des Österreichischen Staatsarchiv 45 (1997), p. 111-185.

Elmarsafy Ziad, The Enlightenment Qur'an. The Politics of Translation and the Construction of Islam, Oxford, Oneworld, 2009.

ESPAGNE Michel, "Lessing et les hérétiques ", Revue germanique internationale 9 (2009), p. 133-145.

-, « De Heyne à Lachmann. Biographies héroïques de philologues allemands ", in Ch. KöNIG et D. ThOUARD (dir.), La Philologie au présent. Pour Jean Bollack, Villeneuve d'Ascq, Presses universitaires du Septentrion, 2010, p. 127-139.

-, Nora LAFI et Pascale RABAUlT-FeUerhahn (dir.), Silvestre de Sacy. Le projet européen d'une science orientaliste, Paris, Cerf-a, 2014.

—, Gotthold Ephraim Lessing, Paris, Belin (Voix allemandes), 2016.

FABINI Hermann, Atlas der siebenbürgisch-sächsischen Kirchenburgen und Dorfkirchen, t. 1: Text, Hermannstadt, Monumenta, $2002^{3}$.

FATA Márta et SCHINDLING Anton (dir.), Calvin und Reformiertentum in Ungarn und Siebenbürgen. Helvetisches Bekenntnis, Ethnie und Politik vom 16. Jahrhundert bis 1918, Münster, Aschendorff (Reformationsgeschichtliche Studien und Texte, 155), 2010.

FAZEKAS István, « Dorfgemeinde und Konfessionswechsel in Ungarn im späten 16. und 17. Jahrhundert ", in J. BAHLCKE et A. STROHMEYER (dir.), Konfessionalisierung in Ostmitteleuropa. Wirkungen des religiösen Wandels im 16. und 17. Jahrhundert, Stuttgart, Steiner (Forschungen zur Geschichte und Kultur des östlichen Mitteleuropa, 7), 1999, p. 339-350.

Fick Monika, Lessing-Handbuch. Leben - Werk - Wirkung, Stuttgart, Metzler, $2016^{4}$.

Forlines F. Leroy, Classical Arminianism. A Theology of Salvation, Nashville, Tenn., Randall House, 2011.

FRIEDRICH Markus et SCHUNKA Alexander (dir.), Orientbegegnungen deutscher Protestanten in der Frühen Neuzeit = Zeitsprünge, 16 1/2, 2012. 
GALLIEN Claire, L'Orient anglais. Connaissance et fictions au XVIII siècle, Oxford, Voltaire Foundation (Studies on Voltaire and the Eighteenth Century, 2011, 10), 2011.

-, "Turkey and the Middle East (Representations of) ", in G. DAY et J. LYNCH (dir.), The Encyclopedia of English Literature 1660-1789, Oxford, Wiley-Blackwell, 2015, p. 1278-1281.

GARCIA Humberto, Islam and the English Enlightenment 1670-1840, Baltimore, Johns Hopkins University Press, 2012.

GAUTIER Antoine, en coll. avec DE TESTA Marie, Drogmans, diplomates et ressortissants européens auprès de la Porte ottomane, Istanbul, Isis, 2013.

GHERMANi Naïma, "Confession ", in O. Christin, Dictionnaire des concepts nomades en sciences humaines, Paris, Métailié, 2011, p. 117-132.

GILLET Olivier, "L'histoire de la Transylvanie. Le différend historiographique entre Hongrois et Roumains ", Revue belge de philologie et d'histoire 75 (1997), p. 457-485.

GotThard Axel, Das Alte Reich 1495-1806, Darmstadt, Wissenschaftliche Buchgesellschaft (Geschichte Kompakt), 20135.

GrAF Tobias P., "Of Half-Lives and Doubles Lives. "Renegades" in the Ottoman Empire and Their Pre-Conversion Ties, ca. 1580-1610 ", in P. W. Firges, T. P. Graf, Ch. Roth et G. TulasoĞLu (dir.), Well-Connected Domains. Towards an Entangled Ottoman History, Leiden-Boston, Brill (The Ottoman Empire and its History. Politics, Society and Economy, 57), 2014, p. 131-149.

Greyerz Kaspar von, JaKubowski-Tiessen Manfred, KaUfmann Thomas et LEHMANN Hartmut (dir.), Interkonfessionalität - Transkonfessionalität - binnenkonfessionelle Pluralität. Neue Forschungen zur Konfessionalisierungsthese, Gütersloh, Gütersloher Verlagshaus (Schriften des Vereins für Reformationsgeschichte, 201), 2003.

GROETSCH Ulrich, Hermann Samuel Reimarus (1694-1768). Classicist, Hebraist, and Enlightenment Radical in Disguise, Leiden-Boston, Brill (Brill's Studies in Intellectual History, 237).

GüNDISCH Konrad, Das Bild des Anderen in Siebenbürgen. Stereotype in einer multiethnischen Region, Köln-Weimar-Wien, Böhlau (Siebenbürgisches Archiv, Dritte Folge, 33), 1998.

-, "Cluj [-Napoca] », in H. Rotн (dir.), Siebenbürgen, Stuttgart, Kröner (Handbuch der historischen Stätten, 330), 2003, p. 57-63.

Gunnoe, Charles D., Jr., Thomas Erastus and the Palatinate. A Renaissance Physician in the Second Reformation, Leiden-Boston, Brill (Brill's Studies in Church History and Religious Culture, 48), 2011.

-, " The Evolution of Erastianim: Hugo Grotius's Engagement with Erastus ", Grotiana 34 (2013), p. 41-61. 
HEINEMANN Friedrich Karl Otto von, Die Herzogliche Bibliothek zu Wolfenbüttel. Ein Beitrag zur Geschichte deutscher Büchersammlungen, Wolfenbüttel $1894^{2}$, réimp. Amsterdam, Van Heusden, 1969.

HERTz Deborah, " Konversionen in Europa », in E.-V. KoTOwsKi (dir.), Handbuch zur Geschichte der Juden in Europa, t. 2: Religion, Kultur, Alltag, Darmstadt, Wissenschaftliche Buchgesellschaft, 2001, p. 322-335.

Heyberger Bernard, García Arenal Mercedes, Colombo Emanuele et Vismara Paola (dir.), L'Islam visto da Occidente. Cultura e religione del Seicento europeo di fronte all'Islam, Milano, Marietti, 2009.

Hitzel Frédéric, "Connaissance de la langue turque en Occident (Xvi ${ }^{\mathrm{e}}$-XIX ${ }^{\mathrm{e}}$ siècles) ", in H. ANAmur (dir.), Hasan-Âli Yücel Anma Kitabı - Ceviri: Ekinler ve Zamanlar Kavşağl/Hommage à Hasan-Âli Yücel — La traduction: carrefour des cultures et des temps, Yıldız Teknik Üniversitesi, 1997, p. 39-46.

—, L'Empire ottoman, $X V^{e}-X V I I I^{e}$ siècles, Paris, Les Belles Lettres (Guide Belles Lettres des civilisations, 6), $2002^{2}$.

-, "L'Europe occidentale vue par les Ottomans, Xvie-XviII ${ }^{\mathrm{e}}$ siècles ", in J.-L. Bacqué-Grammont, A. Pino et S. Khoury (dir.), D’un Orient l'autre. Actes des troisièmes journées de l'Orient (Bordeaux, 2-4 octobre 2002), Paris-Louvain, Peeters (Cahiers de la Société asiatique, nouvelle série, 4), 2005, p. 171-187.

HOLDER Beat, « Konversionen und der Handlungsspielraum der Untertanen in der Eidgenossenschaft im Zeitalter der reformierten Orthodoxie ", in H. R. SCHMidT, A. Holenstein et A. WÜRGLER (dir.), Gemeinde, Reformation und Widerstand. Festschrift für Peter Blickle zum 60. Geburtstag, Tübingen, Bibliotheca Academica, 1998, p. 281-291.

HoLt Peter M., " The Study of Islam in Seventeenth- and Eighteenth Century England », Journal of Early Modern History 2 (1998), p. 113-123.

Holz Hans Heinz, "Lessing und Leibniz. Pluralismus, Perspektivität und Wahrheit ", in P. FREIMARK (dir.), Lessing und die Toleranz. Beiträge der 4. Internationalen Konferenz der Lessing Society in Hamburg vom 27. bis 29. Juni 1985, Detroit etc., Wayne State University Press etc., 1986, p. 11-22.

HoRn Curt, Johann Sylvanus und die Anfänge des Heidelberger Antitrinitarismus. Ein Beitrag zur pfälzischen Kirchengeschichte, Heidelberg, Koester, 1913.

Horsch Silvia, Rationalität und Toleranz. Lessings Auseinandersetzung mit dem Islam, Würzburg, Ergon (Ex Oriente Lux, 5), 2004.

Hourani Albert Habib, Islam in European Thought, Cambridge, Cambridge University Press, 1991, tr. fr. L'islam dans la pensée européenne, Paris, Naufal, 1995. 
IORGA Nicolae, Geschichte des Osmanischen Reiches. Nach den Quellen dargestellt, 5 vol., Gotha, Perthes, 1908-1913, réimp. Darmstadt, Wissenschaftliche Buchgesellschaft, 1997.

JaumanN Herbert, Handbuch Gelehrtenkultur der Frühen Neuzeit, t. I: Biobibliographisches Repertorium, Berlin-New York, De Gruyter, 2004.

JoLLEY Nicholas, « Leibniz and Locke on Socinianism ", Journal of the History of Ideas, 39 (1978), p. 233-250.

JÜRGENS Henning P. et WeLleR Thomas (dir.), Religion und Mobilität. Zum Verhältnis vom raumbezogener Mobilität und religiöser Identitätsbildung im frühneuzeitlichen Europa, Göttingen, Vandenhoeck \& Ruprecht (Veröffentlichungen des Instituts für Europäische Geschichte Mainz, Beiheft 81), 2010.

KaUfMANN Thomas, Dreißigjähriger Krieg und Westfälischer Friede. Kirchengeschichtliche Studien zur lutherischen Konfessionskultur, Tübingen, Mohr Siebeck (Beiträge zur Historischen Theologie, 104), 1998.

-, " Die theologische Bewertung des Judentums im Protestantismus des späteren 16. Jahrhunderts (1530-1600), in ID., Konfession und Kultur. Lutherischer Protestantismus in der zweiten Hälfte des Reformationsjahrhunderts, Tübingen, Mohr Siebeck (Spätmittelalter und Reformation, Neue Reihe, 29), 2006, p. 112-154.

-, "Türckenbüchlein”. Zur christlichen Wahrnehmung "türkischer" Religion in Spätmittelalter und Reformation, Göttingen, Vandenhoeck \& Ruprecht (Forschungen zur Kirchen- und Dogmengeschichte, 97), 2008.

—, "Das Bekenntnis im Luthertum des konfessionellen Zeitalters ", Zeitschrift für Theologie und Kirche 105 (2008), p. 281-314.

-, " The Christian Perception of Islam in the Late Middle Ages and in the Reformation ", Comparativ. Zeitschrift für Globalgeschichte und vergleichende Gesellschaftsforschung 20 (2010), p. 43-57.

-, " Kontinuitäten und Transformationen im okzidentalen Islambild des 15. und 16. Jahrhunderts ", in L. GALL et D. WilloweIT (dir.), Judaism, Christianity, and Islam in the Course of History. Exchange and Conflicts, München, Oldenbourg (Schriften des Historischen Kollegs, Kolloquien, 82), 2011, p. 287-306.

KeRTSCHER Hans-Joachim et STÖcKMANN Ernst (dir.), Ein Antipode Kants? Johann August Eberhard im Spannungsfeld von spätaufklärerischer Philosophie und Theologie, Berlin-New York, De Gruyter (Hallesche Beiträge zur europäischen Aufklärung, 46), 2012.

KeUL István, Early Modern Religious Communities in East-Central Europe. Ethnic Diversity, Denominational Plurality and Corporative Politics in the Principality of Transylvania (1526-1591), Leiden-Boston, Brill (Studies in Medieval and Reformation Traditions, 143), 2009. 
KIRSCHER Roger, Théologie et Lumières. Les théologiens "éclairés” autour de la revue de Friedrich Nicolai, "Allgemeine Deutsche Bibliothek ", 17651792, Villeneuve d'Ascq, Presses universitaires du Septentrion (Histoire et civilisations), 2001.

KLEIN Dietrich et Platow Birte (dir.), Wahrnehmung des Islam zwischen Reformation und Aufklärung, Paderborn, Fink, 2008.

KLEIN Michael, "Zwei Lutheraner an der Hohen Pforte. Leben, Reisen und religionspolitisches Wirken der Tübinger Theologen Stephan Gerlach und Salomon Schweigger ", in F. SCHWEITZER (dir.), Kommunikation über Grenzen. Kongressband des XIII. Europäischen Kongresses für Theologie, 21.-25. September 2008 in Wien, Gütersloher Verlagshaus (Veröffentlichungen der Wissenschaftlichen Gesellschaft für Theologie, 33), 2009, p. 533-552.

KLÖCKNER Thomas, "Heinrich Alting (1583-1644). Erste Einblicke in eine Biographie (zugleich ein Beitrag zur Netzwerktätigkeit der Reformierten im ausgehenden 16. Jahrhundert) ", in A. EusterschULTE et H. WÄLzHOLZ (dir.), Anthropological Reformations - Anthropology in the Era of Reformation, Göttingen, Vandenhoeck \& Ruprecht (Refo500 Academic Studies, 28), 2015, p. 459-478.

KNOBLAUCH Hubert, KRECH Volkhard et WOHLRAB-SAHR Monika (dir.), Religiöse Konversion. Systematische und fallorientierte Studien in soziologischer Perspektive, Konstanz, Universitäts-Verlag Konstanz (Passagen \& Transzendenzen, 1), 1998.

Koch Ernst et WaLlmanN Johann (dir.), Ernst Salomon Cyprian (1673-1745). Zwischen Orthodoxie, Pietismus und Frühaufklärung, Gotha, Forschungsund Landesbibliothek Gotha (Veröffentlichungen der Forschungs- und Landesbibliothek Gotha, 34), 1996.

Kосн Ernst, Kirchenleitung in Überganszeiten. Zum Lebenswerk von Ernst Salomon Cyprian (1673-1745), Groß Oesingen, Verlag der Lutherischen Buchhandlung Harms, 1997.

KöHLER Mathias, Heiliggeistkirche Heidelberg, Regensburg, Schnell \& Steiner (Kleine Kunstführer, 1184), $2006^{4}$.

KöSSLING Rainer et WARTENBERG Günther (dir.), Joachim Camerarius, Tübingen, Narr (Leipziger Studien zur klassischen Philologie, 1), 2003.

KoHNLE Armin, Kleine Geschichte der Kurpfalz, Karlsruhe, Braun, (Regionalgeschichte - fundiert und kompakt) (2005), $2014^{5}$.

Kollar René, « Konversion III », in G. KRAUSE et G. MÜLLER (dir.), Theologische Realenzyklopädie, t. 19, Berlin-New York, De Gruyter, 1990, p. 566-573.

Кот Stanislas, "L'influence de Michel Servet sur le mouvement antitrinitarien en Pologne et en Transylvanie ", in B. O. BECKER (dir.), Autour de 
Michel Servet et de Sébastien Castellion, Haarlem, H. D. Tjeenk Willink \& Zoon N. V., 1953, p. 72-115.

KRSTIĆ Tijana, Contested Conversions to Islam. Narratives of Religious Change in the Early Modern Ottoman Empire, Stanford, CA, Stanford University Press, 2011.

Sebastian KüHN, «Dissimulatio als gelehrte Praxis? Politik sozialer Beziehungen in gelehrten Netzwerken ", in W. LI et S. NOREIK (dir.), G. W. Leibniz und der Gelehrtenhabitus. Anonymität, Pseudonymität, Camouflage, Köln-Weimar-Wien, Böhlau, 2016.

KunKLER Stephan, Zwischen Humanismus und Reformation. Der Humanist Joachim Camerarius (1500-1574) im Wechselspiel von pädagogischem Pathos und theologischem Ethos, Hildesheim-New York, Olms (Theologische Texte und Studien, 8), 2000.

KURZ Marlene et WINKELBAUER T. (dir.), Glaubenswechsel = Wiener Zeitschrift zur Geschichte der Neuzeit, 7/2 (2007).

Kuschel Karl-Josef, Vom Streit zum Wettstreit der Religionen. Lessing und die Herausforderung des Islam, Düsseldorf, Patmos (Weltreligionen und Literatur, 1), 1998.

LAERKE Mogens, "Leibniz, la censure et la libre pensée ", Archives de philosophie 70 (2007), p. 273-287.

LAGRÉE Jacqueline, La Raison ardente. Religion naturelle et raison au XVII $I^{e}$ SIĖCLE, Paris, Vrin (Philologie et Mercure), 1991.

Launay, Marc de, "Leo Strauss et la découverte du classicisme ésotérique chez Lessing ", Les Études philosophiques, 2/2003, p. 245-259.

LAURENS Henry, La "Bibliothèque orientale " de Barthélemi d'Herbelot. Aux sources de l'orientalisme, Paris, Maisonneuve et Larose (Publications du Département d'islamologie de l'Université Paris-Sorbonne, 6), 1978.

LEBEAU Christine (dir.), L'Espace du Saint-Empire. Du Moyen Âge à l'époque moderne, Strasbourg, Presses universitaires de Strasbourg, 2004.

LÉCHот Pierre-Olivier, « Entre irénisme et controverse. La réécriture historique de la différence confessionnelle chez le théologien palatin Heinrich Alting (1583-1644) », in B. FORCLAZ (dir.), L'Expérience de la différence religieuse dans l'Europe moderne (XVI-XVIII $I^{e}$ siècles), Neuchâtel, Alphil, 2013, p. 649-369.

LEPPIN Volker et WIEN Ulrich A. (dir.), Konfessionsbildung und Konfessionskultur in Siebenbürgen in der Frühen Neuzeit, Stuttgart, Steiner (Quellen und Studien zur Geschichte des östlichen Europa, 66), 2005.

LindEBOom Johannes, Austin Friars. A History of the Dutch Reformed Church in London 1550-1950, The Hague, Nijhoff, 1950. 
LinDHolm Stefan, Jerome Zanchi (1516-1590) and the Analysis of Reformed Scholastic Christology, Göttingen, Vandenhoeck \& Ruprecht (Reformed Historical Theology, 37), 2016.

LORBER Michael, "Alchemia oeconomica - Johann Joachim Bechers (16351682) Sozialutopismus am Schnittpunkt von Projektemacherei, Staatsräson und Universalwissenschaft ", in P.-A. ALt, J. EMING, T. RENZ et V. WELS (dir.), Magia daemoniaca, magia naturalis, zouber. Schreibweisen von Magie und Alchemie in Mittelalter und Früher Neuzeit, Wiesbaden, Harrassowitz (Episteme in Bewegung, 2), 2015, p. 339-375.

LotZ-Heumann Ute, Missfelder Jan-Friedrich et Pohlig Matthias (dir.), Konversion und Konfession in der Frühen Neuzeit, Gütersloh, Gütersloher Verlagshaus (Schriften des Vereins für Reformationsgeschichte, 205), 2007.

LOWE, Kate, "Representing" Africa. Ambassadors and Princes from Christian Africa to Renaissance Italy and Portugal, 1402-1608, Cambridge, Cambrige University Press (Transactions of the Royal Society, VI, 17), 2007.

LOZAR Angelika et SCHASER Angelika, « Die Rückkehr zum “wahren Glauben”. Konversionen im 17. Jahrhundert », Frühneuzeit-Info 13 (2002), p. 65-74.

LuCKMANN Thomas, "Kanon und Konversion ", in A. Assmann et J. AssmanN (dir.), Kanon und Zensur. Beiträge zur Archäologie der literarischen Kommunikation, München, Fink (Archäologie der literarischen Kommunikation, 2), 1987, p. 38-46.

Luebre David M., Poley Jared, RYan Daniel C. et SABEAN David Warren (dir.), Conversion and the Politics of Religion in Early Modern Germany, New York, etc., Berghahn Books (Spektrum, 3), 2012.

LÜPKE Johannes von, Wege der Weisheit. Studien zu Lessings Theologiekritik, Göttingen, Vandenhoeck und Ruprecht (Göttinger theologische Arbeiten, 41), 1989.

MADER Eric-Oliver, “ “...wegen der Conversion Irr und Perplex gemacht”. Wahrnehmungen, Darstellungen und Vorbedingungen der Konversion des Pfalzgrafen Wolfgang von Pfalz-Neuburg zum Katholizismus (1613/14)” ", Düsseldorfer Jahrbuch 75 (2004/2005), p. 109-142.

—, "Staatsräson und Konversion. Politische Theorie und praktische Politik als Entscheidungshintergründe für den Übertritt Wolfgang Wilhelms von Pfalz-Neuburg zum Katholizismus ", in H. KugELER, Ch. SEPP, G. WOLF (dir.), Internationale Beziehungen in der Frühen Neuzeit. Ansätze und Perspektiven, Hamburg etc., Lit (Wirklichkeit und Wahrnehmung in der Frühen Neuzeit, 3), 2006, p. 120-150.

—, " Fürstenkonversionen zum Katholizismus in Mitteleuropa im 17. Jahrhundert. Ein systematischer Ansatz in fallorientierter Perspektive ", Zeitschrift für Historische Forschung 34 (2007), p. 403-440. 
—, " Die Konversion Wolfgang Wilhelms von Pfalz-Neuburg. Zur Rolle von politischem und religiös-theologischem Denken für seinen Übertritt zum Katholizismus ", in U. Lotz-Heumann, J.-F. Missfelder et M. Pohlig (dir.), Konversion und Konfession in der Frühen Neuzeit, Gütersloh, Gütersloher Verlagshaus (Schriften des Vereins für Reformationsgeschichte, 205), 2007, p. 107-146.

—, " Konfessionalität im Hause Pfalz-Neuburg. Zur Bedeutung des Faktors "Konversion” für das konfessionelle Profil einer Herrscherdynastie ", in B. MAUER (dir.), Barocke Herrschaft am Rhein um 1700. Kurfürst Johann Wilhelm II. und seine Zeit, Düsseldorf, Droste (Veröffentlichungen aus dem Stadtarchiv Düsseldorf, 20), 2009, p. 95-115.

-, " Conversion Concepts in Early Modern Germany: Protestant and Catholic », in D. M. LuebKe, J. Poley, D. C. Ryan, D. W. Sabean (dir.), Conversion and the Politics of Religion in Early Modern Germany, New York, etc., Berghahn Books (Spektrum, 3), 2012, p. 31-48.

MAdonia Claudio, "Marcello Squarcialupi ", in A. Gordon KInDER (dir.), Alumbrados of the Kingdom of Toledo. Jacobus Acontius, Baden-Baden/ Bouxwiller, Koerner (Bibliotheca dissidentium, XVI), 1994, p. 119-170.

MARNEF Guido, "Protestant Conversions in an Age of Catholic Reformation. The Case of Sixteenth-Century Antwerp ", in E. ANDOR et I. G. TóTH (dir.), Frontiers of Faith. Religious Exchange and the Constitution of Religious Identities, 1400-1750, Budapest, Central European University (Cultural Exchange in Europe, 1), 2001, p. 255-265.

MARRASSINI Paolo, "Sul problema del giudaismo in Etiopia ", in B. CHIESA (dir.), Correnti culturali e movimenti religiosi del giudaismo, Roma, Carucci (Associazione Italiana per lo Studio del Giudaismo, Testi e Studi, 5), 1987, p. 175-183.

MARTIN Philippe et SUIRE Éric (dir.), Les Convertis. Parcours religieux, parcours politiques, tome I: Période moderne, Paris, Classiques Garnier (Constitution de la modernité, 2), 2016.

Martinez D’Alòs-Moner Andreu, "Paul and the Other. The Portuguese Debate on the Circumcision of the Ethiopians ", in V. BöLL, S. KaPLAN, A. MARTinez D'Alòs-Moner et E. SoKolinsKaia (dir.), Ethiopia and the Missions. Historical and Anthropological Insights, Münster etc., Lit (Afrikanische Studien, 25), 2005, p. 31-51.

MATUZ Josef, « Die Pfortendolmetscher zur Herrschaftszeit Süleymāns des Prächtigen », Südost-Forschungen 34 (1975), p. 26-60.

Mennecke-Haustein Ute, "Konversionen ", in W. ReInHARD et H. Schilling (dir.), Die katholische Konfessionalisierung, Münster, Aschendorff (Reformationsgeschichtliche Studien und Texte, 135), 1995, p. 243-257. 
-, Conversio ad Ecclesiam. Der Weg des Friedrich Staphylus zurück zur vortridentinischen katholischen Kirche, Gütersloh, Gütersloher Verlagshaus (Quellen und Forschungen zur Reformationsgeschichte, 74), 2003.

Merkle Benjamin R., Defending the Trinity in the Reformed Palatinate. The Elohistae, Oxford, Oxford University Press (Oxford Theology and Religion Monographs), 2015.

MESCHENDÖRFER Hans, MitTELSTRASS Otto (éd.), Siebenbürgen auf alten Karten. Lazarus/Tannstetter 1528, Johannes Honterus 1532, Wolfgang Lazius 1552/56, Gundelsheim am Neckar, Arbeitskreis für Siebenbürgische Landeskunde Heidelberg (Historisch-landeskundlicher Atlas von Siebenbürgen, Beiheft), 1996.

MiLDE Wolfgang, "Studien zu Lessings Bibliothekariat in Wolfenbüttel (1770-1781). Bücherausleihe und Büchererwerbung ", Lessing Yearbook 1 (1969), p. 99-125 et 2 (1970), p. 162-180.

MisSFELDT Antje (dir.), Gottfried Arnold, radikaler Pietist und Gelehrter. Jubiläumsgabe von und für Dietrich Blaufuß und Hanspeter Marti, KölnWeimar-Wien, Böhlau, 2011.

Mills Kenneth et Grafton Anthony (dir.), Conversion. Old Worlds and New, Rochester (NY), Rochester University Press (Studies in Comparative History), 2003.

MitTelstrass Otto (éd.), Ortsnamenbuch, Gundelsheim am Neckar, Arbeitskreis für Siebenbürgische Landeskunde Heidelberg (Historisch-landeskundlicher Atlas von Siebenbürgen, 1), 1992.

- (éd.), Topographie der Ortschaften. Karte des Großfürstentums Siebenbürgen, Maßstab 1: 300000, Gundelsheim am Neckar, Arbeitskreis für Siebenbürgische Landeskunde Heidelberg (Historisch-landeskundlicher Atlas von Siebenbürgen, 2), 1993.

MOore Evelyn, "Lessings Rettung des Cardanus. Zur Entstehung einer epistemologischen Polemik ", in W. MAUSER et G. SASSE (dir.), Streitkultur. Strategien des Überzeugens im Werk Lessings, Tübingen, Niemeyer, 1993, p. 392-400.

MORLET Sébastien (dir.), Le Traité de Porphyre contre les chrétiens. Un siècle de recherches, nouvelles questions, Paris, Institut d'études augustiniennes (Collection d'études augustiniennes, série Antiquité), 2011.

Motika Raoul, «Adam Neuser. Ein Heidelberger Theologe im Osmanischen Reich ", in S. PRÄTOR, Ch. K. NEUMANN (dir.), Frauen, Bilder und Gelehrte. Studien zu Gesellschaft und Künsten im Osmanischen Reich. Festschrift Hans Georg Majer, t. 2, Istanbul, Simurg, 2002, p. 523-538.

MüHLING Andreas, Caspar Olevian 1536-1587. Christ, Kirchenpolitiker und Theologe, Zug, Achius (Studien und Texte zur Bullingerzeit, 4), 2008. 
MÜLLER Detlev G., "Eusèbe Renaudot ", in Biographisch-Bibliographisches Kirchenlexikon, Herzberg, Bautz, t. 8, 1994, col. 34-44.

MÜLLER Ralf C., Franken im Osten. Art, Umfang, Struktur und Dynamik der Migration aus dem lateinischen Westen in das Osmanische Reich des 15./16. Jahrhunderts auf der Grundlage von Reiseberichten, Leipzig, Eudora, 2005.

—, " Der umworbene "Erbfeind”. Habsburgische Diplomatie an der Hohen Pforte vom Regierungsantritt Maximilians I. bis zum "Langen Türkenkrieg” - ein Entwurf ", in M. KuRZ, M. ScheUtz, K. VocelKa et Th. WinKELBAUER (dir.), Das Osmanische Reich und die Habsburgermonarchie, Wien, Böhlau (Mitteilungen des Instituts für Österreichische Geschichtsforschung, Ergänzungsbd. 48), 2005, p. 251-279.

-, Prosopographie der Reisenden und Migranten ins Osmanische Reich (13961611), 10 vol., Leipzig, Eudora, 2006.

MüNCH Paul, Zucht und Ordnung. Reformierte Kirchenverfassungen im 16. und 17. Jahrhundert (Nassau-Dillenburg, Kurpfalz, Hessen-Kassel), Stuttgart, Klett-Cotta (Spätmittelalter und frühe Neuzeit, 3), 1978.

Mulsow Martin, Die drei Ringe. Toleranz und clandestine Gelehrsamkeit bei Mathurin Veyssière La Croze (1661-1739), Tübingen, Niemeyer (Hallesche Beiträge zur europäischen Aufklärung (abr. HBEI), 16), 2001.

Mulsow Martin, "Mehrfachkonversion, politische Religion und Opportunismus im 17. Jahrhundert - Ein Plädoyer für die Indifferentismusforschung ", in K. von Greyerz, M. JaKubowsKi-TiEsSEN, Th. KaUfManN et H. LEHMANN (dir.), Interkonfessionalität - Transkonfessionalität binnenkonfessionelle Pluralität. Neue Forschungen zur Konfessionalisierungsthese, Gütersloh, Gütersloher Verlagshaus (Schriften des Vereins für Reformationsgeschichte, 201), 2003, p. 132-150.

- et PopkIN Richard H. (dir.), Secret Conversions to Judaim in Early Modern Europe, Boston, Brill (Brill's Studies in Intellectual History, 122), 2004.

- et RoHLs Jan (dir.), Socianianim and Arminianim. Calvinists and Cultural Exchange in Seventeenth-Century Europe, Leiden-Boston, Brill (Brill's Studies in Intellectual History, 134), 2005.

Mulsow Martin, « Islam und Sozinianismus. Eine Parallelwahrnehmung der Frühen Neuzeit ", in D. KLEIN et B. Plato (dir.), Wahrnehmung des Islam zwischen Reformation und Aufklärung, Paderborn, Fink, 2008, p. 27-39.

—, "Socinianim, Islam and the Radical Uses of Arabic Scholarship ", Al-Qantara. Revista de estudios árabes 31 (2010), p. 549-586.

-, " Mikrogramme des Orients. Johann Christoph Wolfs Notizhefte und seine Cudworth-Lektüre ", in D. THOUARD, F. VollhardT et F. MARIANI ZINI (dir.), Philologie als Wissensmodell, Berlin etc., De Gruyter (Pluralisierung und Autorität, 20), 2010, p. 345-395. 
-, " Exil, Kulturkontakt und Ideenmigration in der Frühen Neuzeit ", in H. Jaumann (dir.), Diskurse der Gelehrtenkultur in der Frühen Neuzeit. Ein Handbuch, Berlin-New York, de Gruyter, 2010, p. 441-464.

-, " Der Haupttäter entkam. Ein Fall religiöser Doppelspionage und Koranverehrung ", Frankfurter Allgemeine Zeitung, 27.04.2011.

- (dir.), Between Philology and Radical Enlightenment. Hermann Samuel Reimarus (1694-1768), Leiden-Boston, Brill (Brill's Studies in Intellectual History, 203), 2011.

-, "Adam Neusers Brief an Sultan Selim II. und seine geplante Rechtfertigungsschrift. Eine Rekonstruktion anhand neuer Manuskriptfunde ", in F. VOLLHARDT (dir.), Religiöser Nonkonformismus und frühneuzeitliche Gelehrtenkultur, Berlin, Akademie-Verlag (Quellen und Darstellungen zur Geschichte des Antitrinitarismus und Sozinianismus in der Frühen Neuzeit, 2), 2014, p. 293-318.

-, « Fluchträume und Konversionsräume zwischen Heidelberg und Istanbul. Der Fall Adam Neuser ", in M. Mulsow (dir.), Kriminelle - Freidenker - Alchemisten. Räume des Untergrunds in der Frühen Neuzeit, Köln, Böhlau, 2014, p. 33-60.

-, " Adam Neuser ", in D. Thomas et J. Chesworth (dir.), Christian-Muslim Relations. A Bibliographical History, t. 7: Central and Eastern Europe, Asia, Africa and South America (1500-1600), Leiden-Boston, Brill, 2015, p. 420-425.

Multhammer Michael, Lessings 'Rettungen'. Geschichte und Genese eines Denkstils, Berlin-New York, De Gruyter (Frühe Neuzeit, 183), 2013.

-, " Die Bibliothek als akademischer Untergrund. Der junge Lessing in Wittenberg ", in M. Mulsow (dir.), Kriminelle - Freidenker - Alchemisten. Räume des Untergrunds in der Frühen Neuzeit, Köln-Weimar-Wien, Böhlau, 2014, p. 575-595.

NIEWÖHNER Friedrich et RÄDLE Fidel (dir.), Konversionen im Mittelalter und in der Frühneuzeit, Hildesheim-New York, Olms (Hildesheimer Forschungen, 1), 1999.

OвоRni Teréz, "Le royaume des Szapolyai, du royaume de Hongrie orientale à la principauté de Transylvanie (1541-1571) ", in O. CHALINE et M.-F. SAUdRAIX-VAJDA (dir.), La Hongrie ottomane, XVI ${ }^{e}$-XVII ${ }^{e}$ siècles = Histoire, économie et société, 3/2015, p. 65-77.

OsIER Jean-Pierre, Faust Socin ou le christianisme sans sacrifice, Paris, Cerf (Patrimoines), 1996.

PHILIPPI Paul, « Sylvanus und Transylvanien. Ein Stück Tolenranzgeschichte zwischen Heidelberg und Siebenbürgen ", in W. DOERR (dir.), Semper Apertus. Sechshundert Jahre Ruprecht-Karls-Universität Heidelberg 13861986, t. 1: Mittelalter und Frühe Neuzeit, 1386-1803, Berlin etc., Springer, 1985, p. 213-230. 
PIRNÁT Antal, Die Ideologie der Siebenbürger Antitrinitarier in der 1570er Jahren, Budapest, Verlag der Ungarischen Akademie der Wissenschaften, 1961.

Pollmann Judith, "A Different Road to God. The Protestant Experience of Conversion in the Sixteenth Century ", in P. VAN DER VEER (dir.), Conversions to Modernities. The Globalization of Christianity, New York etc., Routledge, 1996, p. 47-64.

Pons Georges, Gotthold Ephrä̈m Lessing et le christianisme, Paris, Didier, 1964.

PRESS Volker, Calvinismus und Territorialstaat. Regierung und Zentralbehörden der Kurpfalz 1559-1619, Stuttgart, Klett (Kieler Historische Studien, 7), 1970.

—, " Die "Zweite Reformation" in der Kurpfalz ", in H. Schilling (dir.), Die reformierte Konfessionalisierung. Das Problem der "Zweiten Reformation", Gütersloh, Mohn (Schriften des Vereins für Reformationsgeschichte, 195), 1986, p. 104-129.

QUAKATZ Manja, “Gebürtig aus der Türckey”. Zu Konversion und Zwangstaufe osmanischer Muslime im Alten Reich um 1700 ", in B. ScHMIDTHABERKAMP (dir.), Europa und die Türkei im achtzehnten Jahrhundert Europe and Turkey in the Eighteenth Century, Göttingen, Bonn University Press/V \& R unipress, 2011, p. 417-430.

RAABE Mechthild, Die fürstliche Bibliothek in Wolfenbüttel und ihre Leser. Zur Geschichte des institutionellen Lesens in einer norddeutschen Residenz 1664-1806, Wolfenbüttel, Steuber, 1997.

RAABE Paul, "Lessing und die Gelehrsamkeit. Bemerkungen zu einem Forschungsthema ", in E. P. HARRIS et R. R. SCHADE (dir.), Lessing in heutiger Sicht. Beiträge zur Internationalen Lessing-Konferenz, Cincinnati, Ohio, 1976, Bremen etc., Jacobi, 1977, p. 65-88.

REESE Olaf, Lutherische Metaphysik im Streit. Berichte von Calovs antisozinianische Feldzüge, Diss., Univ. Göttingen, 2009.

REH Albert M., "Große Themen in kleiner Form. Lessings "Rettungen” eine europäische Apologetik ", in W. BARNER et A. M. REH (dir.), Nation und Gelehrtenrepublik. Lessing im europäischen Zusammenhang, Detroit etc., Wayne State University Press etc. (Lessing Yearbook, Sonderband), 1984, p. 175-184.

REIFENBERG Bernd, Lessing und die Bibliothek, Wiesbaden, Harrassowitz (Wolfenbütteler Schriften zur Geschichte des Buchwesens, 23), 1995.

REINHARDT Rudolf, « Konvertiten und deren Nachkommen in der Reichskirche der Frühen Neuzeit ", Rottenburger Jahrbuch für Kirchengeschichte 8 (1989), p. 9-37. 
Rejchtrová Noemi, Václav Budovec z Budova, Praha, Melantrich, 1984.

RoLING Bernd, "Humphrey Prideaux, Eric Fahlenius, Adrian Reland, Jacob Ehrhardt und die Ehre des Propheten: Koranpolemik im Barock ", in D. KleIN et B. Platow (dir.), Wahrnehmung des Islam zwischen Reformation und Aufklärung, Paderborn, Fink, p. 61-76.

Rотн Erich, Die Reformation in Siebenbürgen. Ihr Verhältnis zu Wittenberg und der Schweiz, Köln-Wien, Böhlau (Siebenbürgisches Archiv, Dritte Folge, 2/4), 2 vol., 1962-1964.

Rотн Harald (dir.), Siebenbürgen, Stuttgart, Kröner (Handbuch der historischen Stätten, 330), 2003.

—, Kurze Geschichte Siebenbürgens, Köln-Weimar-Wien, Böhlau, $2007^{3}$.

RotT Hans, "Neue Quellen für eine Aktenrevision des Prozesses gegen Sylvan und seine Genossen ", Neues Archiv für die Geschichte der Stadt Heidelberg und der rheinischen Pfalz 8 (1910), p. 184-259.

RUPPELT Georg et SolF Sabine (dir.), Lexikon zur Geschichte und Gegenwart der Herzog-August-Bibliothek Wolfenbüttel, Wiesbaden, Harrassowitz (Lexika europäischer Bibliotheken, 1), 1992.

SAADA Anne, "Die Universität Göttingen. Traditionen und Innovationen gelehrter Praktiken », in H. E. BöDEKER, Ph. BüTTGEN et M. ESPAGNE (dir.), Die Wissenschaft vom Menschen in Göttingen. Wissenschaftliche Praktiken, institutionelle Geographie, europäische Netzwerke, Göttingen, Vandenhoeck \& Ruprecht (Veröffentlichungen des Max-Planck-Instituts für Geschichte, 237), 2008, p. 23-46.

ScHAAB Meinrad, "Die Kurpfalz als frühestes reformiertes Territorium im Reich und seine Einwirkung auf Pfalz-Zweibrücken ", in M. SсHAAB (dir.), Territorialstaat und Calvinismus, Stuttgart, Kohlhammer (Veröffentlichungen der Kommission für geschichtliche Landeskunde in BadenWürttemberg. Reihe B, Forschungen, 127), 1993, p. 34-86.

SCHASER Angelika, "Inclusion et exclusion. La recherche sur les conversions religieuses en Allemagne à l'époque moderne ", in Ph. BüTTGEN et Ch. Duhamelle (dir.), Religion ou confession. Un bilan franco-allemand sur l'époque moderne (XVI $I^{e}$-XVIII $I^{e}$ siècles), Paris, Éditions de la Maison des Sciences de l'Homme (Colloquium), 2010, p. 577-594.

SCHILling Heinz, Konfessionskonflikt und Staatsbildung. Eine Fallstudie über das Verhältnis von religiösem und sozialem Wandel in der Frühneuzeit am Beispiel der Grafschaft Lippe, Gütersloh, Mohn (Quellen und Forschungen zur Reformationsgeschichte, 48), 1981.

-, Die reformierte Konfessionalisierung in Deutschland. Das Problem der "Zweiten Reformation", Gütersloh, Mohn (Schriften des Vereins für Reformationsgeschichte, 195), 1985. 
—, « Die niederländischen Exulanten des 16. Jahrhunderts. Ein Beitrag zum Typus der frühneuzeitlichen Konfessionsmigration ", Geschichte in Wissenschaft und Unterricht 43 (1992), p. 67-78.

-, " Confessional Migration as a Distinct Type of Old European Longdistance Migration ", in S. CAVACIOCCHI (dir.), Le migrazioni in Europa, Secc. XIII-XVIII, Firenze, Le Monnier (Pubblicazioni, Istituto Internazionale di Storia Economica “F. Datini”, Prato, serie II, 25), 1994, p. 175-189.

- (dir.), Kirchenzucht und Sozialdisziplinierung im frühneuzeitlichen Europa, Berlin, Duncker \& Humblot (Zeitschrift für historische Forschung, Beiheft 16), 1994.

—, " Die frühneuzeitliche Konfessionsmigration », in K. J. BADE (dir.), Migration in der europäischen Geschichte seit dem späten Mittelalter, Osnabrück, Institut für Migrationsforschung und Interkulturelle Studien (IMIS-Beiträge, 20), 2002, p. 67-89.

-, « Die frühneuzeitliche Konfessionsmigration. Calvinisten und sephardische Juden im Vergleich ", in H. P. JÜRGENS et Th. WELLER (dir.), Religion und Mobilität. Zum Verhältnis vom raumbezogener Mobilität und religiöser Identitätsbildung im frühneuzeitlichen Europa, Göttingen, Vandenhoeck \& Ruprecht (Veröffentlichungen des Instituts für Europäische Geschichte Mainz, Beiheft 81), 2010, p. 113-136.

ScHILLING Johannes, "Konversionen” in der frühen Reformationszeit ", in F. NIEWÖHNER et F. RÄDLE (dir.), Konversionen im Mittelalter und in der Frühneuzeit, Hildesheim-New York, Olms (Hildesheimer Forschungen, 1), 1999, p. 43-57.

SCHINDLING Anton et ZIEGLER Walter (dir.), Die Territorien des Reichs im Zeitalter der Reformation und Konfessionalisierung, t. 7: Der Südwesten, Münster, Aschendorff (Katholisches Leben und Kirchenreform im Zeitalter der Glaubensspaltung, 35), 1993.

ScHмIDT Georg, "Die Zweite Reformation in den Reichsgrafschaften. Konfessionswechsel aus Glaubensüberzeugungen und aus politischem Kalkül ", in M. SсHAAB (dir.), Territorialstaat und Calvinismus, Stuttgart, Kohlhammer (Veröffentlichungen der Kommission für geschichtliche Landeskunde in Baden-Württemberg, Reihe B, Forschungen, 127), 1993, p. 97-136.

ScHMIDT Hans, "Konversion und Säkularisation als politische Waffe zum Ausgang des konfessionellen Zeitalters. Neue Quellen zur Politik des Herzogs Ernst August von Hannover am Vorabend des Friedens von Nymwegen ", Francia 5 (1977), p. 182-230.

SchMolinsky Sabine, « Prophetia in der Bibliothek? Die Lectiones memorabiles des Johannes Wolf », in K. BERGDOLDT et W. LUDWIG (dir.), Zukunftsvoraussagen in der Renaissance, Wiesbaden, Harrassowitz (Wolfenbütteler Abhandlungen zur Renaissanceforschung, 23), 2005, p. 89-130. 
—, « Im Angesicht der Endzeit? Positionen zur den Lectiones memorabiles des Johannes Wolf (1600) ", in W. BRANDES et F. SCHMIEDER (dir.), Endzeiten. Eschatologie in den monotheistischen Weltreligionen, Berlin-New York, De Gruyter (Millenium-Studien 16), 2008, p. 369-417.

SCHNABEL-SchÜLE Helga, « Der große Unterschied und seine kleinen Folgen. Zum Problem der Kirchenzucht als Unterscheidungskriterium zwischen lutherischer und reformierter Konfession in der frühen Neuzeit ", in M. HAGEMEIER et S. HoLTZ (dir.), Krisenbewußtsein und Krisenbewältigung in der frühen Neuzeit. Festschrift für Hans-Christoph Rublack, Frankfurt a. M. etc, Lang, p. 197-214.

SCHNEIDER Heinrich, " Lessing und das Ehepaar Reiske », in ID., Lessing. Zwölf biographische Studien, Bern, Francke, 1951, p. 110-165.

SCHNEIDER Ulrich Johannes (dir.), Jöchers 60000. Ein Mann. Eine Mission. Ein Lexikon, Leipzig, Universitätsbibliothek (Schriften aus der Universitätsbibliothek Leipzig, 11), 2008.

-, "Jöcher's Anthropology of Scholars ", in A. Holenstein, H. STEINKE et M. STUBER (dir.), Scholars in Action. The Practice of Knowledge and the Figure of the savant in the 18th Century, Leiden-Boston, Brill (Scientific and Learned Cultures and their Institutions), 2013, t. 1, p. 195-204.

Scнотт Christian-Erdmann, " Der erste polnische Historiograph in deutscher Sprache. Samuel Friedrich Lauterbach (1662-1728) », Beiträge zur ostdeutschen Kirchengeschichte 4 (2001), p. 12-27.

SCHREINER Klaus, "Rechtgläubigkeit als "Band der Gesellschaft”. Zur eidlichen Verpflichtung von Staats- und Kirchendienern auf die Formula Concordiae und das "Konkordienbuch" ", in M. BRECHT et R. SCHWARZ (dir.), Bekenntnis und Einheit der Kirche. Studien zum Konkordienbuch, Stuttgart, Calwer Verlag, 1980, p. 351-379.

-, «Iuramentum religionis. Entstehung, Geschichte und Funktion des Konfessionseides der Staats- und Kirchendiener im Territorialstaat der Frühen Neuzeit », Der Staat (1985), p. 211-246.

ScHULzE Winfried, Reich und Türkengefahr im späten 16. Jahrhundert. Studien $z u$ den politischen und gesellschaftlichen Auswirkungen einer äußeren Bedrohung, München, Beck, 1978.

Schunka Alexander, " Exulanten, Konvertiten, Arme und Fremde. Zuwanderer aus der Habsburgermonarchie in Kursachsen im 17. Jahrhundert ", Frühneuzeit-Info 14 (2003), p. 66-78.

SeELIGer-ZeIss Anneliese, Die Peterskirche, Universitätskirche Heidelbergs, Regensburg, Schnell \& Steiner (Kleine Kunstführer, 1595), $2006^{2}$.

SELDERHUis Herman et Wriedt Markus (dir.), Konfession, Migration und Elitenbildung. Studien zur Theologenausbildung des 16. Jahrhunderts, Leiden-Boston, Brill (Brill's Series in Church History, 31), 2007. 
SIEBENHÜNER Kim, " Glaubenswechsel in der Frühen Neuzeit. Chancen und Tendenzen einer historischen Konversionsforschung ", Zeitschrift für Historische Forschung 34 (2007), 243-272.

-, Art. " Konversion (Einleitung) ", in F. JAEGER (dir.), Enzyklopädie der Neuzeit, t. 6, Stuttgart-Weimar, Metzler, 2007, p. 1171-1174.

—, " Conversion, Mobility and the Roman Inquisition in Italy around 1600 », Past \& Present 200 (2008), p. 5-35.

- - et JunEja Monika (dir.), Religious Conversion in Medieval and Early Modern Societies $=$ Medieval History Journal 12/2 (2009).

SMiTh Justin E. H., Divine Machines. Leibniz and the Sciences of Life, Princeton, Princeton University Press, 2011.

Snow David et MACHALEK Richard, "The Sociology of Conversion ", Annual Review of Sociology 10 (1984), p. 167-190.

SOMMER Andreas Urs, "Geschichte und Praxis bei Gottfried Arnold ", Zeitschrift für Religions- und Geistesgeschichte 54 (2002), p. 210-243.

Sosio Libero, "Paolo Sarpi, un frate nella rivoluzione scientifica ", in C. PIN (dir.), Ripensando Paolo Sarpi. Atti del Convegno Internazionale di Studi nel $450^{\circ}$ anniversario della nascità di Paolo Sarpi, Venezia, Ateneo Veneto (Ricerche Storiche, 6), 2006, p. 183-236.

SOUTHERN Richard W., Western Views of Islam in the Middle Ages, Cambridge (Mass.), Harvard University Press, 1966.

Stockhausen Annette von et Brennecke Hanns Christoph (dir.), Von Arius zum Athanasium. Studien zur Edition der "Athanasius Werke ", BerlinNew York, De Gruyter (Texte und Utersuchungen zur Geschichte der altchristlichen Literatur, 164), 2010.

STOLlBERG-RILINGER Barbara, Des Kaisers alte Kleider. Verfassungsgeschichte und Symbolsprache des Alten Reiches, München, Beck, 2013², tr. fr. Ch. DuHAMElle, Les Vieux habits de l'empereur. Une histoire culturelle des institutions du Saint-Empire à l'époque moderne, Paris, Éditions de la Maison des Sciences de l'Homme (Bibliothèque allemande), 2013.

STREBE Horst, Lessing und die Zensur, Wolfenbüttel, Lessing-Akademie (Wolfenbütteler Vortrags-Manuskripte, 11), 2011.

SUTTER FICHTNER Paula, Emperor Maximilian II, New Haven, Yale University Press, 2001.

Szcucki Lech (dir.), Faustus Socinus and His Heritage, Kraków, Polish Academy of Arts and Sciences, 2005.

-, "In the Spinozian Circle (Christopher Sandius Jr) ", Przeglad Filozoficzno-Literacki 6 (2007), p. 289-311.

Thomas David et MALlEtT Alex (éd.), Christian Muslim Relations. A Bibliographical History Online, Leiden-Boston, Brill, mise en ligne 2011. 
Tollet Daniel, La Conversion et le politique à l'époque moderne, Paris, Presses de l'Université Paris-Sorbonne (Mythes, critique et histoire), 2009.

TREUE Wolfgang, « Aufsteiger oder Außenseiter? Jüdische Konvertiten im 16. und 17. Jahrhundert ", Aschkenas. Zeitschrift für Geschichte und Kultur der Juden 10 (2000), p. 307-336.

Troitzsch Ulrich, "Becher als Techniker und Erfinder ", in G. FRÜHSORGE et G. F. STRASSER (dir.), Johann Joachim Becher (1635-1682), Wiesbaden, Harrassowitz (Wolfenbütteler Arbeiten zur Barockforschung, 22), 1993, p. 85-101.

UlBRICH Claudia, "Hat man also ein solches Blutbad, Würgen und Wüten in der Stadt gehört und gesehen, daß mich solches jammert wider zu gedencken...” Religion und Gewalt in Michael Heberer von Brettens Aegyptica [sic] servitus von 1610 ", in K. VON GREYERZ (dir.), Religion und Gewalt. Konflikte, Rituale, Deutungen (1500-1800), Göttingen, Vandenhoeck \& Ruprecht (Veröffentlichungen des Max-Planck-Instituts für Geschichte, 215), 2006, p. 85-108.

UlLENDORF Edward, Ethiopia and the Bible, London, Oxford University Press, 1968.

-, " The Confessio Fidei of King Claudius of Ethiopia ", Journal of Semitic Studies 32 (1987), p. 42-50.

ULMER Bernd, " Die autobiographische Plausibilität von Konversionserzählungen ", in W. SPARN (dir.), Wer schreibt meine Lebensgeschichte? Biographie, Autobiographie, Hagiographie und ihre Entstehungszusammenhänge, Gütersloh, Güterloher Verlags-Haus, 1990, p. 287-295.

URvoY Dominique, "La religion musulmane et la preuve de la divinité de Jésus selon Jacques Abbadie (1656-1727) », Islamo-Christiana 12 (1986), p. 73-91.

VALENTIN Jean-Marie et VeIT Patrice (dir.), La confessionnalisation dans le Saint-Empire, XVIe-XVIIIe siècles = Études germaniques 57/3, juillet-septembre 2002.

VAN DEN HeUvel Gerd, Leibniz im Netz. Die frühneuzeitliche Post als Kommunikationsmedium der Gelehrtenrepublik um 1700, Hameln, C. W. Niemeyer (Lesesaal. Kleine Spezialitäten aus der Gottfried Wilhelm Leibniz Bibliothek - Niedersächsische Landesbibliothek), 2009.

VEINSTEIN Gilles, "L'administration ottomane et le problème des interprètes ", in B. MARINO (dir.), Études sur les villes du Proche-Orient, $X V I^{e}-X I X^{e}$ siècle. Hommage à André Raymond, Damas, Institut français d'études arabes de Damas (Études arabes, médiévales et modernes), 2001, p. 65-79. 
VERMEER Hans Josef, "Apparent Contradictions in 16th Reports on Turkey ", in H. ANAMUR (dir.), Aspects culturels de la traduction. En hommage à Hasan-Âli Yüsel, Istanbul, Yıldız Teknik Üniversitesi, p. 85-96.

VISSER Derk (dir.), Controversy and Conciliation. The Reformation and the Palatinate 1559-1583, Eugene, OR, Pickwick, 1986.

VolKLAND Frauke, « Konfession, Konversion und soziales Drama. Ein Plädoyer für die Ablösung des Paradigmas der "konfessionellen Identität" ", in $\mathrm{K}$. von GReyerz, M. JAKUbowsKi-Tiessen, Th. KaUfMANn et H. LeHMANN (dir.), Interkonfessionalität - Transkonfessionalität - binnenkonfessionelle Pluralität. Neue Forschungen zur Konfessionalisierungsthese, Gütersloh, Gütersloher Verlagshaus (Schriften des Vereins für Reformationsgeschichte, 201), 2003, p. 91-104.

VOLKMER Gerald, Das Fürstentum Siebenbürgen 1541-1691. Außenpolitik und völkerrechtliche Stellung, Kronstadt, Aldus/Heidelberg, Arbeitskreis für Siebenbürgische Landeskunde, 2002.

VOLLHARDT Friedrich, " Das theologiekritische Spätwerk Lessings. Hinweise zu neueren Forschungen », German Quarterly 64 (1991), p. 220 - 224.

—, " Kritik der Apologetik », in M. FAUSER (dir.), Gotthold Ephraim Lessing. Neue Wege der Forschung, Darmstadt, Wissenschaftliche Buchgesellschaft, 2008, p. 182-198 (première publication in P.-A. Alt, A. KošENINA, H. ReInHARdT et W. Riedel (dir.), Prägnanter Moment. Studien zur deutschen Literatur der Aufklärung und Klassik. Festschrift für Hans-Jürgen Schings, Würzburg, Königshausen \& Neumann, 2002, p. 29-47.

-, "Lessings Lektüre. Anmerkungen zu den "Rettungen", zum "Faust”Fragment, zu der Schrift über "Leibniz von den ewigen Strafen" und zur “Erziehung des Menschengeschlechts” ", Euphorion 100 (2006), p. 359-393.

-, " Lessing, Reimarus und einige der Folgen ", in G. FrANK, A. HALLACKER et S. LALLA (DIR.), Erzählte Vernunft. Festschrift Wilhelm Schmidt-Biggemann, Berlin, Akademie-Verlag, 2006, p. 329-340.

-, " Gefährliches Wissen und die Grenzen der Toleranz. Antitrinitarismus im 17. Jahrhundert ", in Andreas PIETSCH et Barbara STOLLBERG-RILINGER (dir.), Konfessionelle Ambiguität. Uneindeutigkeit und Verstellung als religiöse Praxis in der Frühen Neuzeit, Gütersloh, Gütersloher Verlagshaus (Schriften der Vereins für Reformationsgeschichte, 214), 2013, p. 221237.

-, « Gotthold Ephraim Lessing und die Toleranzdebatten der Frühen Neuzeit ", in ID. (dir.), Toleranzdiskurse in der Frühen Neuzeit, Berlin-Boston, De Gruyter (Frühe Neuzeit, 198), 2015, p. 381-415.

-, " Lessings Kritik ", in K. BREMER et C. SPOERHASE (dir.), Gelehrte Polemik II = Zeitsprünge 19 1/4 (2015), p. 293-311.

—, « Die Ringparabel in G. E. Lessings Nathan der Weise. Aktualität - Historizität - Kontiguität », in A. Aurnhammer, G. CANTARutTI et ID. (dir.), Die 
drei Ringe. Entstehung, Wandel und Wirkung der Ringparabel in der europäischen Literatur und Kultur, Berlin-Boston, De Gruyter (Frühe Neuzeit, 200), 2016, p. 207-236

—, Gotthold Ephraim Lessing, München, Beck (Beck Wissen 2789), 2016.

Voss Jürgen, "Mannheim. Residenz der Kurfürsten von der Pfalz ", in K. ANDERMANN (dir.), Residenzen. Aspekte hauptstädtischer Zentralität von der Frühen Neuzeit bis zum Ende der Monarchie, Sigmaringen, Thorbecke (Oberrheinische Studien, 10), 1992, p. 323-336.

WALTON Robert C., « Der Streit zwischen Thomas Erastus und Caspar Olevian über die Kirchenzucht in der Kurpfalz in seiner Bedeutung für die internationale reformierte Bewegung ", Monatshefte für evangelische Geschichte des Rheinlandes 37-38 (1988-1989), p. 205-246.

Weismann Christoph, "Auf Kanzeln, Kathedern und in Kutschen. Jakob Andreae als Universitäts- und Kirchenpolitiker ", in U. KÖPF, S. LORENZ et D. R. BAUER (dir.), Die Universität Tübingen zwischen Reformation und Dreißigjährigem Krieg, Thorbecke, Ostfildern (Tübinger Bausteine zur Landesgeschichte, 14), 2010, p. 119-140.

Wendebourg Dorothea, Reformation und Orthodoxie. Der ökumenische Briefwechsel zwischen der Leitung der Württembergischen Kirche und Patriarch Jeremias II. von Konstantinopel in den Jahren 1573-1581, Göttingen, Vandenhoeck \& Ruprecht (Forschungen zur Kirchen- und Dogmengeschichte, 37), 1986.

WeSEL-Roth Ruth, Thomas Erastus. Ein Beitrag zur Geschichte der reformierten Kirche und zur Lehre von der Staatssouveranität, Lahr/Baden, Schauenburg (Veröffentlichungen des Vereins für Kirchengeschichte der in der evangelischen Landeskirche in Baden, 15), 1954.

WHELAN Ruth, «The Dean of Killaloe », Lias 14 (1987), p. 101-117.

-, " From Christian Apologetics to Enlightened Deism. The Case of Jacques Abbadie (1656-1727) ", Modern Language Review 87 (1992), p. 32-40.

-, " Le Christ de Jacques Abbadie ", in M.-C. PITASsI (dir.), Le Christ entre orthodoxie et Lumières, Genève, Droz (Histoire des idées et critique littéraire, 332), 1994, p. 139-162.

—, " Jacques Abbadie, ou le seuil politique de l'apologétique ", in N. BRUCKER (dir.), Apologétique 1650-1802. La nature et la grâce, Bern-Berlin etc., Lang (Recherches en littérature et spiritualité, 18), 2010, p. 109-125.

WiCKERSHAM Jane, "Results of the Reformation. Ritual, Doctrine and Religious Conversion ", The Seventeenth Century 18 (2003), p. 266-289.

WiEN Ulrich A. (dir.), Reformation, Pietismus, Spiritualität. Beiträge zur siebenbürgisch-sächsischen Kirchengeschichte, Köln-Weimar-Wien, Böhlau (Siebenbürgisches Archiv, 41), 2011. 
-, BRANDT Julia et BALOGH András F. (dir.), Radikale Reformation. Die Unitarier in Siebenbürgen, Köln-Weimar-Wien, Böhlau (Studia Transylvanica, 44), 2013.

Wilbur Earl Morse, A History of Unitarianism, 2 vol., Cambridge (Mass.), Harvard University Press, 1946-1952.

Williams D. H., « Monarchianism and Photinus of Sirmium as the Persistent Heretical Face of the Fourth Century ", The Harvard Theological Review 39 (2006), p. 187-206.

Williams George Hunston, The Polish Brethren. Documentation of the History and Thought of Unitarianism in the Polish-Lithuanian Commonwealth and in the Diaspora 1601-1685, Missoula, Mont., Scholars Press (Harvard Theological Studies, 30), 1980.

—, " Unterschiede zwischen dem polnischen und dem siebenbürgisch-ungarischen Unitarismus und ihre Ursachen ", in W. DEPPERT, W. ERDT, A. DE GROот (dir.), Der Einfluß der Unitarier auf die europäisch-amerikanische Geistesgeschichte, Frankfurt a. M. etc., Lang, 1990, p. 33-57.

WiNKELBAUER Thomas, "Karrieristen oder fromme Männer? Adelige Konvertiten in den böhmischen und österreichischen Ländern um 1600 », in B. Chocholáč, L. JAn, T. KNOz (dir.), Nový Mars Moravicus, aneb, Sborník př́spěvků, jež věnovali Prof. Dr. Josefu Válkovi jeho žáci a přátelé k sedmdesátinám, Brno, Matice Moravská, 1999, p. 431-451.

WIRSCHING Andreas, "Ob ich gleych ein armer eynfeltiger lay bin”. Kurfürst Friedrich III von der Pfalz und das konfessionelle Zeitalter ", in E. AXMACHER et K. SCHWARZWÄLLER (dir.), Belehrter Glaube. Festschrift für Johannes Wirsching zum 65. Geburtstag, Frankfurt a. M. etc., Lang, 1994, p. 373-399.

Wolgast Eike, Reformierte Konfession und Politik im 16. Jahrhundert, Heidelberg, Winter (Schriften der Philosophisch-Historischen Klasse der Heidelberger Akademie der Wissenschaften, 10), 1998.

-, " Reformation und Gegenreformation ", in M. SCHAAB et H. SCHWARZMAIER (dir.), Handbuch der baden-württembergischen Geschichte, t. I/2: Vom Spätmittelalter bis zum Ende des Alten Reiches, Stuttgart, Klett-Cotta (Veröffentlichung der Kommission für Geschichtliche Landeskunde in Baden-Württemberg), 2000, p. 145-306.

Wollgast Siegfried, Philosophie in Deutschland zwischen Reformation und Aufklärung 1550-1650, Berlin, Akademie-Verlag, 1988.

WoTschKe Theodor, "Christoph Thretius. Ein Beitrag zur Geschichte des Kampfes der reformierten Kirche gegen den Antitrinitarismus in Polen ", Altpreussische Monatsschrift 44/1, p. 1-42 et 44/2 (1907), p. 151-210.

ZEEDEN Ernst Walter, "Calvinistische Elemente in der Kurpfälzischen Kirchenordnung von 1563 ", in ID., Konfessionsbildung. Studien zur 
Reformation, Gegenreformation und katholischen Reform, Stuttgart, KlettCotta (Spätmittelalter und frühe Neuzeit, 15), p. 286-313.

ZuBER Valentine (dir.), Michel Servet, 1511-1553. Hérésie et pluralisme du XVI ${ }^{e}$ au XXI $I^{e}$ siècle, Paris, Champion (Colloques, congrès et conférences sur la Renaissance européenne, 56), 2007. 
INDEX DES NOMS 



\section{Avant 1900}

A

ABbAdIE, Jacques ${ }^{\mathrm{a}}$ : 23, 25, 26, 27, 67, 68

ALCIATUS, Johannes (Giovanni Paolo

Alciati della Motta): 111, 153

Alesius, Dyonisius: 145

Alting, Heinrich: 84, 85, 104, 106, 120, 122, 123, 142, 151, 158

ÁLVARES, Francisco: 156, 179

ANDREAE, Jacob (Andreä): 131, 132, 164

ARIUS: 92, 100, 144, 147, 148

ARMGART, Martin: 145

ARNOLD, Gottfried: 111, 152

AsSEMANI, Joseph Simon: 19, 65

ATHANASE d'Alexandrie: 41, 93, 148

Auguste, électeur de Saxe: 84, 143, 144

B

BÁTHORY, Étienne (István), et famille: 126, 141, 145, 157, 161

BAumann, Kaspar: 16, 143, 144, 156, 158

BEATRIX, princesse de Bade, comtesse palatine de Simmern: 138

BECHER, Johann Joachim: 49, 52, 78, 136, 166

BEKEs, Gáspár, émissaire de Transylvanie: 12, 141, 149, 152, 158

BENEDICT, prédicateur à Temeşvar: 88, 89,146

BÉRANGER de Tours: 6, 7, 40

BEYRLIN, Jakob: 16, 169

BIANDRATA (Blandrata), Giorgio: 24, $67,68,76,127,138,140,143,153$, 157, 161

BIBLIANDER, Theodor: 66, 131, 163

Budowecz von Budowa, Wenzel Wilhelm (Václav Budovec z Budova): 112, 135, 154, 165

BULLINGER, Heinrich: 140, 144

C

CALIXT, Georg: 153

a. Les noms propres sont référencés dans l'orthographe de leur première apparition dans le texte.
Calov, Abraham: 111, 153

Calvin, Jean: 13, 140, 144, 148, 165

CAMERARIUS, Joachim (Liebhard): 93, 148

CARDAN, Jérôme: 8, 20, 59, 65

CHARLES, margrave de Bade-Durlach: 157

CIRLER, Stephan, secrétaire de Frédéric III, électeur du Palatinat: 145

CochläUs, Johannes: 59, 60

Constantin Ier, empereur romain: 93, 147, 148

CRATO, Johannes (Krafft von Krafftheim): 101, 150

CRELL, Samuel: 127, 128, 130, 131, 133, 161

CYPRIAN, Ernst Salomon: 120, 123, 125, 153, 158, 159, 160

CyRILLE d'Alexandrie: 131, 163, 164

D

DANEAU, Lambert: 68, 157

DAsYPoDIUS, Theophilus: 86, 144

DÁvid, Ferenc (Davidis): 13, 24, 62, 67, $68,88,116,128,129,130,133,138$, 141, 144, 145, 146, 157, 161, 162

DAVID II, roi d’Éhiopie: 156

DE GóIs, Damião: 156, 157

DENZINGER, Heinrich Joseph Dominikus: 148, 156

DIPNISIUS: Voir ALESIUS

DöRING, Heinrich: 73, 191

E

EBERHARD, Johann Jakob: 75, 195

EBERT, Johann Arnold: 7, 60

ERASTUS, Thomas: 11, 61, 62, 77, 134, 140, 141, 150, 160, 165

EusÈBE de Nicomédie, évêque de Constantinople: 147

F

FERDINAND Ier, empereur germanique: 142, 150

FRÉDERIC-GUILLAUME I ${ }^{\mathrm{er}}$, électeur de Brandebourg: 67 
FRÉDÉRIC III, électeur du Palatinat: 11, $12,14,82,83,84,86,106,120,122$, $138,140,143,144,145,149,152$, 159, 165

\section{G}

GELAWDÉWOS, roi d’Éthiopie (Claude, Atsnaf Sagad Ier): 156

GERBER, Christian: 32, 111, 153, 180

GERLACH, Stephan: 13, 17, 26, 28, 29, 32 , 33, 34, 49, 51, 52, 66, 68, 69, 71, 76, 77, 112, 113, 115, 131, 132, 134, 135, 136, 154, 155, 157, 163, 164, 165

GLIRIUS, Matthias: 129, 130, 141, 162. Voir VEHE, Matthias

GODEFROY, Denys: 159

GoEZE, Johann Melchior: 21, 43

GÖTZE, Georg Heinrich: 111, 153

GRÉGOIRE XIII, pape: 162

GRoTIUS, Hugo: 123, 124, 125, 159

GÜNDISCH, Konrad: 144

\section{$\mathrm{H}$}

HARVEY, William: 53, 77

HEBERER, Michael: 112, 135, 154, 165

HEERBRAND, Jacob: 71, 113, 155, 164

HEINECCIUS, Johann Michael: 31, 51, 52, $70,76,77,83,84,85,113,135,136$, 139, 141, 155, 165, 166

HERBELOT, Barthélemy d': 19, 64

HÉRODOTE: 69

Heyne, Christian Gottlob: 7, 59

HORACE: 8, 39, 59

HORNBEEK: 159

HORNBEEK, Johannes: 159

HuET, Pierre-Daniel: 152

HyDE, Thomas: 21, 66

\section{I}

IsTHUANFIUS, Nicolaus (Miklós Istvánffy): 105, 107, 151, 152

J

JEAN II Casimir, roi de Pologne: 153

JEAN II, comte palatin et duc de Simmern: 138

JEAN-SIGISMOND, Jean II Szapolyai, roi de Hongrie, voïvode de Transylvanie: 139, 141, 145, 146, 161
JÉRÉMIE II, patriarche de Constantinople: 164

JöchER, Christian Gottlieb: 31, 70, 81, 82, 84, 85, 135, 138, 142, 143, 165

JuLES, duc de Brunswick-Lunebourg: 137

$\mathrm{K}$

KNITTEL, Franz Anton: 73

$\mathrm{L}$

LA CROzE, Mathurin Veyssière (de): 17, $24,25,27,50,63,67,74,77,125,127$, 151, 160, 161, 166, 169

LADISLAS IV Vasa, roi de Pologne: 153

LAUTERBACH, Samuel Friedrich: 126, 160, 161

LAVATER, (Johann) Ludwig: 134, 165

LEIBNIZ, Gottfried Wilhelm: 6, 10, 23, $24,25,26,27,43,44,45,46,47,48$, $49,50,51,52,53,56,57,64,66,67$, $68,69,74,75,76,77,78,125,126$, $136,137,160$

LIsTHIUs, Johann (János Liszthy), évêque de Vészprem: 151

LOCKE, John: 44, 75

LouIs VI, comte palatin: 12, 149, 150

LUDEWIG, Johann Peter von: 113, 155

$\mathrm{M}$

MADER, Theophil: 103, 150

MAJOR, Georg (Meyer): 128, 161

MANuEl Ier, roi de Portugal: 156

MARBACH, Johannes: 149

MARIGNY, Abbé de: 19, 64

MATTHIAS Corvin Ier, roi de Hongrie: 144, 151

MAXIMILIEN II, empereur germanique: 106, 139, 141, 142, 145, 147, 150, 151, 158, 162, 174

MELANCHTHON, Philipp (Schwartzerdt): 148, 150, 154, 161

MÉLIUSZ, Peter: 161

MIEG, Ludwig Christian: 66, 70, 84, 142, 158, 160

$\mathrm{N}$

NEBEL, Daniel: 66, 70, 84, 142, 158, 160

NICOLAI, Friedrich: 43 
O

OCKLEY, Simon: 19, 64

OLEviAn, Caspar: 11, 140

$\mathrm{P}$

Palaeologus, Jacobus (Giacomo da Chio): 62, 70, 129, 130, 157, 162, 163

Pareus, Daniel (Wängler): 120, 158, 159

Paul de Tarse: 29, 93, 94, 103, 111

PAULUS, imprimeur à Şimand: 88,89 , 146

PETRI, Melchior: 149

PHILIPPI, Ferdinand: 145

Photin, évêque de Sirmium: 82, 139

PIE V, pape: 146

PolonUs, Matthias: 129. Voir VeHE, Matthias

PoQuinus, Petrus (Pierre Bouquin): 99, 149

PORPHYRE de Tyr: 131, 163, 164, 200

Possevinus, Antonius (Antonio Possevino): 129, 162

POTTER, Melchior: 96

PRIDEAUX, Humphrey: 65, 66

$\mathrm{R}$

REIMARUS, Heinrich Samuel: 7, 9, 21, 22, 39, 65, 66

RELAND, Hadrian: 20, 65

RENAUDOT, Eusèbe: 19, 64, 65

RODOLPHE II, empereur germanique: 150

RUARUS (Ruar), Martin: 111, 153

\section{S}

SALE, George: 20, 21, 65, 66

SANDIUS Christophorus (Christoph Sand): 32, 107, 111, 117, 129, 133, 152, 158, 162, 165

SARPI, Paolo: 77

SCHLEIERMACHER, Friedrich Daniel Ernst: 56

SCHULTENS, Albert: 19, 65

SELIM II, sultan ottoman: 5, 16, 17, 29, $30,32,52,63,66,69,70,77,82,123$, 139, 143, 152, 159, 160, 169

SERVET, Michel: 10, 49, 50, 51, 53, 62, $76,77,136,138,162,165$
SIGISMOND Ier, roi de Hongrie puis empereur germanique: 144

SigIsmond II Auguste, grand-duc de Lituanie et roi de Pologne: 144

SINZENDORF, Joachim Graf von, émissaire impérial: 154

Socin, Faust (Faustus Socinus, Fausto Sozzini): 24, 66, 67, 116, 125, 126, $128,130,138,157,161,162,163$

Socin, Lelio (Laelius Socinus, Lelio Sozzini): 126, 138, 161

Soliman le Magnifique, sultan ottoman: 15, 139

SOMMER (Sumer), Johann (Johannes Sommerus): 87, 129, 144, 146, 162, 165

SONER, Ernst: 24, 77, 153

SPANHEIM, Frédéric le Jeune: 120, 158, 159

SPINOZA, Baruch: 78, 152

SQUARCIALUPUS, Marcellus (Marcello Squarcialupi): 130, 163

STRUVE, Burkhard Gotthelf: 84, 103, $104,108,110,120,121,123,143$, 150, 152, 159

SUTER, Jacob: 60, 83, 129, 140, 141

SYLVAN, Johann (Johannes Sylvanus): $12,13,14,18,60,63,83,84,85,91$, $92,94,95,103,118,119,120,129$, $134,140,141,143,144,147,152$, 158, 159, 162

$\mathrm{T}$

Thretius, Christoph: 86, 144, 145

TRAUTSONIUS, Johannes (Johann von Trautson), noble autrichien: 105, 151

$\mathrm{U}$

UHL, Johann Ludwig: 161

UNGNAD VON SONNEGG, David, ambassadeur impérial: 13, 28, 69, 132, 154, 164

V

VALDÉS, Juan de: 8

VeHE, Matthias: 12, 60, 83, 85, 103, 129, 140, 141, 143, 153, 165

VOLTAIRE: 19 


\author{
W \\ WEBER, Johann Baptist, vice-chancelier \\ impérial: 105, 151 \\ WIssowatiUs, Andreas: 23, 24, 25, 26, \\ 27, 47, 66, 67 \\ WiTROusk, Piotr (Petrus), superinten- \\ dant des antitrinitaires polonais: 66 , \\ 68, 132, 163, 164 \\ WOLFGANG, comte palatin et duc de \\ Deux-Ponts, duc de Palatinat-Neu- \\ bourg: 157 \\ WOLF (Wolff), Johann: 115, 157, 158
}

\section{$\mathrm{Z}$}

ZAGA Zabo (Șaggā Za'āb), prêtre et diplomate éthiopien: 34, 71, 115

ZANCHIUS Hieronymus (Girolamo Zanchi): 133, 134, 150, 165

\section{Après 1900}

A

ALMOND, Ian: 64

AL-SHAMMARY, Zahim M. M.: 64

ANER, Karl: 74

ANGERBAUER, Wolfgang: 155

ANTOGNAZZA, Maria Rosa: 66

APPOLD, Kenneth: 153

ARBERRY, A. J.: 64

Asche, Matthias: 73

AURNHAMMER, Achim: 72

B

BÄBLER, Balbina: 59

BALÁzS, Mihály: 62, 146

BALIBAR, Étienne: 78

BALOGH, András F.: 62

BARBERO, Alessandro: 146

BARNER, Wilfried: 59, 137

BAUSI, Alessandro: 156

BAUTZ, Friedrich-Wilhelm: 138, 150, 155, 161

BECKER, Judith: 143

BECK, Philippe: 60, 62, 142

BEHRINGER, Wolfgang: 78

BENEDICT, Philip: 161

BENRATH, Gustav Adolf: 142

BERINDEI, Minhea: 146

BERNARDINI, Michele: 63

BEUTEL, Albrecht: 74

BEYER, Michael: 161
BIEGEL, Gerd: 137

BINDER, Ludwig: 72, 145

BLAUFUSS, Dietrich: 152, 153

BLED, Jean-Paul: 146

BoBZIN, Hartmut: 66

BoHNEN, Klaus: 59, 60

BORRELLI, Clara: 63

BRANDT, Julia: 62

BREMER, Kai: 62

BRENNECKE, Hanns Christoph: 148

BRÖER, Ralph: 76, 150

BuRCHILL, Christopher J.: 60, 66, 68, 71, 140, 141, 145, 164, 165

BÜTTGEN, Philippe: 61, 72, 73, 74, 75, 77

C

CANTARUtTI, Giulia: 72

CANTIMORI, Delio: 138, 153

CASTALDINI, Alberto: 162

CAZACU, Matei: 154

CERBo, Anna: 63

Colombo, Emanuele: 63

COUDERT, Allison P.: 163

D

DAGRON, Tristan: 66

DAKHLIA, Jocelyne: 63

DÁN, Robert: 62, 141

DAUGIRDAS, Kestutis: 66

DAUNICHT, Richard: 137

DEFLERS, Isabelle: 61 
DÉNY, Jean: 146

DEVENTER, Jörg: 62

DINGEL, Irene: 161

Dixon, C. Scott: 153

DRECOLL, Volker Henning: 148

DRÜLL, Dagmar: 151

DUCHESNEAU, François: 77

DuHAMELLE, Christophe: 61, 73, 142

DuRI, Abd al-Aziz: 160

\section{$\mathrm{E}$}

EBERT, Hans-Georg: 65

EDEL, Andreas: 142, 151

ELMARSAFY, Ziad: 64

ESPAGNE, Michel: 59, 64

F

FIRPO, Massimo: 162, 164

FORLINES, F. Leroy: 160

FRANK, Jakob: 139, 153

FRÜHSORGE, Gotthard: 78, 166

G

GARCÍA-ARENAL, Mercedes: 63

GARCIA, Humberto: 64

GHERMANI, Naïma: 73

GILLET, Olivier: 139

GIMARET, Daniel: 142

GOTTHARD, Axel: 142

GREYERZ, Kaspar von: 62, 154

GROETSCH, Ulrich: 65

GunNOE, Charles D., Jr: 61, 160, 165

\section{$\mathrm{H}$}

HANSTEIN, Thoralf: 65

HARNACK, Adolf von: 164

HEINEMANN, Karl Otto von: 137

HEYBERGER, Bernard: 63

Holt, Peter M.: 64

Holtzmann, Heinrich: 142

HORN, Curt: 144

HoRSCH, Silvia: 64

\section{I}

IORGA, Nicolae: 139

$\int_{\text {JAKUbowski-TiEsSEn, Manfred: } 62}$
JAUMANN, Herbert: 62, 161

JOLLEY, Nicholas: 75

$\mathrm{K}$

KAISER, Wolfgang: 63

KANTOROWICZ, Hermann: 149

KAPLAN, Steven: 156

KAUFMANN, Thomas: 62, 66, 68, 69, 73

KERTSCHER, Hans-Joachim: 75

KEUL, István: 62, 139

KIRSCHER, Roger: 74

KLEIN, Dietrich: 64

KLEIN, Michael: 155

KLÖCKNER, Thomas: 142

КосH, Ernst: 153, 158

KÖHLER, Mathias: 138

KössLING, Rainer: 148

KRSTIĆ, Tijana: 70

KüHN, Sebastian: 68

KUNKLER, Stephan: 148

KusCHEL, Karl-Josef: 64

$\mathrm{L}$

LAERKE, Mogens: 67

LAFI, Nora: 64

LAGRÉE, Jacqueline: 68, 78

LAUNAY, Marc de: 60

LEBEAU, Christine: 61

LÉCHOT, Pierre-Olivier: 142, 149

LEHMANN, Hartmut: 62

LEPPIN, Volker: 62

LINDEBOOM, Johannes: 143

LINDHOLM, Stefan: 150

LORBER, Michael: 166

LotZ-HeUMANN, Ute: 62

LUEBKE, David M.: 62

LÜPKE, Johannes von: 72

$\mathrm{M}$

MADER, Éric-Olivier: 62

MAdONIA, Claudio: 163

MARRASSINI, Paolo: 156

MARTINEZ D’Alòs-Moner, Andreu: 156

MATUZ, Josef: 147

MERKLE, Benjamin R.: 68

MitZsChKE, Paul: 143

MORLET, Sébastien: 164

MouT, M. E. H. N.: 69 
MÜHLING, Andreas: 140

MÜLLER, Detlev G.: 65

MÜLLER, Ralf C.: 63, 69

Mulsow, Martin: 17, 59, 63, 65, 66, 67, 68, 69, 70, 77, 150, 160, 163

MulthAMmER, Michael: 59, 60

MuRR, Sylvia: 160

\section{$\mathrm{N}$}

NESSELRATH, Heinz-Günther: 59

NIEWÖHNER, Friedrich: 153

\section{$\mathrm{O}$}

OBORNI, Teréz: 139

OGONOWsKI, Zbigniew: 66

OSIER, Jean-Pierre: 138

\section{$\mathrm{P}$}

PIRnÁT, Antal: 62

Platow, Birte: 64

PoHLIG, Matthias: 62

POLEY, Jared: 62

PONS, Georges: 74

PRESS, Volker: 61, 145

$\mathrm{R}$

RAABE, Mechtild: 137

RAABE, Paul: 137

RABAULT-FeUERHAHN, Pascale: 64

RADIN, Max: 149

REESE, Olaf: 153

REIFENBERG, Bernd: 137

REINHARD, Wolfgang: 73

ROHLS, Jan: 68

RoLING, Bernd: 65

Rотн, Erich: 62

RoTH, Harald: 62, 139, 145

RUPPELT, Georg: 137

RYAN, Daniel C.: 62

\section{S}

SAADA, Anne: 59

SABEAN, David Warren: 62

SÁNCHEZ García, Encarnación: 63

ScHILLING, Heinz: 61, 62

SchiLSON, Arno: 59, 60, 137, 144, 146, 156

SCHINDLING, Anton: 61
SCHMOLINSKY, Sabine: 157

SCHNABEL-SCHÜLE, Helga: 61

SCHNEIDER, Hans: 153

SCHNEIDER, Ulrich Johannes: 138

ScHoTT, Christian-Erdmann: 161

SCHREINER, Klaus: 72

SCHULZE, Winfried: 62

SEELIGER-ZEISS, Anneliese: 138

SELLA, Domenico: 153

SHOULSON, Jeffrey S.: 163

SMITH, Justin E. H.: 77

SoLF, Sabine: 137

SOMMER, Andrea Urs: 153

Sosio, Libero: 77

STOCKHAUSEN, Annette von: 148

STOLLBERG-RILINGER, Barbara: 142

STRASSER, Gerhard F.: 78, 166

STREBE, Horst: 60

SUTTER Fichtner, Paula: 142

$\mathrm{T}$

TAZBIR, Janusz: 153

THOUARD, Denis: 59, 60

TroITZsCH, Ulrich: 78

U

ULBRICH, Claudia: 154

ULLENDORF, Edward: 156

URvoy, Dominique: 68

V

VALENTIN, Jean-Marie: 61

vaN Den Heuvel, Gerd: 78

VeINSTEIN, Gilles: 146, 147

VEIT, Patrice: 61

VINCENT, Bernard: 63

VISMARA, Paola: 63

VISSER, Derk: 61

VOLKMER, Gerald: 139

VOLLHARDT, Friedrich: 59, 63, 72

Voss, Jürgen: 69

W

WALLMANN, Johannes: 153, 158

WALTON, Robert C.: 140

WARTENBERG, Günther: 148, 161

WeISMANN, Christoph: 164

WENDEBOURG, Dorothea: 68, 69 
WESEL-RoTH, Ruth: 61, 165

WHELAN, Ruth: 67, 68

WIEN, Ulrich A.: 62, 72, 145

WILBUR, Earl Morse: 137, 157

WiLLIAMS, D. H.: 139, 157, 165

WILLIAMS, George Hunston: 157

WIRSCHING, Andreas: 138

WOLGAST, Eike: 61

WOLLGAST, Siegried: 153

WoTsCHKE, Theodor: 144

Z

ZEEDEN, Ernst Walter: 61

ZIEGLER, Walter: 61

ZUBER, Valentine: 165 

INDEX DES LIEUX 

A

ALBA Julia (Gyulafehérvár, Karlsburg, Weissenburg) ${ }^{\text {a: }} 91$

ALTDORF: 150, 153

AMBERG: 82, 85, 95, 96, 109, 117, 139, 143, 150

AMSTERDAM: 52, 77, 137, 152, 161, 194

ANNABERG: 153

AugsBourg: 14, 39, 141, 142

B

BABYLONE: 28

BÂLE: 138, 150, 160, 163

BEŁŻYCE: 157

BERLIN: 148, 160

BERNE: 10

BOURGES: 140, 149, 157

BRESLAU: 150

\section{C}

CAMBRIDGE: 64

CHIOS: 70, 162

CLAusenbourg (Klausenburg, Kolozsvár, Cluj): 13, 38, 87, 88, 116, 129, 141, 144, 145, 146, 193

COBOURG: 158

Cologne: 138,141

CONSTANTINOPLE (Istanbul): 13, 14, 16, $17,19,28,29,30,31,32,53,57,63$, $66,70,77,81,82,83,86,90,91,92$, $94,98,101,111,112,113,135,137$, $146,147,148,150,154,155,156$, 158, 162, 163, 164, 181, 184, 202

Cracovie: $13,86,144,165$

D

DEBRECEN: 12, 95, 149

DÉvA (Diemrich, Schlossberg, Denburg): 157

F

FEUDENHEIM: 140

FRANEKER: 65

FRAUSTADT (Wschowa): 160

a. Les noms de lieux sont référencés dans l'orthographe de leur première occurrence dans le texte.
G

GENÈVE: 10, 15, 86, 99, 123, 138, 140, 148, 150, 153, 165

GотнA: 17, 28, 29, 63, 143, 158

GÖTTINGEN: 7, 59

GRÜNSFELD: 140

$\mathrm{H}$

HANOVRE: 52

HEIDELBERG: 160

HEIDELBERG: 5, 11, 12, 15, 17, 30, 60, 61, $63,66,82,83,84,87,88,91,94,95$, $99,100,101,103,104,112,113,119$, $122,124,138,140,141,142,143$, 144, 145, 147, 148, 149, 150, 151, $154,155,159,162$

HELMSTEDT: 153, 158

HERBORN: 140

I

IÉNA: 143, 153

J

JÉRUSALEM: 35

$\mathrm{K}$

KÖNIGSBERG: 152

KÖNIGSWINTER: 141

L

LADENBOURG: 83, 140, 141

LEIPZIG: 93, 138, 143, 148, 149, 153

LEYDE: 65, 159

LONDRES: 13, 67, 86, 143

LÜBECK: 153

LUGUSCH (Lugoj): 89, 146

LUTRE: 83

$\mathrm{M}$

MANNHEIM: 27, 69, 210

MARBOURG: 141, 142, 143

MoHÁcs: 14, 139

$\mathrm{N}$

NeUBourg: 96, 143, 144

$\mathrm{P}$

Padoue: 150, 151 
PARIS: 13, 86, 144

PASSAU: 141

PRAGUE: 105, 106, 150, 154, 162

PRESBOURG (Bratislava): 12, 95, 102, 109, 149, 171

$\mathrm{R}$

RATISBONNE: 140,141

RoME: 40, 93, 138, 148, 162

$\mathrm{S}$

SCHIMAN: 88, 89, 146

SCHINTAU: 143

SPIRE: $12,16,83,84,96,104,105,106$, $108,109,117,126,139,140,141$,

$143,145,149$

$\mathrm{T}$

TEMEŞVAR: 88, 89, 146, 154, 158

TÜBINGEN: 13, 113, 131, 141, 148, 154, 155,164
V

VÉSZPREM: 151

VIENNE: 88, 140, 145, 150

W

WEIDENHEIM: 83, 140

WITTENBERG: $59,62,138,144,145,148$, 150, 153, 157, 158, 161, 191, 202, 204

WOLFENBÜTTEL: 5, 6, 7, 21, 27, 39, 41,

$43,50,59,65,73,137,143,153,155$, 164, 179, 186, 194, 200, 203 


\section{Table des matières}

\section{Philippe Büttgen}

Confession et migration - L'islam des lumières …...................... 3

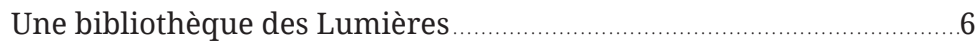

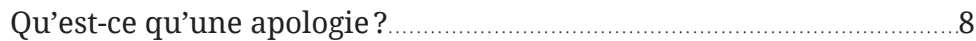

Adam Neuser

Philosophie du Saint-Empire …..................................................... 14

La lettre trouvée

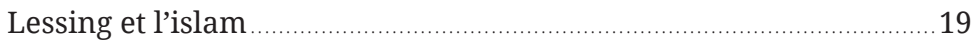

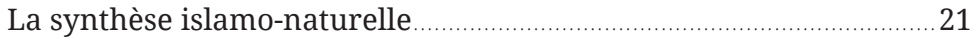

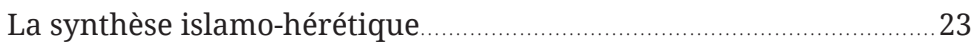

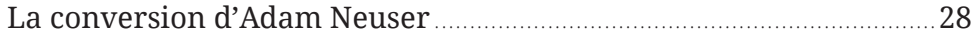

La confession de foi d'Adam Neuser ...................................................... 30

Nathan et l'interdit de la conversion ……............................................. 34

Lessing et l'interdit de la confession .................................................. 39

Confession et conséquence .......................................................... 41

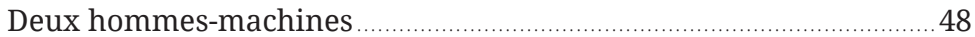

La religion naturelle aujourd'hui .......................................................53

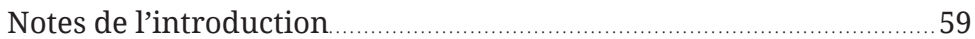

G. E. Lessing - Adam Neuser 79

Adam Neuser, quelques informations authentiques .........................81

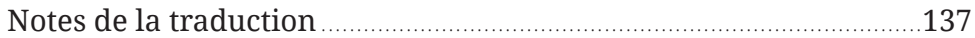

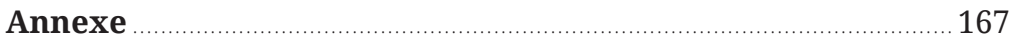

Lettre d'Adam Neuser au sultan Selim II (1570) ................................169

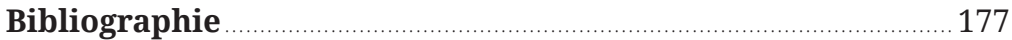

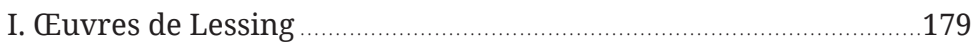

II. Sources

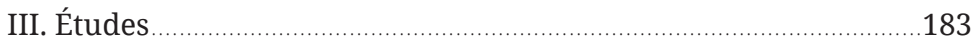

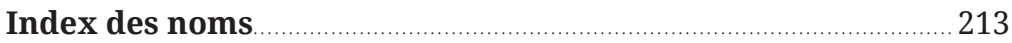

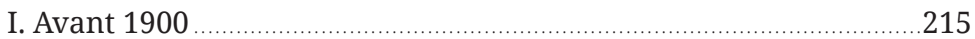

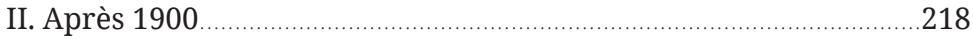

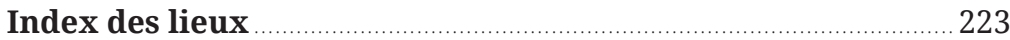




\section{Déjà parus aux éditions DEMOPOLIS}

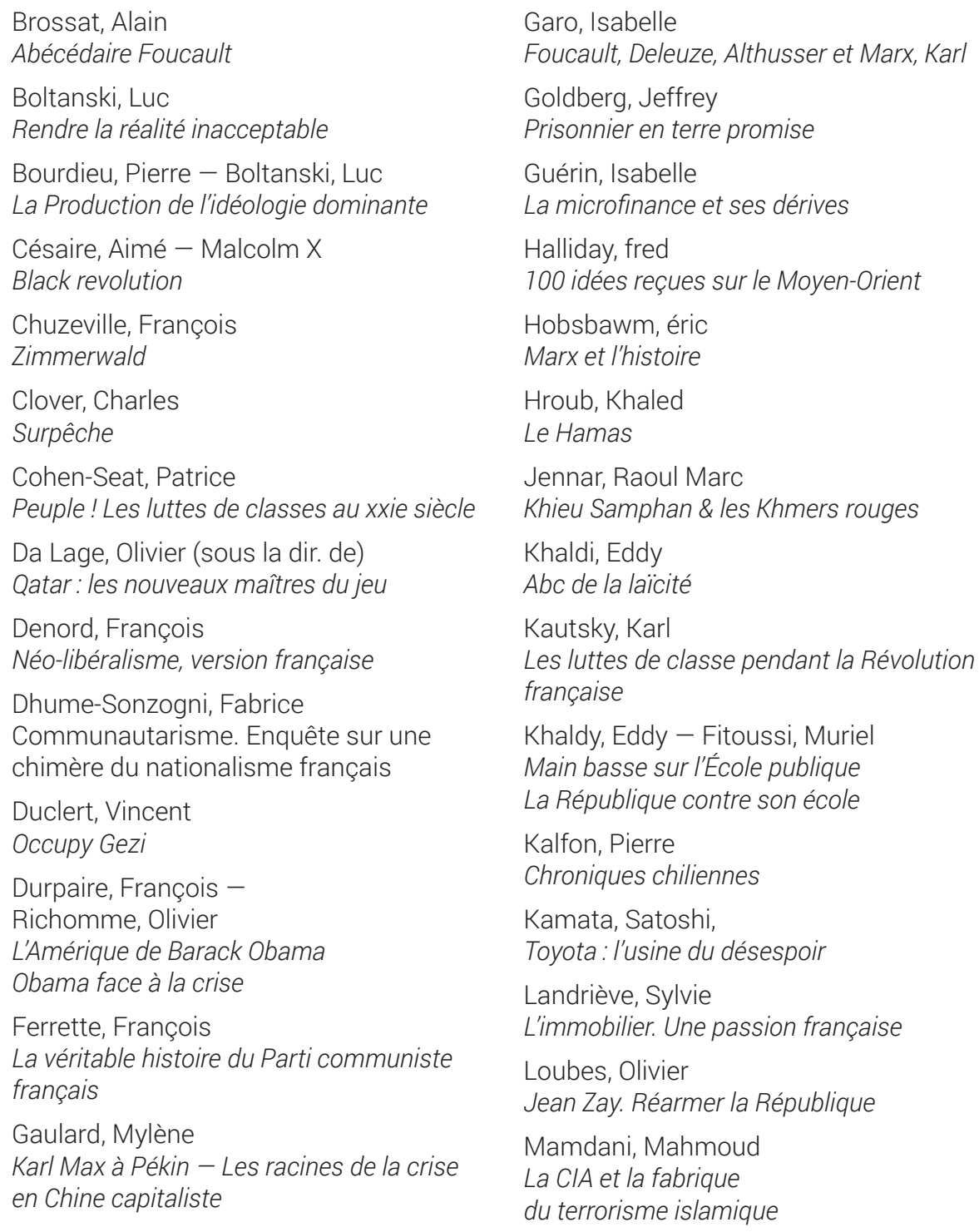


Mendes France, Pierre

Liberté Liberté chérie

Nadaud, Stéphane

Les Japons de Kenzaburo Oé

Labat, Séverine

Les islamistes tunisiens - entre l'état et la mosquée

Latour, Bruno - Lippman, Walter

Le public fantôme

Lénine

Petit manuel pour rompre avec le capitalisme

1914, repenser le nationalisme et la guerre

Mandani, Mahmood

La ClA et la fabrique du terrosisme

islamiste

Marx, Karl

Qu'est-ce que le capitalisme?

Les Crises du capitalisme

Le Capital financier

Mordillat, Gérard -

Prieur, Jérôme

De la crucifixion considérée

comme un accident du travail

Gérard Mordillat présente

« Le fascisme » de Mussolini

Nsar, Vali

Le renouveau chiite

Pivert, Marceau

Une histoire populaire de la laïcité

Prochasson, Christophe

L'Empire des émotions : les historiens dans la mêlée

Rebérioux, Madeleine

Vive la République

Rodinson, Maxime

Islam et capitalisme

Sassen, Saskia

Critique de l'État

Saurin, Patrick

Les prêts toxiques : une affaire d'état

Shah, Sonia

Cobayes humains : le grand secret des

essais pharmaceutiques

Uchitelle, Louis

Le salarié jetable

Wallerstein, Immanuel

L'Universalisme européen :

de la colonisation au droit d'ingérence

Wilkinson, Richard

L'égalité, c'est la santé

Winder, Simon

James Bond

Walt, Stephen

Pourquoi le monde n'aime plus les états-

Unis

Whitaker, Brian

Parias: Gays et Lesbiennes dans le monde arabe 


\section{Collection « Quaero »}

Cassin, Barbara et Wosny, Danièle (dir.) Les intraduisibles du patrimoine en Afrique subsaharienne

Dawod, Hosham (dir.)

La constante " Tribu », variations arabo-

musulmanes

Cassin, Barbara et Gorog, Françoise

Psychanalyser en langues. Intraduisibles et langue chinoise

Ehrenfreund, Christian et Schreiber, JeanPhilippe (dir.)

Les marranismes. De la religiosité cachée à la société ouverte

Ethis, Emmanuel

Le cinéma près de la vie

Fernadez Garcia, Alicia et Petithomme, Mathieu,

Contester en Espagne

Fontaine, Alexandre

Aux heures suisses de l'école républicaine

Ghasarian, Christian

Rapa. Île du bout du monde, île dans le monde

\section{Collection Philosophie en cours}

Carsin, Didier,

Montesquieu, les lois et les mœurs

Cavaillé, Christian

Les jeux de langage chez Wittgenstein

Chauve, Alain

Le Tractacus : logique et métaphysique
Ghosn, Katia

Rachid El-Daiif. Le roman arabe dans la tourmente de la modernsisation

Aubert-Nguyen, Hoai Huong et Espagne, Michel (dir.)

Le Vietnam. Une histoire de transferts

culturels

Niveleau, Charles-édouard (dir.)

Vers une philosophie scientifique - Le

programme de Brentano

Oléron Evans, Emilie

Nikolaus Pevsner. Arpenteur des arts

Rabault-Feuerhahn,

Pascale (dir.)

Théorie intercontinentales - Voyages du comparatisme postcolonial

Salamagne, Michèle- $\mathrm{H}$. et Thominet, Patrick (dir.),

Accompagner. Trente ans de soins palliatifs en France

XIAO Yingying,Une subjectivité fuide

Sfez, Gérald

Machiavel et la vérité politique

Tomès, Arnaud

Castoriadis. L'imaginaire, le rationnel et le réel 

Achevé d'imprimer en France en 2017

dans les ateliers de Dupli-print à Domont (95)

$N^{\circ}$ d'impression:

Dépôt légal : avril 2017 